\title{
Finite Element Analysis of Tubular Track System
}

\author{
by
}

Karel Jef Stefaan Verlinde

Thesis presented in partial fulfilment of the requirements for the degree of Master of Science in Civil Engineering at the University of Stellenbosch

Department of Civil Engineering, University of Stellenbosch,

Private Bag X1, Matieland 7602, South Africa.

Supervisor: Dr. J.A.v.B. Strasheim

December 2012 


\section{Declaration}

By submitting this thesis electronically, I declare that the entirety of the work contained therein is my own, original work, that I am the owner of the copyright thereof (unless to the extent explicitly otherwise stated) and that I have not previously in its entirety or in part submitted it for obtaining any qualification.

Signature:

K.J.S. Verlinde

Date:

Copyright (C) 2012 Stellenbosch University

All rights reserved. 


\section{Synopsis}

The Tubular Track (TT) railway system is a twin beam modular railway system consisting of two reinforced concrete $(\mathrm{RC})$ beams on which steel rails are continuously supported. The beams are linked with galvanised steel gauge tie bars and continuously supported by soil foundations, and can be used to replace conventional sleeper and ballast railway support. The TT railway system has in the past been analysed with various analysis methods, but were found to obtain conflicting results. The conflicting results means that one of the analysis methods used for the analysis and design of TT railway sections is either an underestimation or overestimation of section displacements, forces, and stresses; or both methods could even be incorrect. The main emphasis of this investigation is therefore to develop and verify static and dynamic analysis methods and modeling techniques which can be used to simulate the TT railway system accurately. The results and models of the previous analyses are not explicitly investigated in this dissertation, but serve as a motivation for this investigation.

The TT system is supported by several soil strata providing vertical support, but geometrically modeling the subgrade strata in the analysis models adds a high level of complexity, and is not feasible for general analysis where soil conditions are mostly unknown. The elastic foundation theory is therefore used to accurately simulate the interaction between beam and foundation and therefore sufficiently simplifies the analysis models. Simplification of a subgrade foundation by simulating a soil stiffness supporting the TT beam is investigated and analysed by comparing finite element analysis (FEA) results of various soil models using parameters of four known soil formations currently in use at TT railway sections. The FEA of the subgrade formations indicates that there is a linear relationship between the modulus of subgrade reaction for a square plate bearing test and a rectangular, infinitely long plate representing the subgrade support for the TT beams. A square plate bearing test can therefore be performed on site and modified to represent the actual subgrade support stiffness of the TT railway structure, whereafter it can be used for the analysis and design of the TT system using one of the proposed analysis methods.

The analysis models used range from simple theoretical models based on elastic foundation principles, to two-dimensional (2D) beam elements, and ultimately to complex three-dimensional (3D) solid finite element models. The models used for the analyses are the Single and Double Beam elastic foundation, PROKON 2D beams, ABAQUS 2D beams and ABAQUS 3D solid element models. The alternative analysis methods considered should provide a clear indication of which analysis methods are accurate and feasible for design of the TT system. An in-situ reference 
model with known deflections and design parameters specific to a TT railway section is used to analyse the different analysis methods' accuracy and validity. The Double Beam, ABAQUS 2D and ABAQUS 3D models were found to provide very similar displacements, bending moments and shear forces for a static analysis, whereas the PROKON and Single Beam models provide unsatisfactory results. The PROKON beam model underestimates the bending moments and shear forces in the rail, and overestimates bending moments and shear forces in the RC beam by a considerably margin. This result can lead to the underdesigning of the rail which could possibly force the RC beam to be subjected to larger maximum bending moments and shear forces than for what it was originally designed for, thereby nullifying or possibly even exceeding the amount for which it was overdesigned. This effectively accelerates material fatigue, which might be the possible cause of the small cracks in the $\mathrm{RC}$ beams which have been found on some TT railway sections, which is currently being investigated. A graphical user interface of the Double Beam method is provided for quick and efficient analysis.

Empirical methods used to simulate the dynamic nature of a railway system are often used in the industry to simplify the dynamic loading by determining a dynamic amplitude factor (DAF) to be applied to a static load. An implicit dynamic FEA is therefore performed to obtain the DAF for the reference section, which is subsequently used for the comparison with in-situ deflection results. The results of dynamic analysis validates the proposed empirical analysis method, as the displacements obtained were very similar to actual field test results, thereby also verifying the accuracy of the proposed analysis methods. The sensitivity of the TT system to design parameters is also investigated to indicate to which parameters the design is sensitive to and where small variations of these parameters require due consideration for future and analysis of the TT railway system. 


\section{Samevatting}

Die Tubular Track (TT) spoorweg stelsel is 'n dubbel balk modulêre treinspoor sisteem bestaande uit twee gewapende beton balke waarop staal spore voortdurend ondersteun word. Die balke word gekoppel deur gegalvaniseerde staal stawe vir laterale styfheid en word deurlopend ondersteun deur grond fondamente, en kan gebruik word om konvensionele dwarslêer en ballast spoorweg ondersteuning te vervang. Die TT spoorweg stelsel was in die verlede met verskeie analiseringsmetodes ontleed, maar het teenstrydige resultate gewerf. Die teenstrydige resultate beteken dat een van die analise metodes wat gebruik word vir die analisering en ontwerp van TT spoorweg seksies 'n onderskatting of oorskatting van verplasings, kragte, en spannings is; of beide metodes kan selfs verkeerd wees. Die hoofklem van hierdie ondersoek is dus die ontwikkeling en verifikasie van statiese en dinamiese analitiese metodes en modellering tegnieke wat gebruik kan word om die TT spoorweg stelsel akkuraat te simuleer. Die resultate en modelle van die vorige ontledings word nie uitdruklik in hierdie proefskrif ondersoek nie, maar dien as 'n motivering van hierdie ondersoek.

Die TT stelsel word ondersteun deur verskeie grond strata wat vertikale ondersteuning verskaf, maar meetkundige modellering van die grond strata in die ontledingsmodelle veroorsaak 'n hoë vlak van kompleksiteit wat nie bruikbaar is vir algemene analises waar grondeienskappe meestal onbekend is. Die elastiese fondament teorie word daarom gebruik om die interaksie tussen die balk en die fondament akkuraat te simuleer, en vereenvoudig dus die analitiese modelle voldoende. Vereenvoudiging van 'n grond fondament deur 'n grond styfheid ondersteuning van die TT balk te simuleer is ondersoek en ontleed deur die resultate van eindige element analises van verskillende grond modelle te vergelyk. Bekende ontwerp parameters van vier bekend grondformasies wat tans gebruik word by TT spoorweg seksies word vir hierdie analises gebruik. Die eindige element analises van die grondformasies dui daarop aan dat daar 'n lineêre verwantskap tussen die modulus van grond reaksie vir 'n vierkantige plaat dratoets en 'n reghoekige, oneindige lang plaat dratoets bestaan. 'n Vierkantige plaat dratoets kan dus op terrein uitgevoer en aangepas word om die werklike styfheid van die grond ondersteuning van die TT spoorweg sisteem voor te stel.

Die analitiese modelle wat gebruik word wissel van eenvoudige teoretiese modelle wat gebaseer is op elastiese fondament beginsels, twee-dimensionele (2D) balk elemente, asook komplekse driedimensionele (3D) soliede eindige element modelle. Die modelle wat gebruik is vir die ondersoek is die Enkel en Dubbel Balk elastiese fondament, PROKON 2D balke, ABAQUS 2D balke en 
ABAQUS 3D soliede element modelle. Hierdie reeks bied 'n duidelike aanduiding watter analiseringsmetodes akkuraat en haalbaar is vir die ontwerp van die TT stelsel. 'n In-situ verwysingsmodel met bekende defleksies en ontwerp parameters wat spesifiek is vir 'n TT spoorweg seksie word gebruik om die akkuraatheid en geldigheid van die verskillende analitiese metodes te analiseer. Die Dubbel Balk, ABAQUS 2D en ABAQUS 3D modelle verkry baie soortgelyke verplasings, buigmomente en skuifkragte vir 'n statiese analise, terwyl die PROKON en Enkel Balk modelle onbevredigende resultate verkry. Die PROKON model onderskat die maksimum buigmomente en skuifkragte in die staal spoor, en oorskat buigmomente en skuifkragte in die gewapende beton balk. Hierdie resultaat kan moontlik lei tot die onderontwerp van die staal spoor en dwing moontlik vir die gewapende beton balk om blootgestel te word aan groter buigmomente en skuifkragte as vir wat dit oorspronklik ontwerp is, en verontagsaam sodoende moontlik die kragte waarvoor dit oorontwerp is. Dit versnel effektief materiaal vermoeiing, wat die moontlike oorsaak is van die klein krake wat gevind is in die gewapende beton balke op sommige TT spoorweg seksies wat tans ondersoek word. 'n Grafiese gebruikerskoppelvlak van die Dubbel Balk model is verskaf vir vinnige en doeltreffende ontleding.

Empiriese metodes om die dinamiese aard van 'n spoorweg-stelsel te simuleer word dikwels gebruik in die bedryf om dinamiese belasting te vereenvoudig deur middel van die gebruik van 'n dinamiese amplitude faktor (DAF) wat op 'n statiese belasting aangewend word. 'n Implisiete dinamiese eindige element analise word dus uitgevoer om die DAF te ondersoek, wat daarna gebruik word vir die vergelyking met die in-situ defleksie resultate van die in-situ verwysingsmodel. Die resultate van die dinamiese analise bevestig dat die voorgestelde empiriese analise metode gebruik kan word, omdat die verplasings wat verkry baie soortgelyk was aan werklike veld toets resultate, en daardeur ook die verifiëring van die akkuraatheid van die voorgestelde analise metodes bewerkstellig. Die sensitiwiteit van die TT stelsel vir ontwerp parameters word ook ondersoek om aan te dui watter parameters die ontwerp voor sensitief is, en waar klein variasie in hierdie ontwerp parameters behoorlike oorweging vereis vir die toekomstige analisering en ontwerp van die TT spoorweg stelsel. 


\section{Acknowledgements}

I would like to express my gratitude to the following people for their input and support during my post-graduate studies:

Doctor JAvB Strasheim for his guidance, support and encouragement for my thesis.

Professor JA Wium for his valuable insight.

Greg Mitchell of FEAS (Pty) Ltd for his technical support with the finite element models.

My parents for their support and encouragement throughout my under-graduate and postgraduate studies.

My girlfriend Jackie Davidoff who has stuck with me during the long years of my studies, even when I retreated to my work for months on end. I could not imagine how I would have finished this thesis if it were not for her constant love and faith in me. 


\section{Contents}

List of Figures $\quad$ x

List of Tables $\quad$ xiv

List of Abbreviations $\quad$ xv

$\begin{array}{ll}\text { Nomenclature } & \text { xvi }\end{array}$

\begin{tabular}{lll}
\hline & Introduction & $\mathbf{1}$
\end{tabular}

1.1 Aims of Investigation $\ldots \ldots \ldots \ldots \ldots \ldots$

2 Tubular Track System 5

$2.1 \quad$ Continuously Supported Railway Advantages . . . . . . . . . . . . . . . 6

2.2 Tubular Track System Loading and Components . . . . . . . . . . . . . . . . 7

2.2 .1 System Components Excluded from Models . . . . . . . . . . . . . . 11

3 Literature Review 13

3.1 Elastic Foundation Theory $\ldots \ldots \ldots \ldots \ldots$

$3.1 .1 \quad$ Introduction . . . . . . . . . . . . . . . . . . . . . . . . . 13

$3.1 .2 \quad$ Elastic Foundation Model $\ldots \ldots \ldots$. . . . . . . . . . . . 14

3.1 .3 Elastic Foundation Model Derivation . . . . . . . . . . . . . . . . . 15

3.1 .4 Transformed-Section Method . . . . . . . . . . . . . . . . . . . 18

3.1 .5 Double Beam Model . . . . . . . . . . . . . . . . . . . . . 20

$3.1 .6 \quad$ MATLAB Graphical User Interface . . . . . . . . . . . . . . . . . . 23

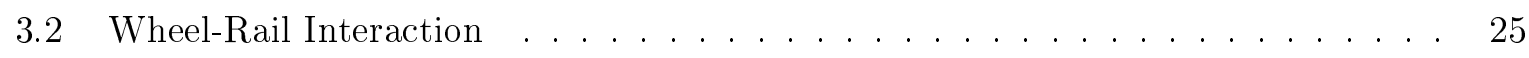

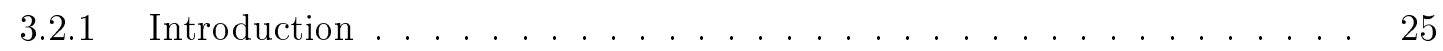

3.2 .2 Wheel-Rail Guidance . . . . . . . . . . . . . . . . . . 26

3.2 .3 Hertz Contact Mechanics . . . . . . . . . . . . . . . . . . . . . . . 28

3.3 Load Factors . . . . . . . . . . . . . . . . . . . . . . . . . . . . . . . . . . . . . 32

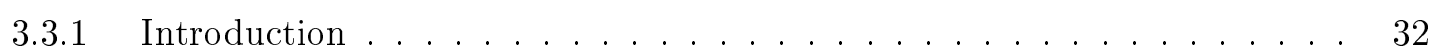

$3.3 .2 \quad$ Static Load Application . . . . . . . . . . . . . . . . . . . . . 32

3.3 .3 Dynamic Load Factors . . . . . . . . . . . . . . . . . . . . . . . . . . . . . . . . . . . . . . .

3.3 .4 Modal Frequency Analysis . . . . . . . . . . . . . . . . . . . . . . 40

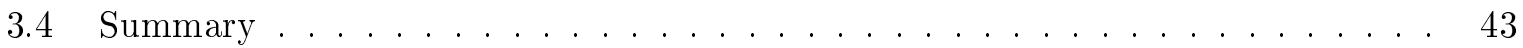


\begin{tabular}{|lll}
4 & Research Methodology & 45
\end{tabular}

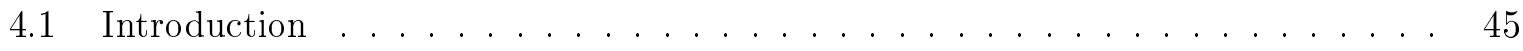

4.2 Scope of Research $\ldots \ldots \ldots \ldots \ldots \ldots$. . . . . . . . . . . . . . . . 45

4.3 Analysis Methodology $\ldots \ldots \ldots \ldots$. . . . . . . . . . . . . 46

4.4 Limitations of Research $\ldots \ldots \ldots \ldots$. . . . . . . . . . . . . . . . . . . . 48

\begin{tabular}{|lll}
5 & Two-Dimensional Finite Element Analysis & 49
\end{tabular}

$5.1 \quad$ Finite Element Method Introduction . . . . . . . . . . . . . . . . . . . . . . . 49

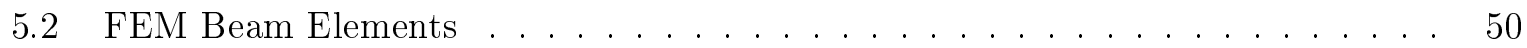

5.2 .1 Element Types . . . . . . . . . . . . . . . . . 50

5.3 Reference Model Properties . . . . . . . . . . . . . . . . . . . . . . . 51

$5.3 .1 \quad$ Model Symmetry Analysis $\ldots \ldots \ldots \ldots$. . . . . . . . . . . . . . . . . . . . . . . . . 52

5.4 PROKON Frame Analysis Model . . . . . . . . . . . . . . . . . . . . . 55

$5.4 .1 \quad$ PROKON Frame Analysis Results . . . . . . . . . . . . . . . . . 57

5.5 Single Beam on Elastic Foundation . . . . . . . . . . . . . . . . . . . . 59

5.5.1 Single Beam on Elastic Foundation Analysis Results . . . . . . . . . . 60

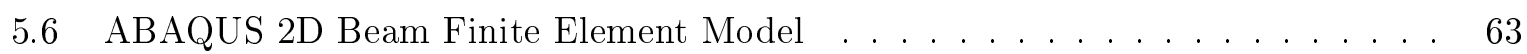

5.6 .1 ABAQUS 2D Beam Analysis Results . . . . . . . . . . . . . . . . 64

5.7 Double Beam Model . . . . . . . . . . . . . . . . . . . 67

5.7 .1 Double Beam Model Results . . . . . . . . . . . . . . . . . . . . 68

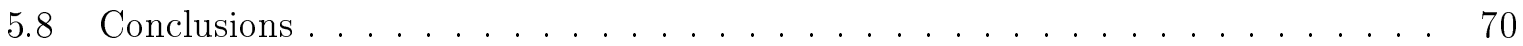

6 Three-Dimensional Finite Element Analysis $\quad 72$

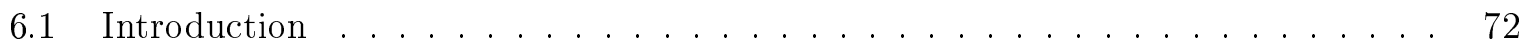

$6.2 \quad$ FEM Solid Elements . . . . . . . . . . . . . . . . . . . . . . . . . . . 72

$6.2 .1 \quad$ Element Type and Mesh Density . . . . . . . . . . . . . . . . 72

6.3 Contact and Interaction Modeling . . . . . . . . . . . . . . . . . . . . . . . . . . . . .

6.4 Subgrade Support Analysis . . . . . . . . . . . . . . . . . . . . . . . . 76

6.5 Modulus of Subgrade Reaction Analysis . . . . . . . . . . . . . . . . . . . . . . . . . . . . . . . . 80

6.5 .1 Introduction . . . . . . . . . . . . . . . . . . . . 80

$6.5 .2 \quad$ Soil Analysis Methodology . . . . . . . . . . . . . . . . . . . . . . . . . . . . 81

6.5 .3 Subgrade Formation FEM Analysis . . . . . . . . . . . . . . . . . 81

6.5 .4 Modulus of Subgrade Reaction Range . . . . . . . . . . . . . . . . . 86

6.5 .5 Limitations of Subgrade Analysis . . . . . . . . . . . . . . . 86

6.6 3D Static Tubular Track Model . . . . . . . . . . . . . . . . . . . . . . . . . 87

6.7 3D Static Model Analysis Results $\ldots \ldots \ldots$. . . . . . . . . . . . . . . 89

6.8 Conclusions . . . . . . . . . . . . . . . . . . . . . . . . . . . . . . . . 95

\begin{tabular}{|lll}
\hline & Dynamic Finite Element Analysis & 96
\end{tabular}

7.1 Introduction $\ldots \ldots \ldots \ldots \ldots \ldots \ldots$

7.2 3D Dynamic Tubular Track Model $\ldots \ldots \ldots \ldots$. . . . . . . . . . . 96

7.3 3D Model Dynamic Analysis Results . . . . . . . . . . . . . . . . . . . . . . . . 98 


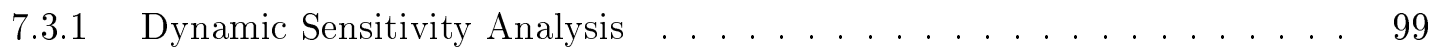

7.3 .2 Full-Scale Dynamic FEA with no Damping . . . . . . . . . . . . . . . . 100

7.3 .3 Dynamic FEA of TT System . . . . . . . . . . . . . . . . . . . . . . . . . . . . . . . . . . . . . . . . . . . . . . . .

7.4 Conclusions . . . . . . . . . . . . . . . . . . . . . . . 103

\begin{tabular}{lll}
\hline & Evaluation of FEA Results & 104
\end{tabular}

8.1 Introduction . . . . . . . . . . . . . . . . . . . . 104

8.2 Interaction Analysis $\ldots \ldots \ldots \ldots$. . . . . . . . . . . . . . . . 104

$8.2 .1 \quad$ Interaction Analysis Results . . . . . . . . . . . . . . . . . 106

8.3 Comparison of Static Analysis Methods . . . . . . . . . . . . . . . . . . 109

8.4 Dynamic Amplitude Factor Analysis . . . . . . . . . . . . . . . . . . 115

8.5 Field Test Results Comparison . . . . . . . . . . . . . . . . . . . 116

8.6 Design Sensitivity Analysis $\ldots \ldots \ldots \ldots$. . . . . . . . . . . . . 118

$8.6 .1 \quad$ Modulus of Subgrade Reaction Sensitivity . . . . . . . . . . . . . . 118

8.6 .2 Load Magnitude Sensitivity . . . . . . . . . . . . . . . . . . . . . . . . . . . . . . . . . . . . . . . . . . . . . . . . .

8.7 Conclusions . . . . . . . . . . . . . . . . . . . . . . . . . . . . . 123

9 Conclusions and Recommendations $\quad 126$

9.1 Conclusions . . . . . . . . . . . . . . . . . . . . 126

9.2 Recommendations . . . . . . . . . . . . . . . . . . . . . . . . . . . 129

9.3 Suggestions for Future Research $\ldots \ldots \ldots$. . . . . . . . . . . 130

\begin{tabular}{lr}
\hline Bibliography & 131
\end{tabular}

\begin{tabular}{ll}
\hline Appendices & 135
\end{tabular}

\begin{tabular}{|l|l|}
\hline A Modal Analysis Results & 136
\end{tabular}

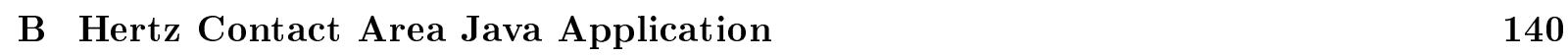

B.1 Class App. . . . . . . . . . . . . . . . . . . . . . . 140

B.2 Class Contact . . . . . . . . . . . . . . . . . . . . . . . . . 141

B.3 Class Integral . . . . . . . . . . . . . . . . . . . . . . . . . . 143

C Elastic Foundation MATLAB GUI Model $\quad 144$ 


\section{List of Figures}

$2.1 \quad$ Illustration of Railway Support Systems $\ldots \ldots \ldots \ldots \ldots$. . . . . . . . . . . . . 5

(a) Tubular Track System [1] . . . . . . . . . . . . . . . . . 5

(b) Ballasted Railway System [2] . . . . . . . . . . . . . . . 5

2.2 The Tubular Track Rail Structure $\ldots \ldots \ldots \ldots$. . . . . . . . . . . . . . . . 6

2.3 Two Adjacent CR11 Vehicles with Wheel Spacing Dimensions in $\mathrm{mm}$. . . . . . . . 7

$2.4 \quad$ Rail Dimensions and Properties $[3] \ldots \ldots \ldots \ldots \ldots \ldots$

(a) Rails Produced in South Africa . . . . . . . . . . . . . . . . . 8

(b) Imported Rails . . . . . . . . . . . . . . . . . . . . . . . 8

$2.5 \quad$ Amandelbult Layout Station 3 Soil Layers $\ldots \ldots \ldots \ldots \ldots$

$3.1 \quad$ Elastic Foundation Approximation $\ldots \ldots \ldots \ldots$. . . . . . . . . . . . 14

(a) Example of Supporting Subgrade Strata . . . . . . . . . . . . . . . . 14

(b) Beam on Elastic Foundation . . . . . . . . . . . . . . . . . . . 14

3.2 Infinite Beam on Elastic Foundation $\ldots \ldots \ldots \ldots \ldots \ldots \ldots$

3.3 Pasternak Foundation Model [4] . . . . . . . . . . . . . . . . . . . 17

3.4 Transformed-Section Method $\ldots \ldots \ldots \ldots$. . . . . . . . . . . . . . . . . . 19

(a) Original Cross Section . . . . . . . . . . . . . . . . . . . . . . . . . . . . . . . 19

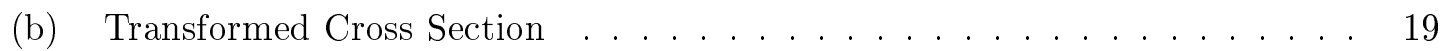

3.5 Continuously Supported Static Double Beam Model . . . . . . . . . . . . . . . . . . . . . . . . . . . . . . . . . . . .

$3.6 \quad$ MATLAB GUI . . . . . . . . . . . . . . . . . . . . . . . . . . . . . . . . 24

3.7 Railway System Guidance System ． . . . . . . . . . . . . . . . . . . . . . . 25

$3.8 \quad$ Influence of Flanging on Lateral Movement [4] $\ldots \ldots \ldots \ldots \ldots \ldots$

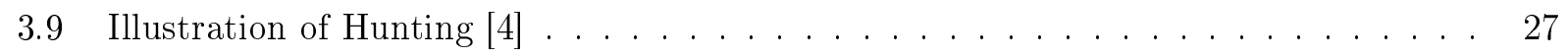

3.10 Examples of contact ellipses on a rail $\ldots \ldots \ldots \ldots \ldots \ldots$

3.11 Single and Two-Point Contact Areas [4] . . . . . . . . . . . . . . . . . . . . 29

(a) Single Point Contact . . . . . . . . . . . . . . . . . . . . . . . . . . . . . . . . . . . 29

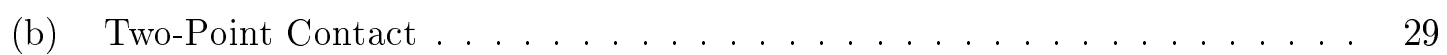

3.12 Elliptical contact between Two Semi-Circular Disks $\ldots \ldots \ldots \ldots$. . . . . . . 30

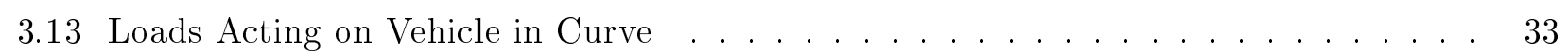

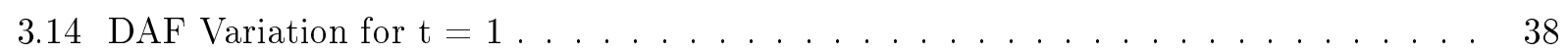

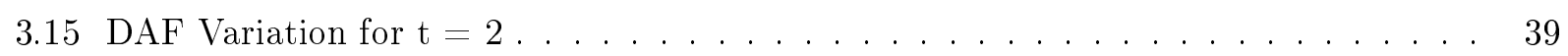

3.16 DAF Variation for $t=3 \ldots \ldots \ldots \ldots \ldots$

3.17 TT Single Beam Frequency Response Factors $\ldots \ldots \ldots$. . . . . . . . . . . . 42 
3.18 Sensitivity Illustration of damping ratio $\ldots \ldots \ldots \ldots \ldots$

$4.1 \quad$ Investigation Process of the TT System $\ldots \ldots \ldots \ldots \ldots$

5.1 Degrees of Freedom in xy Plane $\ldots \ldots \ldots \ldots \ldots \ldots$

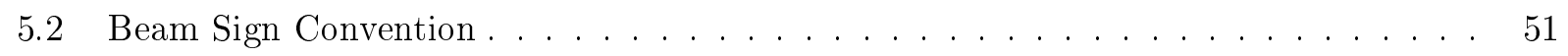

5.3 Illustration of the 8 Bogey Loads Caused by Two Adjacent Vehicles . . . . . . . . . 52

5.4 Deflections Caused by Two Adjacent Vehicles . . . . . . . . . . . . . . . 53

5.5 Bending Moment Diagram Caused by Two Adjacent Vehicles . . . . . . . . . . . . . 54

5.6 Shear Force Diagram Caused by Two Adjacent Vehicles . . . . . . . . . . . . . . 54

$5.7 \quad$ Model Example for FEA $\ldots \ldots \ldots \ldots \ldots \ldots \ldots \ldots$

5.8 PROKON Beam Model $\ldots \ldots \ldots \ldots \ldots \ldots$

5.9 PROKON Beam Model with 3D Rendering . . . . . . . . . . . . . . . . . 56

5.10 PROKON 2D Beam Model Displacements . . . . . . . . . . . . . . . . . . . . . . 57

5.11 PROKON 2D Beam Model Bending Moment Diagram . . . . . . . . . . . . . . 58

5.12 PROKON 2D Beam Model Shear Force Diagram . . . . . . . . . . . . . . . . . 58

5.13 PROKON 2D Beam Model Soil Pressure under Beam . . . . . . . . . . . . . . . . 59

5.14 Single Beam Model Displacements . . . . . . . . . . . . . . . . . . . . . . 60

5.15 Single Beam Model Bending Moment Diagram . . . . . . . . . . . . . . . . . . 61

5.16 Single Beam Model Shear Force Diagram . . . . . . . . . . . . . . . . . . . . . . . . 62

5.17 Single Beam Model Soil Pressure under Beam . . . . . . . . . . . . . . . . . . . . 62

5.18 ABAQUS 2D Beam Model $\ldots \ldots \ldots \ldots \ldots \ldots \ldots \ldots \ldots$

(a) ABAQUS Beam Model . . . . . . . . . . . . . . . . . . . 63

(b) ABAQUS Beam Model with 3D Rendering . . . . . . . . . . . . . . . 63

5.19 ABAQUS 2D Beam Model Displacements . . . . . . . . . . . . . . . . . . 64

5.20 ABAQUS 2D Beam Model Bending Moment Diagram . . . . . . . . . . . . . . . . 65

5.21 ABAQUS 2D Beam Model Shear Force Diagram . . . . . . . . . . . . . . . . . 66

5.22 ABAQUS 2D Beam Model Soil Pressure under Beam . . . . . . . . . . . . . . 66

5.23 Double Beam Model . . . . . . . . . . . . . . . . . . . . . . . . 67

5.24 Double Beam Model Displacements $\ldots \ldots \ldots$. . . . . . . . . . . . . . . . . . . . . . . 68

5.25 Double Beam Model Bending Moment Diagram . . . . . . . . . . . . . . . . . 69

5.26 Double Beam Model Shear Force Diagram . . . . . . . . . . . . . . . . . . . . . 69

5.27 Double Beam Model Soil Pressure under beam . . . . . . . . . . . . . . . . . . 70

6.1 Three-Dimensional Brick Elements . . . . . . . . . . . . . . . . . . 73

(a) Linear 8-Node Brick . . . . . . . . . . . . . . . . . . . . . . . . . . . . . . . 73

(b) Quadratic 20-Node Brick . . . . . . . . . . . . . . . . . . . . . . . . . . . . . 73

6.2 Three-Dimensional Brick Elements . . . . . . . . . . . . . . . . . . 73

(a) Linear 4-Node Tetrahedral . . . . . . . . . . . . . . . . . . . . . . . . . . . . . . . . 73

(b) Quadratic 10-Node Tetrahedral . . . . . . . . . . . . . . . . . . 73

6.3 Comparison between Square and Rectangular PBT . . . . . . . . . . . . . . . 78

6.4 Square Plate Bearing Test $\ldots . \ldots \ldots \ldots$. . . . . . . . . . . . . . . . . 82

6.5 Square Plate Bearing Test displacements $\ldots \ldots \ldots \ldots \ldots \ldots$ 
6.6 Rectangular Plate Bearing Test . . . . . . . . . . . . . . . . . . . . . . 84

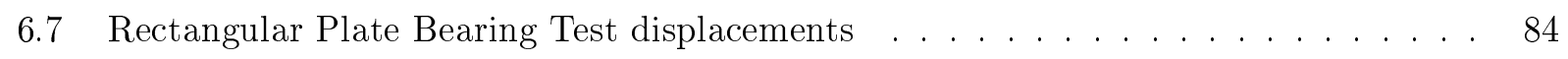

6.8 Plate Bearing Tests Results $\ldots \ldots \ldots \ldots \ldots \ldots \ldots \ldots$

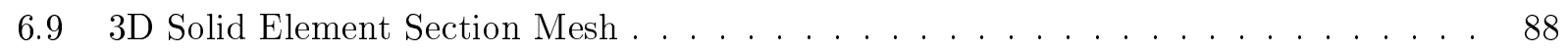

6.10 3D Solid Element Model . . . . . . . . . . . . . . . . . . . . . . . 88

6.11 ABAQUS 3D Model Displacements . . . . . . . . . . . . . . . . . . . . . 89

6.12 ABAQUS 3D Model Displacements . . . . . . . . . . . . . . . . . . . . . . . . . . . 90

6.13 ABAQUS 3D Model Bending Moment Diagram. . . . . . . . . . . . . . . . . . 91

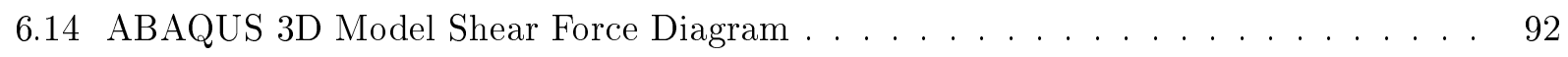

6.15 Soil Pressure Distributions [5] . . . . . . . . . . . . . . . . . . . . . . . . . 92

(a) Uniform Pressure . . . . . . . . . . . . . . . . . . . . . . . . 92

(b) Sandy Soil Non-Uniform Pressure . . . . . . . . . . . . . . . . . . . . . . . . . . . . 92

(c) Clay Soil Non-Uniform Pressure . . . . . . . . . . . . . . . . . . . 92

6.16 ABAQUS 3D Model Soil Pressure under Grout Layer . . . . . . . . . . . . . . . . . . . . 93

6.17 ABAQUS 3D Model Soil Pressure under Grout Layer . . . . . . . . . . . . . . . . 94

6.18 ABAQUS 3D Model RC Pressure $\ldots \ldots \ldots \ldots \ldots$. . . . . . . . . . 94

$7.1 \quad$ Loading Positions of Dynamic Model . . . . . . . . . . . . . . . . . . . . . . . . . . . . . . .

7.2 Example of a Load Amplitude $\ldots \ldots \ldots \ldots \ldots$

7.3 Nodal Load Increments $\ldots \ldots \ldots$. . . . . . . . . . . . . . . . . . . . . . . . . . . . . . 99

$7.4 \quad$ Bending Moment Diagram for $\mathrm{t}=0.218 \mathrm{~s}$ with no Damping . . . . . . . . . . . . 101

7.5 Shear Force Diagram for $\mathrm{t}=0.218 \mathrm{~s}$ with no Damping $\ldots \ldots \ldots$. . . . . . . . 102

7.6 Dynamic Displacements . . . . . . . . . . . . . . . . . . . . . 103

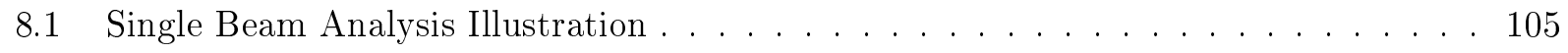

8.2 ABAQUS and PROKON Model Illustrations . . . . . . . . . . . . . . . . . . . . . . . . . . . 106

(a) PROKON Frame Analysis Model Illustration . . . . . . . . . . . . . . 106

(b) ABAQUS 3D Beam Model Illustration Illustrating the Vertical Displacements 106

$8.3 \quad$ Comparison Between Displacements of Various Analysis Methods . . . . . . . . . . . 107

8.4 Comparison Between Bending Moments of Various Analysis Methods . . . . . . . . 107

8.5 Comparison of the Effects of Rigid Links Connections . . . . . . . . . . . . . . 108

$8.6 \quad$ Rail Displacements . . . . . . . . . . . . . . . . . . . . . . . 110

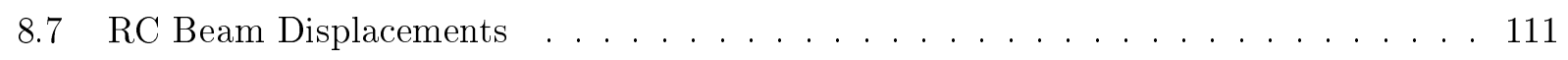

$8.8 \quad$ Comparison of Rail Bending Moment Diagrams . . . . . . . . . . . . . . . . . . . . 112

8.9 Comparison of RC Beam Bending Moment Diagrams . . . . . . . . . . . . . . 112

8.10 Comparison of Rail Shear Force Diagrams . . . . . . . . . . . . . . . . . . . . . . . . . . . . .

8.11 Comparison of RC Beam Shear Force Diagrams . . . . . . . . . . . . . . . . . 114

8.12 Comparison of Soil Pressure Distributions . . . . . . . . . . . . . . . . 115

8.13 Maximum Displacements . . . . . . . . . . . . . . . . . . . . . . 119

8.14 Maximum Bending Moments . . . . . . . . . . . . . . . . . . . . . 119

8.15 Maximum Shear Forces . . . . . . . . . . . . . . . . . . . . . 120

8.16 Maximum Displacements . . . . . . . . . . . . . . . . . . . 121 
8.17 Maximum Bending Moments . . . . . . . . . . . . . . . . . . . 122

8.18 Maximum Shear Forces $\ldots \ldots \ldots$. . . . . . . . . . . . . . . . 123

A.1 Mode Base State . . . . . . . . . . . . . . . . . . . . . . . . . . . 136

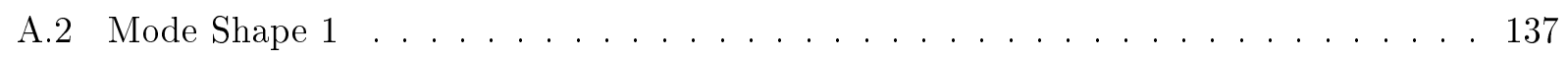

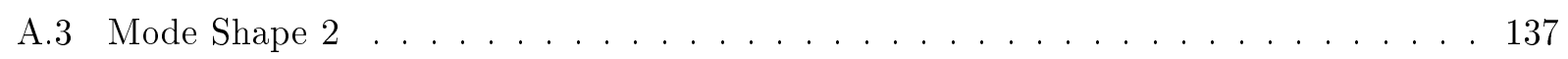

A.4 Mode Shape 3 . . . . . . . . . . . . . . . . . . . . . . . . . . 138

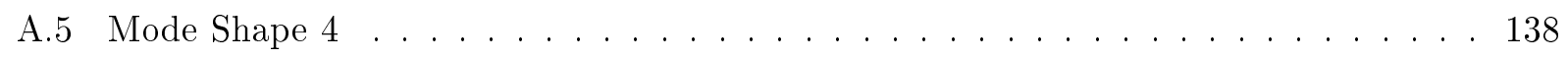

A.6 Mode Shape 5 . . . . . . . . . . . . . . . . . . . . . . . . . . . 139 


\section{List of Tables}

$2.1 \quad$ Rail Dimensions and Properties $[3] \ldots \ldots \ldots \ldots \ldots$

2.2 Elastomeric Pad Material Properties [6] . . . . . . . . . . . . . . . . . 9

2.3 Concrete Material Properties [7] . . . . . . . . . . . . . . . . . . 9

2.4 Reference Formation Section Soil Properties [7] . . . . . . . . . . . . . . . . . . 10

$3.1 \quad$ Kalker's Creepage and Spin Coefficients [4] . . . . . . . . . . . . . . . . . . . 36

3.2 Dynamic Amplification Factor Values [4] . . . . . . . . . . . . . . . . . . 37

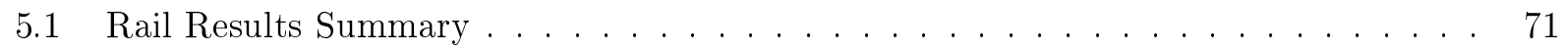

5.2 RC Beam Results Summary . . . . . . . . . . . . . . . . . . . . . 71

6.1 Summary of Element Types $\ldots \ldots \ldots \ldots \ldots \ldots \ldots$

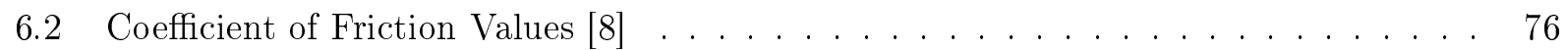

6.3 Modulus of Subgrade Reaction Analysis Results _ . . . . . . . . . . . . . . . . . . . . . . . . . . .

6.4 Range of Elastic Constants . . . . . . . . . . . . . . . . . . . 86

6.5 ABAQUS 3D Results Summary . . . . . . . . . . . . . . . . . . . . . 95

$7.1 \quad$ Dynamic Damping and Time Step Sensitivity Analysis . . . . . . . . . . . . . . . 100

8.1 Amandelbult Layout Section 3 Deflection Measurements [7] . . . . . . . . . . . . . . 117

8.2 Rail Results Summary . . . . . . . . . . . . . . . . . . . . . . . . 124

8.3 RC Beam Results Summary . . . . . . . . . . . . . . . . . . . . . . . 124 


\section{List of Abbreviations}

2D Two-Dimensional

3D Three-Dimensional

BM Bending Moments

DAF Dynamic Amplitude Factor

DoF Degree of Freedom

FEA Finite Element Analysis

FEM Finite Element Method

FWC Flangeway Clearance

LC Load Combination

PBT Plate Bearing Test

RC Reinforced Concrete

SF Shape Factor

TT Tubular Track 


\section{Nomenclature}

\section{Variables}

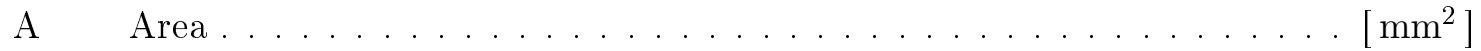

$\mathrm{A}_{\mathrm{s}} \quad$ Shear Cross Section Area . . . . . . . . . . . . . [ $\left.\mathrm{mm}^{2}\right]$

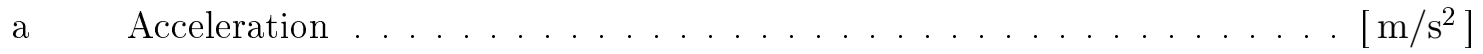

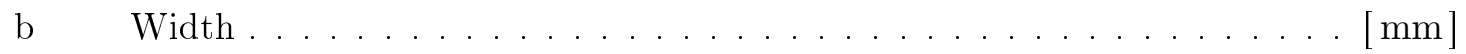

C Wheelset moment of inertia ............... $\left.\ldots \mathrm{m}^{4}\right]$

$\mathrm{C}_{\mathrm{ij}} \quad$ Kalker coefficients .................... . $\ldots \ldots$

c Geometric mean of semi-axes of contact ellipse . . . . . . . . . . [ [mm]

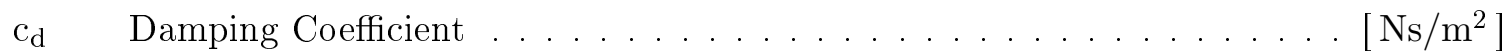

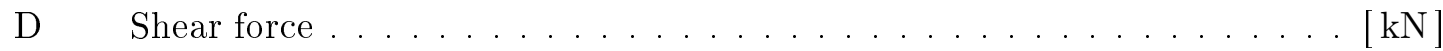

E Modulus of Elasticity/Young's Modulus . . . . . . . . . . . . [MPa]

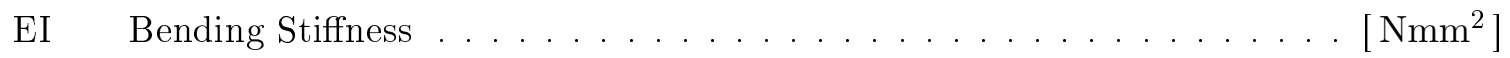

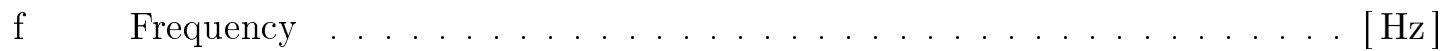

G Shear Modulus . . . . . . . . . . . . . . [MPa]

$\mathrm{H}_{\mathrm{w}} \quad$ Crosswind force acting on train $\ldots \ldots \ldots \ldots \ldots \ldots \ldots \ldots \ldots$

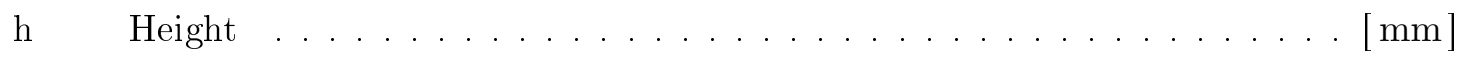

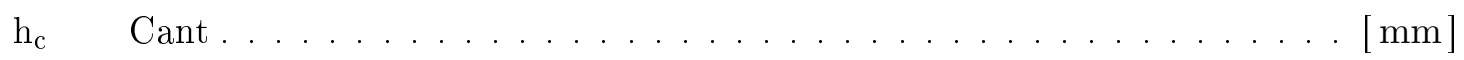

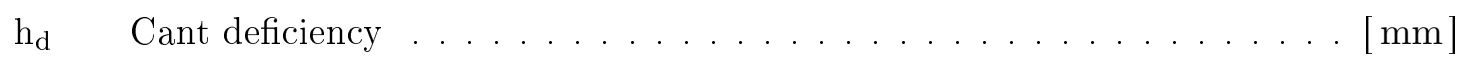

I Moment of Inertia . . . . . . . . . . . . . . . . [ $\left[\mathrm{mm}^{4}\right]$

K Stiffness matrix $\ldots \ldots \ldots \ldots \ldots \ldots \ldots \ldots \ldots \ldots \ldots \ldots$

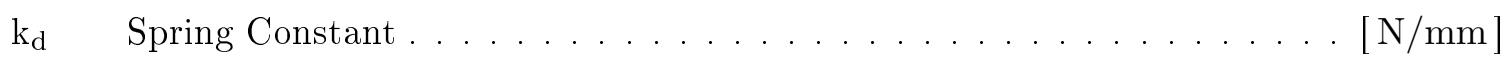

$\mathrm{k}_{\mathrm{eq}} \quad$ Equivalent Foundation Coefficient . . . . . . . . . . . . [ $\left.\mathrm{N} / \mathrm{mm}^{2} / \mathrm{mm}\right]$

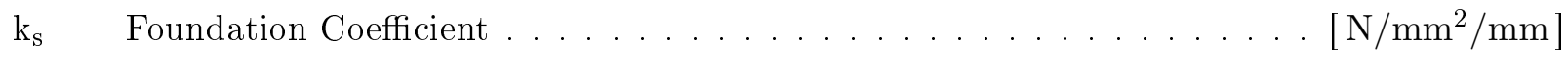

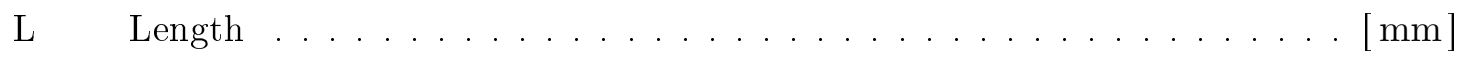

$\mathrm{L}_{\mathrm{c}} \quad$ Characteristic Length $\ldots \ldots \ldots \ldots \ldots \ldots \ldots \ldots \ldots \ldots \ldots \ldots$. . . . . . . . . .

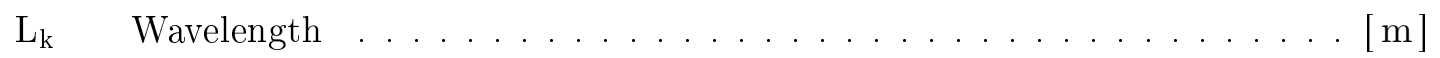

M Bending Moment . . . . . . . . . . . . . . . [ [kNm

m Mass of train per wheelset .............. . . . . . . . 


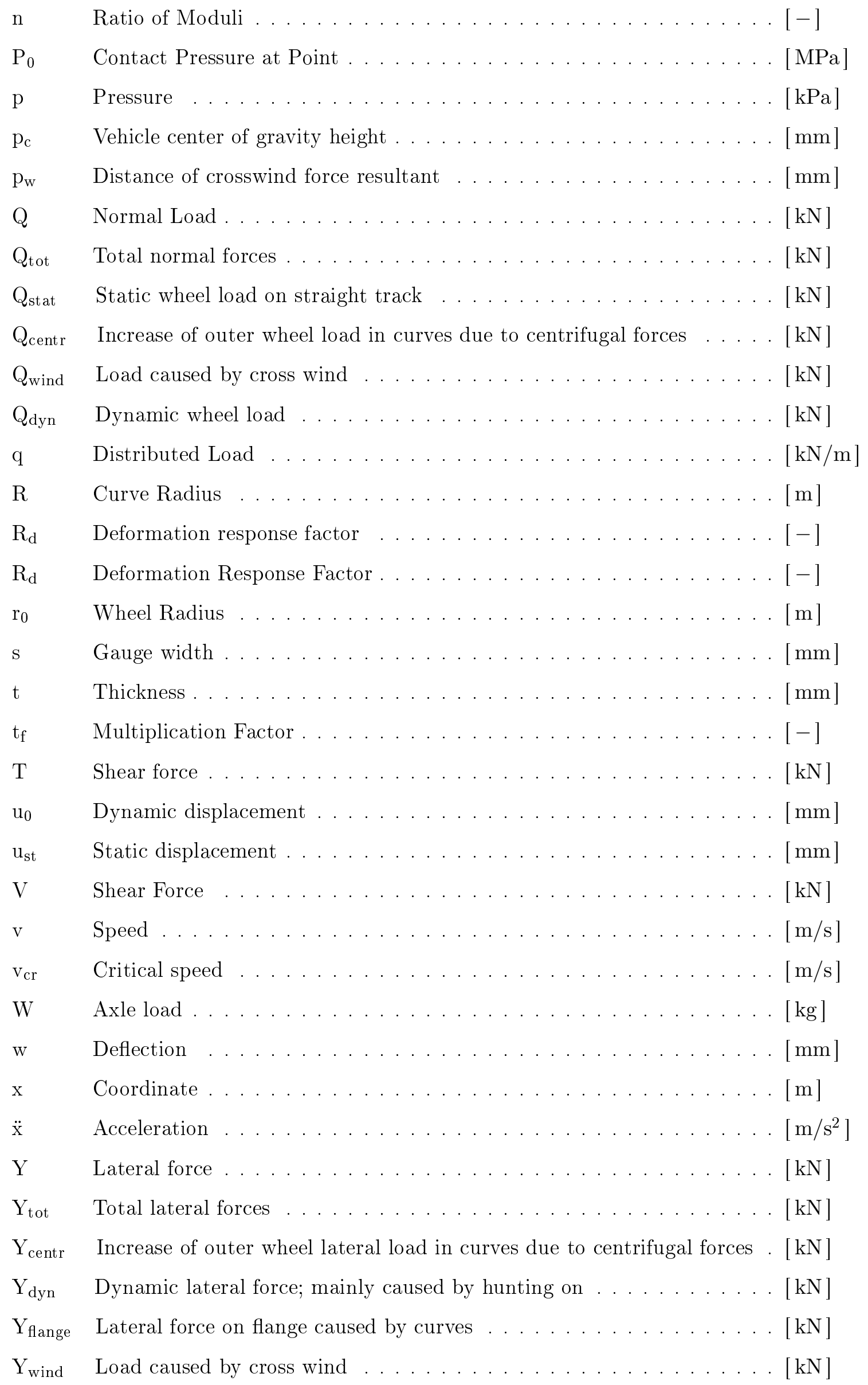




\section{Greek Symbols}

\begin{tabular}{|c|c|c|}
\hline$\alpha$ & Mass-Proportional Constant & {$[-]$} \\
\hline$\beta$ & Stiffness-Proportional Constant & {$[-]$} \\
\hline$\epsilon_{\mathrm{x}}$ & Wheel Slip . . . . & {$[-]$} \\
\hline$\zeta$ & Damping Ratio . . . . . . . . & {$[-]$} \\
\hline$\theta$ & Rotation & {$[\operatorname{deg}]$} \\
\hline$\lambda$ & Wheelset Conicity . & {$[\mathrm{m}]$} \\
\hline$\nu$ & Poisson's Ratio . & {$[-]$} \\
\hline$\rho$ & Density & {$\left[\mathrm{kg} / \mathrm{m}^{3}\right]$} \\
\hline$\sigma$ & Stress & {$[\mathrm{MPa}]$} \\
\hline$\phi$ & Track Quality Factor . . . . . . . & {$[-]$} \\
\hline & Rotational speed & {$[\mathrm{rad} / \mathrm{s}]$} \\
\hline
\end{tabular}




\section{Chapter 1}

\section{Introduction}

This thesis is part of a broader project conducted by the division of Structural Engineering of the Civil Engineering Department at the University of Stellenbosch for Tubular Track (Pty) Ltd. The Tubular Track (TT) railway system is a twin beam modular railway system consisting of two reinforced concrete $(\mathrm{RC})$ beams on which steel rails are continuously supported. The beams are linked with galvanised steel gauge tie bars for lateral stiffness and continuously supported by soil foundations, and can be used to replace conventional sleeper and ballast railway support. The purpose of this dissertation is to perform a static and dynamic finite element analysis (FEA) of the TT railway system using various analysis methods which can be used for the analysis and design of the TT railway system.

The TT railway system can be utilised in various applications, such as in main lines, marshalling yards, urban light rail systems, mining and tunnels and consists of steel rails, reinforced concrete (RC) beams, elastomeric pads, and steel tie bars and will be discussed in more detail in later chapters. Previous FEA have been performed by Transnet using three-dimensional (3D) models by means of the Strand7 finite element method (FEM) software package, and the University of Stellenbosch using two-dimensional (2D) models with the PROKON FEM software package, but yielded conflicting results. The conflicting results mean that one of the analysis methods used for the analysis and design of TT railway sections is either an underestimation or overestimation of section displacements, forces, and stresses; or both methods could even be incorrect. The results and models of the previous analyses are not explicitly investigated in this dissertation, but serve as a motivation for this investigation. The main emphasis of this investigation is rather to develop and verify analysis methods and modeling techniques which can be used to simulate the TT railway system accurately.

Overestimations of the stiffness and load carrying capacity of the TT system leads to an underdesign of displacements, bending moments, and shear forces which could potentially lead to premature failure or increased degradation of the TT system or supporting subgrade strata. Overdesign of the TT system could cause the designer to specify larger steel rail profiles, smaller spacing increments between steel stirrups in the RC beams or larger diameters of the longitudinal and stirrup steel bars, and would lead to an increase in costs of the system, which can be signif- 
icant due to the lengths of typical railway lines. The cost of a railway system is therefore very sensitive to changes in the geometry and section design. TT (Pty) Ltd. placed special emphasis on the shear forces and steel stirrup requirement of the $\mathrm{RC}$ beams due to the cost implication of the amount of steel reinforcement required [9].

Underestimation of the stiffness of the TT system, on the other hand, leads to an overdesign of the system, which also has cost implications. One of the advantages of a continuous railway system such as the TT system is the reduced maintenance relative to traditional ballasted railway sections. Accelerated degradation of the railway system or supporting subgrade formation requires increased maintenance or possibly replacement to ensure safety and operational functions, and therefore also leads to an increase in cost, and defeats the purpose of using the continuous system rather than traditional ballasted systems. Correctly estimating the stiffness and load carrying capacity of the TT system is therefore very important.

The analysis models to be used range from simple theoretical models based on elastic foundation principles, to $2 \mathrm{D}$ beam elements, and ultimately to complex 3D solid finite element models. The alternative analysis methods considered should give a clear indication to which analysis methods are accurate and feasible for design of the TT system. The main purpose of this dissertation is to compare and verify the validity and accuracy of the theoretical, 2D FEM beams, and 3D FEM solid element analysis models subjected to static and dynamic loading cases with in-situ field test results. The validity of empirical methods simulating dynamic loading conditions must also be investigated, as this generally applied method may not necessarily be applicable for continuous railway systems. The verification of the usage of modeling techniques for the analysis of components of the system such as the subgrade foundations, rail profiles, RC beam dimensions, and elastomeric pads will ultimately be made in order to provide accurate and efficient methods for the analysis and design of the TT railway system. The purpose of this dissertation is to ultimately provide a simple finite element model which can be utilised to perform quick and simple analyses.

A reference model with known deflections and design parameters specific to a TT railway section is used to analyse the accuracy and validity of different analysis methods. Simplification of a subgrade foundation by simulating a soil stiffness supporting the TT beam is proposed and analysed by comparing FEA results of soil models using parameters of four known soil formations in use at TT railway sections currently installed. Once the the results of the various analysis methods are verified to be accurate relative to known field test results, the analysis models can then be modified to simulate different conditions such as e.g. subgrade stiffness, track loading magnitudes, and beam properties for the design of other TT railway sections. The sensitivity of the TT system to design parameters is also investigated in later chapters to indicate to which parameters the design is sensitive to i.e. modulus of subgrade reaction, loading and damping magnitudes and where small variations in these parameters require due consideration. 


\subsection{Aims of Investigation}

As stated previously, the aim of this investigation is to perform detailed FEA of the TT railway system using several possible modeling techniques with varying complexity. The models used range from theoretical models based on beams supported by an elastic foundation to full-scale 3D models, applying both static and dynamic loads.

The main objectives of this investigation are as follows:

- Create theoretical models based on elastic theory principles

- Create 2D beam FEM models

- Create 3D solid element FEM models

- Perform static analyses using theoretical, 2D beam and 3D solid element FEA models

- Perform dynamic analyses using 3D models

- Verify the empirical dynamic amplification method

- Verify the accuracy of various analysis techniques by comparing results with each other, as well as field test results

- Develop a 2D model for quick and efficient analysis and design

A railway system is subjected to vertical, lateral, and longitudinal forces which depend on specific design parameters which are highly variable. The magnitude of lateral and longitudinal forces are dependent on for example the curve radius and canting of the vehicle, which vary along the length of a curve, and are therefore not implemented for the general straight track analysis performed in this investigation where the main goal is to obtain a simplified analysis model which can be used for general analysis and design of the TT railway system. Nevertheless, the additional lateral and longitudinal forces are demonstrated in this dissertation and can be implemented in more detailed analyses and designs if required.

The TT railway system is described in Chapter 2. The various components which form part of the continuous TT railway system, and the advantages of this railway system over traditional ballasted railway lines are also described. The exact geometry and design details of the various components are not included to protect TT's intellectual property, but are explained briefly. The material and geometrical properties are kept constant for the various analysis methods for the purpose of comparing the analysis methods, unless stated otherwise.

The literature review and theoretical background relevant to this investigation is presented in Chapter 3 Section 3.1 introduces the elastic foundation theory used for the soil support of the TT railway system, and provides the basis of the theoretical models used for comparison with the more detailed FEA models such as the 2D beam and 3D solid element models. Section 3.2 
investigates the interaction between the wheel of the railway vehicle and the rail supporting it, and describes the guiding mechanisms of railway tracks and loads associated therewith. Section 3.3 subsequently presents a more detailed explanation of the static, dynamic, vertical, lateral, and longitudinal loads acting on the railway structure and the dynamic factors associated with railway analyses. As previously stated, the main focus of this investigation is the vertical loads and not the minor lateral and longitudinal loads, but these are briefly described for background purposes.

The research methodology is presented in Chapter 4 and describes the various analysis methods used for modeling the behaviour of the TT railway system under specific conditions and describes the procedures followed for the acquisition of the required results to ultimately arrive at the conclusions of this investigation. The purpose of Chapter 4 is to present the research methodology followed for the investigation of the TT railway system and the models which are to be investigated using the FEM in combination with elastic foundation theory. The scope and limitations of this investigation are also discussed in Chapter 4.

The 2D and 3D FEM models are described in Chapters 5 and 6 and explain the finite element modeling methods which can be utilised for the analysis of a continuous railway system, such as Chapter 5 which describes and analyses the 2D beam models as well as the theoretical models as investigated in Chapter 3 . Chapter 6 demonstrates the more detailed 3D solid element models which are used for the FEA of soil response of actual TT railway sections for the procurement of a subgrade support stiffness as well as the static analysis of the TT railway structure.

The dynamic analyses are performed in Chapter 7 and investigate the dynamic nature of the TT railway system by investigating the empirical Dynamic Amplitude Factor (DAF) method which is commonly used for the analysis of railway systems. A sensitivity analysis of the influence of damping on the TT structure is also performed.

The comparison and evaluation of the various analysis methods are dealt with in Chapter 8 . The accuracy and feasibility of the analysis methods are verified and compared with one another, and are also compared with field test results obtained for the reference TT layout. The proposed DAF investigated in Chapter 3 and obtained in Chapter 7 is verified by comparing the applied DAF to a static load with the in-situ test results. The sensitivity of the TT railway system to design parameters is also investigated in this chapter, and investigates which parameters must be applied with due consideration.

Conclusions on the accuracy and feasibility of the FEA models are provided in Chapter 9 . Recommendations for the finite element models which can be used for accurate analysis and design of the TT railway system are also given. A recommendation for the most practical analysis method is made for the purpose of future analysis and design of TT railway sections, as well as recommendations for future research on matters which fall outside the scope of this investigation. 


\section{Chapter 2}

\section{Tubular Track System}

Most of the railway lines currently in use are the traditionally ballasted railway types, although more recent applications of railway lines are non-ballasted i.e. continuously supported slab tracks. The design of railway lines are dependant on factors such as construction time, maintenance cost, availability and durability of the railway system. Continuously supported railway lines are noteworthy alternatives to standard ballast and sleeper railway lines, as they provide lower life cycle costs and ease of constructibility due to pre-construction and in-situ assembly [4]. The Tubular Track (TT) railway system represents such a continuously supported railway system, as illustrated in Figure 2.1a.

This modular railway system replaces the conventional ballast and sleeper railway track system used extensively globally, which has remained fundamentally unchanged for over a century, as illustrated in Figure 2.1b. The continuous support prevents the large deflections and localised stress concentrations caused by sleeper spacings, thereby also improving the response of the subgrade foundation to loading.

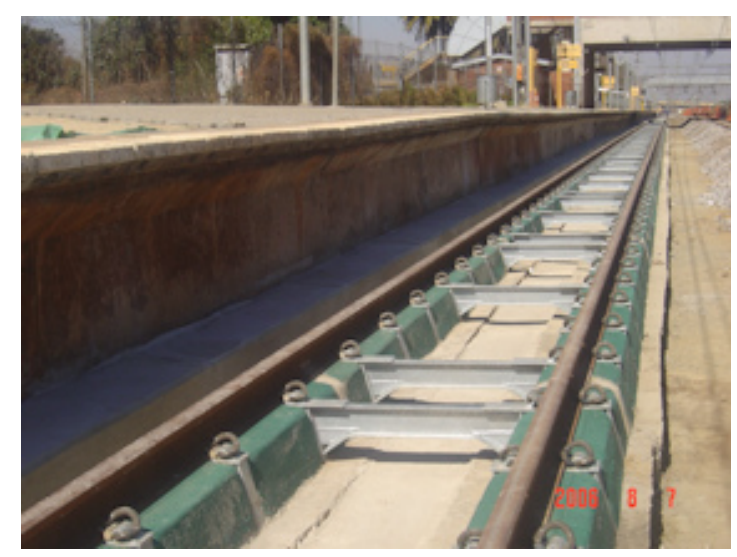

(a) Tubular Track System [1]

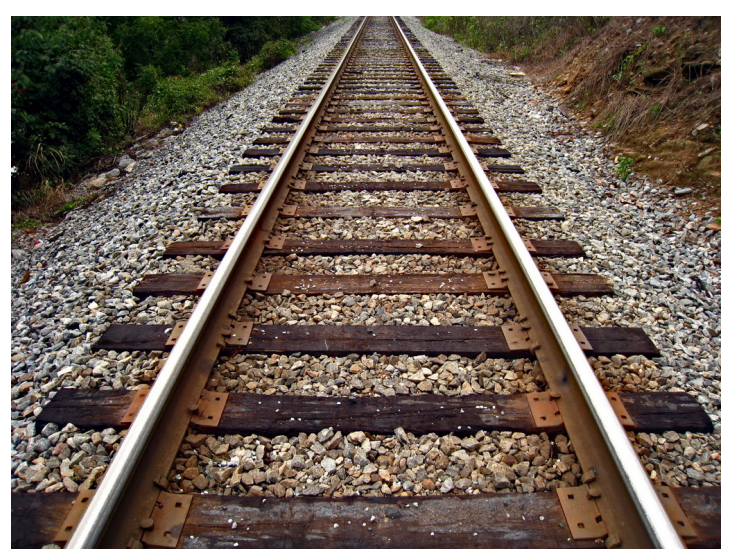

(b) Ballasted Railway System [2]

Figure 2.1: Illustration of Railway Support Systems 
The TT system uses a pre-cast modular railway system which consists of two reinforced concrete (RC) beams linked with galvanised steel gauge tie bars on which steel rails are continuously supported, as illustrated in Figure 2.2. The TT RC beam dimensions and steel reinforcement are optimized according to design axle loads and in-situ geotechnical conditions. The RC beams are pre-cast by pumping self-compacting concrete into geotextile sleeves which contain the reinforcement steel. The geotextile sleeves are placed inside steel formwork which allow the sleeves to bulge slightly over the steel gauge bars, ensuring continuous support. The rails and RC beams are separated by means of an elastomeric pad, which is used to electrically insulate the system and distribute the stresses in the system caused by loading due to the passing train vehicles. The rails are connected to the $\mathrm{RC}$ beams by means of standard fasteners.

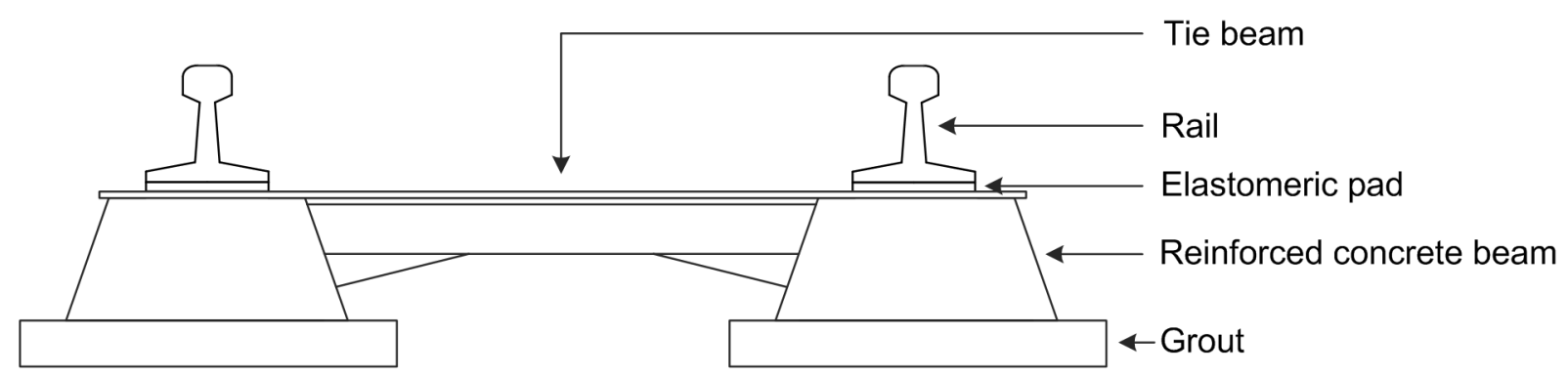

Figure 2.2: The Tubular Track Rail Structure

The galvanised steel gauge tie bars are not cast into the $\mathrm{RC}$ beams, but instead encircle the beams. This ensures that the tie bars do not work loose due to repetitive dynamic loading or interfere with the reinforcement steel of the concrete. The steel gauge tie bars are placed at $3 \mathrm{~m}$ intervals on straight track, and at lesser intervals at curved sections to accommodate for lateral forces and ensuring stability of the railway system [1]. The TT system uses standard railway components such as rail sizes, axle loads and international gauges. This allows for transitions from conventional ballasted track to the TT railway system.

\subsection{Continuously Supported Railway Advantages}

The general problem of ballasted railway tracks is deterioration of the ballast material due to traffic loading and ballast fouling. Regular maintenance is therefore very important to ensure geometrical stability and track alignment. Continuously supported railway systems are known to provide higher lateral and longitudinal stability with smaller deviations of track alignment. The TT railway system has several advantages over conventional ballast and sleeper railway systems, such as:

- Lower maintenance

- Reduced rail stresses

- Constant vertical and horizontal geometry, with simple corrections possible 
- No ballast or tamping costs

- No ballast fouling

- Earthworks savings

- Low life-cycle costs

- Increased service life

\subsection{Tubular Track System Loading and Components}

The performance of a railway system is a function of the response of the system's components subjected to dynamic train bogey loads and is dependant on the railway's vertical and lateral track stability and the composite support stiffness of the various components. Due to the symmetry of the system and the fact that only general straight tracks will be analysed, only a single side of the railway system will be modeled.

The system components of the TT system are briefly explained in this section and will be investigated in further detail in later chapters. The design of the reference layout used for the analysis methods is based on the Amandelbult Layout station 3, and is also discussed in this section.

\section{Tubular Track System Loading}

The wheel spacing of the train loads are based on the CR11 vehicles used at the Amandelbult TT section as illustrated in Figure 2.3 [10]. Each carriage has a bogey at each end, each consisting of two axles, thereby causing four axles to be closely spaced. The wheel loads are applied as point loads for the beam models and as distributed pressure loads for the three-dimensional (3D) models and have a magnitude of 12.5 tonnes or $125 \mathrm{kN}$ for the Amandelbult section. The applied loads do not take factors such as nosing or dynamic impact factors into account, as this is only required for design. The speed of the train, required for the dynamic analyses to obtain the empirical Dynamic Amplification Factor (DAF) is approximately $43 \mathrm{~km} / \mathrm{h}$, as measured at the Amandelbult section.

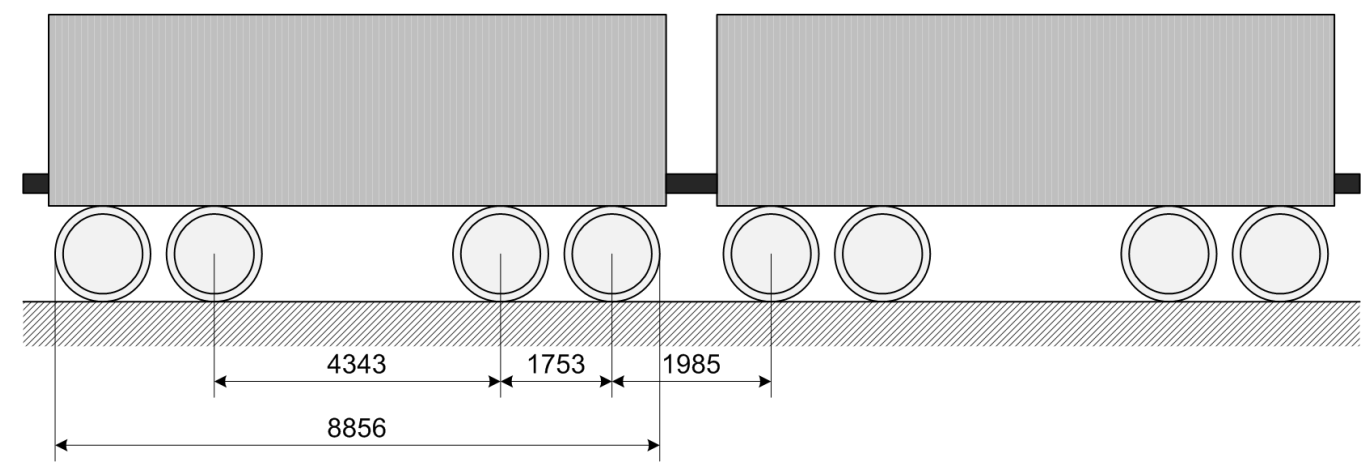

Figure 2.3: Two Adjacent CR11 Vehicles with Wheel Spacing Dimensions in mm 


\section{Rail Model}

The goal of rail cross-section design is based on choosing the most economical design with the required strength and ductility depending on the shape, size, material, and rail hardness [11]. The rail types under investigation for the purpose of this dissertation are standard UIC rails, as illustrated and listed in Figure 2.4 and Table 2.1 respectively. The rail which is used for the investigation of the reference model at the Amandelbult TT railway section is a UIC $48 \mathrm{~kg} / \mathrm{m}$ rail. For the simpler finite element models, such as the two-dimensional (2D) beams and elastic foundation models to be investigated the section and material properties of the rails are merely input parameters and the section profile is not geometrically modeled.

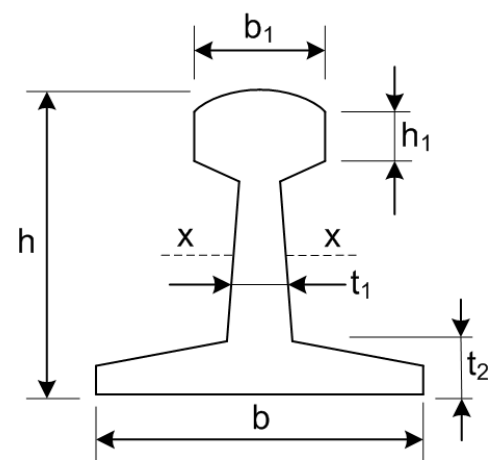

(a) Rails Produced in South Africa

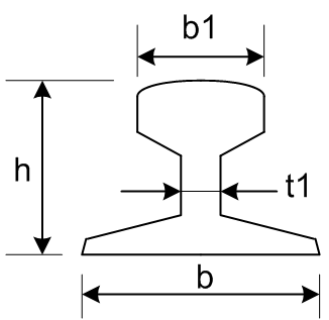

(b) Imported Rails

Figure 2.4: Rail Dimensions and Properties [3]

Table 2.1: Rail Dimensions and Properties [3]

\begin{tabular}{|c|c|c|c|c|c|c|c|c|c|c|c|}
\hline \multirow[b]{2}{*}{ Designation } & \multirow[b]{2}{*}{$\mathrm{m}$} & \multirow[b]{2}{*}{$\mathrm{h}$} & \multirow[b]{2}{*}{$\mathrm{b}$} & \multirow[b]{2}{*}{$\mathrm{b}_{1}$} & \multirow[b]{2}{*}{$\mathrm{h}_{1}$} & \multirow[b]{2}{*}{$t_{1}$} & \multirow[b]{2}{*}{$t_{2}$} & \multirow[b]{2}{*}{$\mathrm{A}$} & \multirow[b]{2}{*}{ I } & \multicolumn{2}{|c|}{ About $\mathrm{x}-\mathrm{x}$} \\
\hline & & & & & & & & & & $Z_{\text {e.top }}$ & $\mathrm{Z}_{\text {e.bot }}$ \\
\hline $\mathrm{kg} / \mathrm{m}$ & $\mathrm{kg} / \mathrm{m}$ & $\mathrm{mm}$ & $\mathrm{mm}$ & $\mathrm{mm}$ & $\mathrm{mm}$ & $\mathrm{mm}$ & $\mathrm{mm}$ & $10^{3} \mathrm{~mm}^{2}$ & $10^{6} \mathrm{~mm}^{4}$ & $10^{3} \mathrm{~mm}^{3}$ & $10^{3} \mathrm{~mm}^{3}$ \\
\hline \multicolumn{12}{|c|}{ Produced in South Africa: } \\
\hline 10 & 9.92 & 63.5 & 63.5 & 35 & 19.4 & 6 & 10.3 & 1.27 & 0.708 & 22.3 & 22.3 \\
\hline 15 & 14.9 & 76.2 & 76.2 & 41.3 & 25.4 & 7.5 & 13.1 & 1.9 & 1.49 & 38.8 & 39.2 \\
\hline 22 & 22.4 & 95.3 & 95.3 & 50 & 31.4 & 10 & 15.5 & 2.86 & 3.48 & 72.8 & 73.1 \\
\hline 30 & 30.2 & 109.5 & 109.5 & 57.2 & 34.9 & 11.5 & 17.5 & 3.85 & 6.27 & 111 & 118 \\
\hline 40 & 40.3 & 127 & 127 & 63.5 & 40.5 & 14 & 19.5 & 5.16 & 11.1 & 167 & 185 \\
\hline 45 & 45.3 & 151 & 127 & 67.5 & 42.9 & 14 & 20.6 & 5.75 & 17.9 & 232 & 244 \\
\hline 48 & 47.6 & 150 & 127 & 68 & 43 & 14 & 25 & 6.08 & 18.2 & 234 & 255 \\
\hline 57 & 57.1 & 165 & 140 & 69.9 & 47.6 & 15.9 & 26.6 & 7.31 & 26.5 & 296 & 244 \\
\hline \multicolumn{12}{|l|}{ Imported: } \\
\hline A65 & 43.1 & 75 & 175 & 65 & & 38 & & & 3.19 & 71.4 & \\
\hline A75 & 56.2 & 85 & 200 & 75 & & 45 & & & 5.31 & 105 & \\
\hline A100 & 74.3 & 95 & 200 & 100 & & 60 & & & 8.58 & 162 & \\
\hline $\mathrm{A} 120$ & 100 & 105 & 220 & 120 & & 72 & & & 13.6 & 235 & \\
\hline
\end{tabular}




\section{Elastomeric pad Model}

The elastomeric railpads are placed between the rails and $\mathrm{RC}$ beams, and protect the RC beam from impact damage and wear as well as providing electrical insulation from the rails. The railpads are also extremely important from a stiffness point of view, because they are much softer than the rails and $\mathrm{RC}$ beams and therefore allow more deflection in the rails whilst also isolating the beams from high-frequency vibrations [12]. The pads allow the vertical stresses to spread over a larger area from the rails to the $\mathrm{RC}$ beams, thereby reducing the high pressure localisation occurrence.

The elastomeric pads used for the purpose of this investigation and the reference Amandelbult section are FC55 elastomeric pads, unless otherwise stated. The elastomeric pad has a static and dynamic stiffness, of which the dynamic stiffness is used in the analysis models as this is more accurate relative to in-situ conditions. The material properties of the FC55 rubber pad are as follows:

Table 2.2: Elastomeric Pad Material Properties [6]

\begin{tabular}{ccccc}
\hline $\begin{array}{c}\text { Young's Modulus } \\
{[\mathrm{MPa}]}\end{array}$ & $\begin{array}{c}\text { Poisson's Ratio } \\
-\end{array}$ & $\begin{array}{c}\text { Density } \\
{\left[\mathrm{kg} / \mathrm{m}^{3}\right]}\end{array}$ & $\begin{array}{c}\text { Static Stiffness } \\
{\left[\mathrm{kN} / \mathrm{mm} / \mathrm{m}^{2}\right]}\end{array}$ & $\begin{array}{c}\text { Dynamic Stiffness } \\
{\left[\mathrm{kN} / \mathrm{mm} / \mathrm{m}^{2}\right]}\end{array}$ \\
\hline 25.2 & 0.35 & 940 & 2932 & 5255 \\
\hline
\end{tabular}

\section{Reinforced Concrete Beam Model}

The reinforcement of the $\mathrm{RC}$ beams will not be modeled in the general analyses as this requires an extremely fine mesh, greatly increasing the number of elements and analysis time. The reinforcement provides additional tensile and shear resistance and therefore decreases the stresses found in the concrete. Excluding the reinforcement from the analysis models produces, although marginal, over-estimations of the deflections and bending moments, thereby adding an additional factor of safety. Once the axial forces, bending moments, and shear forces in the concrete beams are known, the steel reinforcement design can be performed. The RC beams are supported by a concrete filling layer (grout) which provides a larger contact area between the RC beams and the subgrade foundation support and also provides stabilization for rotation. The material properties of the RC beams and grout are listed in Table 2.3 below.

Table 2.3: Concrete Material Properties [7]

\begin{tabular}{lccc}
\hline Material & $\begin{array}{c}\text { Young's Modulus } \\
{[\mathrm{MPa}]}\end{array}$ & $\begin{array}{c}\text { Poisson's Ratio } \\
-\end{array}$ & $\begin{array}{c}\text { Density } \\
{\left[\mathrm{kg} / \mathrm{m}^{3}\right]}\end{array}$ \\
\hline Concrete & 30960 & 0.20 & 2400 \\
Filling layer (grout) & 24768 & 0.25 & 2400 \\
\hline
\end{tabular}




\section{Subgrade Formations}

Four reference sections where the subgrade formation material properties and thickness are available are used for the analysis of the plate bearing tests (PBT), as will be investigated in Chapter 3 and analysed in Chapter 6. Three sections are located at Amandelbult Layout stations 1, 2, and 3 [10]; 7] (referred to as stations A1, A2, and A3 respectively), and one is located at the Pilbara Ore line [13]. These sections can be analysed by means of the finite element method (FEM), because field tests were preformed to investigate the various subgrade strata and their respective material properties. The material properties were acquired by obtaining the relative and cumulative deflections of the respective soil strata by means of multi-depth deflectometers (MDDs) and back-calculating the stiffness of the soil stratum using the known deflections and loading magnitudes [7]. The soil properties for the four reference sections are presented in Table 2.4

Table 2.4: Reference Formation Section Soil Properties [7]

\begin{tabular}{llcccc}
\hline Material & $\begin{array}{c}\text { Young's Modulus } \\
{[\mathrm{MPa}]}\end{array}$ & $\begin{array}{c}\text { Poisson's Ratio } \\
-\end{array}$ & $\begin{array}{c}\text { Density } \\
{\left[\mathrm{kg} / \mathrm{m}^{3}\right]}\end{array}$ & $\begin{array}{c}\text { Stratum Thickness } \\
{[\mathrm{mm}]}\end{array}$ \\
\hline \multirow{3}{*}{ Station A1 } & Top Crusher Run & 220 & 0.3 & 2200 & 200 \\
& Bottom Crusher Run & 141 & 0.3 & 2100 & 200 \\
& Rock Fill & 200 & 0.3 & 2300 & 900 \\
& Clay & 38 & 0.35 & 1700 & 420 \\
& In-situ Norite & 1000 & 0.25 & 2500 & semi-infinite \\
\hline \multirow{5}{*}{ Station A2 } & Top Crusher Run & 102 & 0.3 & 2200 & 200 \\
& Bottom Crusher Run & 212 & 0.3 & 2100 & 200 \\
& Rock Fill & 126 & 0.3 & 2300 & 525 \\
& Clay & 46 & 0.35 & 1700 & 1075 \\
& In-situ Norite & 1000 & 0.25 & 2500 & semi-infinite \\
\hline \multirow{5}{*}{ Station A3 } & Top Crusher Run & 197 & 0.3 & 2200 & 200 \\
& Bottom Crusher Run & 221 & 0.3 & 2100 & 200 \\
& Rock Fill & 203 & 0.3 & 2300 & 430 \\
& Clay & 37 & 0.35 & 1700 & 770 \\
& In-situ Norite & 1000 & 0.25 & 2500 & semi-infinite \\
\hline \multirow{5}{*}{ Pilbara } & Capping Layer & 170 & 0.35 & 2200 & 300 \\
& Selected Fill & 120 & 0.35 & 2100 & 400 \\
& Common Fill & 80 & 0.35 & 2000 & 600 \\
& In-situ & 80 & 0.35 & 1900 & semi-infinite \\
\hline
\end{tabular}

The in-situ norite layers of the Amandelbult stations are assumed to be a semi-infinite layers, which is a medium which extends to infinity in one direction, but is bound at the other. The norite layer is modeled as only having a thickness of $800 \mathrm{~mm}$ as it is a very stiff material relative to the other soil layers, which has a Young's modulus of approximately $1000 \mathrm{MPa}$, meaning the deflections in this layer are nearly negligible and will not influence results greatly. The in-situ 
stratum for the Pilbara Ore line is also semi-infinite, but does not have an as high Young's modulus as the norite. The Pilbara in-situ layer thickness is therefore assumed to be $1500 \mathrm{~mm}$ in order to take the additional displacements in this layer into account.

An illustration of one of the soil layers is illustrated in Figure 2.5 and represents the Amandelbult layout station 3 subgrade formation. The Amandelbult layout station 3 represents the reference model which will be used for the comparison of analysis methods in later chapters, whereas the other soil formation sections will only be used for the modulus of subgrade reaction analysis as discussed in the following chapter, and investigated in Chapter 6 .

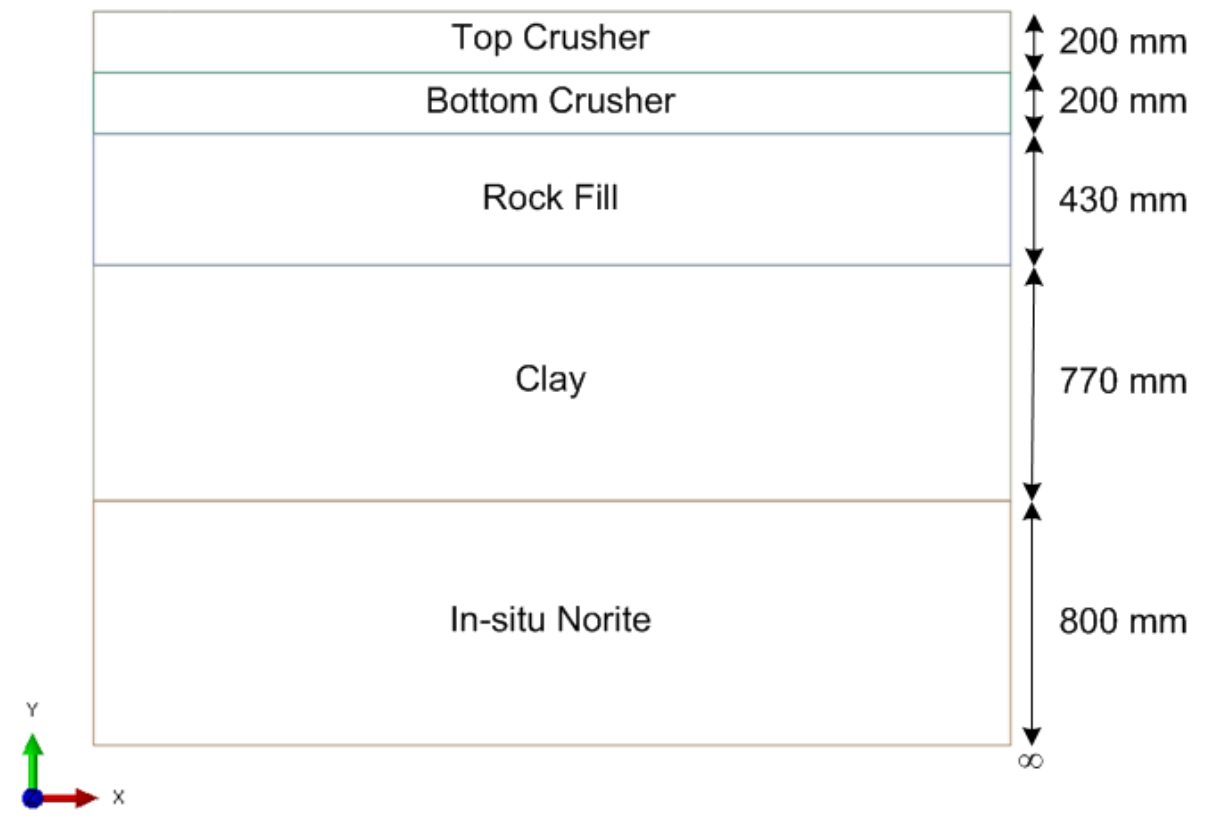

Figure 2.5: Amandelbult Layout Station 3 Soil Layers

\subsubsection{System Components Excluded from Models}

\section{Rail Fasteners}

The clips used to secure the rails to the $\mathrm{RC}$ beams are not geometrically modeled in the finite element models, as they have no significant influence on the investigated vertical displacements, bending moments or shear forces. This allows for simpler finite element models without loss of accuracy.

\section{Steel Tie Beam Model}

The tie beams provide additional stiffness for lateral forces which are at their maximum in curved sections. As previously stated, the general analyses performed for the purpose of this investigation focuses on straight railway sections. The tie beams will therefore not be incorporated in the FEM models, as they provide negligible stiffness for the vertical wheel loads under investigation. Including the tie beams into the analyses will add a level of complexity to the FEM models 
which is beyond the scope of this investigation. The reference model at the Amandelbult railway section is analysed as a straight section with no lateral forces acting on the TT system, which therefore does not require the tie beams to be modeled.

\section{Wheel Model}

The investigation of the train wheel in the finite element models is outside the scope of this investigation, and is therefore only modeled as the resulting forces acting on the rails. A method is required to simulate the contact area between the wheels and rail of the railway system. The wheel-rail contact area interaction is analysed by means of Hertz theory in Section 3.2 , and will be modeled as a single contact point acting on the rail. 


\section{Chapter 3}

\section{Literature Review}

The key literature necessary for this dissertation is investigated and reviewed in this chapter and serves as the basis for the analysis of the Tubular Track (TT) railway system. The first section investigates the substructure of the TT system i.e. the supporting subgrade strata, as well as theoretical methods of modeling the TT system. The second section investigates the steel wheel-rail interaction and train guidance system which is necessary for modeling the contact between the wheel and rail in three-dimensional (3D) analyses. The final section in this chapter investigates the static and dynamic loads associated with railway systems, which were implemented in the finite element analyses (FEA) in later chapters.

\section{$3.1 \quad$ Elastic Foundation Theory}

\subsubsection{Introduction}

The TT system is supported by several soil layers providing vertical support, as illustrated in Figure 3.1a. Geometrically modeling the subgrade strata in the FEM models adds a high level of complexity, and should therefore be simplified. In order to accurately simulate the interaction between beam and foundation and to simplify the FEA, a foundation model is required.

Beams and columns supported elastically along their length are very common in structural configurations. The interaction between the beams and the subgrade support is simulated as an interaction between a deformable body and an elastic medium, as illustrated in Figure $3.1 \mathrm{~b}$. The analysis of a beam on an elastic foundation is based on the assumption that the soil stiffness is directly proportional to the displacement of the beam. This relation can be written as indicated in Equation 3.1.1 [4]. The most common model used for elastic foundation theory was first introduced by E. Winkler, and consists of an infinite number of closely spaced springs where the reaction stress present in a spring at any point is proportional to the displacement of the beam at that point [14, as indicated in Equation 3.1.1. 


$$
\sigma=k_{s} w
$$

where

$\sigma=$ Localised compressive stress in the support $\left[\mathrm{N} / \mathrm{m}^{2}\right]$

$\mathrm{k}_{\mathrm{s}}=$ Modulus of subgrade reaction/Foundation modulus $\left[\mathrm{N} / \mathrm{m}^{2} / \mathrm{m}\right]$

$\mathrm{w}=$ Local displacement of the support $[\mathrm{m}]$

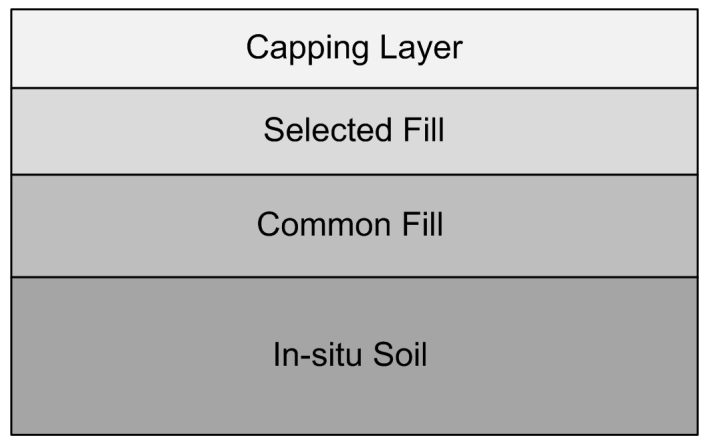

(a) Example of Supporting Subgrade Strata

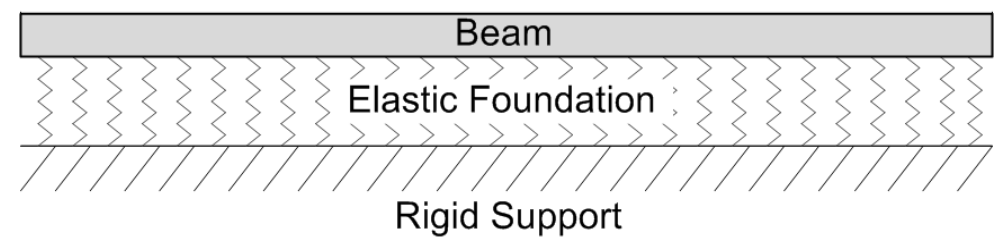

(b) Beam on Elastic Foundation

Figure 3.1: Elastic Foundation Approximation

Due to the nature of the TT system being continuously supported by soil foundations, the support provided by the soils can be simulated by means of elastic foundation theory. This interaction support also greatly simplifies the finite element models as it avoids the need for having to model the various soil layers geometrically.

\subsubsection{Elastic Foundation Model}

The Winkler elastic foundation model simulates the stiffness characteristics of the actual system by replacing the supporting soil by a bed of closely spaced elastic springs resting on a rigid base [15], and is the simplest way to simulate an elastic supporting medium. The continuous beam is considered to be an Euler-Bernoulli beam in which the shear force deformation is not considered. An elastic foundation makes the assumption that the pressure in the foundation is at every point proportional to the deflection of the beam at that point, and is independent of the deflections of 
other parts of the foundation. The Winkler elastic foundation theory has proven to adequately calculate stresses and deflections in railroad tracks [14]. Experiments by A. Föppl found that the deformation in subsoils is mainly localised at the loaded regions [16], which satisfies Winkler's assumption that there is a complete lack of continuity in the foundation where the soil acts as independent supporting springs supporting a continuous beam.

Instead of modeling the TT system with supporting subgrade strata, the foundation can be modeled as a single elastic stiffness input parameter known as the modulus of subgrade reaction, also known as the foundation modulus, $\mathrm{k}_{\mathrm{s}}$, greatly simplifying the analysis [17]. The assumption that the soil exhibits elastic behaviour is acceptable, due to the small deflections obtained in the TT system and subgrade support (Mostly less than $1.5 \mathrm{~mm}$ maximum vertical deflection). The modulus of subgrade reaction $\mathrm{k}_{\mathrm{S}}$ of a supporting soil can be obtained by either performing an insitu plate bearing test (PBT), a subgrade FEA, or a screw-plate test. The method for obtaining the modulus of subgrade reaction for the TT railway system is investigated in further detail in Chapter 6. The influence of the modulus of subgrade reaction of a subgrade is very important for the accurate procurement of the deflections of a structure supported by an elastic medium. The sensitivity of the system to the foundation modulus will therefore also be investigated in a later chapter. The single beam on elastic foundation theory is derived in the following section.

\subsubsection{Elastic Foundation Model Derivation}

To obtain the differential equations necessary for the derivation of the Winkler foundation model, one first needs to consider equilibrium conditions of the infinitely long beam element illustrated in Figure 3.2 [4].

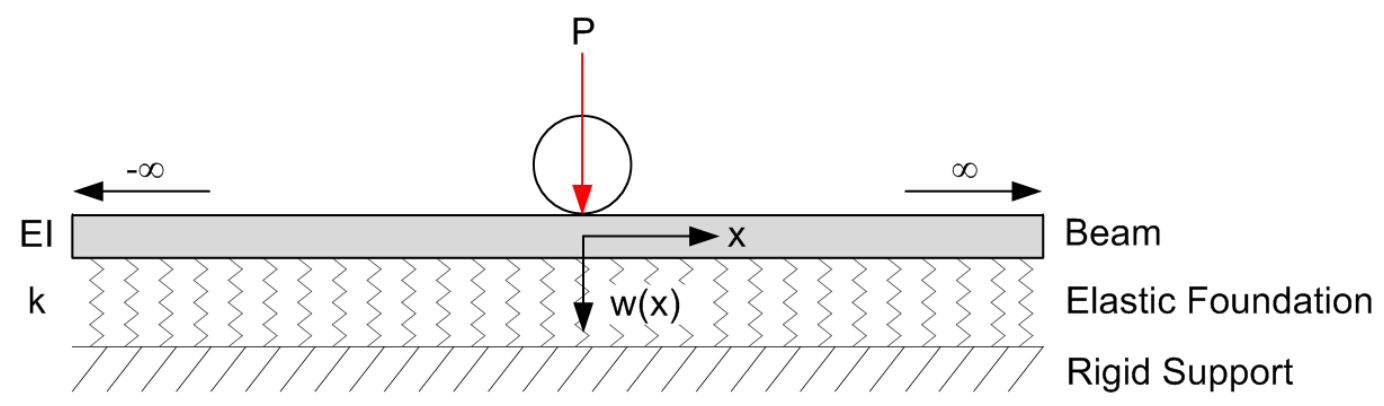

Figure 3.2: Infinite Beam on Elastic Foundation

The Winkler foundation differential equation is derived from equilibrium conditions using EulerBernoulli beam theory as follows:

$$
E I \frac{d^{4} w}{d w^{4}}+k w=q(x)
$$


where:

$$
\begin{array}{ll}
\text { EI } & =\text { bending stiffness }\left[\mathrm{Nm}^{2}\right] \\
\mathrm{k} & =\text { foundation coefficient }\left[\mathrm{N} / \mathrm{m}^{2}\right] \\
\mathrm{q}(\mathrm{x}) & =\text { distributed load }[\mathrm{N} / \mathrm{m}] \\
\mathrm{w} & =\text { displacement }[\mathrm{m}]
\end{array}
$$

Since the point loads are very large relative to weight of the beams, we can assume the distributed load $\mathrm{q}(\mathrm{x})$ to be negligible. Equation 3.1 .2 therefore changes into a homogeneous equation, as follows:

$$
E I \frac{d^{4} w}{d w^{4}}=-k w
$$

This equation can now be used to derive the shear forces, bending moments, rotations, and deflections present in the beam by integrating using known boundary conditions. For a single infinitely long beam with a single point load acting in the center of the beam as in Figure 3.2. where symmetry is applied at the point load i.e. at $\mathrm{x}=0$. The boundary conditions and further derivations are as follows:

The boundary conditions for $\mathrm{x}>0$ :

$$
w(\infty)=0 ; \quad \frac{d w}{d x}(0)=0 ; \quad \frac{d^{3} w}{d x^{3}}(0)=\frac{P}{2}
$$

Now let $\mathrm{w}=e^{t x}$

therefore: $\frac{d^{4} w}{d x^{4}}=t^{4} e^{t x}$; input in Equation 3.1.3

$$
t^{4} e^{t x}+\frac{k}{E I} e^{t x}=0
$$

With $e^{t x} \neq 0$ follows:

$$
t^{4}=-\frac{k}{E I}
$$

This equation has 4 roots:

$$
\begin{gathered}
t_{1}=-t_{3}=\sqrt[4]{\frac{k}{4 E I}}(1+i)=\mu(1+i) \\
t_{2}=-t_{4}=\sqrt[4]{\frac{k}{4 E I}}(-1+i)=\mu(-1+i)
\end{gathered}
$$

with $\mu=\sqrt[4]{\frac{k}{4 E I}}$

The solution of the homogeneous equation is therefore:

$$
v_{h}=C_{1} e^{\mu(1+i) x}+C_{2} e^{-\mu(1+i) x}+C_{3} e^{\mu(1-i) x}+C_{4} e^{-\mu(1-i) x}
$$

And can also be written as follows:

$$
v_{h}=e^{-\mu x}\left(A_{1} \sin \mu x+A_{2} \cos \mu x\right)+e^{\mu x}\left(B_{1} \sin \mu x+B_{2} \cos \mu x\right)
$$


Where $A_{1}, A_{2}, B_{1}$ and $B_{2}$ are the integration constants. These integration constants are dependant on the loading and support conditions, and can be calculated using the boundary conditions [18.

In order to describe the deformation of a beam supported by an elastic foundation more accurately, the Pasternak foundation model can be used [4]. The Pasternak foundation model is used to describe the shear interaction between the linear spring elements by connecting the springs to a beam which consists only of incompressible vertical elements which can only deform by means of transverse shear. This shear beam can be added to the Winkler elastic foundation model by connecting the shear beam to the existing beam, as illustrated in Figure 3.3 .

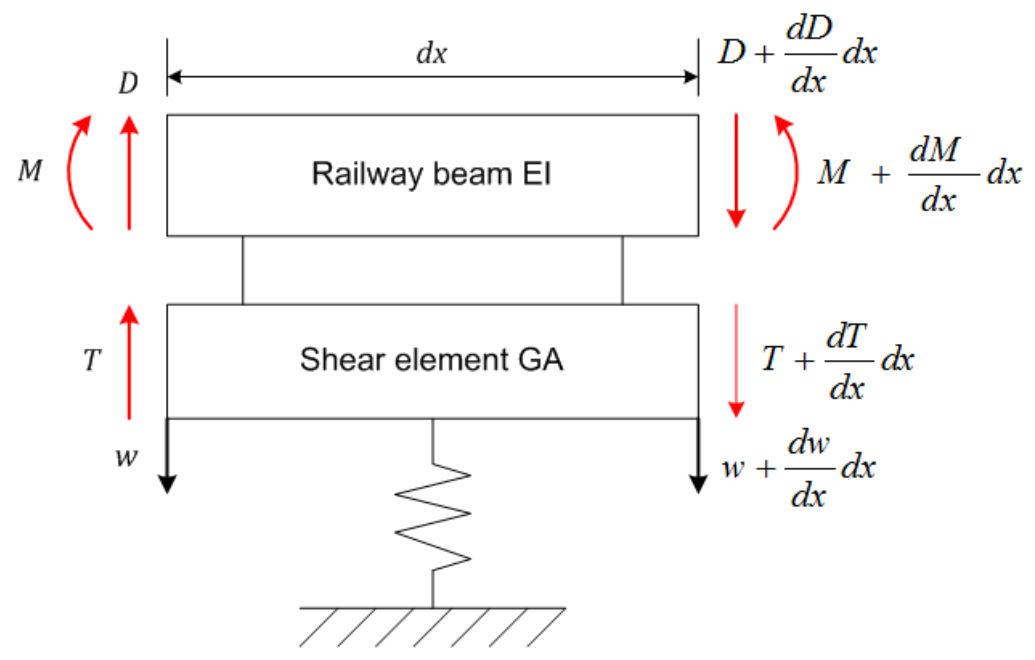

Figure 3.3: Pasternak Foundation Model [4]

Where $\mathrm{M}$ and $\mathrm{D}$ represent an applied bending moment and shear force respectively, whereby equilibrium requires that:

$$
\begin{gathered}
\frac{d D}{d x} d x+\frac{d T}{d x} d x=k w d x \\
D d x=\frac{d M}{d x} d x
\end{gathered}
$$

Where the shear element cannot produce bending moments. A linear relation between the shear force and shear angle is found by taking the relationship between shear stress and stress into account, and demonstrates that [4]:

$$
T=G A_{s} \frac{d w}{d x}
$$

where

$\mathrm{T}=$ Shear force $[\mathrm{N}]$

$\mathrm{G}=$ Shear modulus of foundation $\left[\mathrm{N} / \mathrm{m}^{2}\right]$

$\mathrm{A}_{\mathrm{s}}=$ Shear cross section area $\left[\mathrm{m}^{2}\right]$ 
Equations 3.1.6 and 3.1.8 can now be combined to obtain a differential equation similar to Equation 3.1 .2 but taking the shear stiffness of the soil foundation into account as follows:

$$
E I \frac{d^{4} w}{d w^{4}}-G A_{s} \frac{d^{2} w}{d x^{2}}=-k w
$$

Where the shear modulus can be calculated using the soil's Young's modulus, E, and Poisson's ratio, $\nu$, as follows:

$$
G=\frac{E}{2(1+\nu)}
$$

This model, though, requires the Young's modulus and Poisson's ratio of the subgrade formation to be known. These parameters are not generally obtained for the analysis and design of the TT system, as will be explained in Chapter 6. The shear element is therefore not included in the theoretical models based on elastic foundation principles, but can be investigated should the required parameters be known and additional accuracy required.

A shortcoming of the classic elastic foundation theory is that it only considers a single homogeneous beam. The TT system consists of several connected homogeneous beams, such as the rail, reinforced concrete $(\mathrm{RC})$ beam, and grout and is therefore a non-homogeneous system. In order to circumvent this shortcoming, the Transformed-Section Method can be used to transform the TT system into a single homogeneous beam, and will be discussed in Section 3.1.4. Winkler's classic single beam analysis method, however, also cannot take the influence of the elastomeric pad into account. The elastomeric pad is used to distribute large localised pressure over larger areas, thereby reducing the occurrence of pressure localisation, whilst also providing damping for the dynamic loads. The effect of the additional stiffness of the elastomeric pads can be analysed by means of the Double Beam Model, which represents a double-layer model of the elastic foundation model, and is discussed in Section 3.1 .5 .

\subsubsection{Transformed-Section Method}

Classic beam on elastic foundation theory can only be used to analyse a single homogeneous beam on an elastic support. The TT system is by nature a non-homogeneous beam, due to there being a steel rail, RC beam, elastomeric pad, and grout layers. The TT system can however be converted into a single homogeneous beam representation by means of the Transformed-Section Method. By transforming the non-homogeneous TT railway system into a single homogeneous beam simplifies the railway model interactions. The interactions such as friction and slip movement between the parts, and the additional stiffness provided by the elastomeric pads are ignored when using the Transformed-Section Method, because the various components are now assumed to be a single part. The transformed model therefore represents a model where the parts are fixed to each other with no ability to slip or displace relative to one another.

The Transformed-Section Method can be used to essentially treat a non-homogeneous beam the same way as a homogeneous beam, by essentially changing the width of a section by a factor 
dependant on the modulus of elasticity of the material as illustrated in Figure 3.4

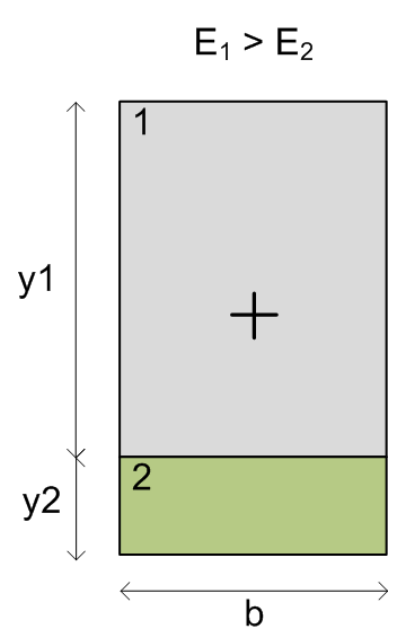

(a) Original Cross Section

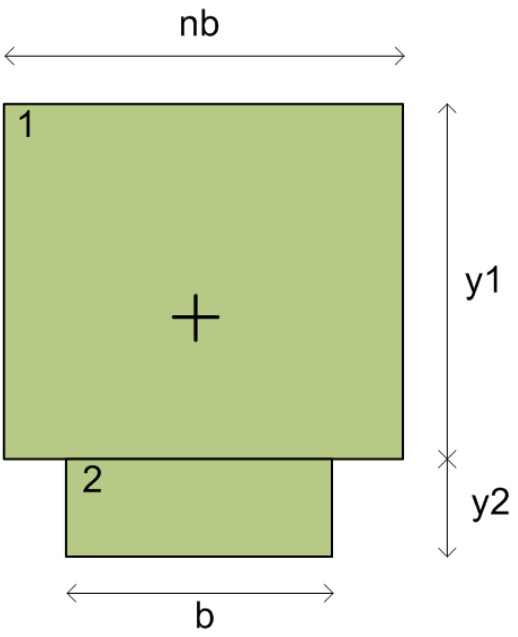

(b) Transformed Cross Section

Figure 3.4: Transformed-Section Method

To obtain the neutral axis of the cross-section, a material is widened by altering the less stiff material with the ratio of moduli, $n$, which is calculated as follows:

$$
n \equiv \frac{E_{1}}{E_{2}}
$$

where:

$E_{1}$ is the modulus of elasticity of the stiffer reference material

$E_{2}$ is the modulus of elasticity of the less stiff material

The sections are only widened, whereas the height, $y$, of the sections remain constant. The neutral axis therefore passes through the transformed homogeneous section, just as it would for the original non-homogeneous section. The modulus of elasticity of the reference material is now used for the entire section, with the non-reference materials being "widened" according to their respective moduli of elasticity [19].

The neutral axis passes through the centroid of the section under investigation, and the flexural stress distributions of the two materials are calculated using the flexure formulas which take the ratio of moduli into account:

$$
\sigma_{x 1}=n \frac{-M y}{I_{t}}
$$

and

$$
\sigma_{x 2}=\frac{-M y}{I_{t}}
$$


where:

$\mathrm{I}_{\mathrm{t}}=$ Moment of inertia of the transformed section $\left[\mathrm{m}^{4}\right]$

$\mathrm{M}=$ Bending moment $[\mathrm{Nm}]$

The steps required to transform a non-homogeneous section are as follows:

- Sketch the transformed section using the ratio of moduli $n$

- Locate the neutral axis

- Compute the moment of inertia $I_{t}$ for the transformed section

- Use the flexure formulas to compute the stresses

The transformed moment of inertia and the modulus of elasticity can now be used to obtain the displacements, soil pressure, shear force and bending moment diagram of a transformed homogeneous beam [19]. Comparisons of this simplified beam analysis method with models where interactions between the parts are taken into account will be discussed in a later chapter.

\subsubsection{Double Beam Model}

The Winkler elastic foundation model is very useful for the prediction of the general behaviour of a single homogeneous beam on elastic support. This model, though, is not sufficient for the investigation of the influence of the elastomeric rail pads or the relative translation between interacting parts.

A more accurate and realistic model is the Double Beam model, which represents a two-layer model of a continuously supported beam supported by an elastic foundation. The upper beam represents the steel rail, while the lower beam represents the RC beam, as illustrated in Figure 3.5. The stiffness of the elastomeric pad, $\mathrm{k}_{1}$, is modeled between the upper and lower beams, whilst $\mathrm{k}_{2}$ simulates the elastic soil foundation as in the single beam elastic foundation theory.

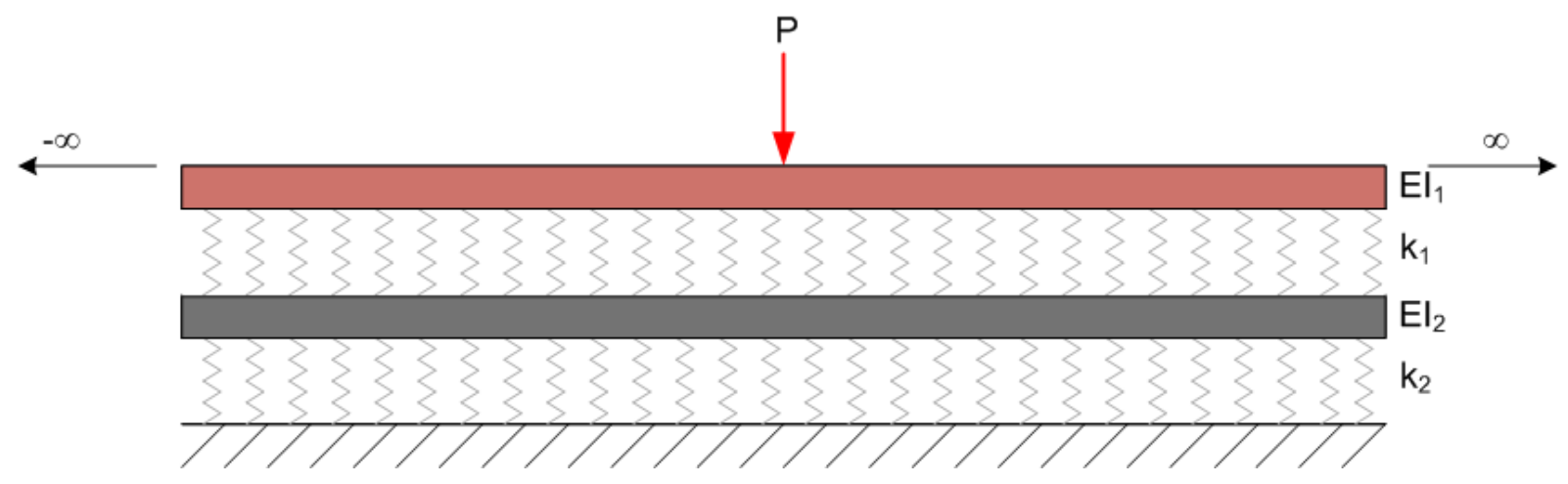

Figure 3.5: Continuously Supported Static Double Beam Model 
where:

$\mathrm{k}_{1} \quad=$ Elastomeric pad static or dynamic stiffness $[\mathrm{N} / \mathrm{m}]$

$\mathrm{k}_{2} \quad=$ Elastic foundation stiffness $[\mathrm{N} / \mathrm{m}]$

$\mathrm{EI}_{1}=$ Bending stiffness of upper beam $\left[\mathrm{Nm}^{2}\right]$

$\mathrm{EI}_{2}=$ Bending stiffness of lower beam $\left[\mathrm{Nm}^{2}\right]$

If the assumption is again made that the weight of the beams can be ignored, the differential equations of the upper and lower beams of the Double Beam model are calculated similarly as the Winkler foundation model as follows [4]:

$$
\begin{gathered}
E I_{1} \frac{d^{4} w_{1}}{d x^{4}}+k_{1}\left(w_{1}-w_{2}\right)=0 \\
E I_{2} \frac{d^{4} w_{2}}{d x^{4}}+\left(k_{1}+k_{2}\right) w_{2}-k_{1} w_{1}=0
\end{gathered}
$$

From 3.1 .14 we have:

$$
w_{2}=\frac{E I_{1}}{k_{1}} \frac{d^{4} w_{1}}{d x^{4}}+w_{1}
$$

and

$$
\frac{d^{4} w_{2}}{d x^{4}}=\frac{E I_{1}}{k_{1}} \frac{d^{8} w_{1}}{d x^{8}}+\frac{d^{4} w_{1}}{d x^{4}}
$$

Substituting Equations 3.1.16 and 3.1.17 into 3.1.15 will cancel out $\mathrm{w}_{2}$. We now have the following differential equation of the upper beam:

$$
\frac{d^{8} w_{1}}{d x^{8}}+A \frac{d^{4} w_{1}}{d x^{4}}+B w_{1}=0
$$

where:

$$
A=\frac{k_{1}\left(I_{1}+I_{2}\right)+k_{2} I_{1}}{E I_{1} I_{2}} \quad \text { and } \quad B=\frac{k_{1}}{E I_{1}} \frac{k_{2}}{E I_{2}}
$$

Similarly as for the Winkler model the general equation can be obtained substituting $\mathrm{w}_{1}$ with $\mathrm{e}^{\mathrm{tx}}$ (where $\left.\mathrm{e}^{\mathrm{tx}} \neq 0\right)$, resulting in a characteristic equation of the 8 th order with roots as follows:

$$
t_{1,2,3,4}=( \pm 1 \pm i) \sqrt[4]{\frac{\alpha+\beta}{4}} \quad \text { and } \quad t_{5,6,7,8}=( \pm 1 \pm i) \sqrt[4]{\frac{\alpha-\beta}{4}}
$$

where:

$$
\alpha=\frac{A}{2} \quad \text { and } \quad \beta=\sqrt{\frac{A^{2}}{4}-B}
$$


For simplification purposes we can now substitute $\sqrt[4]{\frac{\alpha+\beta}{4}}=\lambda_{1}$ and $\sqrt[4]{\frac{\alpha-\beta}{4}}=\lambda_{2}$.

Equation 3.1 .18 can now be written as the general solution of the deflections of the upper beam as follows:

$$
\begin{aligned}
& y_{1}=e^{\lambda_{1} x}\left(C_{1} \cos \lambda_{1} x+C_{2} \sin \lambda_{1} x\right)+e^{-\lambda_{1} x}\left(C_{3} \cos \lambda_{1} x+C_{4} \sin \lambda_{1} x\right) \\
& +e^{\lambda_{2} x}\left(C_{5} \cos \lambda_{2} x+C_{6} \sin \lambda_{2} x\right)+e^{-\lambda_{2} x}\left(C_{7} \cos \lambda_{2} x+C_{8} \sin \lambda_{2} x\right)
\end{aligned}
$$

Substituting Equation 3.1.19 into Equation 3.1.16 yields the general solution for the deflections of the lower beam as follows:

$$
\begin{aligned}
& y_{2}=\left[1-(\alpha+\beta) \frac{E I_{1}}{k_{1}}\right]\left[e^{\lambda_{1} x}\left(C_{1} \cos \lambda_{1} x+C_{2} \sin \lambda_{1} x\right)+e^{-\lambda_{1} x}\left(C_{3} \cos \lambda_{1} x+C_{4} \sin \lambda_{1} x\right)\right. \\
& +\left[1-(\alpha-\beta) \frac{E I_{1}}{k_{1}}\right] e^{\lambda_{2} x}\left(C_{5} \cos \lambda_{2} x+C_{6} \sin \lambda_{2} x\right)+e^{-\lambda_{2} x}\left(C_{7} \cos \lambda_{2} x+C_{8} \sin \lambda_{2} x\right)
\end{aligned}
$$

The distribution of the pressure under the upper and lower beam, $\mathrm{p}_{1}$ and $\mathrm{p}_{2}$ respectively, can subsequently be calculated as follows [14]:

$$
p_{1}=k_{1}\left(w_{1}-w_{2}\right) \quad \text { and } \quad p_{2}=k_{2} w_{2}
$$

The total compressibility of the foundation can still be kept constant by using Equation 3.1.22,

$$
\frac{1}{k_{e q}}=\frac{1}{k_{1}}+\frac{1}{k_{2}}
$$

therefore:

$$
k_{e q}=\frac{k_{1} k_{2}}{k_{1}+k_{2}}
$$

where $\mathrm{k}_{\mathrm{eq}}$ represents the equivalent foundation coefficient. This stiffness value can be used in the single beam elastic foundation model to investigate the total compressibility of the supporting soil, taking the stiffness of the elastomeric pad into account.

These general solutions can now be solved by providing the boundary conditions, which are dependant on the loading since an infinitely long beam is used. This derivation only investigates the effects of a single point load on the railway system. As previously mentioned, the TT railway system is subjected to various types of load combinations. The combination of the bogey loads causes the differential equations to become statically indeterminate. A statically indeterminate 
beam is where there are more equations of equilibrium than there are boundary conditions, and can therefore not be solved using the same method as above. The equations as derived above are linear differential equations since the deflection function and its derivatives are to the first power i.e. linear. The deflections and subsequent derivatives of a beam subjected to several loads can therefore be obtained by means of linear superposition, which is used to obtain the deflections and derivatives of statically indeterminate beams. The superposition method basically allows the effects of the loads to be investigated separately and create a combined effect by adding the displacement solutions. The statically indeterminate beam is therefore broken down into multiple statically determinate subproblems which can be analysed separately and combined [19]. By using superposition any number of loads, representing train bogies, acting on the railway system can be analysed.

\subsubsection{MATLAB Graphical User Interface}

A MATLAB graphical user interface (GUI) program based on the theory of elastic foundation is included in Appendix $\mathrm{C}$ and is illustrated in Figure 3.6. The GUI program can be used to perform quick and simple analyses of the TT railway system by simply choosing and providing the applicable analysis settings. This program can be set to either analyse a single homogeneous beam on elastic foundation as described in Section 3.1.3 or a Double Beam model as described in Section 3.1.5. Superposition is applied to simulate the multiple bogey loads of the train vehicles. The Single and Double Beam on elastic foundation models are simplified theoretical models and are used for comparison with various other models in order to verify the accuracy of the results relative to beam on elastic foundation principles. These comparisons will be discussed in Chapter 8 


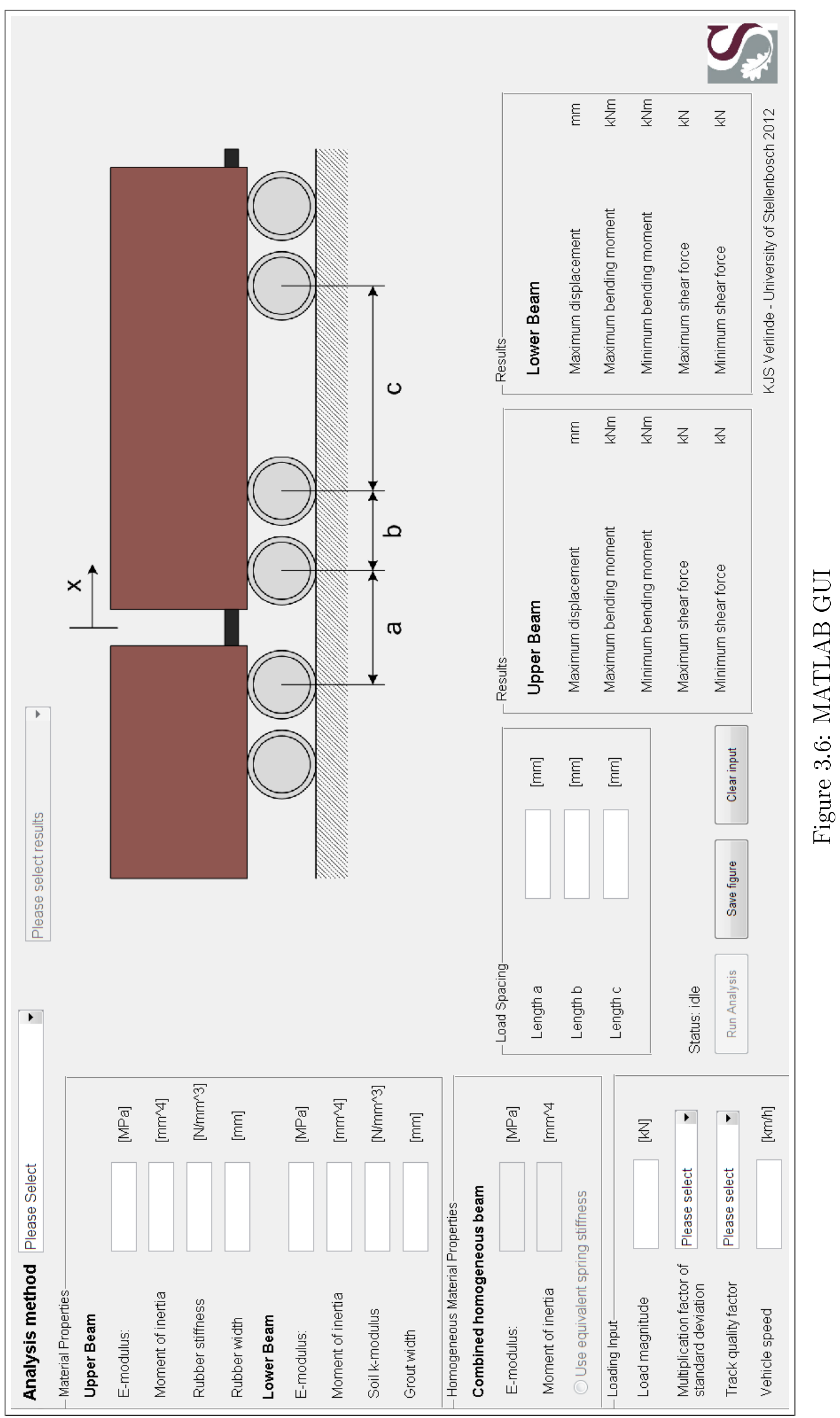




\subsection{Wheel-Rail Interaction}

\subsubsection{Introduction}

A railway system consists of a vehicle suspended on multiple bogies supported by suspension systems and the railway super- and substructures. The TT superstructure consists of the rails, $\mathrm{RC}$ beams, steel tie beams and grout layer which is supported by the substructure i.e. the subgrade strata. The interface between the rail and wheel sets does not only act as support, but also as guidance for vehicle stability [4]. Guidance is provided by the wheel flanges which exert lateral forces on the rails and vice versa when contact between the flange and rail occurs, forcing the vehicle to return to its equilibrium position. The vertical and lateral forces caused by the wheels on the rails act as distributed forces over a small elliptical area. These contact areas are required for 3D FEM models, but not for 2D beam FEM models which apply the point loads at the element nodes of the beams.

The purpose of this section is to provide some insight into the dynamic nature and railway guidance of a railway track, and provide methods of calculating contact areas between two cylindrical bodies for the use in solid element FEA as investigated in Chapter 6. The rail guidance of the TT railway system is illustrated in Figure 3.7.

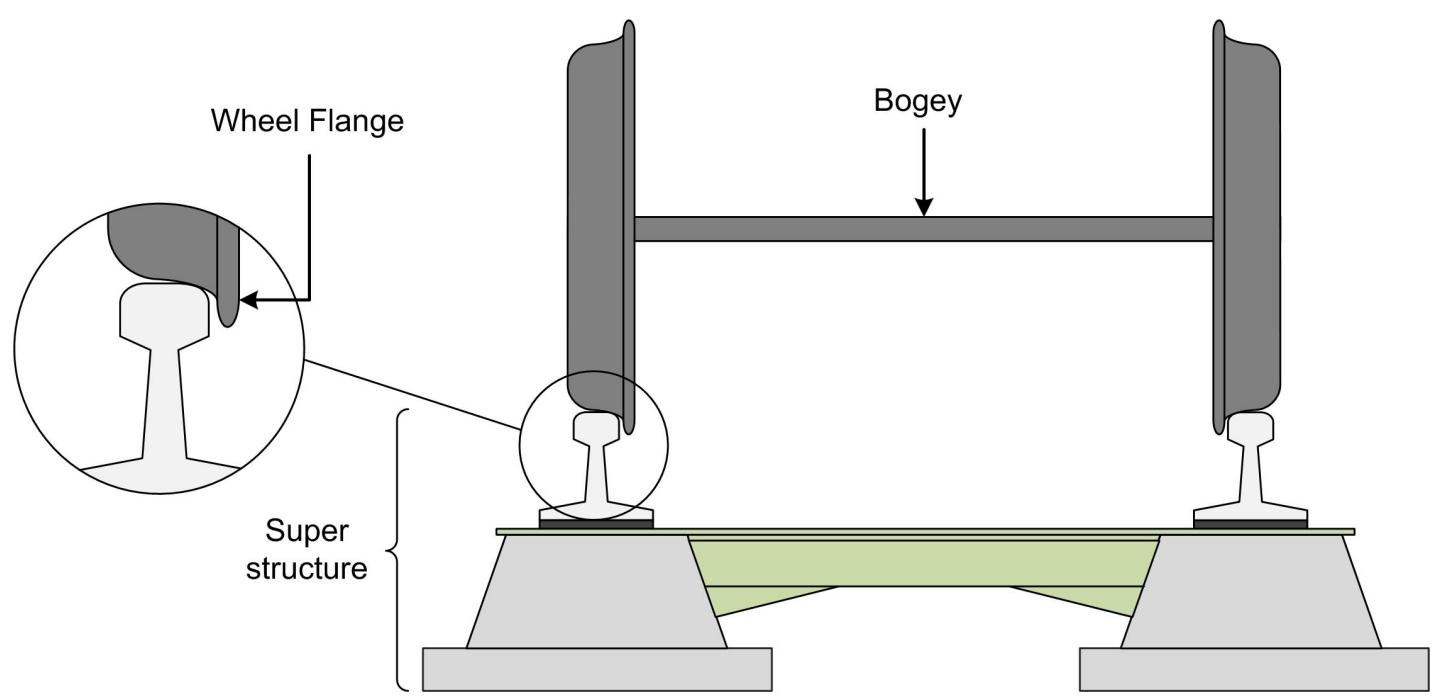

Figure 3.7: Railway System Guidance System

The wheel sets are assumed to act as rigid bodies for simplification purposes. This is because the focus of this dissertation is on the analysis and design of the superstructure and its reaction to loading combinations. The wheel-rail interface will be applied as a resulting force acting on specific areas on the rails, and will therefore not be geometrically modeled in this investigation.

The investigation of the wheel-rail guidance system and the interaction between the wheel and rail are investigated in this section. 


\subsubsection{Wheel-Rail Guidance}

The rail vehicle is guided on the railway track by means of wheels with positive conicity, which exert a centering force when a lateral displacement on the rail occurs. The positive conicity means that the flanges of the wheels are on the inside of the wheels, and will cause the lateral loading to be applied to the outer wheels in curves, which will be combined with an increased vertical load due to momentum and thereby reduces the risk of derailment. The flanges thereby become the primary mode of guidance [12].

Lateral oscillations, due these conical wheels, do occur and can be analysed by means of Klingel's formula for kinematic oscillation [20], as illustrated below.

$$
L_{k}=2 \pi \sqrt{\frac{r_{0} s}{2 \lambda}}
$$

where:

$\mathrm{L}_{\mathrm{k}}=$ wavelength $[\mathrm{m}]$

$\lambda=$ wheelset conicity (inclination) [rad]

$\mathrm{r}_{\mathrm{o}}=$ wheel radius $[\mathrm{m}]$

$\mathrm{s} \quad=$ gauge length $[\mathrm{m}]$

Where the excitation frequency, $f[\mathrm{~Hz}]$, of the oscillation is calculated as:

$$
f=\frac{v}{L_{k}}
$$

where:

$\mathrm{v}=$ speed of $\operatorname{train}[\mathrm{m} / \mathrm{s}]$

The maximum lateral acceleration, $\ddot{x}$, which is a measure of the lateral force can subsequently be calculated as:

$$
\ddot{x}=4 \pi^{2} y_{0} \frac{v^{2}}{L_{k}^{2}}
$$

where:

$\mathrm{y}_{0}=$ lateral displacement of Klingel path

Due to slip on the rails the lateral displacement of the Klingel path will increase with speed until it is equal to half the flangeway clearance ( $f w c)$, which is the clearance between the wheel sets and the track and therefore represents the distance the wheel sets can displace laterally. When this speed is reached flanging occurs, whereby the lateral oscillations cause the onset of hunting. The rail head subsequently comes into contact with the wheel flange resulting in high lateral forces and wear. Hunting causes the harmonic lateral oscillation shape to obtain a zig-zag shape as illustrated in Figure 3.8, thereby causing the wavelength to become shorter ( $\mathrm{L}_{\text {hunting }}$ ), subsequently increasing the frequency until resonance occurs [4]. An illustration of hunting is shown in Figure 3.9. This occurrence produces two-point contact between the wheel and rail, which will be explained in Section 3.2 .3 . 


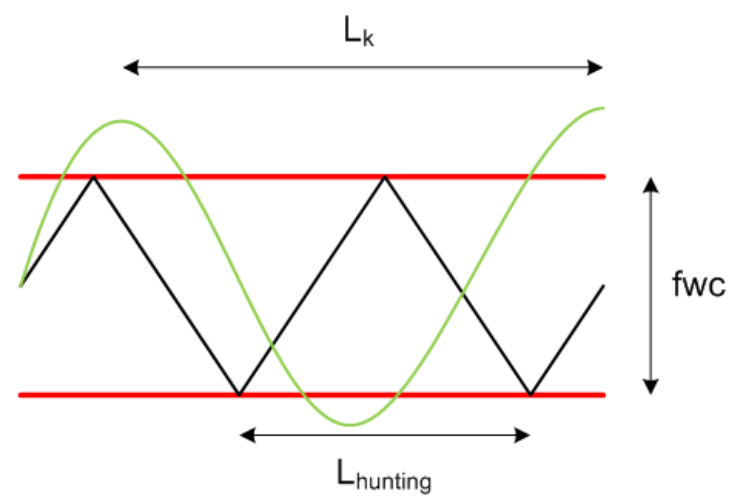

Figure 3.8: Influence of Flanging on Lateral Movement [4]

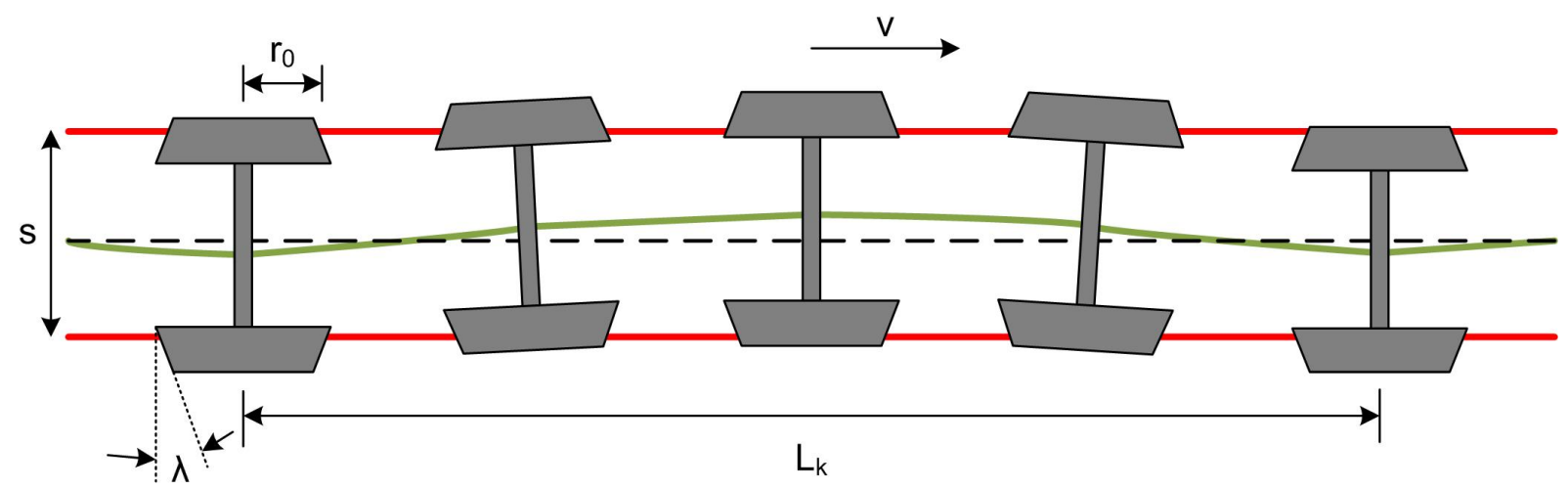

Figure 3.9: Illustration of Hunting [4]

The kinematic nature of a railway system implies that lateral movement of the train always occurs. The oscillation at which this occurs is damped out at speeds below the critical speed, but exhibit resonance behaviour when this speed is surpassed. The critical speed, $\mathrm{v}_{\mathrm{cr}}$, of a vehicle at which derailment can occur can be calculated as :

$$
v_{c r}^{2}=\frac{W r s^{2}}{4 C+m s^{2}}
$$

where

$\mathrm{W}=$ Axle load $[\mathrm{kg}]$

$\mathrm{C}=$ Moment of inertia of wheelset $\left[\mathrm{m}^{4}\right]$

$\mathrm{s} \quad=$ Track gauge $[\mathrm{m}]$

$\mathrm{r} \quad=$ Wheel radius $[\mathrm{m}]$

$\mathrm{m}=$ Wheelset mass $[\mathrm{kg}]$

The additional lateral loads caused by lateral oscillations of a railway vehicle can be implemented in dynamic analyses, but are not implemented in this investigation's models, as it is not required for the purpose of creating the general model for design purposes. The lateral loads caused by hunting can be implemented for future analyses, especially railway sections where lateral loads are significant, such as in curves. 


\subsubsection{Hertz Contact Mechanics}

\section{Introduction}

An accurate method of simulating the interaction between the steel wheel and rail is required for modeling the railway system in complex 3D FEA. The wheel and rail can be simulated as two cylindrical bodies due to their respective curvatures, where the interaction between these two cylindrical bodies can be described using Hertz contact theory. Hertz contact theory models the contact surface between two cylindrical bodies, which is initially only a single point when no loading is applied. Once loading is applied the elastic deformation of the steel of the wheel and the rail creates an elliptic contact area. These contact areas are idealised to be perfectly smooth, without any surface irregularities and are frictionless so only normal pressure is transmitted between the two bodies [21]. Due to the curvature of the rail and wheel, and whether single or two-point contact conditions exist, several contact areas and positions are possible due to the changes in curvature of the rails and wheel relevant to their positions relative to one another. These possible contact area cases are illustrated in Figure 3.10 below.

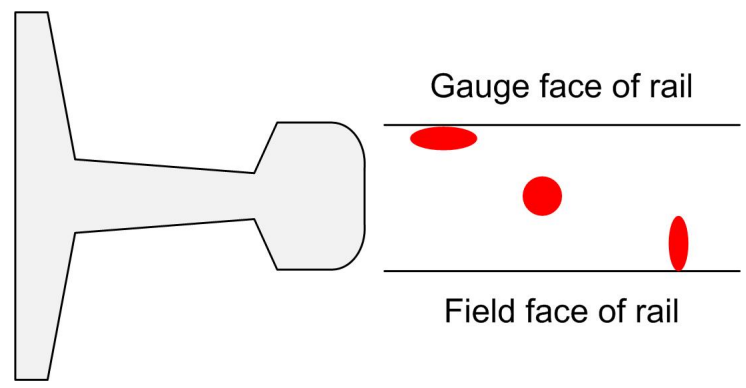

Figure 3.10: Examples of contact ellipses on a rail

The dimensions of these elliptic contact areas depend on the normal force acting on the contact area, curvature of the wheels and rail profiles, vehicle wheel wear, position in curves, and hunting. [4. The areas used for this investigation are calculated in the following section, and are obtained using application programs developed by A.R. Winkler [22] in Java, attached in Appendix B.

When two curved solids are brought into contact with one another, they initially touch at a single point or along a line. As soon as a load or pressure is applied between the two bodies they start to deform, ultimately creating a finite but small contact area which grows in size with increased loading. If this area is small relative to the two bodies and the applied load it could possibly create large localised contact stresses at the area or point of contact. It is therefore important to be able to calculate the magnitude and distribution of these contact stresses [21]. A successful contact area theory was created by H. Hertz (1985) [21] and will be used to illustrate and model these contact areas and stresses. The wheel-rail contact interface is a rolling friction contact with an area of adhesion and slip. For the purpose of this dissertation the slip can be ignored due to the models considering mainly the tread contact, because slip will have an insignificantly small influence on the performance of the global system, which is the focus of this investigation. 


\section{Single and Two-Point Contact}

A single point contact area is a situation where the lateral and normal forces act on the same point. This occurs due to the usage of a worn wheel profile, or on straight sections where the train is not hunting or in a curve. An illustration of single point contact is shown in Figure 3.11a,

In the case of two-point contact, as illustrated in Figure 3.11b, the contact points on the rail do not coincide. This situation mainly occurs in curves on the high rail or during hunting, which causes additional forces on the flange of the wheel. The flange force causes both the wheels to slip in the direction of the inside of the curve, therefore resulting in friction and wear.

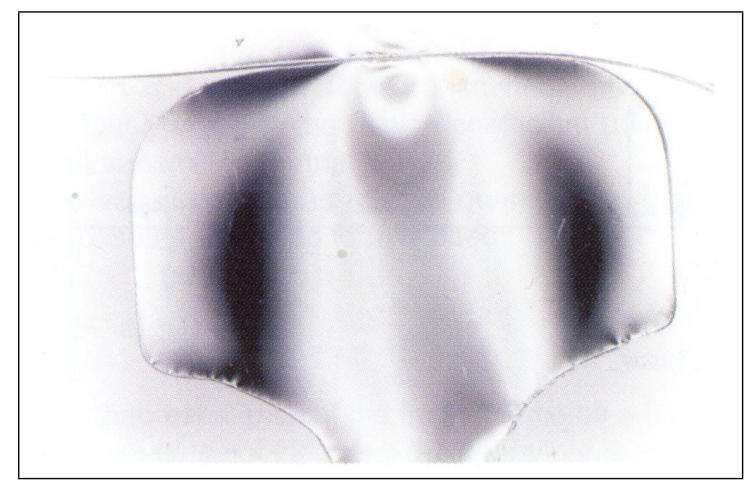

(a) Single Point Contact

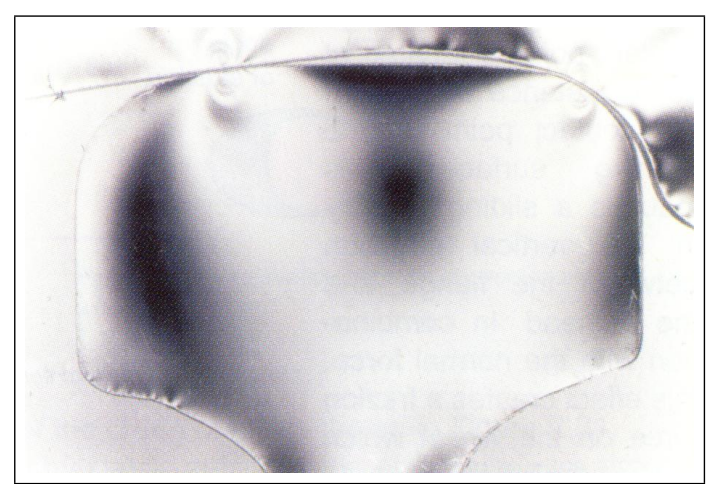

(b) Two-Point Contact

Figure 3.11: Single and Two-Point Contact Areas [4]

As stated previously, the occurrence of two-point contact is only mentioned in this investigation for possible future reference and design, and is not explicitly analysed. The simplified general model is only designed for vertical loads and not the lateral loads also acting on railway systems.

\section{Hertz Contact Theory Derivation}

The calculations and theory used in this section is largely based on the work by K.L. Johnson (1985) [21]. The complete development of the solutions will not be provided here. However, the assumptions and important equations will be provided in order for the results to be understood.

Two semi-circular disks in contact with one another, as illustrated in Figure 3.12 represent the rail and wheel system under investigation. The upper solid representing the wheel has principal radii of curvature, $R_{1}$ and $R_{1}^{\prime}$, while the lower solid representing the rail has principal radii of curvature, $\mathrm{R}_{2}$ and $\mathrm{R}_{2}$. The planes of $\mathrm{R}_{1}$ and $\mathrm{R}_{2}$ intersect each other at an angle $\alpha$ on the tangent plane. The applied load $\mathrm{P}$ is perpendicular to the tangent plane and intersects the point of contact and the centers of curvature. It is assumed that no slip between the bodies can occur. The profiles of the surfaces are continuous up to the second derivative in the contact region; we may therefore express the profile of each surface in the region close to the contact point by the 

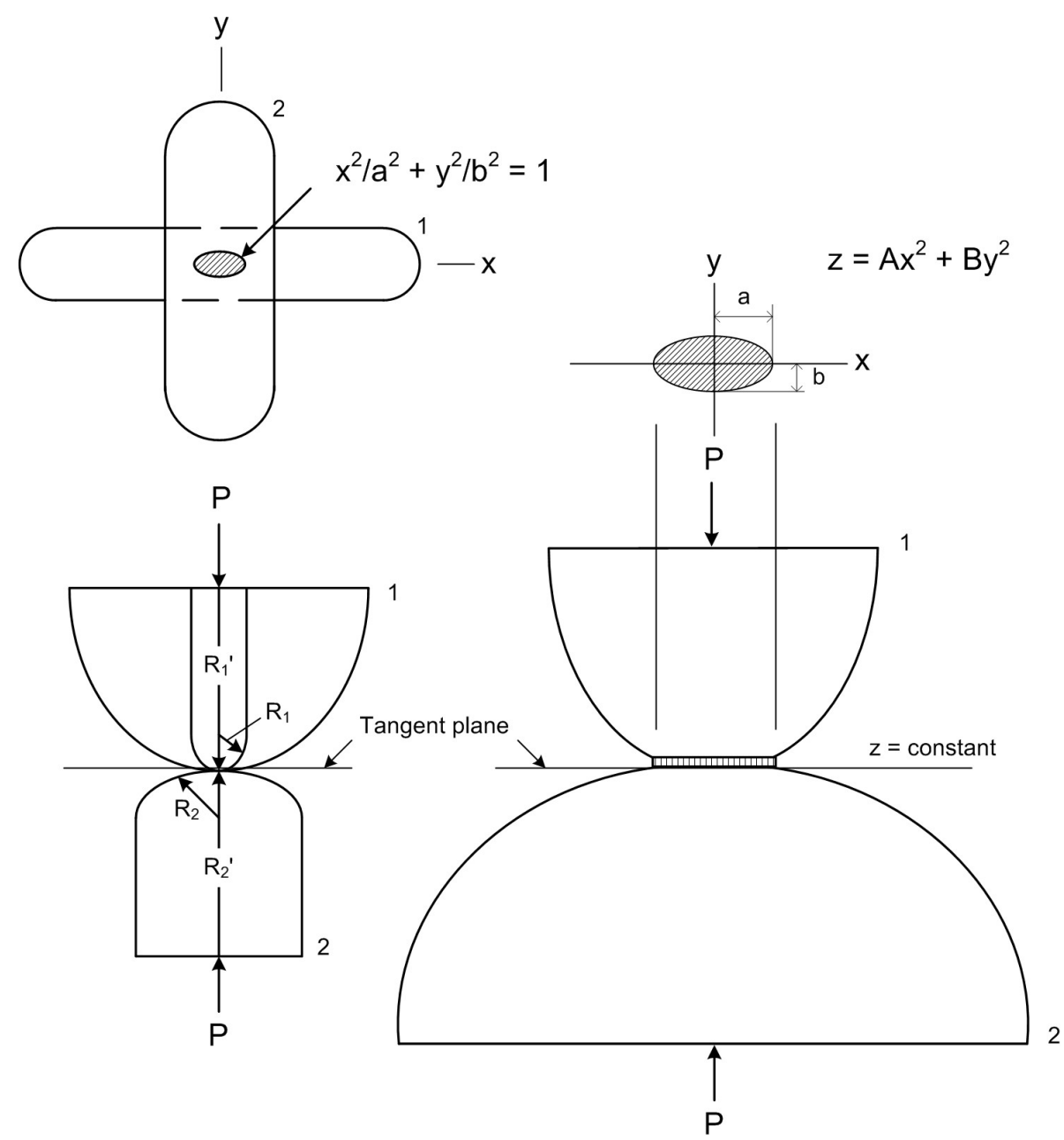

Figure 3.12: Elliptical contact between Two Semi-Circular Disks

expression of the form:

$$
z_{1}=A_{1} x^{2}+B_{1} y^{2}+C_{1} x y+\ldots
$$

where higher order terms in $\mathrm{x}$ and $\mathrm{y}$ are neglected. By approximating Equation 3.2 .5 to find the distance $\mathrm{z}$ between two corresponding points on the two bodies' surfaces we obtain:

$$
z=A x^{2}+B y^{2}
$$

where $\mathrm{A}$ and $\mathrm{B}$ are constants that depend on the principal radii of curvature, as will be calculated later. $\mathrm{X}$ and $\mathrm{y}$ represent the coordinates on the $\mathrm{x}$-and $\mathrm{y}$-axes on the tangent plane, with the origin at the contact point. For a constant value of $z$, the curve representing Equation 3.2.7 is an ellipse. It is assumed that once loading occurs and the two bodies begin to deform elastically, two points which were at equal distances from the tangent plane and are now in contact lie on an elliptical curve whose equation is:

$$
1=\frac{x^{2}}{a^{2}}+\frac{y^{2}}{b^{2}}
$$

as proven extensively in literature [21]; which also yields the accompanying equations for calcu- 
lation of the constants $\mathrm{A}$ and $\mathrm{B}$ :

$$
\begin{gathered}
B=\frac{1}{4}\left(\frac{1}{R_{1}}+\frac{1}{R_{2}}+\frac{1}{R_{1}^{\prime}}+\frac{1}{R_{2}^{\prime}}\right) \\
+\frac{1}{4} \sqrt{\left[\left(\frac{1}{R_{1}}-\frac{1}{R_{1}^{\prime}}\right)+\left(\frac{1}{R_{2}}-\frac{1}{R_{2}^{\prime}}\right)\right]^{2}-4\left(\frac{1}{R_{1}}-\frac{1}{R_{1}^{\prime}}\right)\left(\frac{1}{R_{2}}+\frac{1}{R_{2}^{\prime}}\right) \sin ^{2}(\alpha)} \\
A=\frac{1}{4}\left(\frac{1}{R_{1}}+\frac{1}{R_{2}}+\frac{1}{R_{1}^{\prime}}+\frac{1}{R_{2}^{\prime}}\right) \\
-\frac{1}{4} \sqrt{\left[\left(\frac{1}{R_{1}}-\frac{1}{R_{1}^{\prime}}\right)+\left(\frac{1}{R_{2}}-\frac{1}{R_{2}^{\prime}}\right)\right]^{2}-4\left(\frac{1}{R_{1}}-\frac{1}{R_{1}^{\prime}}\right)\left(\frac{1}{R_{2}}+\frac{1}{R_{2}^{\prime}}\right) \sin ^{2}(\alpha)}
\end{gathered}
$$

In order to obtain the principal stresses, two elliptical integrals are used:

$$
\begin{gathered}
K\left(k^{\prime}\right)=F\left(\frac{\pi}{2}, k^{\prime}\right)=\int_{0}^{\frac{\pi}{2}} \frac{d \theta}{\sqrt{1-k^{\prime 2} \sin ^{2} \theta}} \\
E\left(k^{\prime}\right)=H\left(\frac{\pi}{2}, k^{\prime}\right)=\int_{0}^{\frac{\pi}{2}} \sqrt{1-k^{\prime 2} \sin ^{2} \theta} d \theta
\end{gathered}
$$

where:

$\mathrm{k}=\frac{b}{a}=\cos \theta$

$\mathrm{k}^{\prime}=\sqrt{1-k^{2}}$

to determine the required $\mathrm{k}$ value we use:

$$
\frac{B}{A}=\frac{\left(\frac{1}{k^{2}}\right) E\left(k^{\prime}\right)-K\left(k^{\prime}\right)}{K\left(k^{\prime}\right)-E\left(k^{\prime}\right)}
$$

to obtain the value of semi-minor axis $\mathbf{b}$, and subsequently the value of semi-major axis a of the contact area we use:

$$
b=\sqrt[3]{\frac{3 k E\left(k^{\prime}\right)}{2 \pi} P(\Delta)}=k a
$$

where:

$$
\Delta=\frac{1}{A+B}\left(\frac{1-v_{1}^{2}}{E_{1}}+\frac{1-v_{2}^{2}}{E_{2}}\right)
$$

which can subsequently be used to calculate the contact pressure at the center point of contact:

$$
P_{0}=\frac{3 P}{2 \pi a b}
$$

Equations 3.2 .13 and 3.2 .15 provide the results derived by Hertz contact theory i.e. the contact area required for the 3D FEA as well as the localised pressure magnitude at the contact point between the rail and wheel. 


\subsection{Load Factors}

\subsubsection{Introduction}

The construction and usage of any structure requires the structure to have a certain level of safety and prescribed probability of failure. Railway tracks are designed to withstand numerous load repetitions, which can cause material fatigue. Material fatigue is a very important aspect in railway engineering, as the concrete in the $\mathrm{RC}$ beams can crack and the steel rails can become worn out and change contact surface between the rail and wheel, thereby resulting in different normal and lateral forces. The load parameters of railway systems are largely dependant on bogey loads and the running speed of the vehicles. General analysis and design of a railway system is based on static analysis models which incorporate Dynamic Amplitude Factors (DAF), thereby simulating the dynamic effects of numerous bogies acting on the system. This section investigates the various loads and their respective loading factors which act on a continuous railway system, which are to be used in the various finite element models analysed in this investigation.

\subsubsection{Static Load Application}

The load bearing function of a railway system relies on the principle of stress reduction and distribution, meaning the localised stresses of the bogies are distributed and reduced through the rail, elastomeric pad, RC beam, grout layer and finally through the supporting subgrade.

The loads acting on a railway system can be classified as either quasi-static loads or dynamic loads. Quasi-static loads are loads where inertial effects are negligible i.e. time and inertial mass are irrelevant [4]. As previously stated, general analysis and design of a railway system is commonly based on static loads which incorporate DAFs, thereby simulating the dynamic effects of numerous bogies acting on the system, but still being applied as a static force.

The forces acting on a railway system are vertical, Q, lateral, Y, and longitudinal forces and are often difficult to reliably quantify due to the varying conditions of the track. Vertical forces generally determine the required design bending stiffness of the superstructure system, whereas lateral forces can cause additional wear of the wheel and wheel flanges and also cause derailment. Crosswind effects on a railway system are influenced by aerodynamics and vehicle dynamics and increase lateral loading on a railway system. In loading analyses, the most critical vehicle of a train must be analysed. If the train is composed of homogeneous vehicles, the most critical vehicle is usually the leading vehicle [4. A railway vehicle with all possible applied loads is illustrated in Figure 3.13 . 


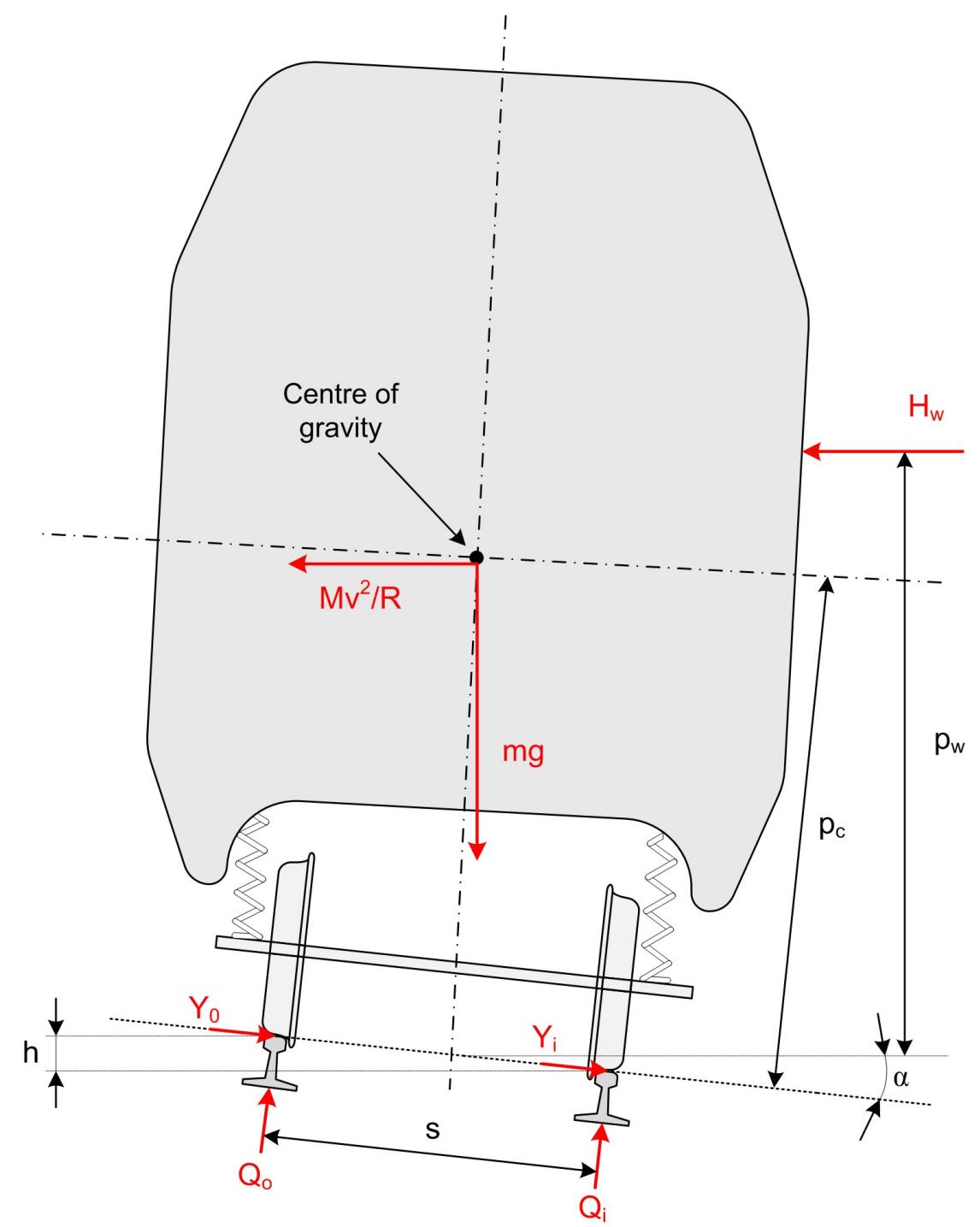

Figure 3.13: Loads Acting on Vehicle in Curve

The loads acting on a railway section are classified as vertical, lateral and longitudinal loads and are calculated as follows:

\section{Vertical Loads}

The total vertical loads are calculated as shown in Equation 3.3.1.

$$
Q_{t o t}=Q_{s t a t}+Q_{c e n t r}+Q_{w i n d}+Q_{d y n}
$$

where:

$\mathrm{Q}_{\text {stat }}=$ Static wheel load on straight track $[\mathrm{N}]$

$\mathrm{Q}_{\text {centr }}=$ Increase of outer wheel load in curves due to centrifugal forces $[\mathrm{N}]$

$\mathrm{Q}_{\text {wind }}=$ Load caused by cross wind $[\mathrm{N}]$

$\mathrm{Q}_{\mathrm{dyn}}=$ Dynamic wheel load $[\mathrm{N}]$ 
From equilibrium consideration of the forces acting on the train with the maximum load acting on the outer rail, $\mathrm{Q}_{\mathrm{o}}$, the maximum vertical load can be calculated as follows:

$$
Q_{\max }=Q_{0}=0.5 m g+m g \frac{p_{c} h_{d}}{s^{2}}+H_{w} \frac{p_{w}}{s}
$$

where:

$$
\begin{aligned}
\mathrm{m} & =\text { Mass of train per wheelset }[\mathrm{kg}] \\
\mathrm{g} & =\text { Gravitational acceleration }\left[\mathrm{m} / \mathrm{s}^{2}\right] \\
\mathrm{p}_{\mathrm{c}} & =\text { Vehicle center of gravity height }[\mathrm{m}] \\
\mathrm{s} & =\text { Gauge width }[\mathrm{m}] \\
\mathrm{H}_{\mathrm{w}} & =\text { Crosswind force acting on train }[\mathrm{N}] \\
\mathrm{p}_{\mathrm{w}} & =\text { Distance of crosswind force resultant }[\mathrm{m}] \\
\mathrm{h} & =\text { Cant }[\mathrm{m}] \\
\mathrm{h}_{\mathrm{d}} & =\frac{s v^{2}}{g R}-h \text { (Cant deficiency) }[\mathrm{m}] \\
\mathrm{v} & =\text { Speed of vehicle }[\mathrm{m} / \mathrm{s}] \\
\mathrm{R} & =\text { Curve radius }[\mathrm{m}]
\end{aligned}
$$

\section{Lateral Loads}

The total lateral wheel loads acting on the rail are similarly calculated as:

$$
Y_{\text {tot }}=Y_{\text {flange }}+Y_{\text {centr }}+Y_{\text {wind }}+Y_{\text {dyn }}
$$

where:

$\mathrm{Y}_{\text {flange }}=$ Lateral force on flange caused by curves $[\mathrm{N}]$

$\mathrm{Y}_{\text {centr }}=$ Increase of outer wheel lateral load in curves due to centrifugal forces $[\mathrm{N}]$

$\mathrm{Y}_{\text {wind }}=$ Load caused by cross wind $[\mathrm{N}]$

$\mathrm{Y}_{\mathrm{dyn}} \quad=$ Dynamic lateral force; mainly caused by hunting on straight track $[\mathrm{N}]$

A vehicle running at a speed $\mathrm{v}$ in a curve $\mathrm{R}$ will experience centrifugal accelerations as calculated in Equation 3.3 .4 .

$$
a=\frac{v^{2}}{R}
$$

Superelevation is only necessary in curves where the vehicle's speed exceeds $40 \mathrm{~km} / \mathrm{h}$ and large curve radii are not possible. The lateral forces acting on each rail can be calculated as follows:

$$
F_{y}=\frac{m v^{2}}{2 R}
$$

Similarly as for the maximum vertical load, the maximum lateral force can be calculated on the outer rail, $\mathrm{Y}_{\mathrm{o}}$, by modifying Equation 3.3 .5 using the cant deficiency as follows:

$$
Y_{\max }=Y_{\mathrm{o}}=m g \frac{h_{d}}{s}+H_{w}
$$

Where the centrifugal and crosswind forces are assumed to be acting only on the outer rail [4]. It is important to note that the prediction of the lateral loads and their corresponding positions do not have great reliability, due to the unpredictability of hunting and the reaction of the train in curves. But can still be used for general lateral force analysis and design. Derailment of 
railway vehicles can occur when the wheel flange climbs the rail when the $\mathrm{Y} / \mathrm{Q}$ ratio exceeds a certain value, because of high lateral forces acting on the outer rail and low vertical loads due to unloaded wheels. An internationally accepted value for the maximum ratio of $\mathrm{Y} / \mathrm{Q}$ is as in Equation 3.3.7 below [23], and can be used as a general safety factor to avoid derailment.

$$
\frac{Y}{Q}<1.2
$$

\section{Longitudinal Loads}

Additional longitudinal forces can also act on the rails. These loads can occur due to:

- Traction

- Wheel spin/slip and braking

- Expansion and contraction due to temperature change

Relative to the applied normal and lateral forces these forces are assumed negligible small, but will nonetheless be discussed in this section.

\section{Wheel-rail Creep}

The longitudinal force acting on the rail occur due to braking or the driving wheels. When the train wheel is angled to the rail, lateral spin can also occur. For the purpose of this dissertation only the frictional forces in the longitudinal direction will be investigated. In a simplified model, one could assume that the longitudinal force is equal to a friction coefficient, $\mu$, times the vertical normal force, Q, as follows:

$$
T_{x}=\mu Q
$$

This equation is only valid when all contact points are about to glide simultaneously. This does not occur, because shear forces create elastic deformations in both the wheel and rail. Gliding is more likely to occur at the rear of the contact point. For smaller values of the applied friction force, elastic effects are dominant. As the frictional force increases, gliding will be more prominent on a larger contact area. The slip of the wheel, $\epsilon_{\mathrm{x}}$, is defined as a relative quantity and can be computed using the following simplified equation [4]:

$$
\epsilon_{x}=\frac{v-\omega r}{v}
$$

where:

$$
\begin{aligned}
\mathrm{v} & =\text { Speed of the train }[\mathrm{m} / \mathrm{s}] \\
\omega & =\text { Rotational speed }[\mathrm{rad} / \mathrm{s}] \\
\mathrm{r} & =\text { Wheel radius }[\mathrm{m}]
\end{aligned}
$$

Equation 3.3 .9 can be used to calculate the traction forces in the longitudinal direction as follows:

$$
T_{x}=G c^{2} C_{11} \epsilon_{x}
$$


where:

$\mathrm{G} \quad=$ Shear modulus $[\mathrm{MPa}]$

$\mathrm{a} \quad=$ Semi-major axis $[\mathrm{mm}]$

$\mathrm{b} \quad=$ Semi-minor axis $[\mathrm{mm}]$

$\mathrm{c}=$ Geometric mean of semi-axes of contact ellips: $\mathrm{c}=\sqrt{a b}[\mathrm{~mm}]$

$\mathrm{C}_{11}=$ Kalker coefficient as illustrated in Table 3.1

Table 3.1: Kalker's Creepage and Spin Coefficients [4]

\begin{tabular}{|c|c|c|c|c|c|c|c|c|c|c|c|c|}
\hline \multirow[b]{2}{*}{$\mathrm{g}$} & \multicolumn{3}{|c|}{$\mathrm{C}_{11}$} & \multicolumn{3}{|c|}{$\mathrm{C}_{22}$} & \multicolumn{3}{|c|}{$\mathrm{C}_{23}=-\mathrm{C}_{32}$} & \multicolumn{3}{|c|}{$\mathrm{C}_{33}$} \\
\hline & $\nu=0$ & $1 / 4$ & $1 / 2$ & $\nu=0$ & $1 / 4$ & $1 / 2$ & $\nu=0$ & $1 / 4$ & $1 / 2$ & $\nu=0$ & $1 / 4$ & $1 / 2$ \\
\hline 0.0 & \multicolumn{3}{|c|}{$\pi^{2} / 4(1-\nu)$} & \multicolumn{3}{|c|}{$\pi^{2} / 4=2.47$} & $\pi \sqrt{g} / 3$ & - & - & \multicolumn{3}{|c|}{$\nu^{2} / 16(1-\nu) \mathrm{g}$} \\
\hline \multirow[t]{9}{*}{$\mathrm{a} / \mathrm{b}$} & 2.51 & 3.31 & 4.85 & 2.51 & 2.52 & 2.53 & 0.334 & 0.473 & 0.731 & 6.42 & 8.28 & 11.7 \\
\hline & 2.59 & 3.37 & 4.81 & 2.59 & 2.63 & 2.66 & 0.483 & 0.603 & 0.809 & 3.46 & 4.27 & 5.66 \\
\hline & 2.68 & 3.44 & 4.8 & 2.68 & 2.75 & 2.81 & 0.607 & 0.715 & 0.889 & 2.49 & 2.96 & 3.72 \\
\hline & 2.78 & 3.53 & 4.82 & 2.78 & 2.88 & 2.98 & 0.72 & 0.823 & 0.977 & 2.02 & 2.32 & 2.77 \\
\hline & 2.88 & 3.62 & 4.83 & 2.88 & 3.01 & 3.14 & 0.827 & 0.929 & 1.07 & 1.74 & 1.93 & 2.22 \\
\hline & 2.98 & 3.72 & 4.91 & 2.98 & 3.14 & 3.31 & 0.93 & 1.03 & 1.18 & 1.56 & 1.68 & 1.86 \\
\hline & 3.09 & 3.81 & 4.97 & 3.09 & 3.28 & 3.48 & 1.03 & 1.14 & 1.29 & 1.43 & 1.5 & 1.6 \\
\hline & 3.19 & 3.91 & 5.05 & 3.19 & 3.41 & 3.65 & 1.13 & 1.25 & 1.4 & 1.34 & 1.37 & 1.42 \\
\hline & 3.29 & 4.01 & 5.12 & 3.29 & 3.54 & 3.82 & 1.23 & 1.36 & 1.51 & 1.27 & 1.27 & 1.27 \\
\hline \multirow[t]{10}{*}{$\mathrm{b} / \mathrm{a}$} & 3.4 & 4.12 & 5.2 & 3.4 & 3.67 & 3.98 & 1.33 & 1.47 & 1.63 & 1.21 & 1.19 & 1.16 \\
\hline & 3.51 & 4.22 & 5.3 & 3.51 & 3.81 & 4.16 & 1.44 & 1.59 & 1.77 & 1.16 & 1.11 & 1.06 \\
\hline & 3.65 & 4.36 & 5.42 & 3.65 & 3.99 & 4.39 & 1.58 & 1.75 & 1.94 & 1.1 & 1.04 & 0.954 \\
\hline & 3.82 & 4.54 & 5.58 & 3.82 & 4.21 & 4.67 & 1.76 & 1.95 & 2.18 & 1.05 & 0.965 & 0.852 \\
\hline & 4.06 & 4.78 & 5.8 & 4.06 & 4.5 & 5.04 & 2.01 & 2.23 & 2.5 & 1.01 & 0.892 & 0.751 \\
\hline & 4.37 & 5.1 & 6.11 & 4.37 & 4.9 & 5.56 & 2.35 & 2.62 & 2.96 & 0.958 & 0.819 & 0.65 \\
\hline & 4.84 & 5.57 & 5.57 & 4.84 & 5.48 & 6.31 & 2.88 & 3.24 & 3.7 & 0.912 & 0.747 & 0.549 \\
\hline & 5.57 & 6.34 & 7.34 & 5.57 & 6.4 & 7.51 & 3.79 & 4.32 & 5.01 & 0.868 & 0.674 & 0.446 \\
\hline & 6.96 & 7.78 & 8.82 & 6.96 & 8.14 & 9.79 & 5.72 & 6.63 & 7.89 & 0.828 & 0.601 & 0.341 \\
\hline & 10.7 & 11.7 & 12.9 & 10.7 & 12.8 & 16 & 12.2 & 14.6 & 18 & 0.795 & 0.526 & 0.22 \\
\hline
\end{tabular}

where:

$\nu=$ Poisson's ratio

$\mathrm{g}=\min (\mathrm{a} / \mathrm{b}, \mathrm{b} / \mathrm{a})$

The $\mathrm{C}_{22}, \mathrm{C}_{23}$ and $\mathrm{C}_{33}$ coefficients are not used in this investigation, but are provided for the sake of completeness. 


\subsubsection{Dynamic Load Factors}

\section{Introduction}

Contrary to static loading which remains constant over time, dynamic loading is loading which changes with time. Dynamic loading is the interaction between the load and structure, and can generally be either periodical, impact or stochastic loads. Structures are characterised by their response to frequencies, and are dependant on the structure's mass, damping and stiffness. These characteristics determine the structure's natural frequencies. If the frequency of an applied load corresponds to the natural frequency of a structure, large displacement amplifications (also known as resonance) may occur [4]. As previously stated, railway systems are commonly analysed and designed using static loads which are amplified using a DAF which takes the dynamic loading of the numerous passing bogies into account. This section investigates the numerical method which can be used for obtaining the DAF of a railway section under investigation.

Dynamic loads in railway systems are caused by:

- Compounding forcing effect of passing bogies

- Rail and foundation irregularities (horizontal and vertical)

- Discontinuities at e.g. rail welds, joints, and switches

- Vehicle defects such as wheel flats or natural vibration

The DAF can be numerically calculated by means of Eisenman's scheme which represents a method generally used for taking vehicle dynamics into account [4].

$$
\begin{gathered}
D A F=1+t \phi \quad \text { if } \quad V<60 \\
D A F=1+t \phi\left(1+\frac{V-60}{140}\right) \quad \text { if } \quad 60 \leqq V \leqq 200
\end{gathered}
$$

where:

$\mathrm{t}_{\mathrm{f}}=$ Multiplication factor, which is dependant on a confidence interval

$\phi=$ Track quality factor

$\mathrm{V}=$ Vehicle speed $[\mathrm{km} / \mathrm{h}]$

Table 3.2: Dynamic Amplification Factor Values [4]

\begin{tabular}{ccc|cc}
\hline Confidence Interval & $\mathrm{t}$ & Application & Track Condition & $\phi$ \\
\hline $68.3 \%$ & 1 & Contact stress, subgrade & Very good & 0.1 \\
$95.4 \%$ & 2 & Lateral load, ballast bed & Good & 0.2 \\
$99.7 \%$ & 3 & Rail stresses, fastenings, supports & Bad & 0.3 \\
\hline
\end{tabular}


A value of 3 is recommended for the multiplication factor of standard deviation, $t_{f}$, as the chance of exceeding the maximum calculated stresses is only $0.15 \%$ [4]. A probability index of $99.7 \%$ means that $0.3 \%$ is the combination of the area exceeding the upper bound, and area below the lower bound.

The sensitivity of the DAF on its determining variables, $\mathrm{t}$ and $\phi$, is illustrated in Figures 3.14 . 3.15 and 3.16 .

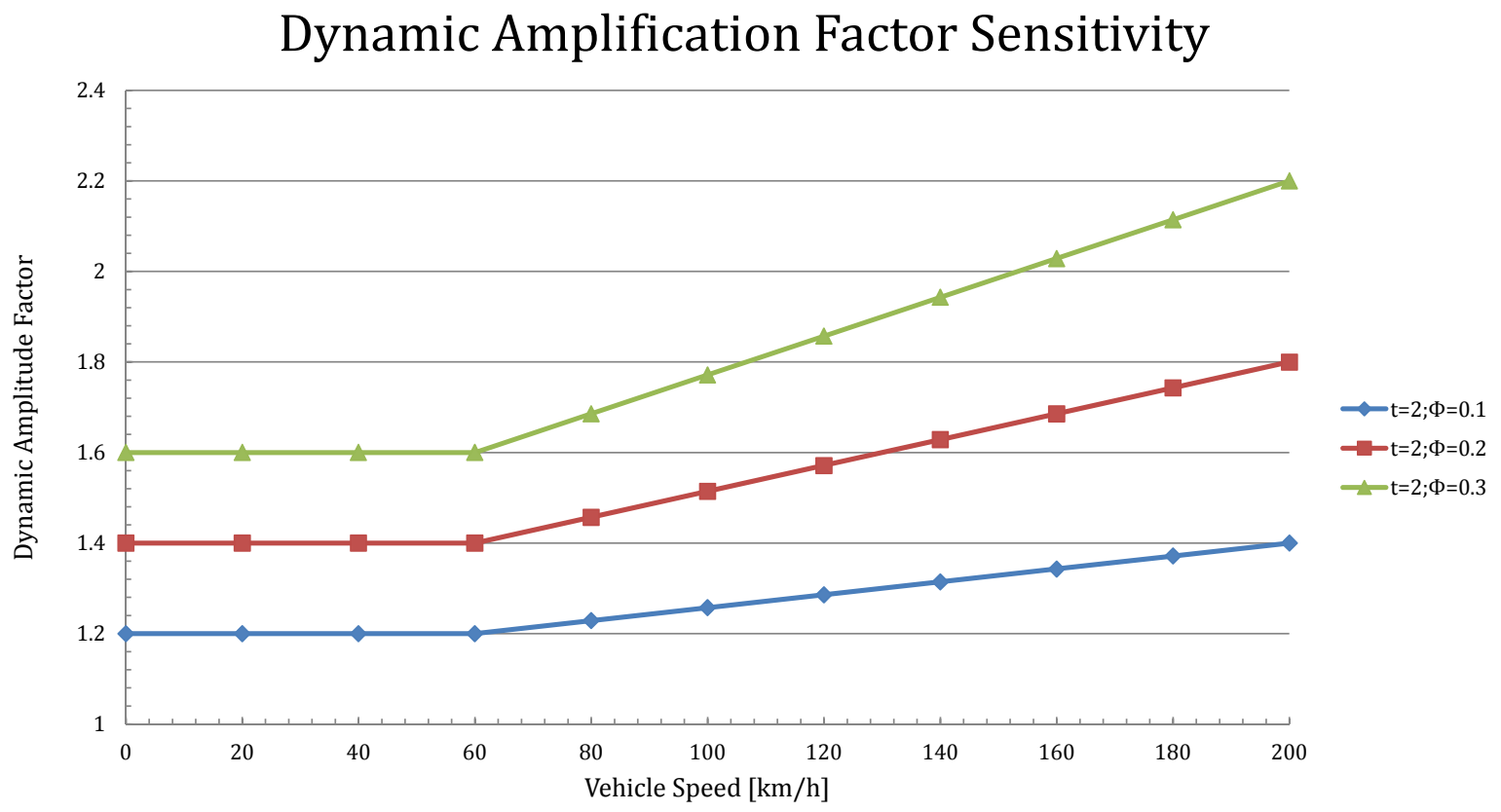

Figure 3.14: DAF Variation for $\mathrm{t}=1$ 


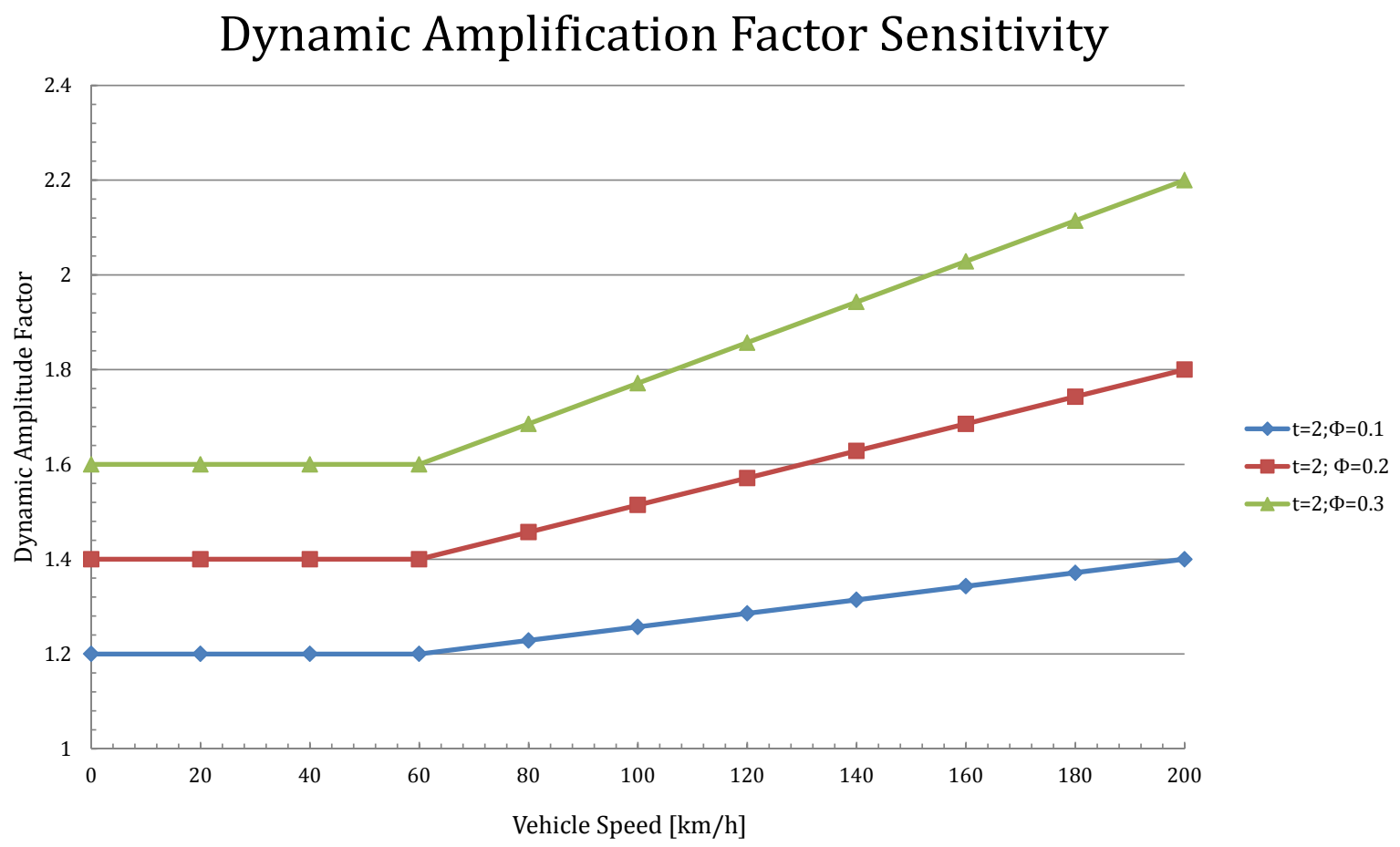

Figure 3.15: DAF Variation for $\mathrm{t}=2$

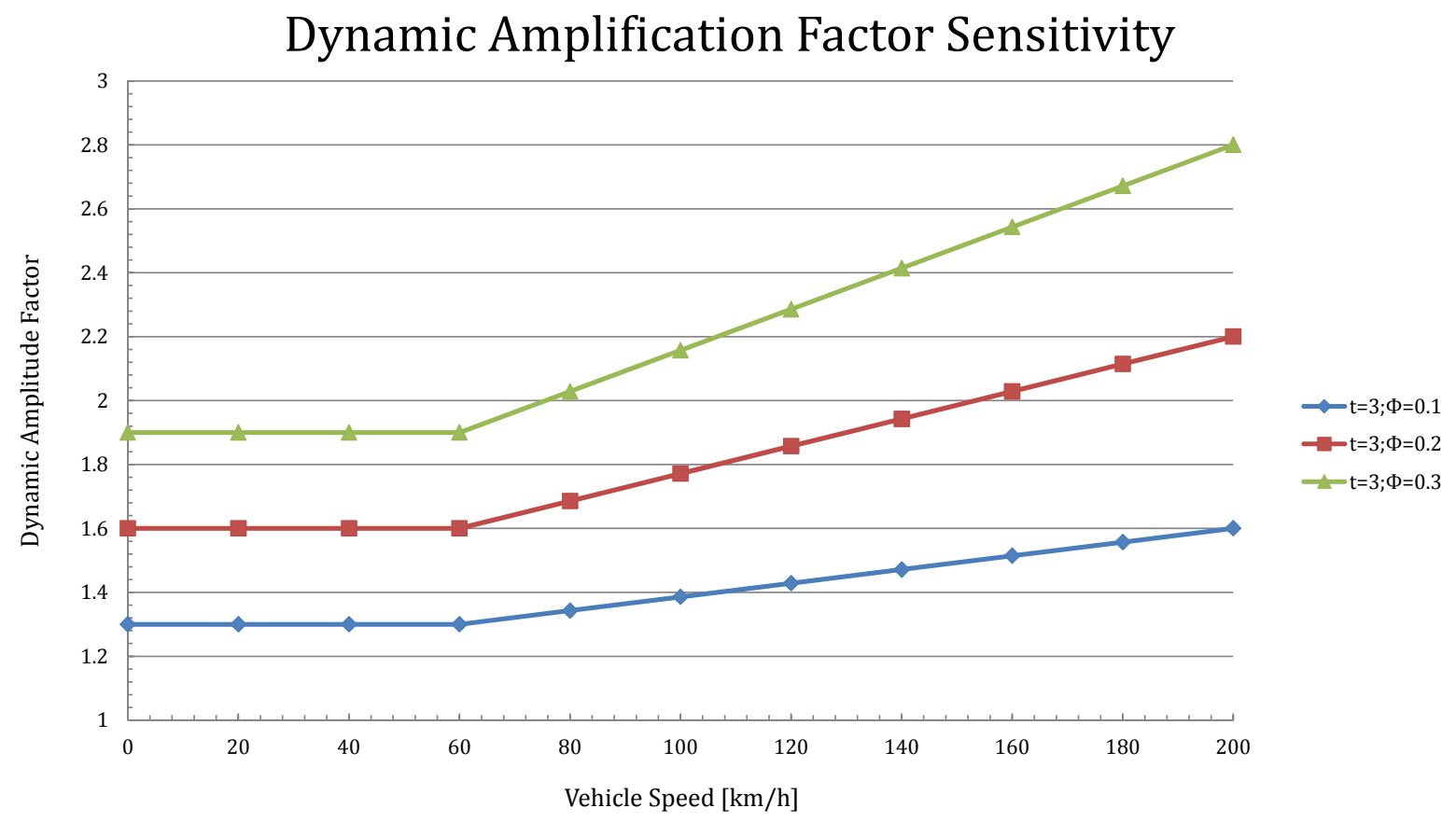

Figure 3.16: DAF Variation for $\mathrm{t}=3$

These figures illustrate the influence of parameter choice on the value of the DAF and can have a significant influence on the displacements of the railway section. Great care should therefore be 
taken when using this amplification factor. The reference model based on the Amandelbult TT section is analysed with both static and dynamic loading applied, thereby obtaining the DAF specific to this railroad section.

\subsubsection{Modal Frequency Analysis}

As previously stated, all systems with mass and stiffness can vibrate at certain frequencies called modal frequencies, or natural frequencies, and in certain shapes called modal shapes. An eigenvalue analysis, also known as modal analysis, can be performed in order to obtain these natural frequencies and corresponding mode shapes [12]. These natural frequencies are important for design for the reduction of vibrations and the prevention of resonance, and can be used to calculate the critical speed of railway vehicle at which hunting and destabilisation will occur. The excitation frequency, $\mathrm{f}$, is calculated as follows [4]:

$$
f=\frac{v}{\lambda}
$$

where:

$\mathrm{v}=$ speed of vehicle $[\mathrm{m} / \mathrm{s}]$

$\lambda=$ wavelength $[\mathrm{m}]$

For small frequencies the wavelength is equal to the characteristic length $\mathrm{L}_{\mathrm{c}}$. The actual wavelength is obtained by multiplying $\mathrm{L}_{\mathrm{c}}$ with $2 \pi$ as follows:

$$
\lambda_{n}=2 \pi L_{c}
$$

where:

$\lambda_{\mathrm{n}}=$ Natural wavelength $[\mathrm{m}]$

The dynamic frequency response function of the Single Beam and Double Beam models is based on the static elastic foundation theory, and can be calculated by means of the Fourier transformation of the displacement response, $\mathrm{w}(\mathrm{t})$, by using a transfer function as follows [4]:

$$
W(f)=H(f) F(f)
$$

where:

$\mathrm{W}(\mathrm{f})=$ Fourier transform of the displacement

$\mathrm{H}(\mathrm{f})=$ Frequency response function

$\mathrm{F}(\mathrm{f})=$ Impulse load response

The frequency response function is therefore calculated as follows:

$$
H(f)=\frac{W(f)}{F(f)}
$$

The differential equations 3.1.14, 3.1.15 and 3.1.2 obtained for the Single and Double Beam models can be transformed for the dynamic analysis by replacing the foundation coefficient, $\mathrm{k}$, 
with a complex coefficient $\mathrm{k}^{*}$ as follows [4]:

$$
k_{s u b}^{*}=k_{s u b}-m_{s u b} \omega^{2}+i c_{s u b} w
$$

where:

$\mathrm{m}=$ Mass per unit length $[\mathrm{kg} / \mathrm{m}]$

$\omega=2 \pi \mathrm{f}[\mathrm{rad} / \mathrm{s}]$

$\mathrm{c}=$ Damping coefficient $\left[\mathrm{Ns} / \mathrm{m}^{2}\right]$

Note: sub refers to upper or lower beam for the Double Beam model

For the TT system where a single point load is acting at $\mathrm{x}=0$, the frequency response function can be calculated as follows [4]:

$$
H(f)=\frac{w(0)}{8 E I \mu^{3}}
$$

where:

$\mu=\sqrt[4]{\frac{k^{*}}{4 E I}}$

Equation 3.3 .18 can now be transformed as follows:

$$
H(f)=\frac{1}{2 k L}\left(\left[1-\frac{f^{2}}{f_{n}^{2}}\right]^{2}+4 \zeta^{2} \frac{f^{2}}{f_{n}^{2}}\right)^{-3 / 8} e^{i \phi}
$$

where:

$$
\phi=-\frac{3}{4} \arctan \left(\frac{2 \zeta \frac{f}{f_{n}}}{1-\frac{f^{2}}{f_{n}^{2}}}\right)
$$

and

$f_{n}=\frac{1}{2 \pi} \sqrt{\frac{k}{m}}$ is the undamped natural frequency

$\zeta=\frac{c}{2 \sqrt{k m}}$ is the damping ratio

The frequency response factors for the TT railway system are illustrated in Figure 3.17. which are based on the Single Beam method and the natural frequencies of the TT system which were obtained using a modal analysis using the 3D ABAQUS dynamic analysis model as will be discussed in Chapter 6. The natural frequencies with their corresponding modal shapes are attached in Appendix A. Figure 3.17 serves only as an approximation and indication of the response when the excitation frequency approaches a natural frequency, thereby causing resonance. The applied frequencies should therefore be below the first natural frequency in order to avoid resonance. 


\section{Frequency Response Factors}

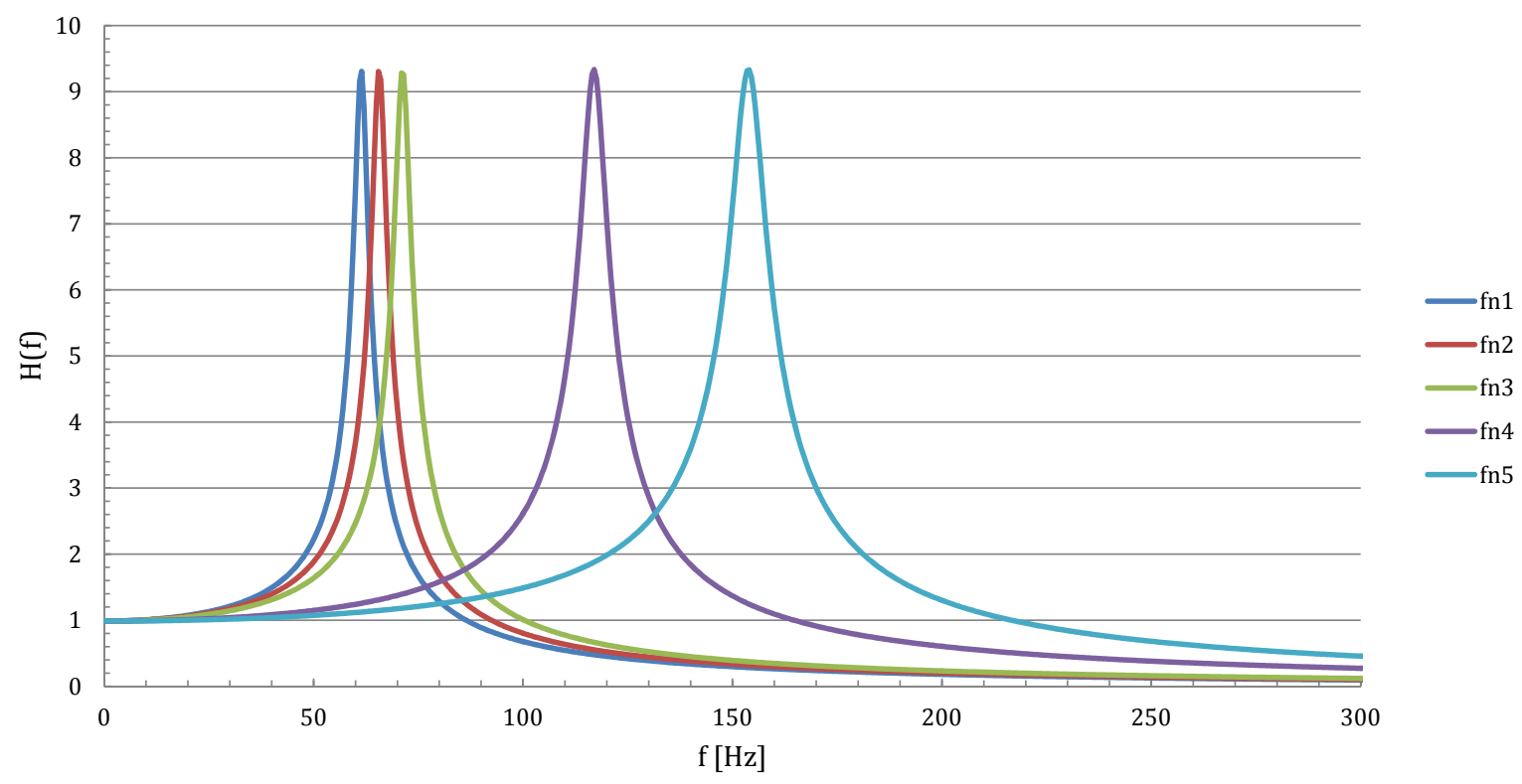

Figure 3.17: TT Single Beam Frequency Response Factors

For the Amandelbult reference section the excitation frequency of the train traveling at $43 \mathrm{~km} / \mathrm{h}$ and with a characteristic length of $6.7 \mathrm{~m}$, using Equation 3.3 .13 and 3.3.14 can be calculated as being $0.284 \mathrm{~Hz}$, which is way below the first natural frequency and therefore causes no resonance in the TT system. This indicates that frequency excitation only occurs at very high train speeds. The unknown damping ratio of the TT railway system has a large effect on the frequency response of the system. The sensitivity of the system to varying damping ratios is illustrated in Figure 3.18 and therefore indicates the necessity of choosing the correct damping ratio of the system in order to obtain an accurate response. 


\section{Damping Ratio Sensitivity}

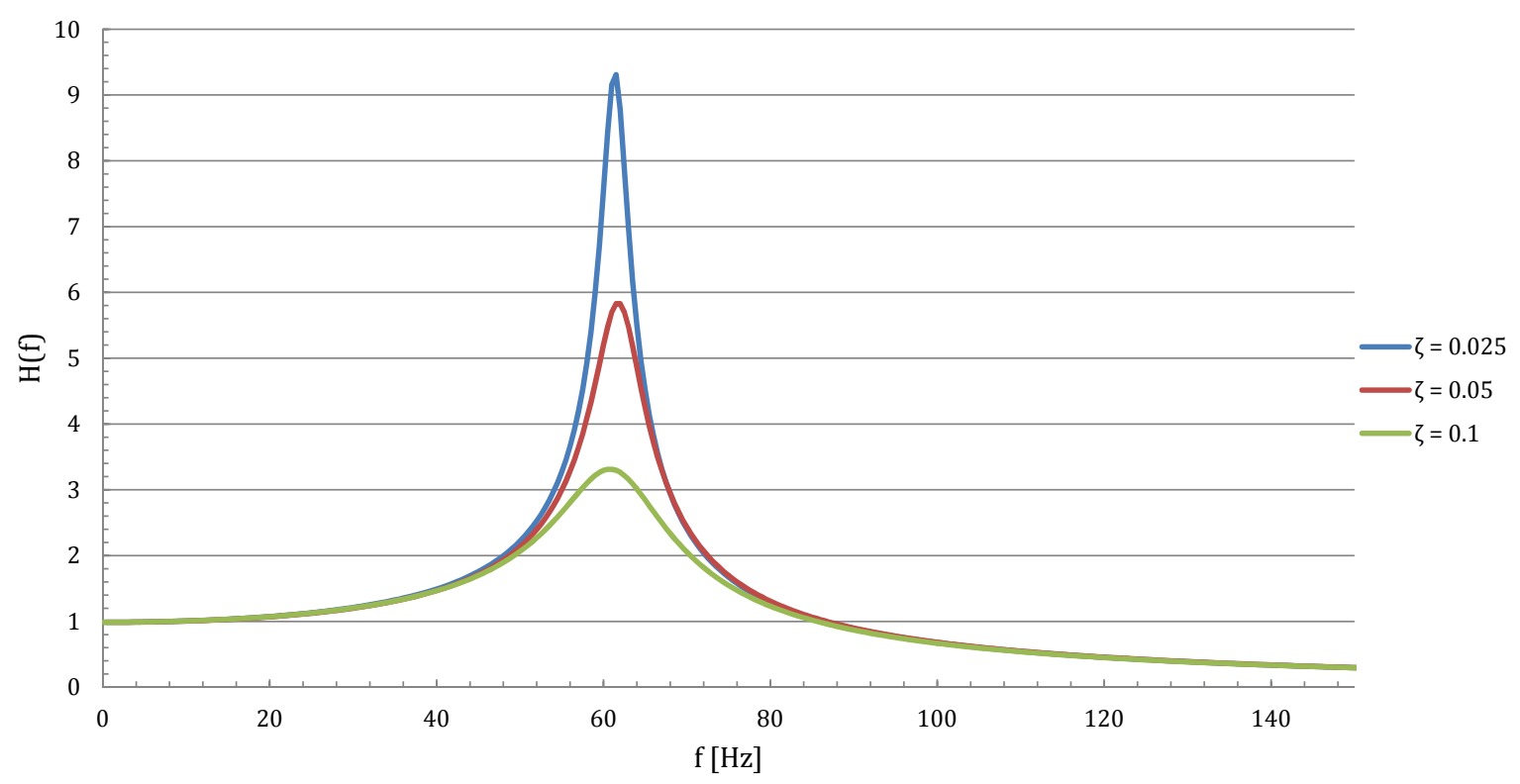

Figure 3.18: Sensitivity Illustration of damping ratio

\subsection{Summary}

Methods required to model the TT system using theoretical models, such as the Beam on Elastic Foundation theory, Double Beam method and accompanying modeling techniques such as the Transformed-Section method were developed in this chapter. These models are used in later chapters for comparison with more detailed 2D beams and 3D solid element models.

Insight into the dynamic nature of a railway system, and the resulting forces and respective contact areas resulting from them are also demonstrated in this chapter. Hertz contact theory is investigated and incorporated in later FEA models for modeling of contact areas and accurate load transfer between the superstructure's components. Providing accurate contact areas reduces the influence of possibly using too small areas which creates high localised pressure-and deflection zones in the rails, or too large areas which decrease the sectional forces in the rails.

Methods of calculating the various vertical, lateral and longitudinal loads which can act on a railway system were investigated in this chapter. The models used for the general analysis and design for the purpose of this investigation do not take all the loads as investigated in this chapter into account, but only apply the vertical wheel loads from bogies. The additional vertical forces generated due to hunting, curves or any other reason are not applied in the general models as they are dependant on specific conditions which cannot be incorporated in the general models and therefore fall outside the scope of this investigation. The calculation of the additional loads 
are however provided for background knowledge and possible future analyses.

A DAF takes the dynamic nature of the railway system into account by multiplying the static force magnitude with the DAF, thereby simulating the dynamic compounding effects of the passing bogies using an empirical approach. This validity of using this empirical amplification method will be investigated in a later chapter.

The magnitude of the damping ratio is found to have a large influence on the frequency response of the system, and will affect the response of the system when the excitation frequency is near a natural frequency. The damping ratio values should therefore be chosen with due consideration. 


\section{Chapter 4}

\section{Research Methodology}

\subsection{Introduction}

The purpose of this chapter is to present the research methodology followed for the investigation of the Tubular track (TT) railway system and the models which are to be investigated using the finite element method (FEM) in combination with elastic foundation theory. The chapter defines the scope and limitations of this investigation, and discusses the methods followed to arrive at the required objective of this investigation.

\section{$4.2 \quad$ Scope of Research}

This dissertation investigates the various analysis methods which can be used to analyse the TT railway system. The displacements of the TT system finite element models are compared to field test results of a reference TT section to verify the usage of the analysis methods. The bending moments and shear forces of the finite element models are subsequently compared to one another. The analysis methods include:

- Single beam on elastic foundation theory

- Double Beam theory

- PROKON 2D beam frame analysis

- ABAQUS 2D beam analysis

- ABAQUS 3D solid element analysis

The purpose of this dissertation is to ultimately provide a simple finite element model which can be utilised to perform quick and simple analyses. The basic process followed in this investigation is demonstrated in Figure 4.1 . 


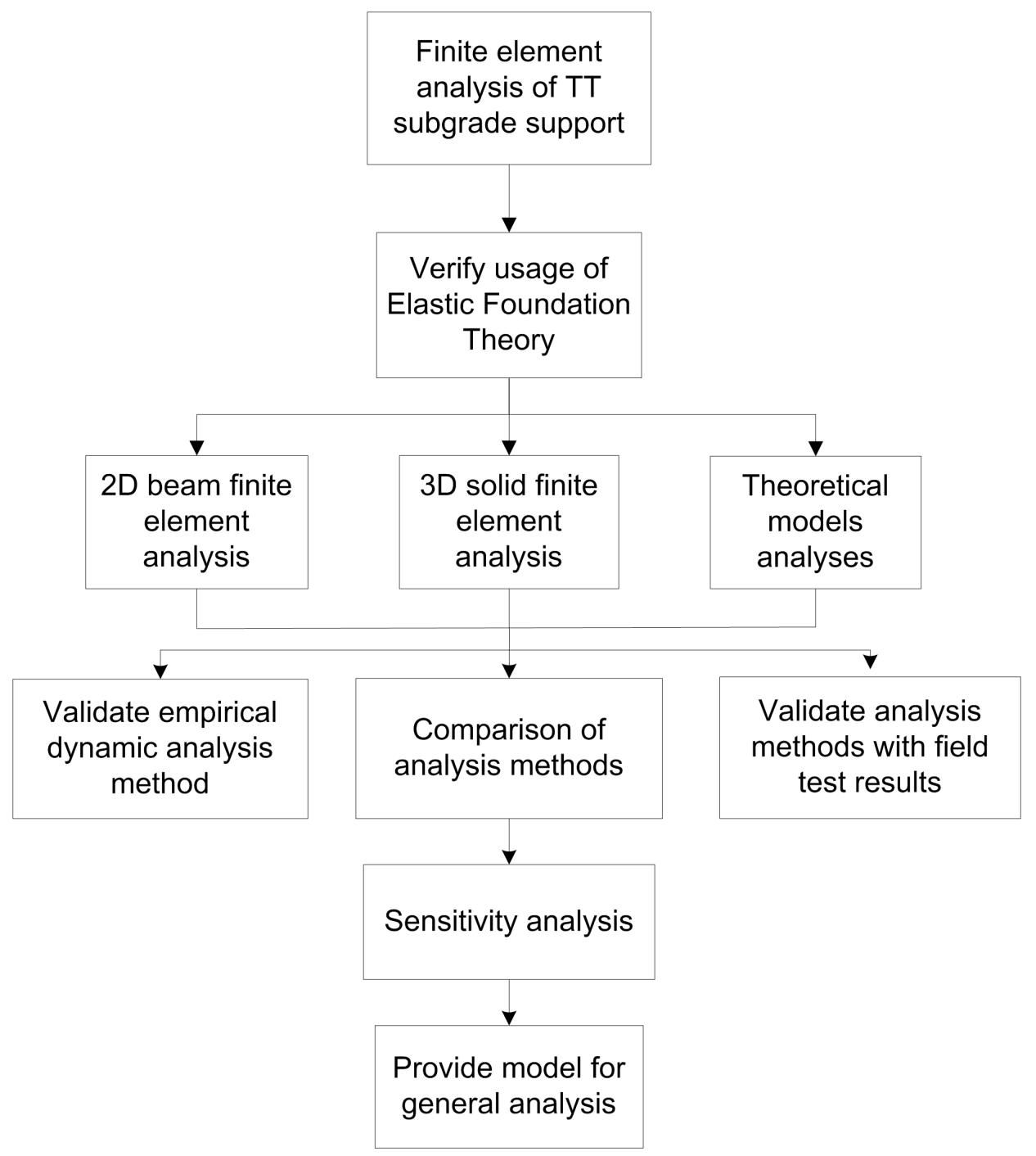

Figure 4.1: Investigation Process of the TT System

\subsection{Analysis Methodology}

This investigation is focused on the analysis of the TT railway system using various modeling techniques. For the analysis models to hold any merit, they have to be based on actual TT railway sections in use. The vertical support provided by the subgrade formation has a significant influence on the displacements obtained, and should therefore be investigated in detail. The subgrade formations have to be simplified to represent a vertical elastic stiffness, which can then be used in all the analysis models. The vertical support provided by the subgrade formations is investigated by means of analysing actual soil formations in use by TT. The design of four TT railway sections and their respective supporting soil formations are known, and provide the necessary design parameters for the analysis of the TT railway section as well as the supporting stiffness provided by the soil formations. Three railway sections are based at the Amandelbult TT railway line, and one section is based at the Pilbara Ore line. The TT modules have approximately $100 \mathrm{~mm}$ gaps between the RC beams, and therefore do not support the rails at these 
gaps. The reference TT railway section is chosen at the Amandelbult TT layout section 3, which is based at the center of a module in order to minimise the effects of the gaps between modules. The vertical stiffness of the soil layers are based on the four TT soil formations and are analysed using an ABAQUS solid element finite element model.

Once the foundation modulus of the reference section is known, it can be utilised in the various analysis models. A comparison is subsequently made between theoretical elastic foundation, 2D beam and 3D solid finite element models subjected to static loading in order to investigate their similarities and accuracy. One of the goals is to verify the similarities between simple theoretical models with complex 3D FEM models. These results, though, represent static analyses which cannot be compared to the field test results which was a test section subjected to a passing train i.e. dynamic loading.

The load system acting on a railway system is generally dependant on the axle loads, running speed of the train and the spacing between bogies. It is common practise to analyse a railway system by means of a static load system, whereby the effects of dynamic loading are taken into consideration by means of a speed coefficient or Dynamic Amplitude Factor (DAF) [4] using an empirical method. The validity of this empirical analysis method is investigated in this dissertation by comparing the empirical amplification method with an implicit dynamic analysis. A dynamic analysis is therefore required for the comparison with the field test results and therefore also the validation of the analysis models. The Amandelbult reference section is therefore analysed by means of static and implicit dynamic analyses, in order to obtain and investigate the DAF for this particular section. This DAF can subsequently be applied to the static reference model in order to investigate whether the obtained results are similar to the displacements obtained from the field test results. The obtained DAF is specific to the Amandelbult reference section and cannot be used for the general FEA model. The purpose of the obtained DAF is therefore only to validate the models using the obtained displacements.

Another goal of this investigation is the development of a general 2D FEA model which can be utilised by TT to perform quick analyses with the use of input parameters. This model can be used to obtain the deflections, bending moment and shear force diagrams of the TT system under investigation. This model can be used for a sensitivity analysis which varies certain input parameters in order to investigate the behaviour of the TT system subjected to specific conditions. Once the displacements, bending moment and shear force diagrams are obtained using the finite element model, the design of the system components such as the rail size, reinforced concrete beam, supporting grout layer, and elastomeric pad can be performed according to the desired standards. 


\subsection{Limitations of Research}

This investigation analyses a straight track section of TT railway with only vertical normal forces acting on the railway system for the purpose of obtaining a simplified FEA model. This is of course a simplification of the railway system which is subjected to lateral and minor longitudinal loads. The lateral forces acting on a railway section are highly variable and depend on numerous factors such as cant, curve radius, running speed, hunting, and tie bar spacing which cannot be taken into account for a general design model. In order to investigate these additional forces a more detailed FEA should be performed to investigate individual railway sections. Only the analysis of the TT railway system is performed in this investigation, and does not focus on specific design of the railway system. Safety factors, other than the DAF, are therefore not included in the analysis as it is outside the scope of this investigation.

The actual damping coefficients of the TT system are also not determined in this investigation, but are however investigated in a sensitivity analysis. 


\section{Chapter 5}

\section{Two-Dimensional Finite Element Analysis}

\subsection{Finite Element Method Introduction}

Research programmes in the field of engineering have conducted experimental studies so as to acquire knowledge and understanding of structures and their structural components under certain conditions. These physical experiments are very useful, yet also very time-consuming and expensive. The application of finite elements provides engineers with the possibility to forego laborious physical experiments and obtain analytical solutions to field problems. The Finite Element Method (FEM) is a method which can be used for the numerical solution of field problems. A Finite Element Analysis (FEA) represents a simulation of field models and is applied to a mathematical problem which is described by differential equations or an integral expression. This mathematical problem is an idealisation of the physical reality whereby geometry, boundary conditions, loads, and material properties are simplified based on the features important in obtaining the required results. Finite element models therefore allow engineers to provide accurate solutions without having to conduct expensive and time-consuming physical experiments [24].

There are various FEA software packages available in the field of engineering, varying in complexity as well as accuracy depending on the model type. For the purpose of modeling the Tubular Track (TT) system, ABAQUS Standard edition version 6.10-2 will be used for the threedimensional (3D) solid models, as well as two-dimensional (2D) beam models. Another FEA software package used is PROKON frame analysis, used for $2 \mathrm{D}$ beam analyses, and PROKON: Analysis of a beam on elastic support, which is based on beam on elastic foundation theory as explained in Section 3.1. The theoretical models as investigated in Chapter 3 will also be investigated and compared with the $2 \mathrm{D}$ beam and $3 \mathrm{D}$ solid element models. 


\subsection{FEM Beam Elements}

This chapter investigates 2D beam FEA methods which can be used to analyse the TT railway system. 2D beam elements, much like one-dimensional bar elements, are widely used in FEA as stand-alone elements or in combination with other element types such as solid or shell (plate) elements. In this chapter we restrict the elements used in the FEA to the linear beam elements which are capable of resisting axial, bending and torsional loads. The linear, also known as firstorder, analysis type is used due to the fact that the material and geometrical properties of the TT railway components remain essentially constant under the applied loads and have negligible deformation. Inertial and non-linear effects such as the crushing of concrete, yielding of steel and membrane-action caused by large lateral deflections are therefore excluded from the quasi-static analysis of the TT system [24].

\subsubsection{Element Types}

The element types used for the various 2D FEA models are as follows:

\section{Beam Elements}

The 2D beams used for the analyses are based on fundamental Euler-Bernoulli beam theory. Euler-Bernoulli beam elements have a node at each end, with two degrees of freedom (DoF) each, namely lateral translation and rotation, as illustrated in Figure 5.1. Lateral displacements are restricted to the 2D xy plane and consider bending deformations only, thereby disregarding transverse shear deformations as taken into account by Timoshenko beam theory. To allow the beam to have axial as well as bending deformations, we add axial DoF $u_{1}$ and $u_{2}$ to nodes 1 and 2 respectively.

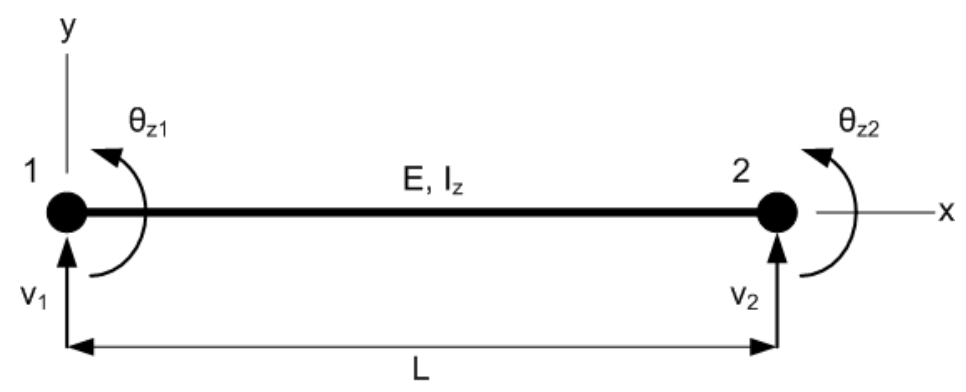

Figure 5.1: Degrees of Freedom in xy Plane

In order to now take transverse shear deformation into account, the bending stiffness is modified, thereby producing the Timoshenko beam element. PROKON frame analysis and ABAQUS automatically uses Timoshenko beam elements if the beam section's shear area is provided. 


\section{Rigid links}

Rigid links are used to connect nodes of different elements by imposing constraints on the DoF to have prescribed translation or rotation to one another. This sort of constraint can either be imposed on the stiffness matrix, or modeled as separate connection beams with a very large stiffness and no discernable weight [24]. The rigid links used to connect the rail, reinforced concrete (RC) beam, elastomeric pad, and grout to one another are modeled as separate beam connections. The stiffness of the rigid links is determined by multiplying the beams' maximum area and stiffness by a given factor, which is by default 1000 in PROKON [25]. The connection type between beam elements must be defined, and can either be fixed i.e. full rotational continuity, pinned i.e. no rotational constraints, or have torsional fixity i.e. constraint for rotation around element axis. The rigid links used in the two-dimensional analyses have pinned fixities as to allow for small rotations and axial displacements between beams.

\subsection{Reference Model Properties}

The 2D and 3D FEA models used for analysis and comparison are based on the Amandelbult Layout station 3 as described previously, so that all the components and variables are constant, except for the analysis method. This will allow for an accurate comparison between analysis methods, and will verify the accuracy of FEM modeling techniques for simplification of the TT railway system under investigation. The analyses are performed as static analyses, and do not take a Dynamic Amplitude Factor (DAF) into account, as it is not required for the purpose of this investigation. The rail and $\mathrm{RC}$ beam are the focus of the investigation, as they are the most important components of the railway system. A bending moment is assumed as positive when the internal moment causes a compression in the top fibres of the beam when a load acts downwards on the segment, and the shear force causes a clockwise rotation of the beam, as illustrated in Figure 5.2 . This convention will be used throughout this dissertation.

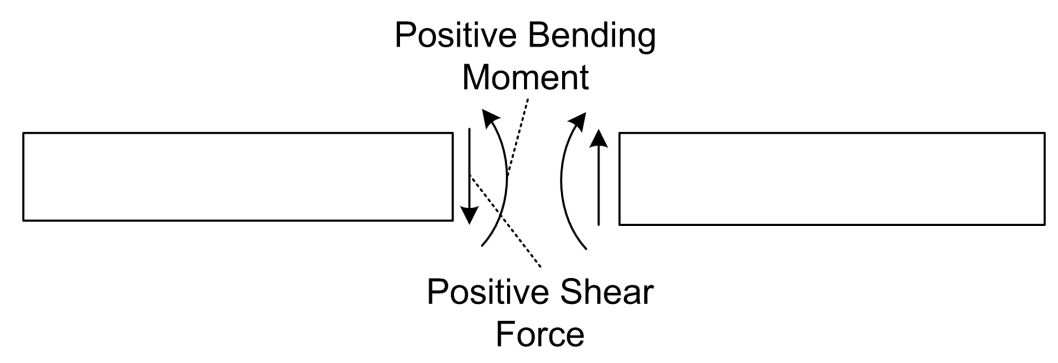

Figure 5.2: Beam Sign Convention 
All results in this investigation use the following units, unless stated otherwise:

$\begin{array}{ll}\text { Distance: } & \mathrm{mm} \\ \text { Displacement: } & \mathrm{mm} \\ \text { Force: } & \mathrm{kN} \\ \text { Pressure: } & \mathrm{MPa} \\ \text { Bending Moment: } & \mathrm{kNm}\end{array}$

The 2D FEA methods that are utilised for the purpose of this investigation are as follows:

- PROKON frame analysis

- Single beam on elastic foundation

- ABAQUS v6.10-2

- Double Beam Method

\subsubsection{Model Symmetry Analysis}

The TT railway system is defined as an infinitely long beam, but cannot be analysed as such for the FEA. The purpose of this analysis is to investigate the length of the concrete beam required to accurately investigate the maximum deflections, bending moments and shear forces in the system for a set load combination with accurate boundary conditions representing symmetry.

As explained in Section 2.2 the train vehicles under investigation are CR11 vehicles, as is the case for the Amandelbult reference model. A CR11 vehicle has a wheel bogey at either sides of the vehicle, where each bogey consists of two axles, as illustrated in Figure 2.3. Two adjacent CR11 vehicles therefore have 4 closely spaced axles. An illustration of the 8 axle loads of two adjacent vehicles under consideration are indicated in Figure 5.3, where P1 to P8 refer to the respective axle loads. Any loads at a distance greater than $2 \mathrm{~m}$ from the point under investigation have been found not to have a significant influence on the displacements of the TT system at that point, and can therefore be ignored.

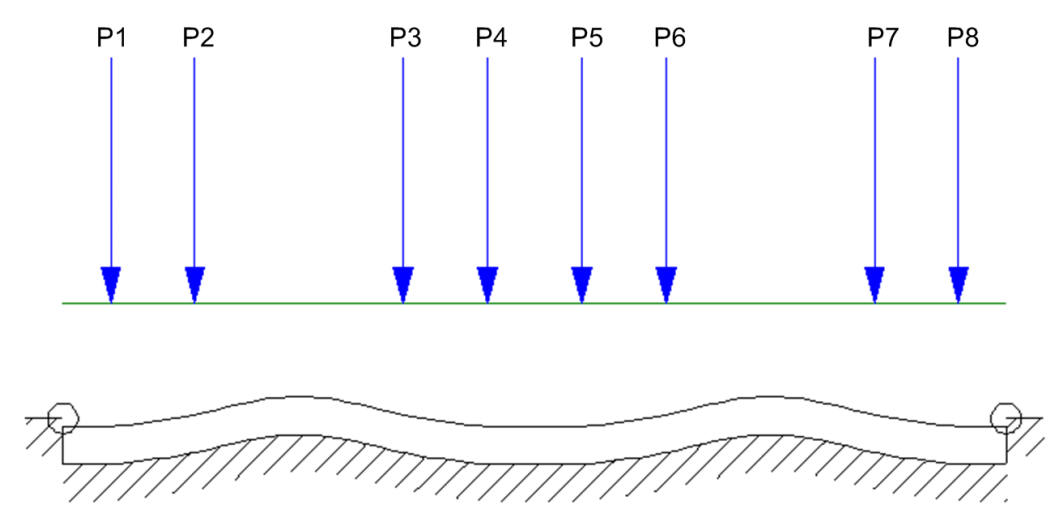

Figure 5.3: Illustration of the 8 Bogey Loads Caused by Two Adjacent Vehicles 
Three Loading Combinations (LC) are investigated for simplification purposes, and are as follows:

8 loads LC1; Representing all eight axle loads for two adjacent vehicles (P1 - P8)

4 loads LC2; Representing four axle loads on a single vehicle (P5 - P8)

2 loads LC3; Representing the first two axle loads of a vehicle (P5 - P6)

The load combinations use rotational boundary conditions at their respective endpoints. The displacements, bending moments and shear forces for the three load combinations obtained for the TT system using the PROKON beam on elastic support software are illustrated in Figures 5.45 .5 and 5.6 respectively.

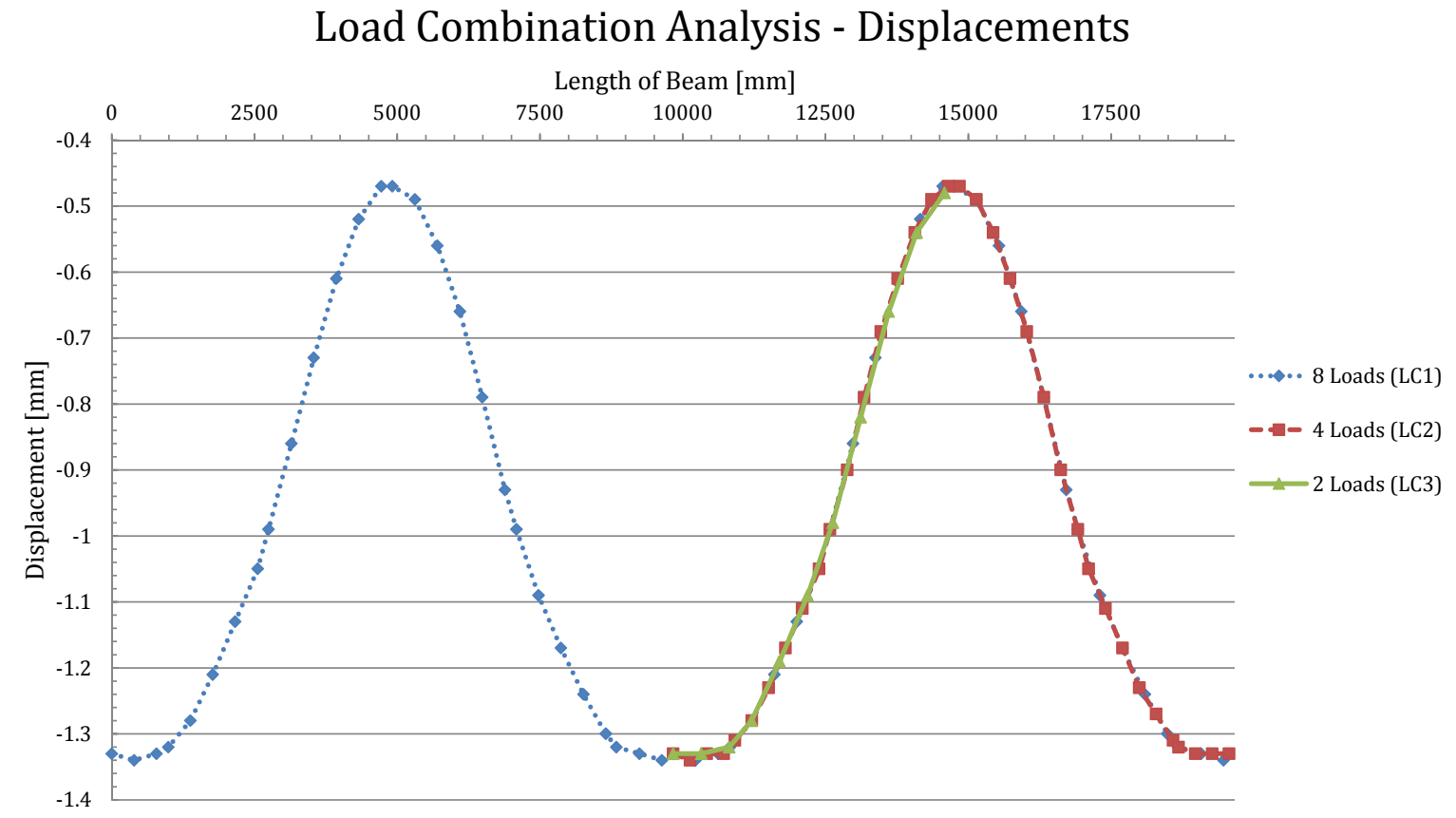

Figure 5.4: Deflections Caused by Two Adjacent Vehicles 


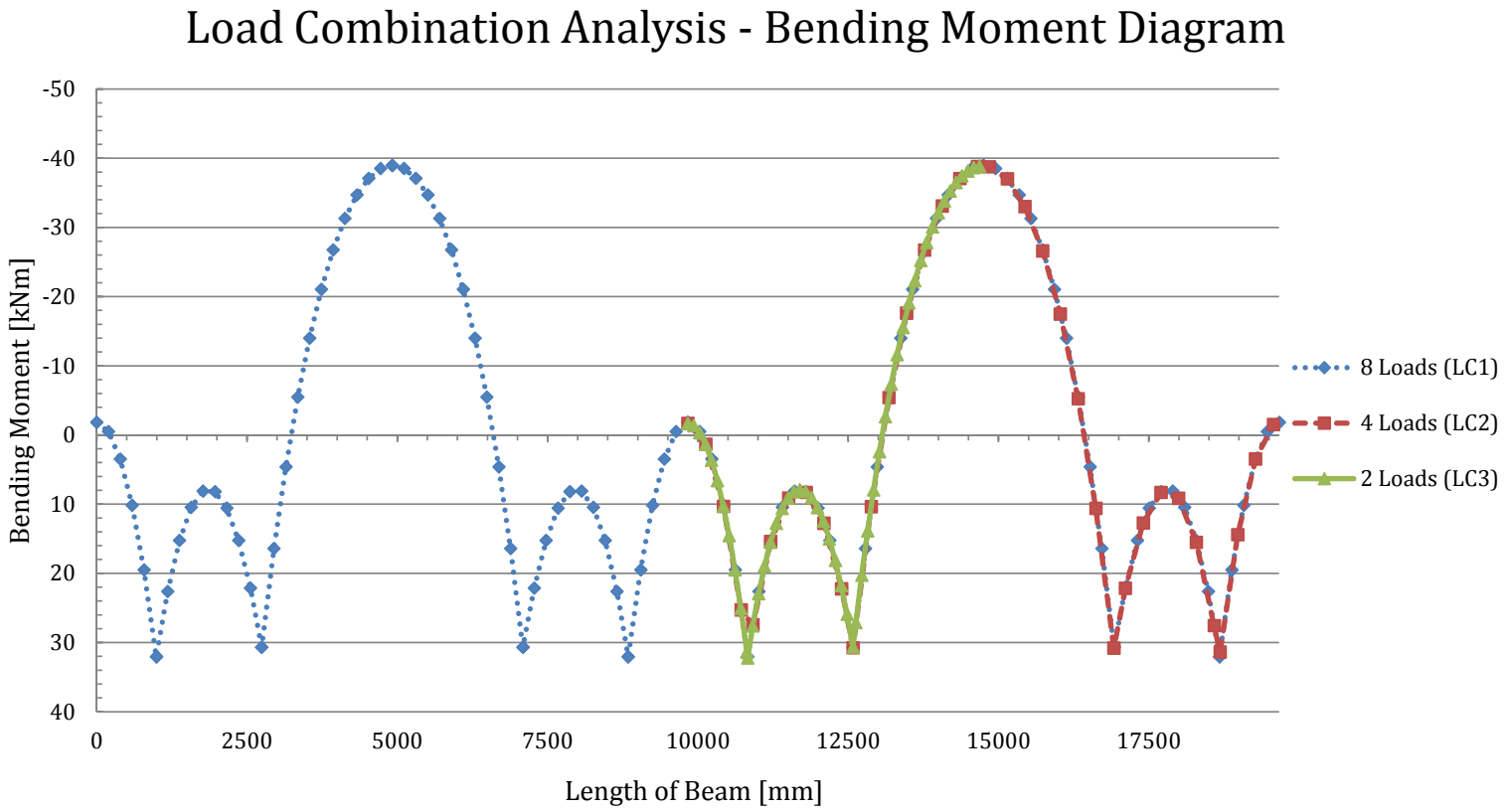

Figure 5.5: Bending Moment Diagram Caused by Two Adjacent Vehicles

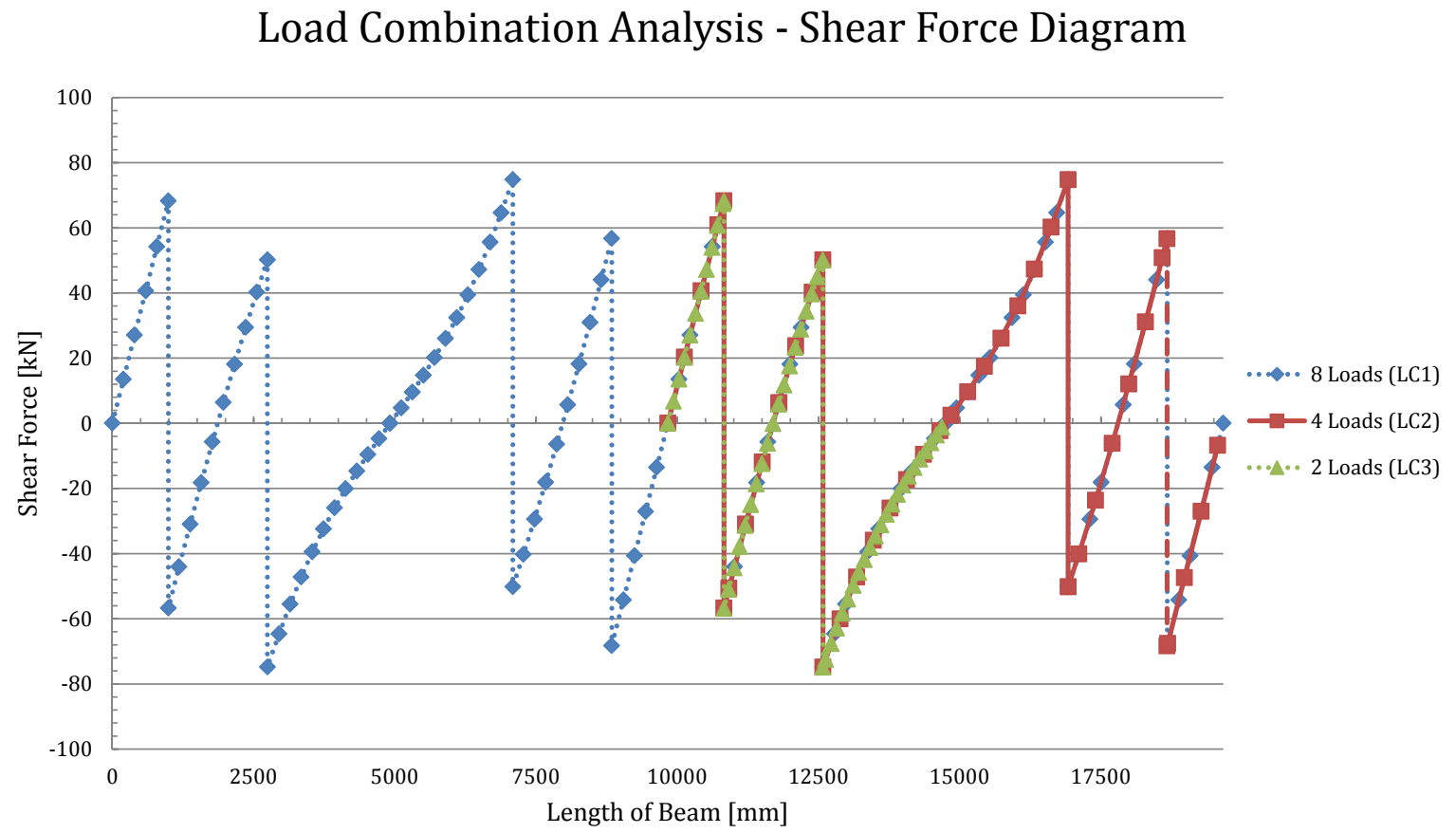

Figure 5.6: Shear Force Diagram Caused by Two Adjacent Vehicles

From Figures 5.4 5.5 and 5.6 it is evident that the three load combinations provide similar results for deflections, bending moment and shear force diagrams, thereby justifying the assumption that 
the loading combination to be used can be the two loads representing two axles at a side of a vehicle (e.g. P5 and P6). The railway section therefore used for analysis in this dissertation is illustrated in Figure 5.7. The results presented throughout this dissertation are between section $\mathrm{A}-\mathrm{A}$ and B-B, as these represent the section applying symmetry conditions as well as points with a slope equal to zero. The analysis models take symmetry conditions into account by using rotation-restricting boundary conditions at the ends.

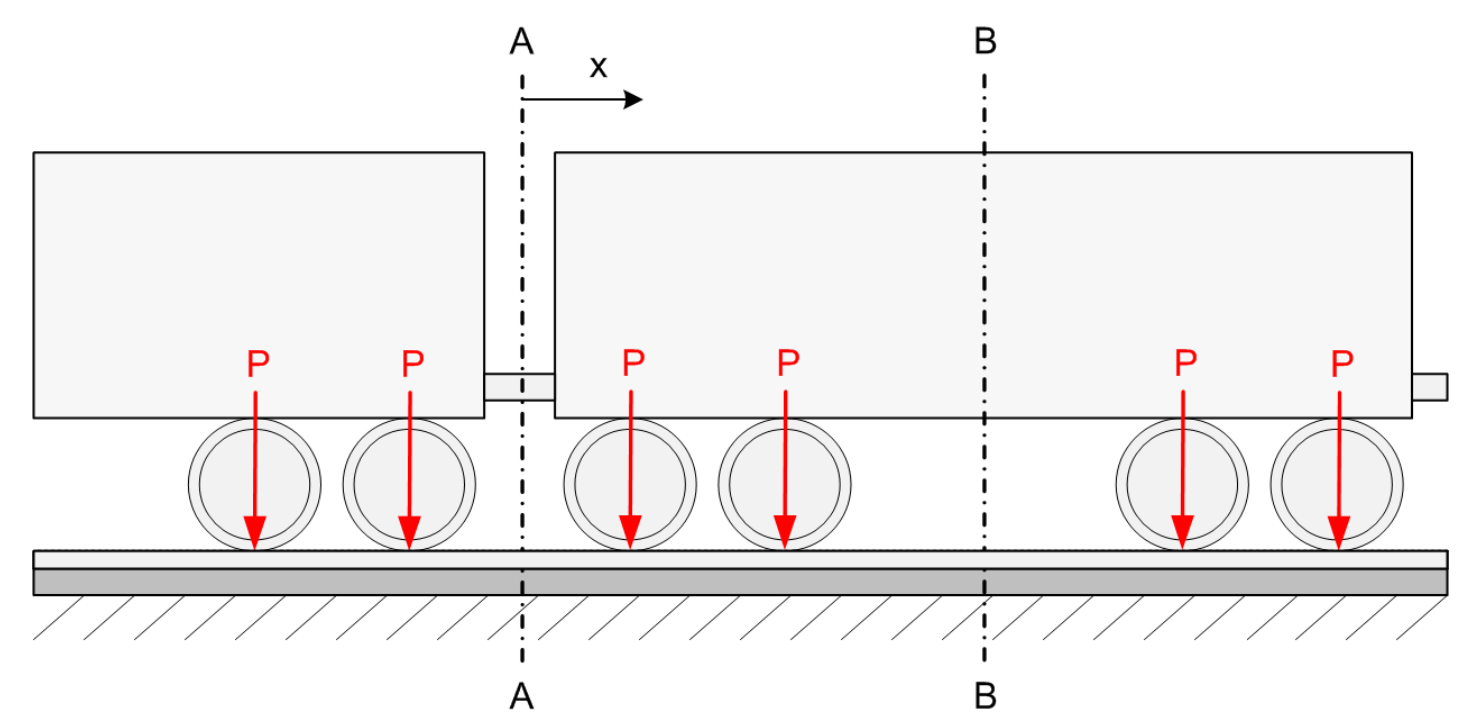

Figure 5.7: Model Example for FEA

\subsection{PROKON Frame Analysis Model}

The PROKON frame analysis software was used previously by consulting engineers and the University of Stellenbosch to analyse the TT railway system. PROKON frame analysis can be used for the analysis of $2 \mathrm{D}$ beams on discrete spring support, and provides the capabilities of creating and modifying quick and simple finite element beam models. Continuous support cannot be explicitly modeled, because the forces, connections and support properties are applied to nodes and cannot be applied along the length of the beams. Simplification of the model is therefore applied by creating nodes at a set interval on the beams, depending on the accuracy required. The rails, $\mathrm{RC}$ beams, and grout are modeled as separate beams connected by rigid links between nodes and supported by springs connected to the grout beam layer. The FC55 elastomeric pads cannot be modeled using PROKON, as the Young's modulus is 25.2 MPa and is therefore below the minimum allowed value of $100 \mathrm{MPa}$.

A spring stiffness can be used to provide elastic links between solid substructures, but can only be input as a stiffness value on a node, and not explicitly as a spring element between nodes where there are physical gaps. The spring stiffness provided by the elastomeric pads between the rail and elastomeric pad cannot be modeled, due to the usage of the rigid links between the beams. The rigid links could however be replaced by beam elements with appropriate axial stiffness to 
model the elastomeric pad, but this is not performed in this investigation in order to investigate the difference between the rigid link and an actual spring element or geometric elastomeric pad as modeled in the $3 \mathrm{D}$ models. The interaction between the beams are difficult to accurately model in $2 \mathrm{D}$ beam analyses, due to the fact that friction and slippage cannot be taken into account by the rigid links as in 3D FEM analyses. The beam model which is analysed with PROKON can also be modeled using an ABAQUS 2D beam element model. This model can include the springs between the rail and RC beam. Similar results were obtained when analysing the similar $2 \mathrm{D}$ models in PROKON and ABAQUS excluding the stiffness of the elastomeric pad. For the purpose of this investigation, the model used for representing the analysis which excludes the elastomeric pad is chosen as PROKON, as it is an easier model to create and use when analysing beams. The PROKON frame analysis model used for this investigation is illustrated in Figures 5.8 and 5.9 .

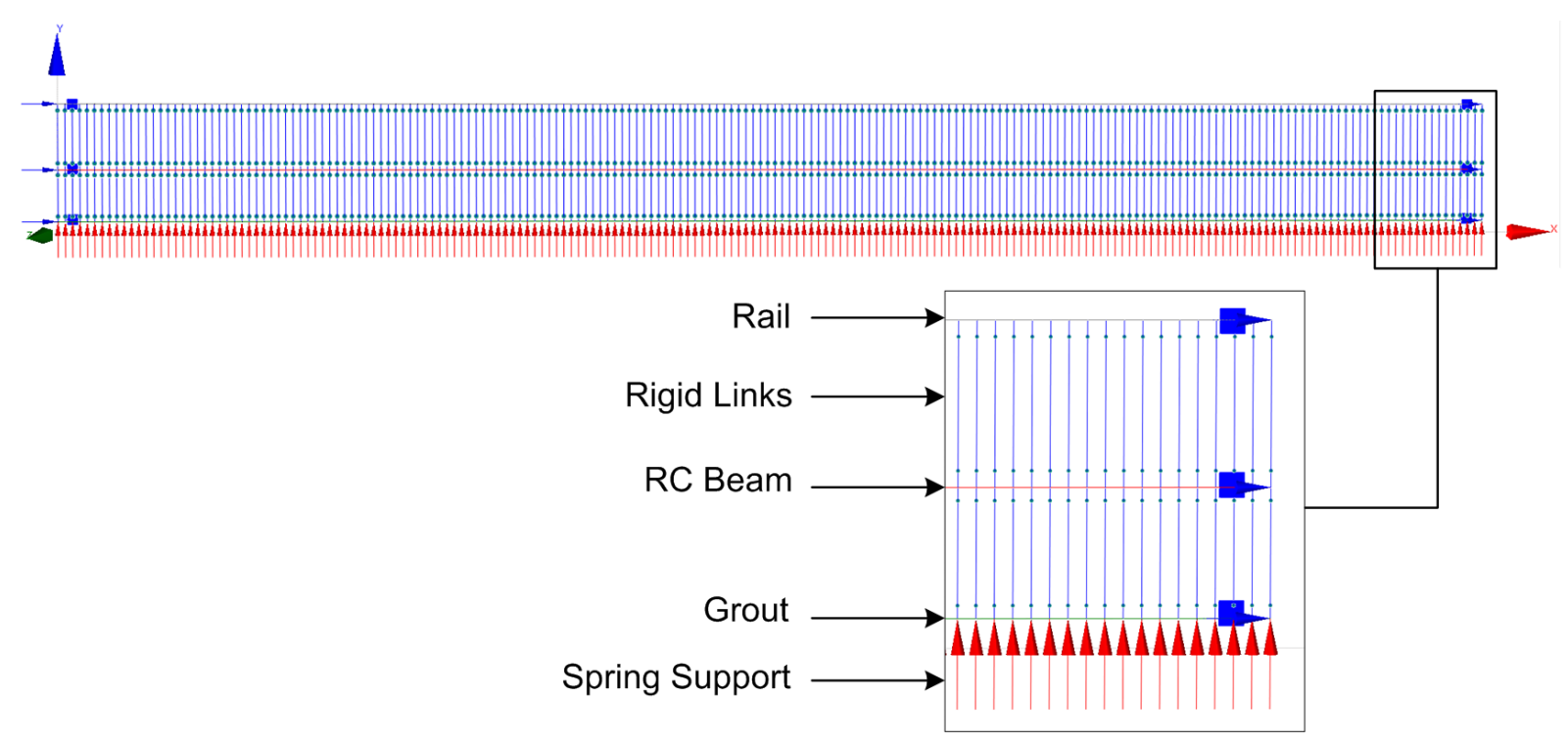

Figure 5.8: PROKON Beam Model

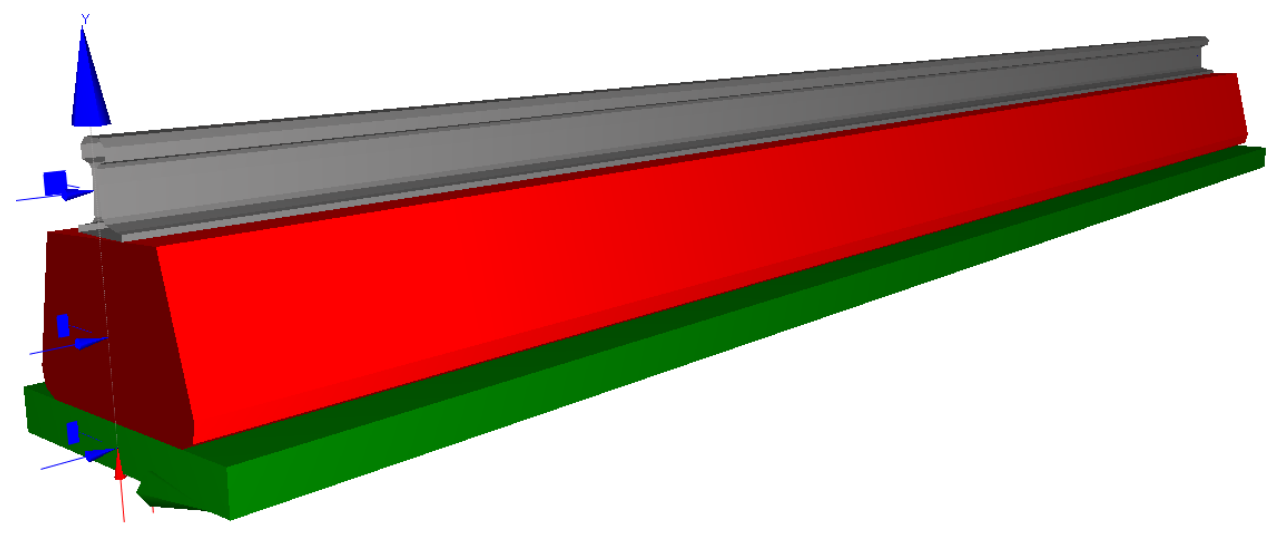

Figure 5.9: PROKON Beam Model with 3D Rendering 


\subsubsection{PROKON Frame Analysis Results}

The results obtained from the PROKON 2D beam FEA are as follows:

\section{Displacement}

The displacements of the rail, $\mathrm{RC}$ beam, and grout in the PROKON 2D beam model are exactly the same due to the restrictions of using the pinned rigid links, as illustrated in Figure 5.10 . The beams are therefore not able to displace relative to each other. The maximum displacement obtained occurs at the first point load and has a magnitude of $-0.95 \mathrm{~mm}$.

\section{PROKON 2D Beam Displacement}

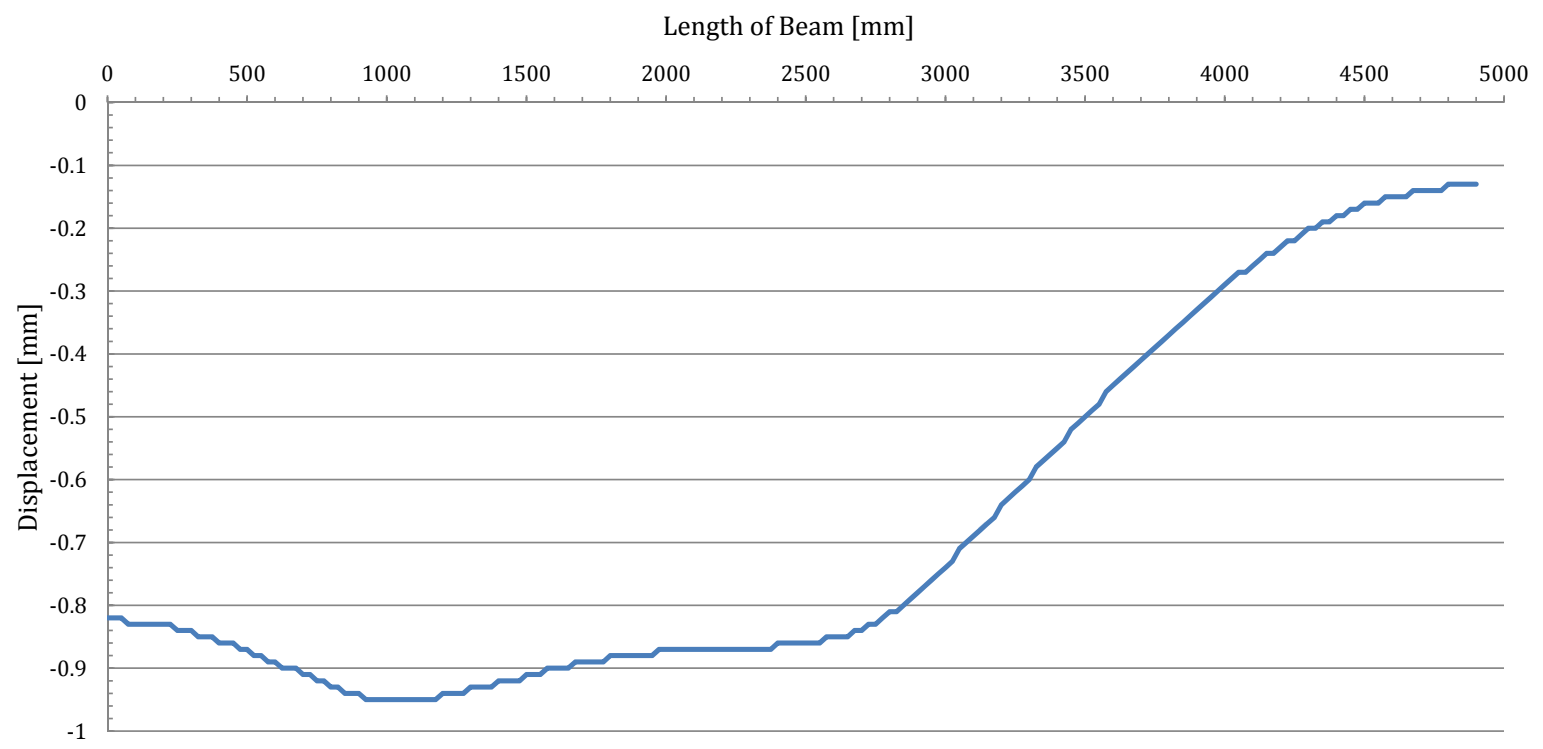

Figure 5.10: PROKON 2D Beam Model Displacements

\section{Bending Moment Diagram}

As can be seen in Figure 5.11 the maximum bending moments in the beams are located at the second point load, whereas the minimum bending moments are located at the ends. The rail's maximum and minimum bending moments are $2.94 \mathrm{kNm}$ and $-1.4 \mathrm{kNm}$ respectively, whereas the $\mathrm{RC}$ beam's maximum and minimum bending moments are $20.63 \mathrm{kNm}$ and $-9.46 \mathrm{kNm}$ respectively. The inflection points of the two beams occur at the same positions, because the rigid links transfer the applied loads vertically through to the support. As stated in Chapter 3 the bending stress in a beam can be calculated using Equation 3.1 .13 where the bending stress is calculated as $\sigma=\frac{-M y}{I}$. The positive and negative bending stresses in the RC Beam at the point of maximum bending moment is calculated as $\sigma^{+}=4.33 \mathrm{MPa}$ and $\sigma^{-}=-3.69 \mathrm{MPa}$ respectively. 


\section{PROKON 2D Beam Bending Moment Diagram}

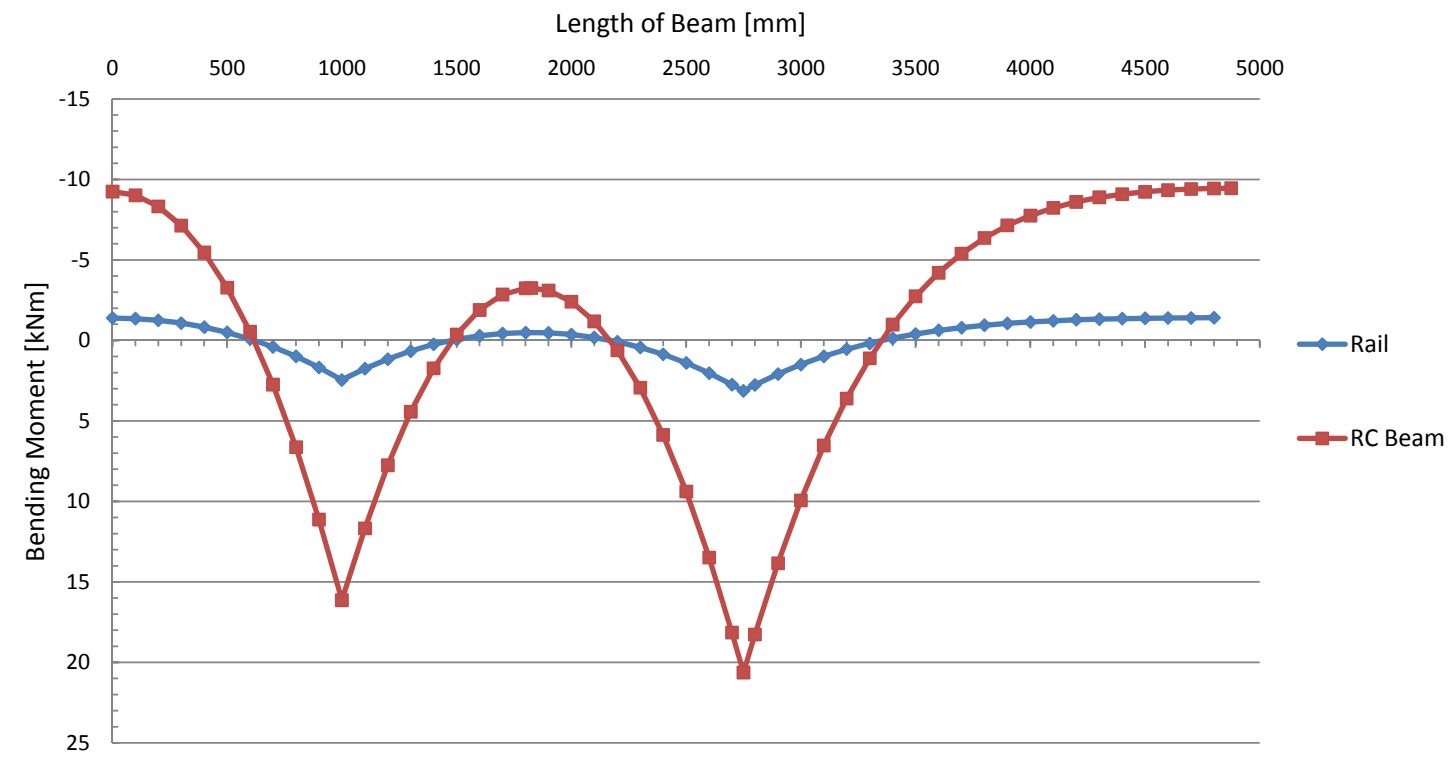

Figure 5.11: PROKON 2D Beam Model Bending Moment Diagram

\section{Shear Force Diagram}

The shear force diagram illustrated in Figure 5.12 shows that the $\mathrm{RC}$ beam also carries most of the shear forces, as the maximum rail shear force is $8.5 \mathrm{kN}$ compared to the $\mathrm{RC}$ beam which has a maximum shear force of $49.9 \mathrm{kN}$.

\section{PROKON 2D Beam Shear Force Diagram}

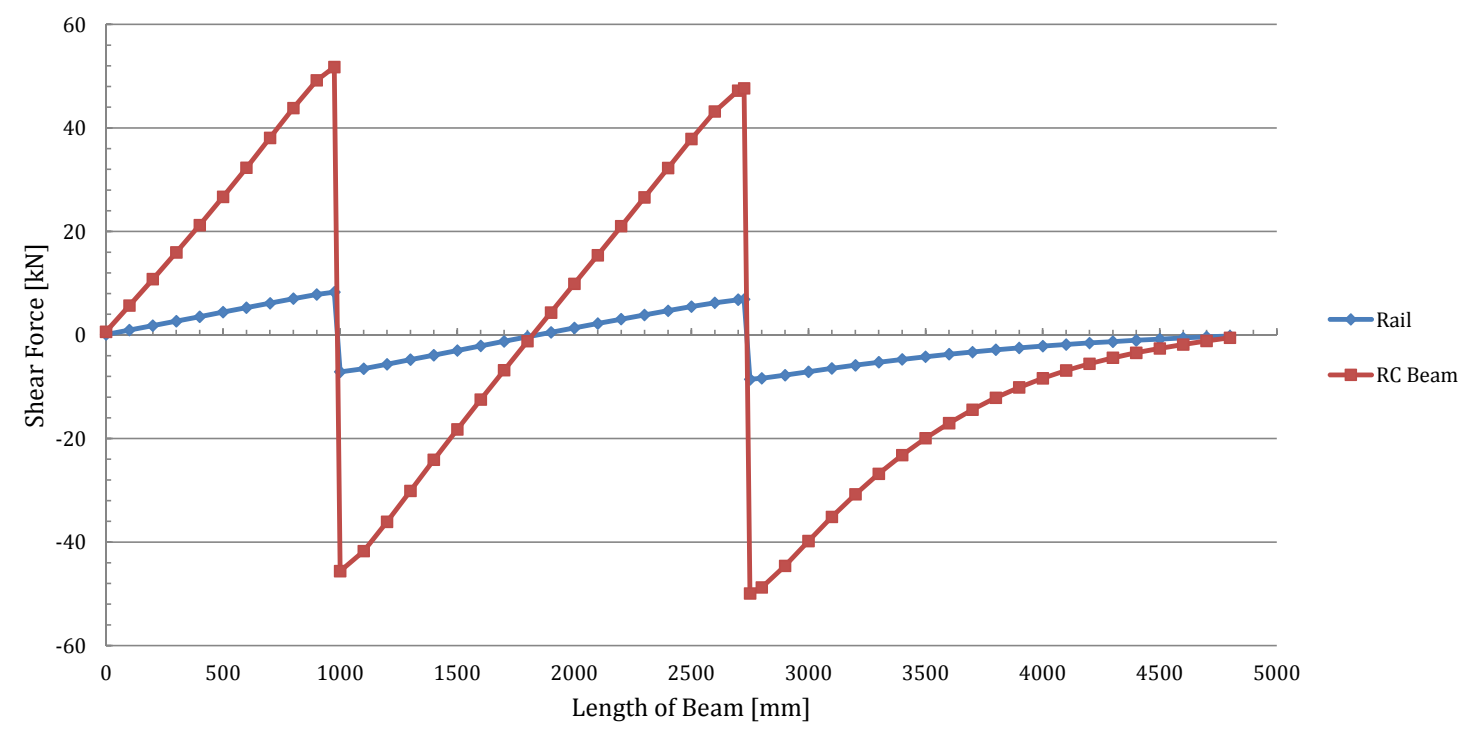

Figure 5.12: PROKON 2D Beam Model Shear Force Diagram 


\section{Soil Pressure Distribution}

The soil pressure as illustrated in Figure 5.13 is dependant on the deflection of the grout under the beam, which was proven to be the same as the other beams, and can be used for the investigation of soil response to loading. The maximum soil pressure under the beam is calculated as $120 \mathrm{kPa}$ at the location of the first point load.

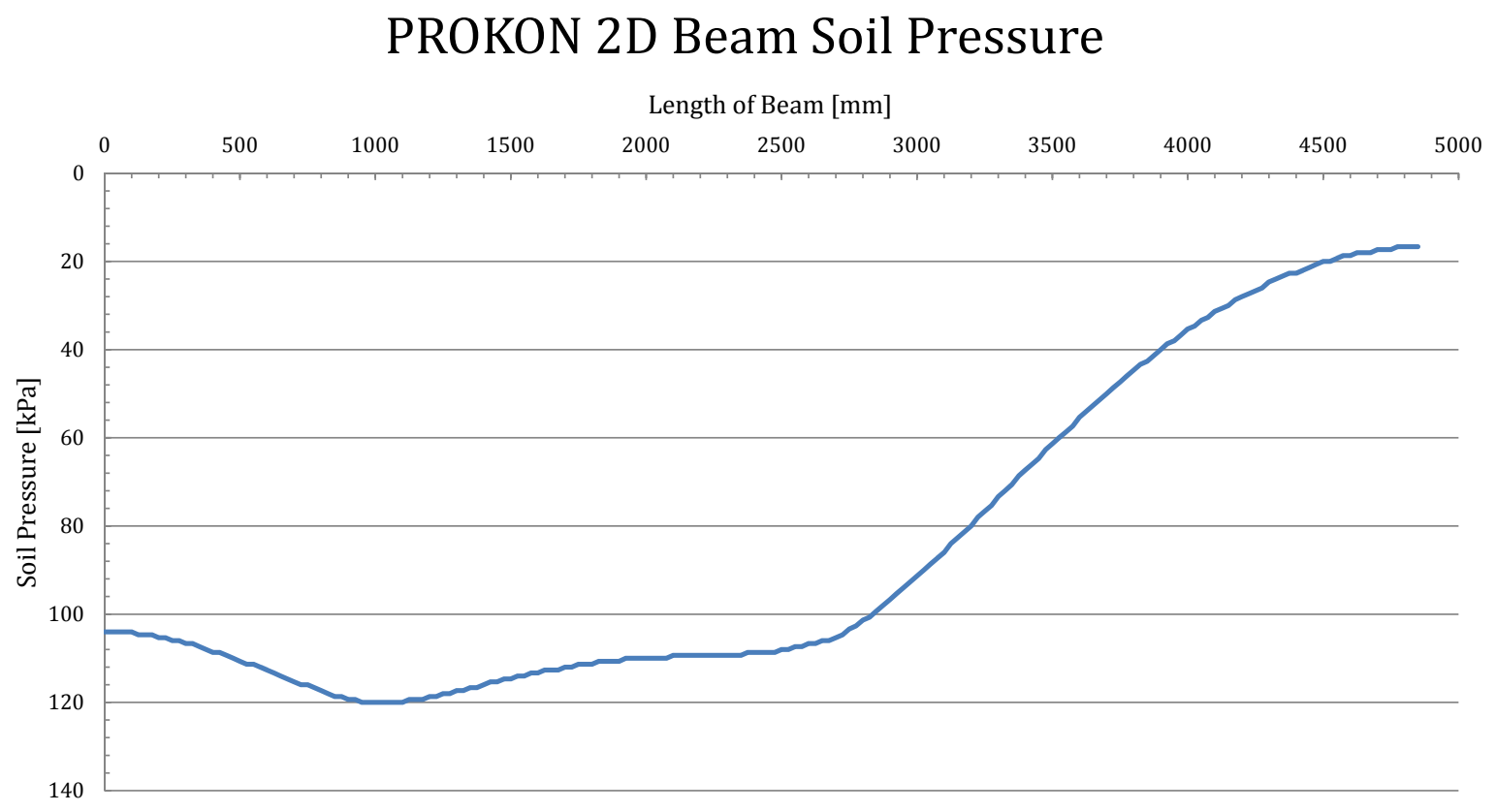

Figure 5.13: PROKON 2D Beam Model Soil Pressure under Beam

\subsection{Single Beam on Elastic Foundation}

PROKON has the capability of performing a linear analysis of a single beam on elastic foundation supported by closely spaced springs. This analysis method is based on the Winkler elastic foundation model as described in Chapter 3. The nodes are placed at close intervals along the length of the beam, and have a minimum of 50 nodes per beam. The single beam used for the analyses in PROKON Beam on Elastic Support can be defined as one or more segments, each able to have their own material and geometric properties. For the purpose of this dissertation, the Transformed-Section Method as described in Section 3.1.4 is used in order to transform the TT system into a single homogeneous beam with a constant support width, $\mathrm{B}_{\mathrm{sec}}$, provided by the grout layer; moment of inertia of the section, $\mathrm{I}_{\mathrm{sec}}$; and Young's Modulus, E, applicable to the whole beam [25].

The PROKON Beam on Elastic Support analysis method was compared to the MATLAB program based on Winkler elastic foundation theory created to analyse the accuracy of the PROKON 
Beam on Elastic Foundation method against Elastic Foundation theory in this section. The results concluded that the two analysis methods are similar, as was expected.

\subsubsection{Single Beam on Elastic Foundation Analysis Results}

The Transformed-Section method was used to transform the TT railway system into a single homogeneous beam. The equivalent spring modulus as calculated with Equation 3.1 .22 is used as it also takes the influence of the elastomeric pad into account, although the effect is not the same as modeling the elastomeric pad explicitly. The equivalent spring stiffness is a parallel combination of the two stiffness coefficients of the soil and elastomeric pad, and takes the total compressibility of the supporting soil into account. The section properties of the transformed beam are as follows:

$$
\begin{aligned}
& \mathrm{E}_{\mathrm{t}}=30960 \mathrm{MPa} \\
& \mathrm{I}_{\mathrm{t}}=4.1 \times 10^{9} \mathrm{~mm}^{4}
\end{aligned}
$$

\section{Displacement}

The displacement of combined homogeneous single beam, as can be seen in Figure 5.14 indicates a maximum displacement of $-1.02 \mathrm{~mm}$.

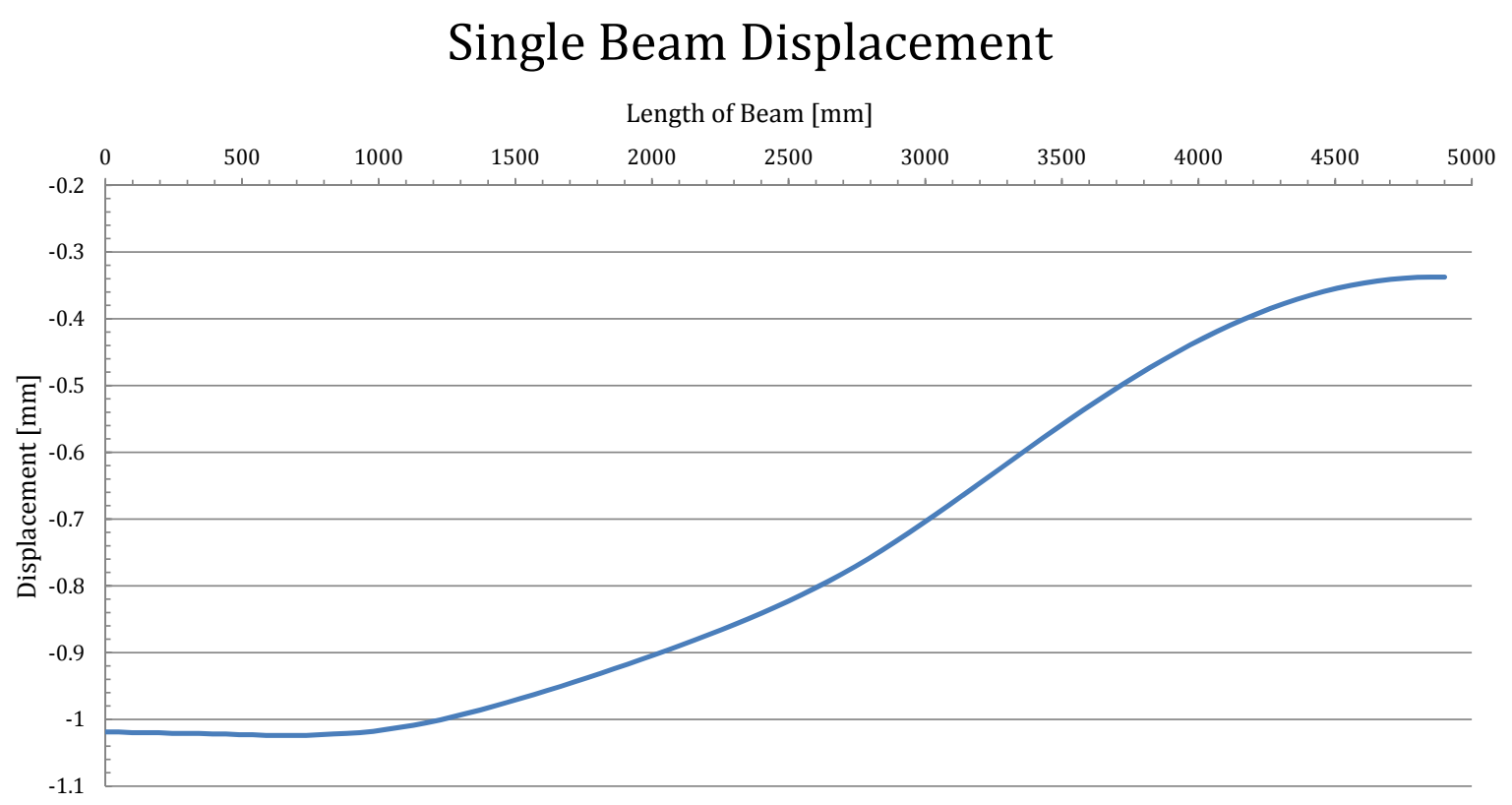

Figure 5.14: Single Beam Model Displacements

\section{Bending Moment Diagram}

As can be seen in Figure 5.15 the maximum bending moment in the transformed homogeneous beam occurs at the second point load with a value of $30.3 \mathrm{kNm}$, whereas the minimum bending 
moment occurring at $\mathrm{x}=4900 \mathrm{~mm}$ is $-33.8 \mathrm{kNm}$. The bending stresses at the maximum bending moment are $\sigma^{+}=6.27 \mathrm{MPa}$ and $\sigma^{-}=-5.35 \mathrm{MPa}$, whereas at the minimum bending moment the bending stresses are $\sigma^{+}=5.97 \mathrm{MPa}$ and $\sigma^{-}=-6.99 \mathrm{MPa}$ respectively.

\section{Single Beam Bending Moment Diagram}

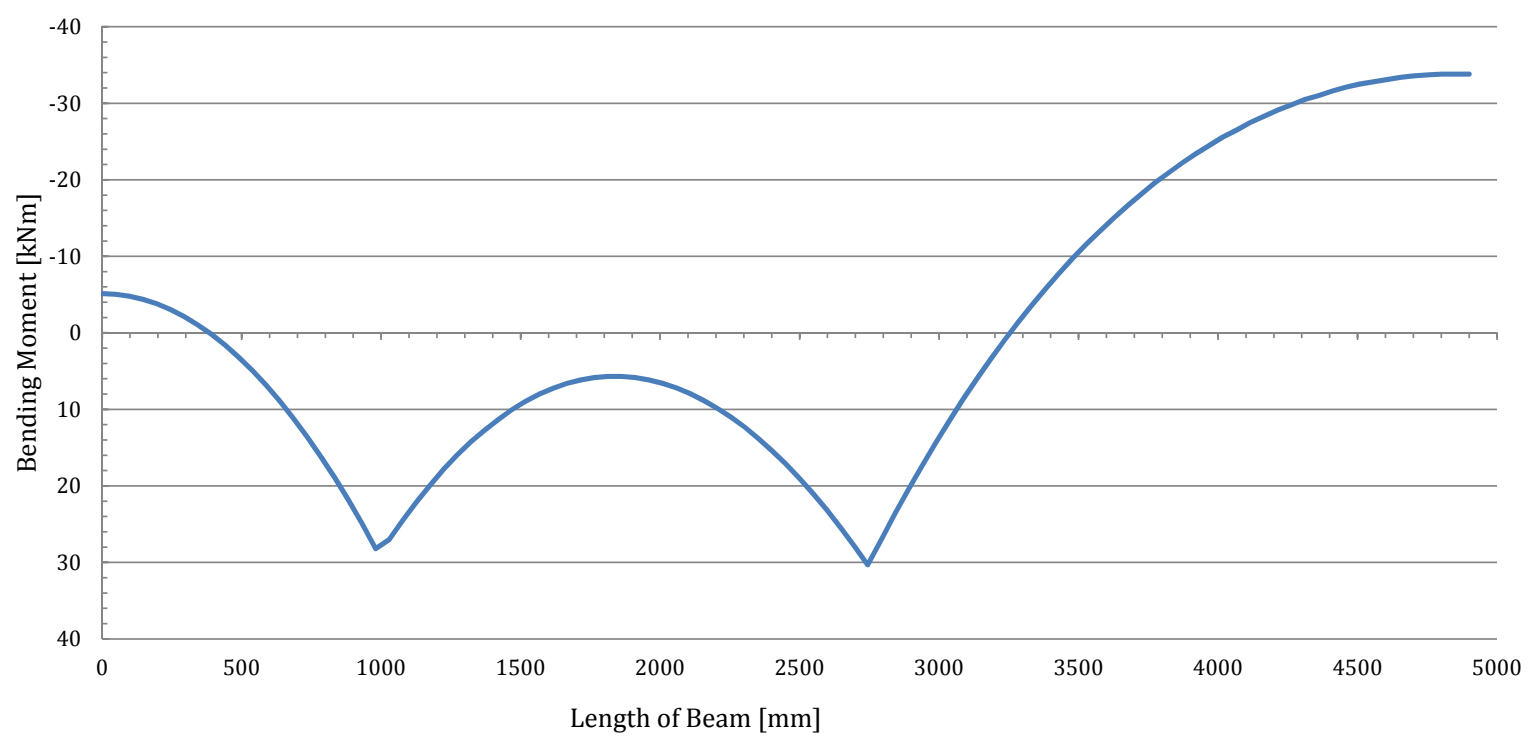

Figure 5.15: Single Beam Model Bending Moment Diagram

\section{Shear Force Diagram}

The shear force diagram illustrated in Figure 5.16 shows a maximum shear force of $69.7 \mathrm{kN}$ at the second point load in the transformed homogeneous beam. 


\section{Single Beam Shear Force Diagram}

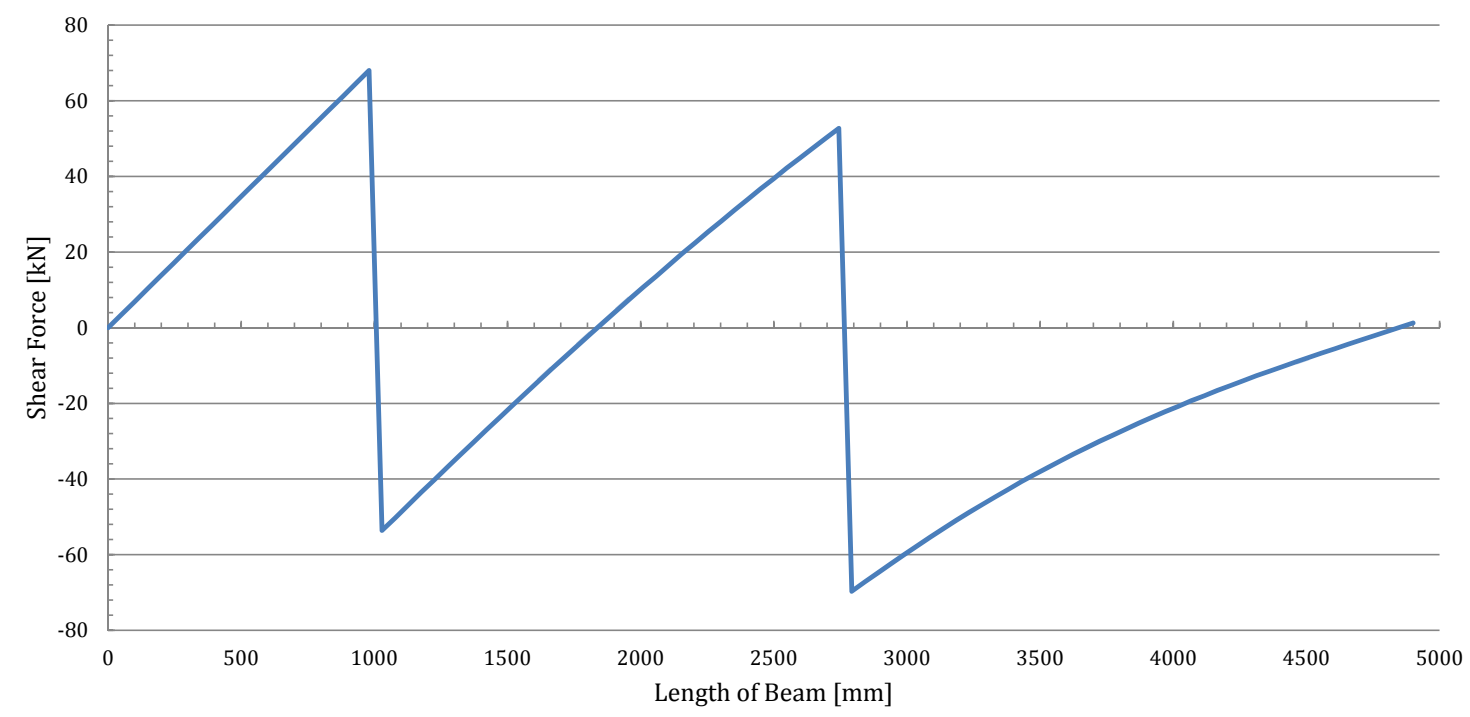

Figure 5.16: Single Beam Model Shear Force Diagram

\section{Soil Pressure Distribution}

The soil pressure as illustrated in Figure 5.17 uses the deflection of the transformed beam to calculate the soil pressure under the beam. The maximum soil pressure for this analysis method is found to be approximately $130 \mathrm{kPa}$.

\section{Single Beam Soil Pressure}

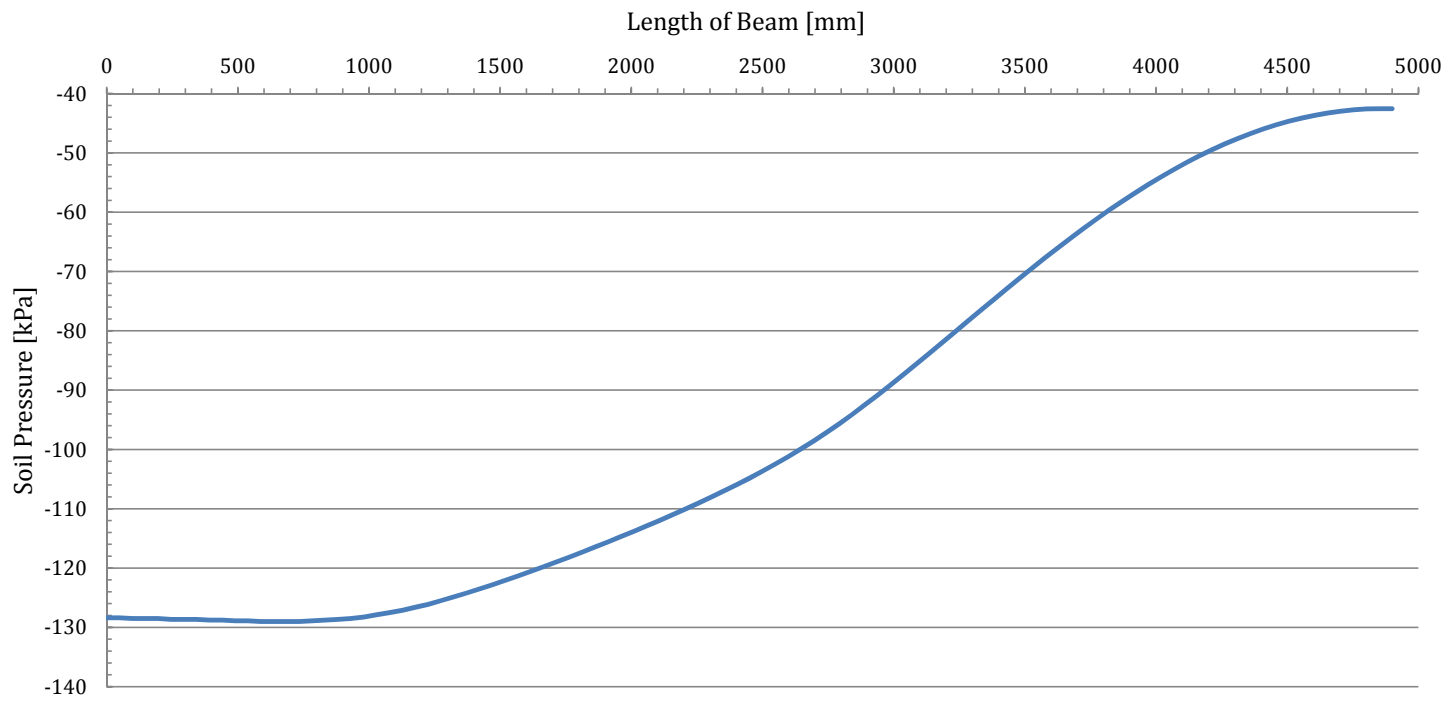

Figure 5.17: Single Beam Model Soil Pressure under Beam 


\subsection{ABAQUS 2D Beam Finite Element Model}

As stated previously, PROKON is unable to model a material with a Young's modulus below $100 \mathrm{MPa}$, thereby not allowing explicit modeling of the elastomeric pads. PROKON can therefore not investigate the influence of the elastomeric pads on the TT railway system, unless beam elements with appropriate axial stiffness are used. As stated previously, the connection between the beams are modeled using rigid links, for the comparison with other models. A model similar to the PROKON Frame Analysis finite element model was modeled using ABAQUS 2D beam elements. ABAQUS allows the usage of the spring connections between separated nodes, simulating the elastomeric pad's stiffness between the rail and RC beam, as illustrated in Figure 5.18a. The modeling of the elastomeric pad is achieved by using spring elements between the nodes of the rail and $\mathrm{RC}$ beam, where the stiffness of the spring elements is obtained by multiplying the stiffness of the elastomeric pad with the width of the rail and the spacing between nodes. For the purpose of this investigation, the dynamic stiffness instead of the static stiffness of the elastomeric pad is used seeing that railway tracks are generally subjected to dynamic loads.

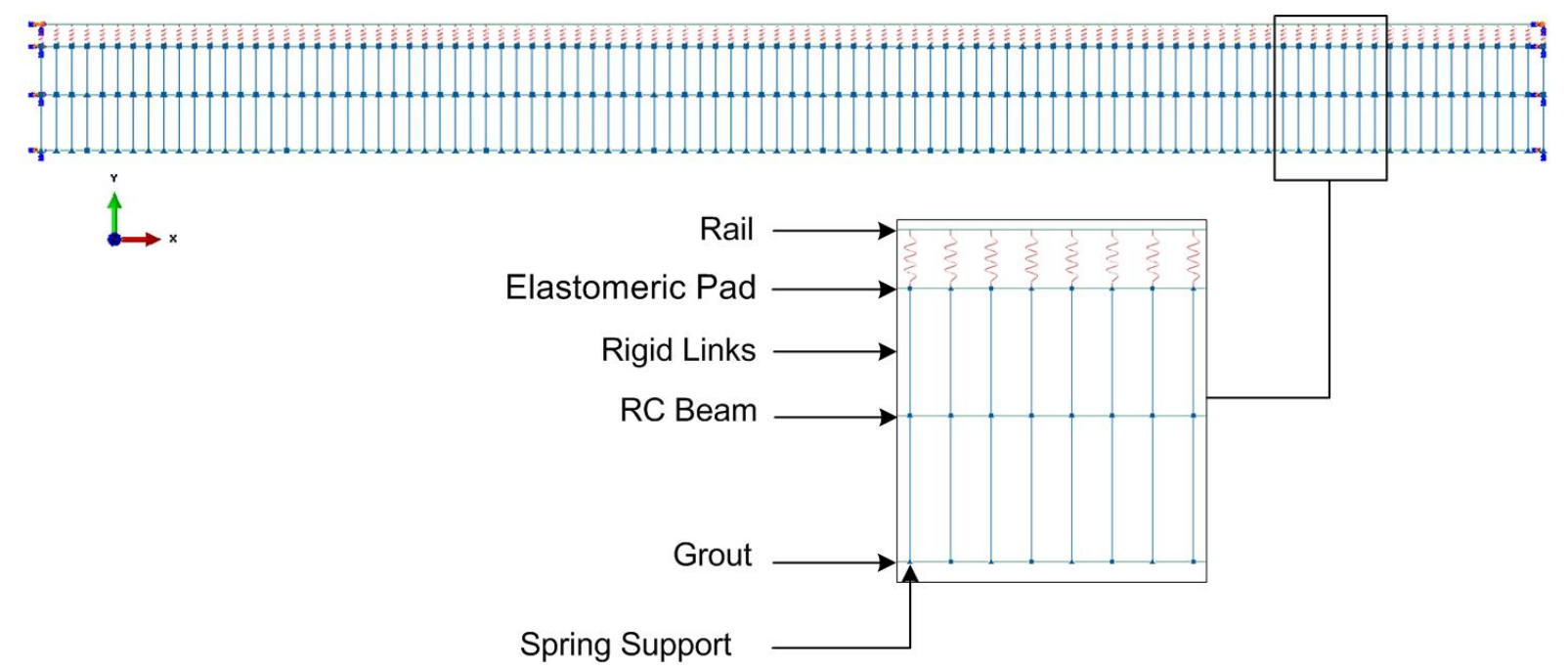

(a) ABAQUS Beam Model

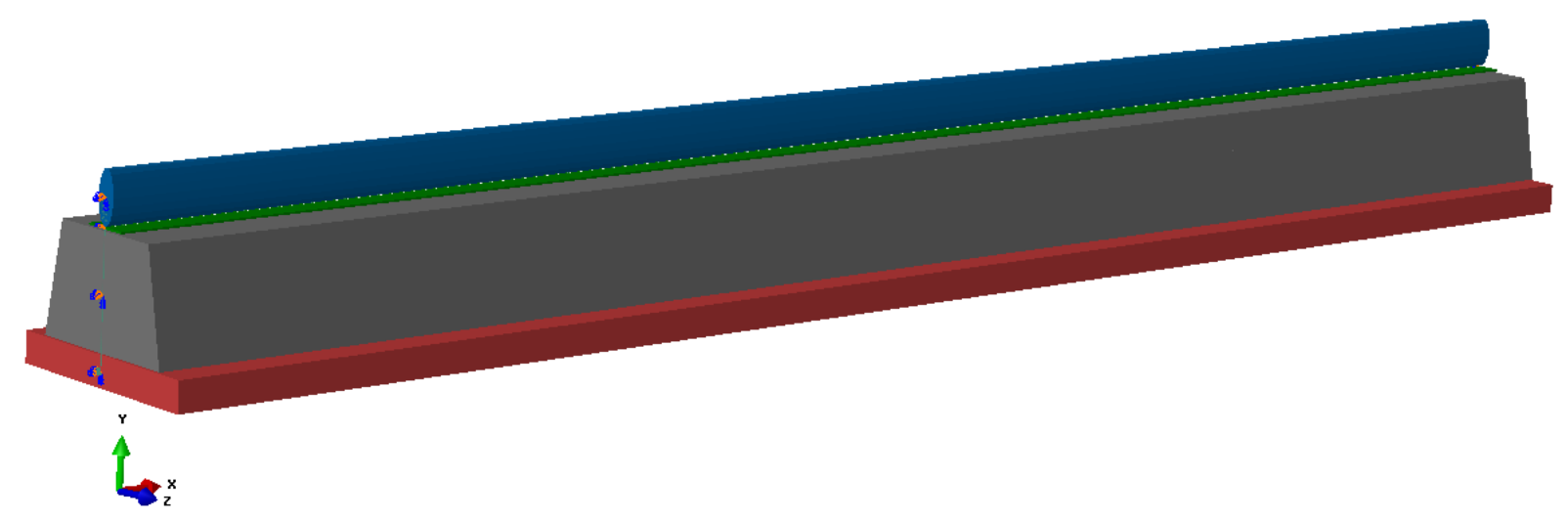

(b) ABAQUS Beam Model with 3D Rendering

Figure 5.18: ABAQUS 2D Beam Model 


\subsubsection{ABAQUS 2D Beam Analysis Results}

\section{Displacement}

The displacements of the upper and lower beams as indicated in Figure 6.12 show maximum displacements of $-1.18 \mathrm{~mm}$ and $-0.95 \mathrm{~mm}$ in the rail and $\mathrm{RC}$ beam respectively. There is a definite difference in displacement shape between the two beams, as the rail displays much larger localised deflections at the point loads than the RC beam which displays less curvature, as expected. This demonstrates the influence of the elastomeric pad modeled as spring elements at the nodes between the RC beam and rail, which allows for localised deflections of the rail.

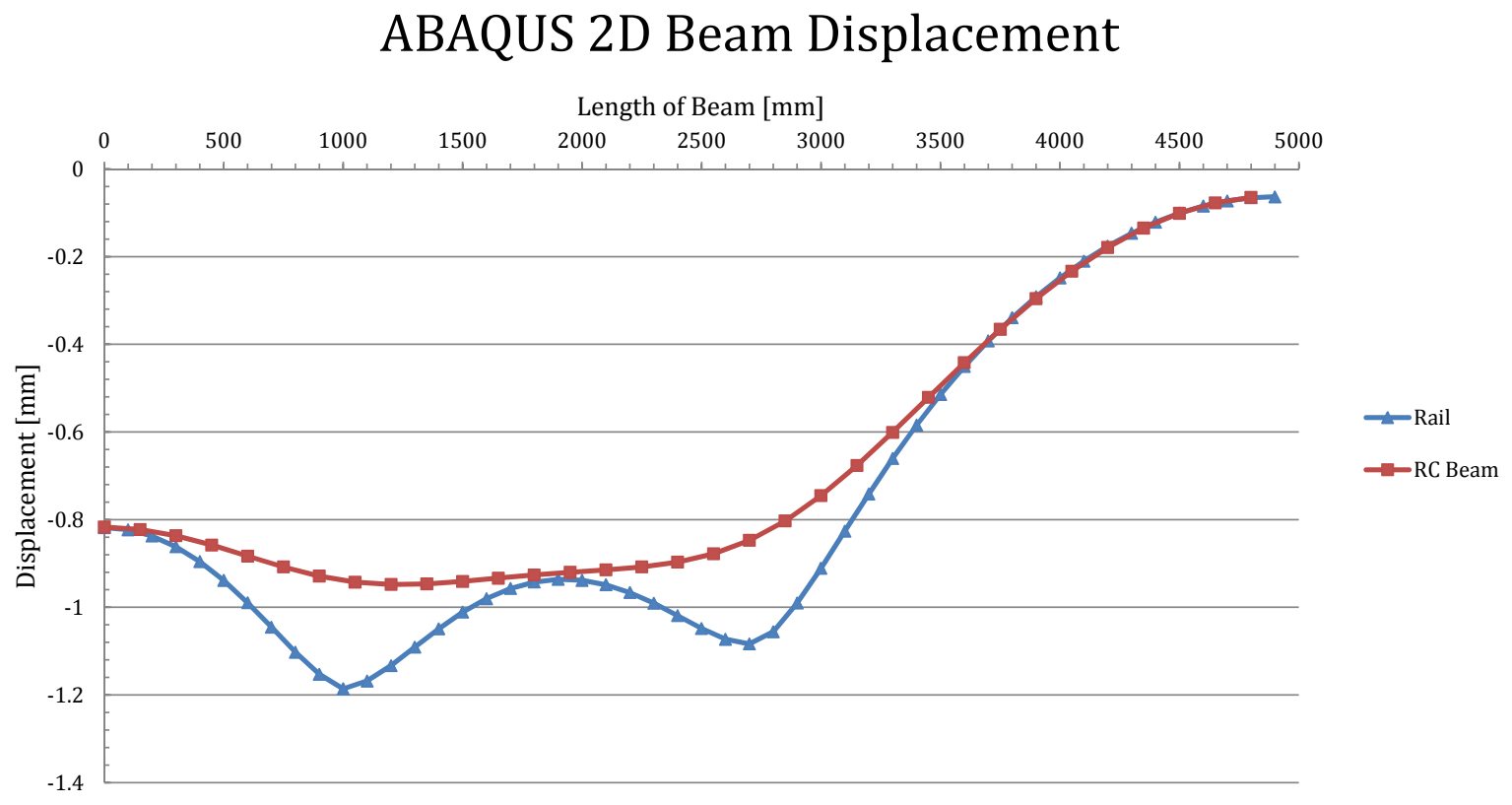

Figure 5.19: ABAQUS 2D Beam Model Displacements

\section{Bending Moment Diagram}

The influence of the elastomeric pad is also demonstrated in Figure 5.20 which shows the damping and pressure distributing effect of the elastomeric pad on the RC beam's bending moment diagram. The maximum bending moments in the rail and $\mathrm{RC}$ beam are $13.2 \mathrm{kNm}$ for both, whereas the minimum bending moments for the rail and $\mathrm{RC}$ beam are $-3.53 \mathrm{kNm}$ and $-11.6 \mathrm{kNm}$ respectively. The RC beam's bending stresses at the maximum bending moment are $\sigma^{+}=2.73$ $\mathrm{MPa}$ and $\sigma^{-}=-2.33 \mathrm{MPa}$, whereas at the minimum bending moment the bending stresses are $\sigma^{+}=2.05 \mathrm{MPa}$ and $\sigma^{-}=-2.4 \mathrm{MPa}$ respectively. 


\section{ABAQUS 2D Beam Bending Moment Diagram}

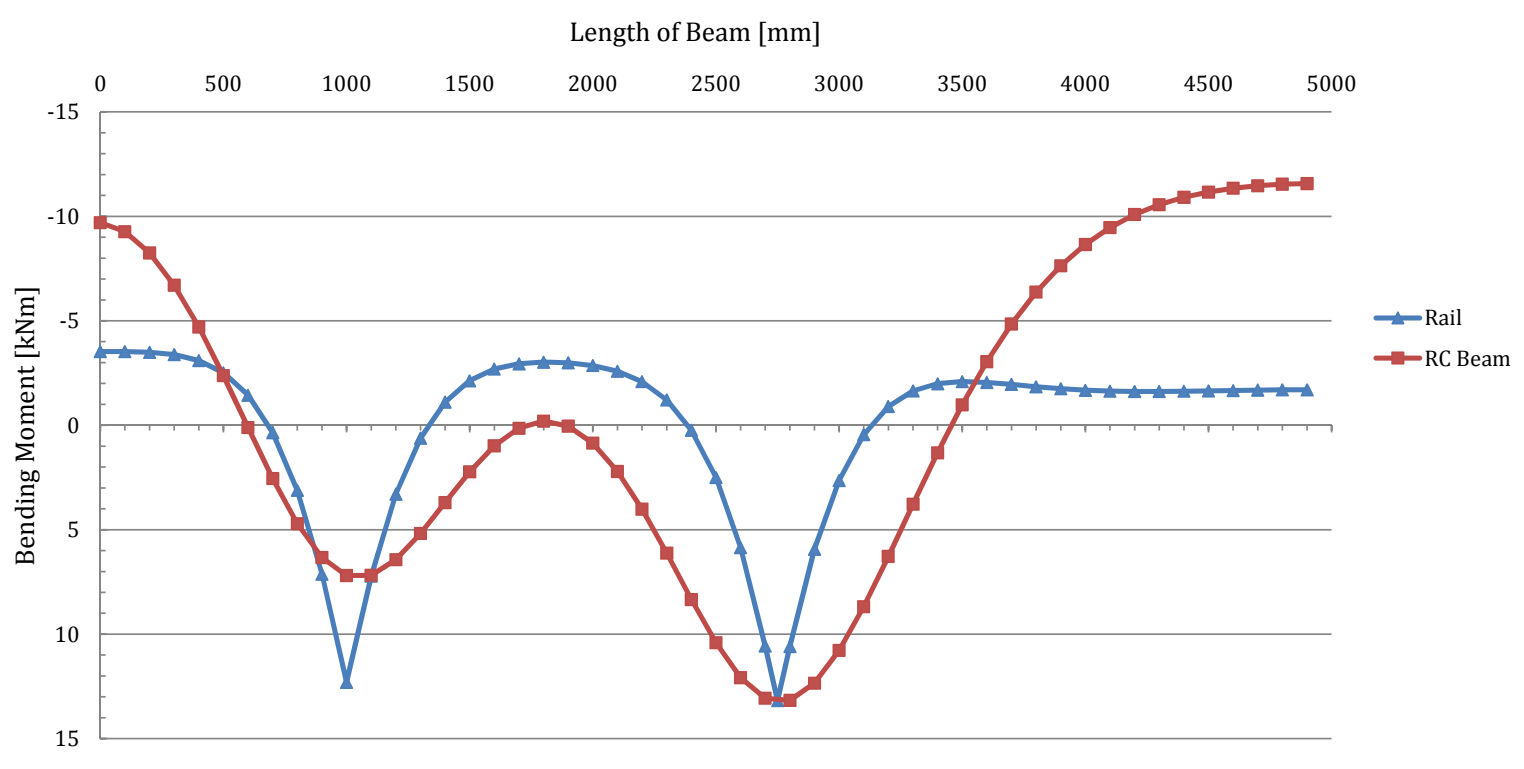

Figure 5.20: ABAQUS 2D Beam Model Bending Moment Diagram

\section{Shear Force Diagram}

The shear force diagram as illustrated in Figure 5.21 is also greatly influenced by the addition of the elastomeric pad. The shear forces in the RC beam follow an almost sinusoidal curve, whereas the rail's shear forces are similar to the shear force curves as obtained in the previous analysis methods. The sinusoidal-like curve of the $\mathrm{RC}$ beam is due to the pressure distribution properties of the elastomeric pad, which avoids the large shear force peaks as found in the rail. This is an extremely important result, as the construction cost of the TT railway system is very much dependant on the cost of the steel, especially the steel reinforcement in the RC beams. By illustrating that the shear forces in the $\mathrm{RC}$ beam do not have the shear force peaks as obtained in the previously more simplified analysis methods, but are rather distributed along the length of the beam, the design of the steel reinforcement can be considerably reduced due to a reduced maximum shear force. The maximum shear force in the rail is $58.9 \mathrm{kN}$ and $24.94 \mathrm{kN}$ in the RC beam, indicating that the steel rail actually carries most of the shear forces in the system, which is as expected. 


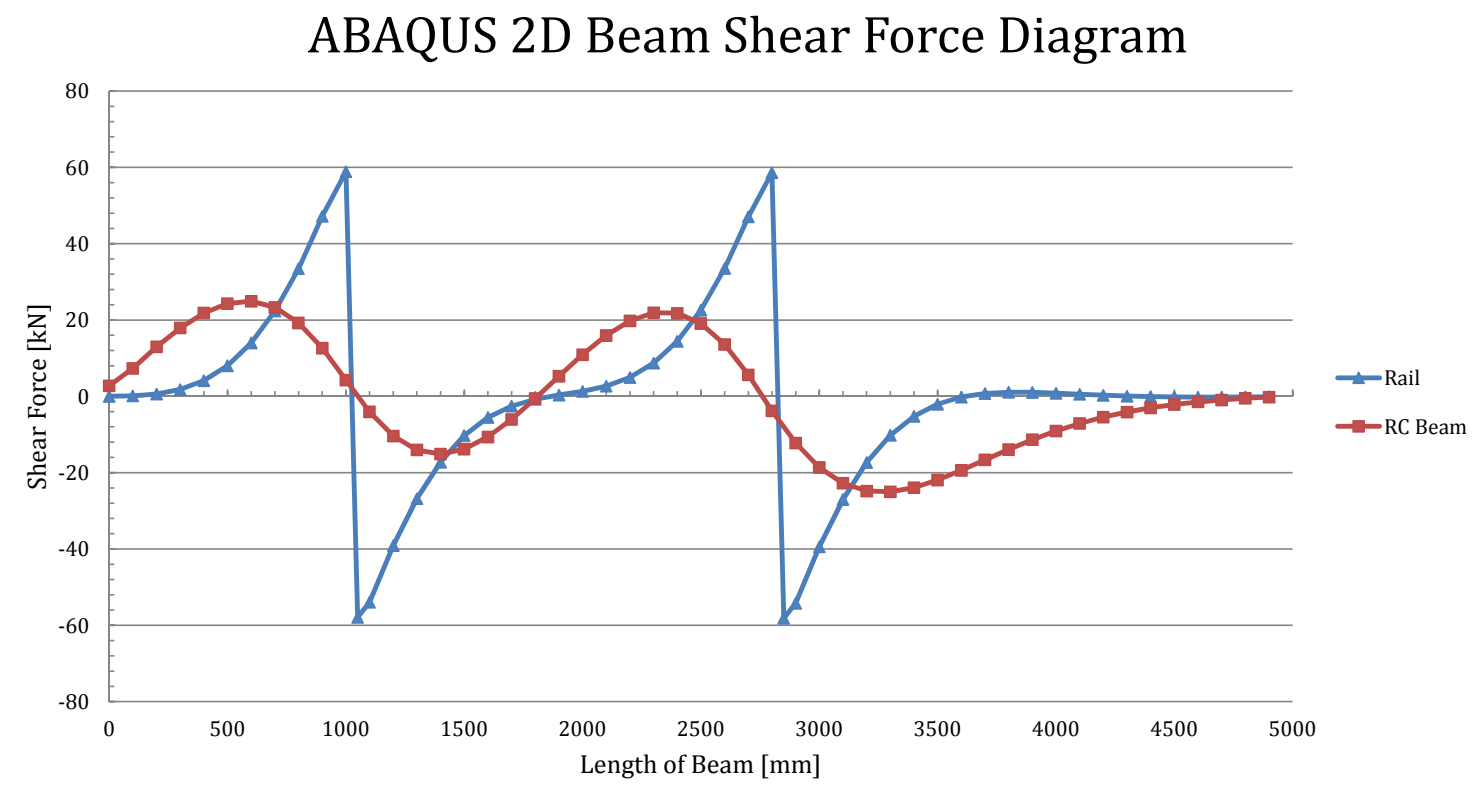

Figure 5.21: ABAQUS 2D Beam Model Shear Force Diagram

\section{Soil Pressure Distribution}

The soil pressure under the TT beam is illustrated in Figure 5.22 and is very similar as in the previous analysis methods used, except that it demonstrates smaller rotations between the point loads. The maximum soil pressure is calculated as $120 \mathrm{kPa}$.

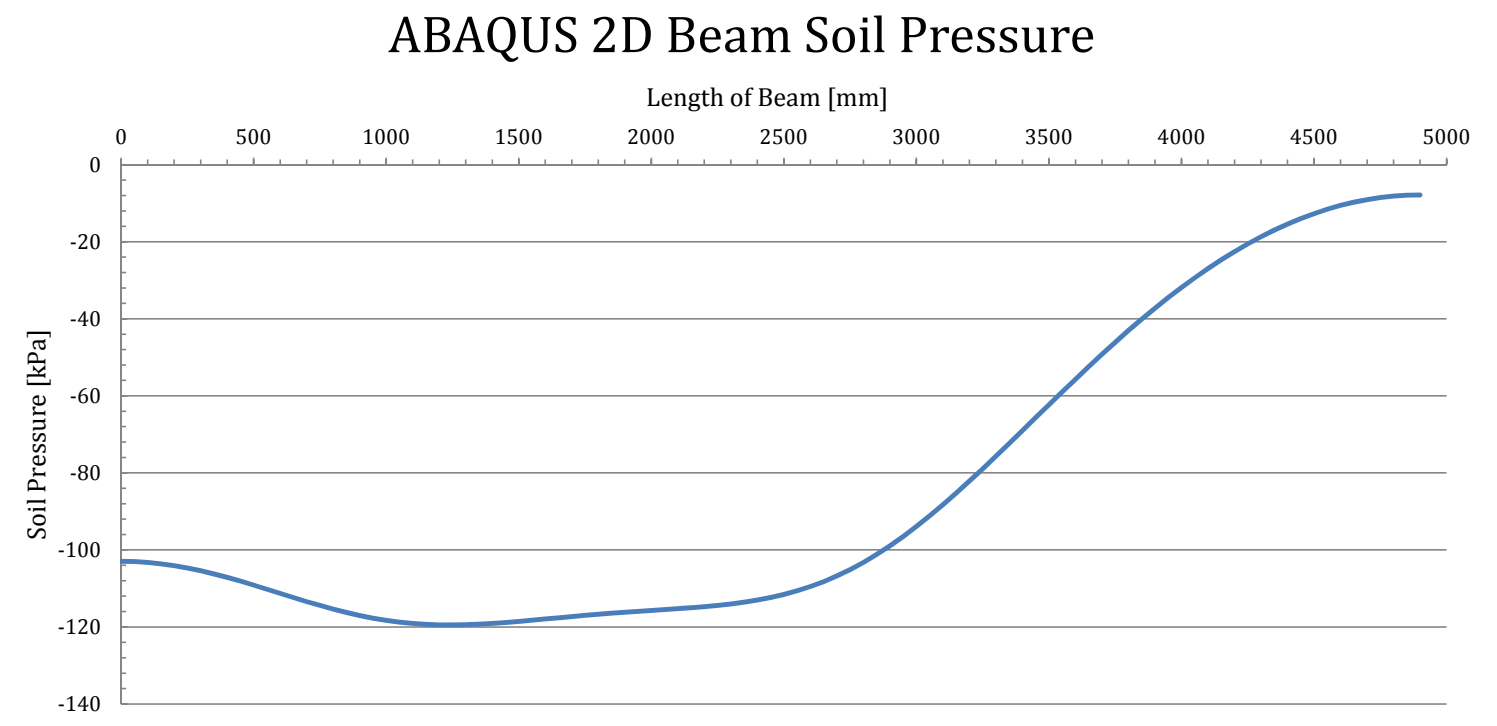

Figure 5.22: ABAQUS 2D Beam Model Soil Pressure under Beam 


\subsection{Double Beam Model}

This theoretical analysis model is as explained in Section 3.1.5previously, and is a means of investigating the TT railway system where the deformation is partly localised and partly continuous. The upper beam as analysed in the Double Beam model represents the localised deflections, whereas the lower beam represents the continuous deflection curve.

The Double Beam model used for this investigation is subjected to the eight bogey loads of the railway vehicles, as explained in Section 5.3.1 and assumes the beam to be of infinite length, thereby not applying boundary conditions on the beam. This a more accurate modeling technique, and is not restricted to a certain length of beam, as the Double Beam is based on a theoretical infinitely long beam. A graphical user interface (GUI) has been created to analyse the Double Beam model by simulating these eight loads acting on the upper beam, which plots the deflection, rotation, bending moment, and shear force diagram of the upper and lower beams, representing the rail and $\mathrm{RC}$ beam respectively. The distributed pressure acting on the foundation of the upper beam, and the resultant pressure on the lower beam is also calculated. The section of the double beam model illustrated in the GUI is between the cut section A-A and B-B which represents the symmetrical model as illustrated in Figure 5.23. An illustration of the GUI is indicated in Section 3.6, whereas the software program of the GUI is attached in Appendix C.

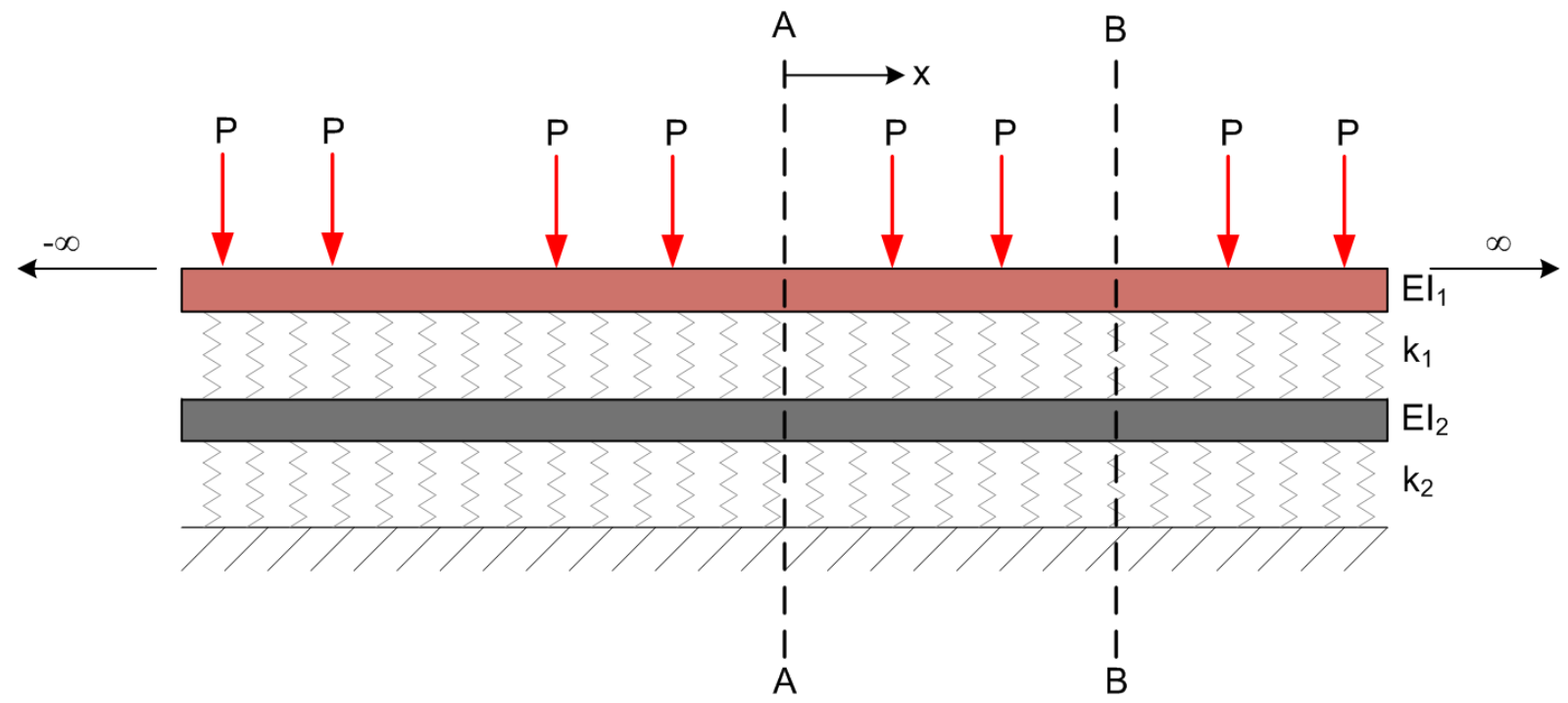

Figure 5.23: Double Beam Model

The upper beam represents the steel rail, whilst the lower beam's displacements are calculated by combining the RC beam with the supporting grout layer using the Transformed-Section method. This is acceptable, as the concrete beams do not undergo sectional deformation or displace relative to one another. The displacement in the grout and $\mathrm{RC}$ beams are therefore the same. The bending moments of the lower beam are calculated by using the displacement equation obtained from the combined lower beam, and multiplying the differentiated displacement equation with the RC beam's material properties in order to obtain the bending moments in the RC beam 
alone, and not the combined beam which was used for calculating the displacements. The shear forces in the lower beam are similarly obtained by differentiating the bending moment equation as obtained for the $\mathrm{RC}$ beam alone.

\subsubsection{Double Beam Model Results}

The results obtained from the Double Beam method are very similar to the results obtained using the ABAQUS 2D beam model, and will therefore only be discussed briefly.

\section{Displacement}

The maximum displacement as illustrated in Figure 5.24 shows that the maximum displacement in the upper beam is $-1.24 \mathrm{~mm}$, whereas the lower beam's maximum displacement is $-0.96 \mathrm{~mm}$.

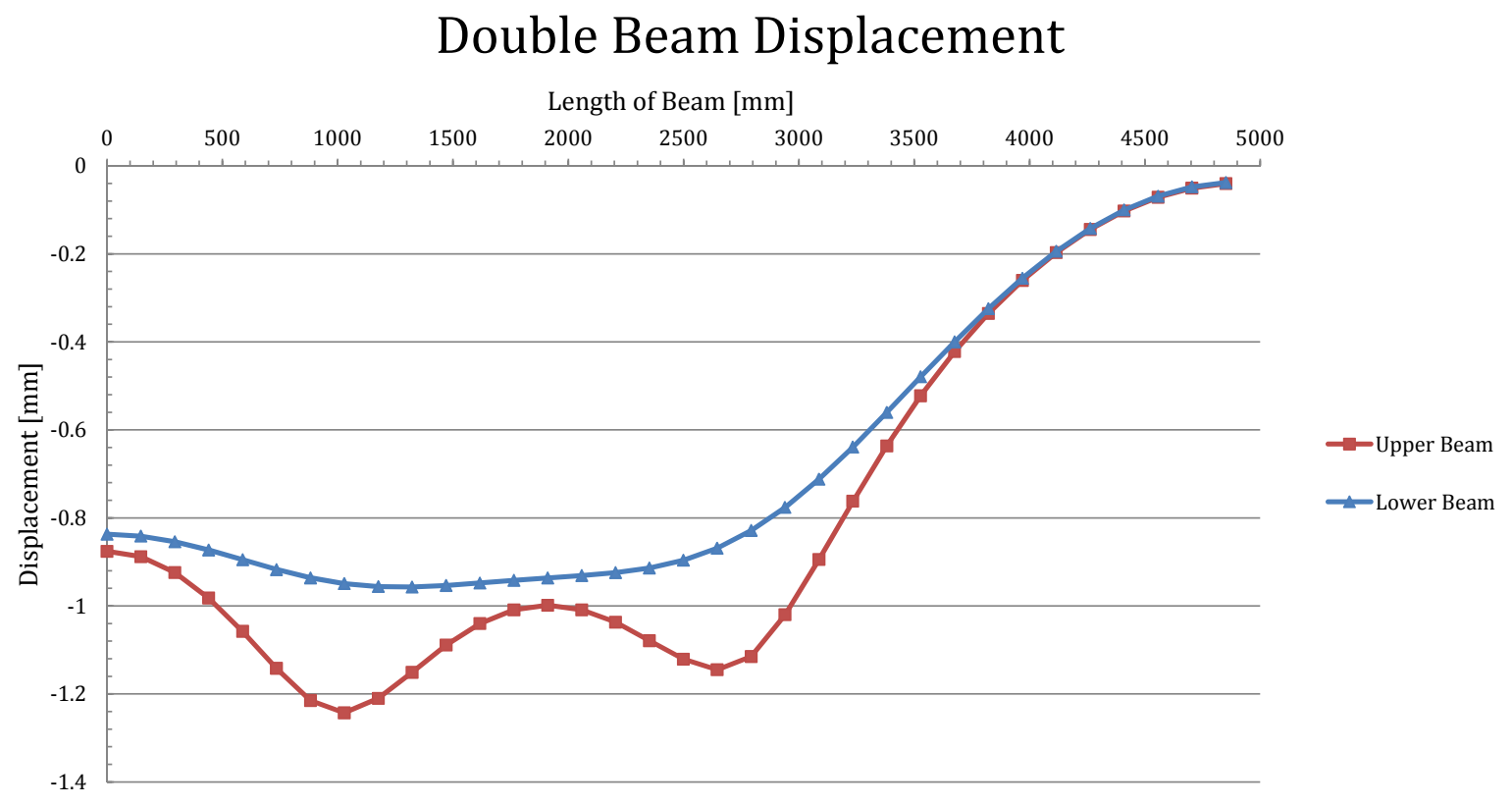

Figure 5.24: Double Beam Model Displacements

\section{Bending Moment Diagram}

The maximum bending moments in the upper and lower beams are $14.3 \mathrm{kNm}$ for both, whereas the minimum bending moments for the upper and lower beams are $-4.08 \mathrm{kNm}$ and $-12.2 \mathrm{kNm}$ respectively, as illustrated in Figure 5.25. The lower beam's bending stresses at the maximum bending moment are $\sigma^{+}=2.96 \mathrm{MPa}$ and $\sigma^{-}=-2.52 \mathrm{MPa}$, whereas at the minimum bending moment the bending stresses are $\sigma^{+}=2.16 \mathrm{MPa}$ and $\sigma^{-}=-2.52 \mathrm{MPa}$ respectively. 


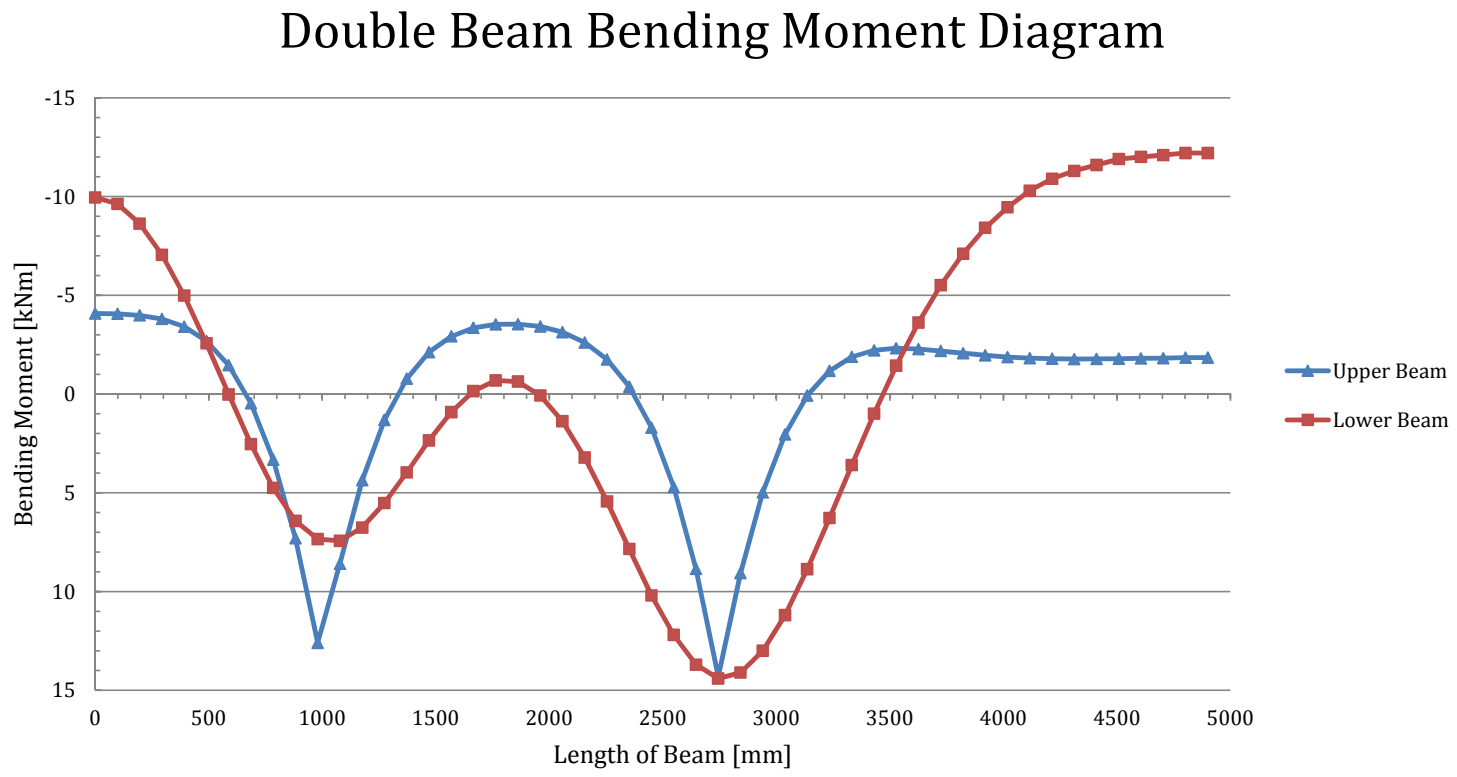

Figure 5.25: Double Beam Model Bending Moment Diagram

\section{Shear Force Diagram}

The maximum shear force in the upper beam is $62.7 \mathrm{kN}$, and $27.2 \mathrm{kN}$ in the lower beam, again illustrating the major influence of the elastomeric pad on the obtained shear forces in the lower beam. The shear force diagrams of the rail and $\mathrm{RC}$ beam are illustrated in Figure 5.26 .

Double Beam Shear Force Diagram

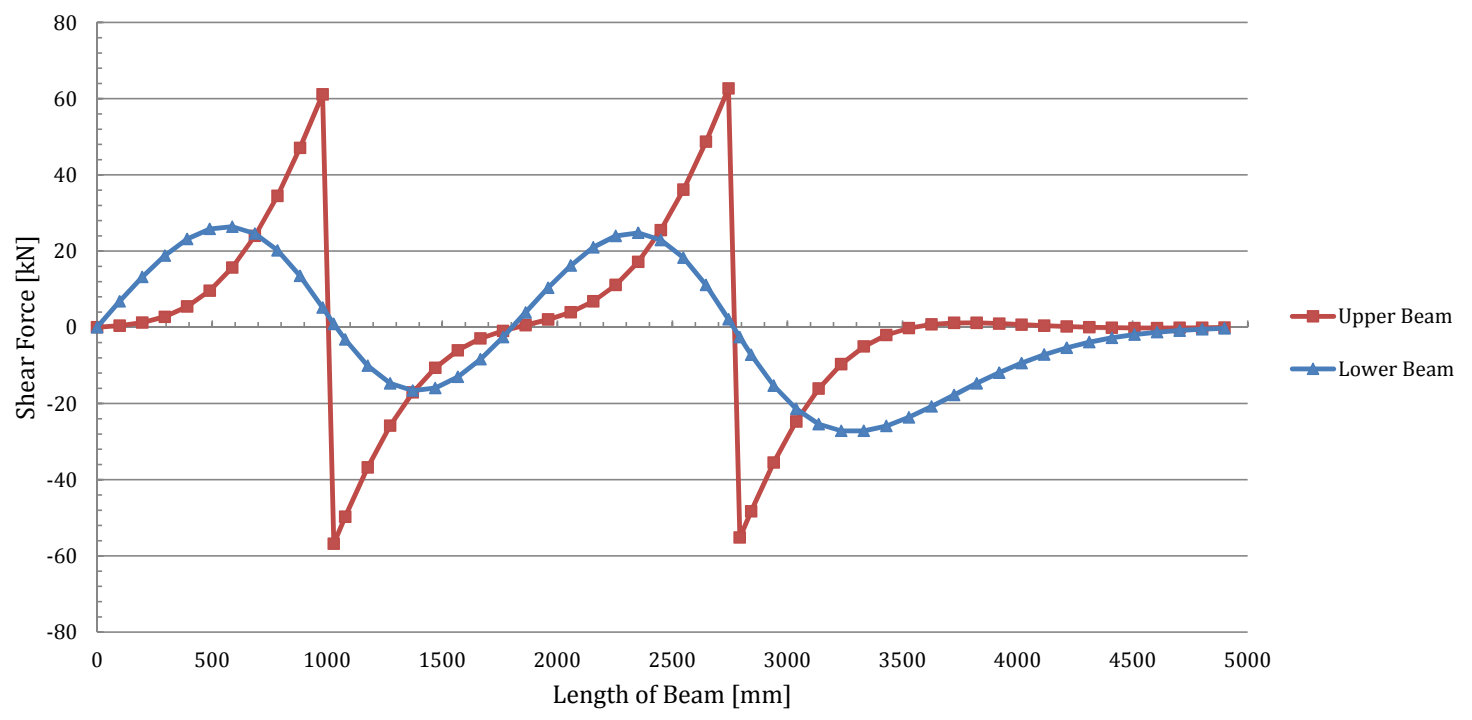

Figure 5.26: Double Beam Model Shear Force Diagram 


\section{Soil Pressure Distribution}

The soil pressure under the lower beam is illustrated in Figure 5.27, and shows a maximum soil pressure of $120 \mathrm{kPa}$.

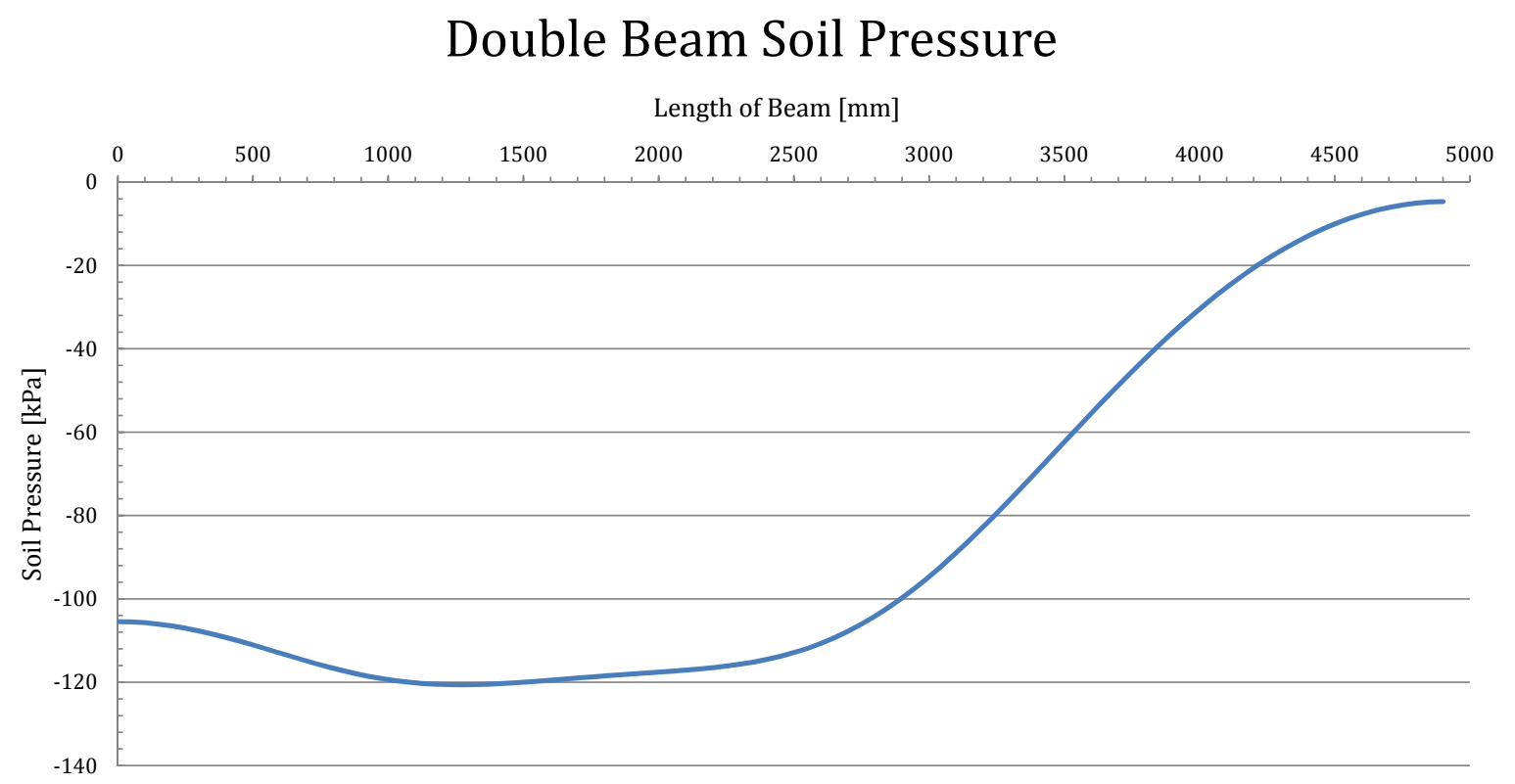

Figure 5.27: Double Beam Model Soil Pressure under beam

\subsection{Conclusions}

This chapter investigates the usage of 2D FEA methods which can be used to investigate the TT railway system in order to obtain the displacements, soil pressure distributions, bending moment and shear force diagrams. The theoretical models as discussed in Chapter 3 are also investigated in this chapter. The various analysis methods used in this chapter show definite differences in results obtained, depending on the simplicity and approximation of the modeling technique. The elastomeric pad, which can also be modeled as spring elements between the rail and $\mathrm{RC}$ beam, allows for pressure distribution and damping of the forces on the system. The inclusion of the elastomeric pad and the stiffness it provides is found to have a significant effect on the displacement of the upper beam/rail as well as the bending moments (BM) and shear forces in the lower beam/RC beam. The choice of analysis method therefore greatly influences the results obtained which are in turn used for design of a railway section, indicating the need for investigating and choosing the correct analysis method. The results obtained from the various analyses are summarised in Tables 5.1 and 5.2. 
Table 5.1: Rail Results Summary

\begin{tabular}{lcccc}
\hline & $\begin{array}{c}\text { Maximum Deflection } \\
{[\mathrm{mm}]}\end{array}$ & $\begin{array}{c}\text { Maximum BM } \\
{[\mathrm{kNm}]}\end{array}$ & $\begin{array}{c}\text { Minimum BM } \\
{[\mathrm{kNm}]}\end{array}$ & $\begin{array}{c}\text { Maximum Shear Force } \\
{[\mathrm{kN}]}\end{array}$ \\
\hline Single Beam & 1.02 & - & - & - \\
Double Beam & 1.24 & 14.3 & -4.08 & 62.7 \\
PROKON & 0.95 & 2.94 & -1.4 & 8.5 \\
ABAQUS 2D & 1.18 & 13.2 & -3.53 & 58.9 \\
\hline
\end{tabular}

Table 5.2: RC Beam Results Summary

\begin{tabular}{lcccc}
\hline & $\begin{array}{c}\text { Maximum deflection } \\
{[\mathrm{mm}]}\end{array}$ & $\begin{array}{c}\text { Maximum BM } \\
{[\mathrm{kNm}]}\end{array}$ & $\begin{array}{c}\text { Minimum BM } \\
{[\mathrm{kNm}]}\end{array}$ & $\begin{array}{c}\text { Maximum Shear Force } \\
{[\mathrm{kN}]}\end{array}$ \\
\hline Single Beam & 1.02 & - & - & - \\
Double Beam & 0.96 & 14.3 & -12.2 & 27.2 \\
PROKON & 0.95 & 20.63 & -9.46 & 49.9 \\
ABAQUS 2D & 0.95 & 13.2 & -11.6 & 24.94 \\
\hline
\end{tabular}

A loading combination and symmetry condition analysis is performed in this chapter to verify the simplification of the TT model from the numerous axle loads into a load combination which only take the two end axles of a single vehicle into account in combination with applied rotation-restricting boundary conditions. The analysis performed verifies the proposed loading combination and is incorporated in the FEA models of this investigation.

The analysis methods in this chapter represent varying types of approximations of the actual TT railway system, but can nonetheless provide accurate finite element simulations with accurate response to loading combinations. Chapter 6 investigates the TT system using ABAQUS' 3D finite solid elements, which represents a more detailed analysis method which can accurately simulate the interactions between the components. The comparison of the various $2 \mathrm{D}$ beam, 3D solid element, theoretical models and field test results is subsequently performed in Chapter 8 and investigates the accuracy of the analysis methods, using the DAF which is obtained in Chapter 7, to ultimately provide a recommendation on which analysis method(s) to use for analysis and design of the TT railway system. 


\section{Chapter 6}

\section{Three-Dimensional Finite Element Analysis}

\subsection{Introduction}

This chapter investigates the three-dimensional (3D) solid finite element analysis (FEA) method which is used to model the Tubular Track (TT) railway system and its supporting subgrade formations using the finite element method (FEM) as described in Chapter 5 . The vertical support provided by the subgrade formations of the reference sections are required for the comparison with in-situ results and the acquisition of the modulus of subgrade reaction. The modulus of subgrade reaction for a square and rectangular, infinitely long footing of the TT system is analysed in order to obtain a relationship between a square and rectangular, infinitely long plate bearing test (PBT), and is analysed using a 3D ABAQUS solid element model. The modulus of subgrade reaction as obtained for the reference section is used for all the analysis models of this investigation.

\subsection{FEM Solid Elements}

The element types and interactions between the TT system components are discussed in this section, and are used for modeling the TT railway system and subgrade analysis models to be analysed later in this chapter.

\subsubsection{Element Type and Mesh Density}

The elements used for the 3D finite element model will be modeled by means of solid elements using the ABAQUS Standard software. The motivation behind the use of the solid elements is their accuracy in obtaining stresses and deflections in models in three dimensions, although they require a sufficiently fine element mesh and the correct geometric order i.e. linear or quadratic. The geometric order of quadrature of an element defines the number of nodes in an element and the order of interpolation. Finite element results may become more accurate if a lower order 
of quadrature is used, but can then become more susceptible to the presence of spurious modes [26]. The spurious modes can be avoided by choosing the correct element formulations for the FEA such as modified elements, hybrid elements, linear or quadratic interpolation, and full or reduced integration.

\section{Hexahedral Elements}

A hexahedral brick element with only nodes at the corners is known as an 8-node brick element and represents a linear first-order element using linear interpolation in each direction, as illustrated in Figure 6.1a. A hexagonal brick element with nodes at the corners as well as mid-sides is known as a 20-node brick, representing a quadratic second-order element using quadratic interpolation, as illustrated in Figure 6.1b. Second-order elements provide higher accuracy at the expense of analysis time.

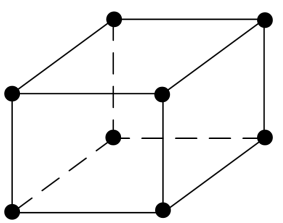

(a) Linear 8-Node Brick

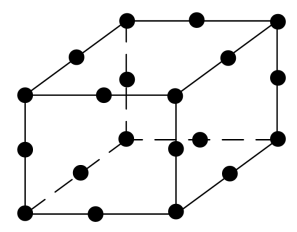

(b) Quadratic 20-

Node Brick

Figure 6.1: Three-Dimensional Brick Elements

\section{Tetrahedral Elements}

Similar to the brick elements, linear and quadratic tetrahedral elements can be utilised to model parts. Tetrahedral elements are very useful in modeling complex shapes, such as the rails, but are however not as accurate as the hexahedral elements in terms of stress/displacement analysis if using first-order interpolation. They are, however, less sensitive to distortion than hexahedral elements. Quadratic interpolation which uses 10 nodes, as illustrated in Figure 6.2b is therefore preferred to linear interpolation which uses 4 nodes as illustrated in Figure 6.2a for tetrahedral elements.

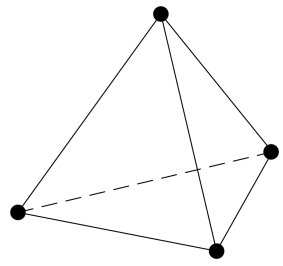

(a) Linear 4-Node Tetrahedral

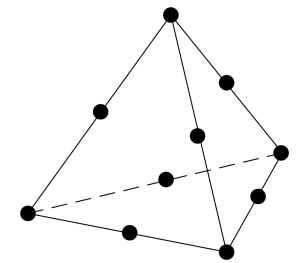

(b) Quadratic 10-

Node Tetrahedral

Figure 6.2: Three-Dimensional Brick Elements 
The solid element types used for the various components for the purpose of this investigation are as follows:

\section{Rail Element Type}

The solid elements used for modeling the rails are second-order modified tetrahedral elements. The preferred hexahedral cannot be used in this case due to the complexity of the geometric shape. The interpolation order is chosen as quadrilateral for increased accuracy, and allows the use of reduced integration. Due to the fact that hard contact interactions are in effect in the TT model (as will be explained later), modified elements are required. Modified elements provide uniform contact pressure situations when hard contact interactions are used and minimise shear and volumetric locking. Modified tetrahedral elements, though, are incompatible when in contact with other regular second-order elements. The elastomeric pads connected to the rails are therefore required to be of first-order elements.

\section{Elastomeric Pad Element Type}

The solid elements used for these parts are hybrid first-order hexahedral elements with reduced integration. A hybrid element is a mixed element where the fields within and on the boundaries are assumed independent and does not require a fine mesh as required by normal element types [24]. The reduction in required nodes therefore reduces the analysis time, whilst still obtaining the required accuracy. Hybrid elements are used primarily for incompressible or almost incompressible material behaviour where the general displacement history cannot be used, as very small changes in deflection lead to very large changes in pressure. Rubber, with a high poisson's ration, is treated as a near-incompressible material because the shear modulus is much smaller than the bulk modulus [26].

\section{Reinforced Concrete and Grout Element type}

The solid elements used for these parts are simple first-order hexahedral elements using reduced integration. Linear elements are allowed in this case as long as a fine enough mesh is used. The usage of first-order, reduced integration in elements can activate spurious modes such as an hourglass mode, as explained earlier. Hourglassing can be an issue with first-order, reduced integration elements, because only a single integration point is used in the element. Hourglass control is therefore uitlised to control the distortion of the geometry of the elements.

A summary of the element types used for the 3D FEA is as shown in Table 6.1 
Table 6.1: Summary of Element Types

\begin{tabular}{lcccc}
\hline Component & Element Type & Interpolation order & Integration & Other \\
\hline Rail & Tetrahedral & Quadratic & Reduced & Modified \\
Rubber pad & Hexahedral & Linear & Reduced & Hybrid \\
Concrete beams & Hexahedral & Linear & Reduced & - \\
\hline
\end{tabular}

\subsection{Contact and Interaction Modeling}

Accurate simulation of real contact behaviour between contacting bodies is dependent on the assigned interaction properties and is required for obtaining accurate results. In a mechanical contact simulation the contact properties between contacting bodies define an interaction. This is achieved by defining the contacting surfaces of the bodies and assigning normal and tangential contact behaviour. The contacting surfaces in the TT system are the rail-rubber, concrete-rubber and concrete-concrete interactions.

The default ABAQUS normal contact pressure-overclosure relationship between components is the "hard" contact surface-to-surface model, which assigns master and slave surfaces. The master and slave surfaces restrain the penetration which can occur between bodies by assigning the material with the highest Young's modulus as the master surface. The "hard" contact relationship minimises the penetration of the slave surface into the master surface at constraint locations, and also does not allow the transfer of tensile stress between the surfaces, which is required for the purpose of this investigation. Separation between surfaces can occur when the contact pressure between them reduces to zero. Separation between the rail-rubber and concrete-rubber are restricted by the usage of clips which hold the rails in place on the $\mathrm{RC}$ beams. Penetration between the parts are minimal; the no-separation relationship between the components is therefore applied. The sliding formulation used is the finite sliding method which allows for arbitrary separation, sliding and rotation of the contact surfaces. A tolerance zone of $1 \mathrm{~mm}$ is specified for adjustment, thereby causing the nodes of the slave surface between the two adjacent surfaces to be adjusted to the nodal positions of the master surface for accurate force transfer between nodes [26].

When surfaces are in contact they transmit normal as well as shear forces across the contact interface. The tangential forces, also known as the friction, is expressed in terms of the shear stresses on this contact interface. Tangential behaviour between contacting bodies is defined by means of the penalty formulation which is well suited for general contact between bodies. The penalty method applies frictional resistance by means of a penalty function [24], and simulates roughness between surfaces, of which the magnitude is dependent on the coefficient of friction between the bodies [26]. The coefficient of friction, $\mu$, is calculated as the ratio between the tangential force to the normal force [27]. The coefficients of friction between the three interacting 
surfaces are summarised in Table 6.2.

Table 6.2: Coefficient of Friction Values [8]

\begin{tabular}{lc}
\hline Interaction & Coefficient of Friction, $\mu$ \\
\hline Rail-Rubber & 0.6 \\
Concrete-Rubber & 0.6 \\
Concrete-Concrete & 0.6 \\
\hline
\end{tabular}

\subsection{Subgrade Support Analysis}

In order to accurately analyse the TT railway system, the vertical stiffness provided by the supporting subgrade formation is required. This stiffness is represented by the modulus of subgrade reaction. This section investigates the modulus of subgrade reaction for the TT railway system, and is used in the FEA in this dissertation.

As stated previously in Chapter 3 the subgrade reaction at any point along a beam supported by an elastic medium is assumed to be directly proportional to the deflection at the specific point, thereby obeying Hooke's Law. The modulus of subgrade reaction is therefore calculated as follows:

$$
k_{s}=\frac{p}{w}
$$

where

$\mathrm{p}=$ ground bearing pressure at a point along beam

$\mathrm{w}=$ vertical displacement at that point

The modulus of subgrade reaction is generally obtained by means of in-situ plate bearing tests (PBT), but can also be obtained using a FEA or a screw-plate test. A screw-plate test obtains the modulus of subgrade reaction without having the need to do any excavations, and penetrates the sand by rotation and can therefore be positioned at a series of depths, above or below the water table. The loading is applied through the shaft of the screw plate [28].

PBTs are performed by using a steel plate of at least $300 \mathrm{~mm}$ square which is placed on top of the foundation under investigation and loaded until a unit deflection is obtained [28]. The deflection vs. load curve is primarily linear while the deflections are relatively small, which is why a unit deflection is prescribed. Previous tests have found that as the width of the plate increases, there is a non-linear increase of the load required to obtain the required deflections [29]. A large range of plate sizes is required to obtain the non-linear curve of the soil bearing capacity, which is not feasible for a railway line which would require numerous detailed tests. A linear response is therefore more feasible, as the TT railway system does not reach non-linearity in the soil reaction under serviceability loading. It is also difficult to perform PBTs with large 
plates which tend to be less rigid than the smaller plates, and also require a large reaction load to obtain the required deflection. Additional rigidity can be obtained by stacking smaller plates on top of the main test plate.

When choosing a size of plate to use for the plate bearing tests, due consideration should be given to the zone of stress influence in the various soil layers under the plate [29]. If a plate has a width of $\mathrm{B}$, the stress bulb under the plate will generally reach a depth of $2 \mathrm{~B}$, depending on the stiffnesses of the soil layers. The influence of the depth the stress bulb reaches can be substantial depending on whether weaker layers are at lower depths, such as at the Amandelbult layout section 3 which has a weak clay layer approximately $800 \mathrm{~mm}$ deep. The size and shape of the footing for the PBT therefore has a significant influence on the modulus of subgrade reaction. A comparison is therefore made to investigate the difference between the modulus of subgrade reaction of the standard square PBT and a rectangular, infinitely long PBT, which represents the actual footing of the TT railway system.

The variation in displacements and vertical stress of the square and rectangular PBTs are illustrated in Figure 6.3. where the left-hand-side figures represent the displacement and vertical stress for the square PBT, and the right-hand-side figures represent the displacement and vertical stress for the rectangular PBT with a characteristic length. The applied forces are such that they obtain a unit deflection in both models. These results show a similar displacement bulb under the loading area for both analysis methods, as is to be expected. The vertical stresses, however, illustrate different stress bulbs under the loading area. This is due to the shape of the loaded plate, where the rectangular plate is much longer than the square plate, therefore having a larger area and a larger total force acting on the model. This allows stress to extend deeper in the formations under the vertical plate than the square plate, which is one of the reasons why the rectangular PBT requires a smaller distributed pressure on the plate than the square plate.

The approximation of using a rectangular PBT, compared to a square PBT, is a better representation of actual in-situ conditions, because it takes the actual shape of the footing of the TT system into account. This analysis method is recommended for a FEA of subgrade formations, but is not practically feasible for in-situ PBTs. 


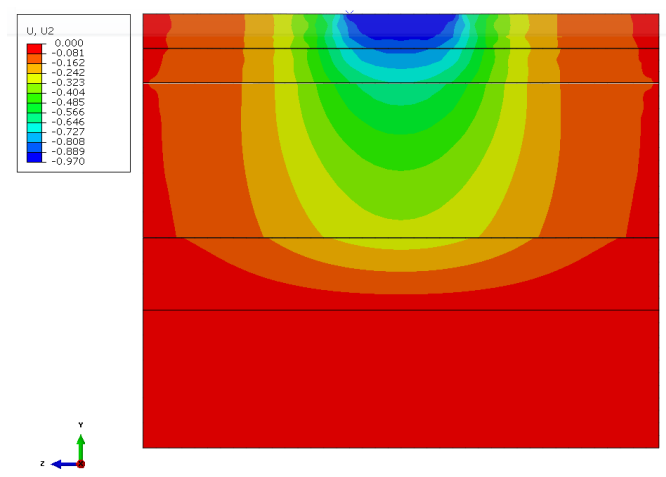

(a) Square PBT Displacement

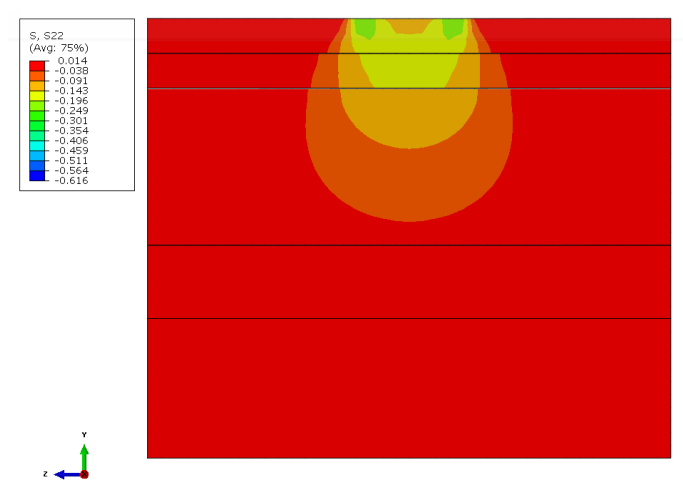

(c) Square PBT Vertical Stress

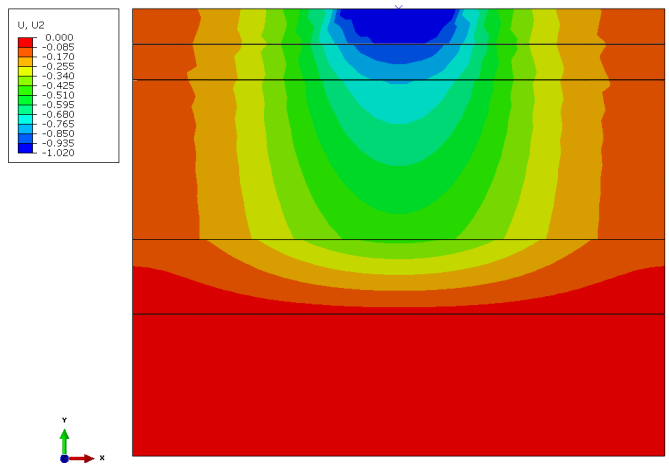

(b) Rectangular PBT Displacement

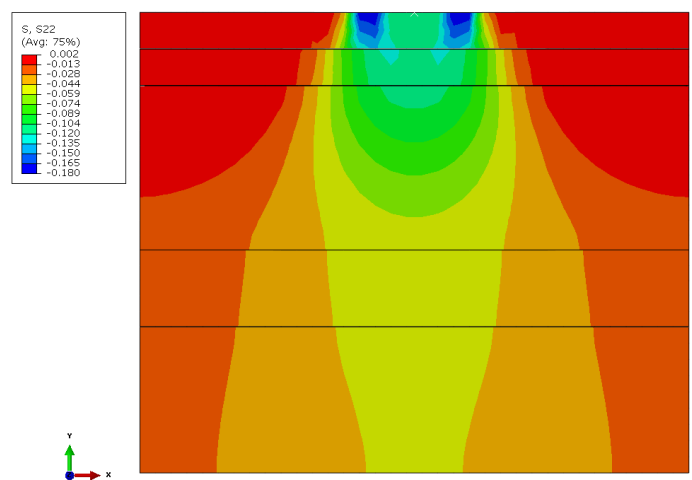

(d) Rectangular PBT Vertical Stress

Figure 6.3: Comparison between Square and Rectangular PBT

The usage of a small plate of say $300 \mathrm{~mm}$, will only influence the displacements and stresses in the soil to a depth of approximately $600 \mathrm{~mm}$. If this plate was to be used at the Amandelbult layout 3 railway section's soil analysis, it would only consider the top two crusher layers, and about half of the rock fill layer, thereby ignoring the considerably weaker clay layer to some extent. The usage of the plate of $300 \mathrm{~mm}$ width would therefore require a much higher loading pressure, due to the stronger soil layers having the greatest influence on the deflection of the plate, and would therefore overestimate the modulus of subgrade reaction and subsequently underestimate the deflection of the TT system. The usage of a larger plate is therefore suggested to take the stiffnesses of the other soil layers into account. The most accurate width of plate to use should have a similar width as the supporting grout layer.

The estimation of an accurate numerical value of the modulus of subgrade reaction is difficult to achieve as soil conditions can change rapidly over a short distance, therefore requiring numerous soil support stiffness analyses. The response of a soil foundation differs greatly depending on the size and shape of the rigid plate loading the soil. The results of a square PBT must be extrapolated for larger footings, such as the rectangular footing of the grout layer which has a width B and an infinite length. Performing PBTs using large rectangular plates is, however, uneconomical and technically nearly impossible. The results of regular square PBTs must therefore 
be extrapolated to represent the correct shape and size as required for the beam acting on the soil foundation. The modulus of subgrade reaction for a rectangular footing with finite length, $\mathrm{L}$, and width, B, can be calculated as follows [29]:

$$
k_{s}=k_{1} \frac{m+0.5}{1.5 m}
$$

where

$\mathrm{k}_{1}=$ value obtained from the square PBT

$\mathrm{m}=\mathrm{L} / \mathrm{B}$

Since an infinitely long beam is the most correct simulation of the TT railway system, the value of $\mathrm{L}$ strives towards infinity, thereby also increasing the value of $\mathrm{m}$ correspondingly. Equation 6.4 .2 must therefore be simplified using L'hôpital's rule which uses derivatives to help evaluate limits. L'hôpital's rule is applied as follows:

$$
\lim \frac{f(x)}{g(x)}=\lim \frac{f^{\prime}(x)}{g^{\prime}(x)}
$$

given that both $\mathrm{f}(\mathrm{x})$ and $\mathrm{g}(\mathrm{x})$ strive towards zero or $\pm \infty$ if

$$
\lim \frac{f^{\prime}(x)}{g^{\prime}(x)}
$$

has a finite value or if the limit is $\pm \infty$.

Equation 6.4 .2 is therefore simplified using L'hôpital's rule (differentiated with respect to m) as follows:

$$
k_{s}=k_{1} \frac{1}{1.5}=0.67 k_{1}
$$

As can be seen, the foundation modulus of an infinitely long beam strives towards $0.67 k_{1}$ (where 0.67 represents a shape factor, SF) as the length strives towards infinity. Although Equation 6.4 .2 is often used to evaluate the modulus of subgrade reaction of soils supporting rectangular footing, it is not necessarily accurate when modified for infinitely long rectangular footings. Bowles (1996) does also not recommend the usage of Equation 6.4 .2 for general cases, as it represents a very simplified representation of soil response. The accuracy of the SF of 0.67 is therefore questioned, and will be investigated here. Equation 6.4.6 represents the current proposed equation for the use of modifying the results of square PBTs for rectangular, infinitely long footings.

$$
k_{s}=S F \times k_{1}
$$

There are methods available to investigate and calculate the equivalent modulus of subgrade reaction of rectangular, infinitely long beams based on square PBTs, but these methods are dependant on detailed soil characteristics such as the Young's modulus and poisson ratio of a soil layer, which are not readily available for general use. In order to take multiple soil layers into account, which is more realistic and accurate for this investigation, the soil layers must first be 
transformed into a single layer with representative characteristics, and then again be transformed in order to represent an infinitely long, rectangular beam. These methods and transformations, as is the nature of geotechnical analyses and knowledge of in-situ soil conditions, are based on a number of simplifications and assumptions, as discussed with K. Jenkins [30], and are therefore not used in this investigation. The design and response analysis of a TT railway section (which can span great lengths) is generally based on results obtained from in-situ PBTs, and not necessarily detailed soil analyses as performed at the Amandelbult and Pilbara railway sections. The soil characteristics such as soil layer thickness, Young's modulus, and poisson ratio are not economically feasible to investigate at general soil analysis points, therefore meaning that only the results of the PBTs will be available for analysis and design. Providing analysis methods should therefore be based on the modulus of subgrade reaction obtained from PBTs.

The accuracy of Equation 6.4.5 must be investigated by comparing the results with FEA of soil foundations, in order to validate whether reasonable accuracy is obtained with this method. Due to the fact that an infinitely long beam can also not be modeled in FEA software, it is designed to have a characteristic length whereby if longer sections are investigated it would provide similar results, and can therefore be used to simulate an infinite length in FEA models. The characteristic length of an infinitely long beam is therefore used to predict the length of the beam which has a relevant influence on the required results and can be calculated as follows:

$$
L_{c}=\sqrt[4]{\frac{4 E I}{k_{1}}}
$$

where

$\mathrm{E}=$ Young's modulus of beam $[\mathrm{MPa}]$

$\mathrm{I}=$ Moment of inertia of beam $\left[\mathrm{mm}^{4}\right]$

Where the values of $\mathrm{E}$ and I are obtained by means of the Transformed-Section Method discussed in Chapter 3 .

\subsection{Modulus of Subgrade Reaction Analysis}

\subsubsection{Introduction}

It has become common practise in structural design to investigate the support stiffness by performing a FEA of the soil foundation. FEA applied soil formations is still not well developed and is therefore subjected to limitations such as the unknown complex interactions between soil particles, occurrence of soil non-linearity and non-homogeneous strata. The finite element soil models used in this investigation are simplified and make assumptions of in-situ soil conditions, but are still able to provide relatively accurate representations of in-situ soil formation stiffness. A simulation of the PBT can be made by modeling the soil layers using 3D solid FEA. Once the foundation modulus has been obtained by means of in-situ PBTs or FEA, it can be used in the finite element models for analysis of the $2 \mathrm{D}$ and $3 \mathrm{D}$ superstructures. In $2 \mathrm{D}$ beam models this modulus of subgrade reaction can be modeled as a spring support, whereas it can be input as a 
supporting elastic foundation interaction in 3D FEA and changed according to the geotechnical conditions at certain railway sections.

The investigation of the modulus of subgrade reaction of the reference models at the three Amandelbult sections and the Pilbara ore line section are performed in order to be able to compare results of finite element models to obtain a valid shape factor. The PBT simulations of the Amandelbult sections and the Pilbara iron ore line section are investigated in the following section.

\subsubsection{Soil Analysis Methodology}

As discussed in Section 6.4 a method is required for obtaining the modulus of subgrade reaction for an infinitely long rectangular footing when only the results of square PBTs are available for design. Equation 6.4.5 provides an approximation by deducing the foundation modulus for an infinitely long, rectangular footing foundation from the results of a square PBT. This approximation will be investigated in this section by comparing Equation 6.4.5 with rectangular footings with characteristic lengths of the TT railway line at the three Amandelbult layout sections, as well as the Pilbara Ore line using FEA. A recommendation of method or SF will subsequently be made for future analyses and design.

The process of analysing the modulus of subgrade reaction of an infinitely long, rectangular footings with finite elements is performed in this section as follows:

1. Obtain modulus of subgrade reaction, $\mathrm{k}_{1}$, from square PBT

2. Obtain Young's modulus, E, and moment of inertia, I, for combined homogeneous beam using the Transformed-Section Method

3. Obtain characteristic length, $\mathrm{L}_{\mathrm{c}}$, with Equation 6.4.7

4. Obtain foundation modulus of rectangular footing, $\mathrm{k}_{\mathrm{s}}$, with width $\mathrm{B}$ and length $\mathrm{L}_{\mathrm{c}}$

5. Compare $\mathrm{k}_{1}$ and $\mathrm{k}_{\mathrm{s}}$ and obtain $\mathrm{SF}$ for use in Equation 6.4.6

\subsubsection{Subgrade Formation FEM Analysis}

In this section the soil support of the three Amandelbult railway sections and the Pilbara Ore line section are investigated by means of finite element models using ABAQUS' 3D solid elements. This is done by modeling the various soil layers and simulating the loading plate by loading a rigid surface until a unit deflection is obtained. The pressure load which produces a unit deflection over the applied area represents the modulus of subgrade reaction, $\mathrm{k}_{\mathrm{s}}$, of the soil.

Design parameters of a subgrade FEM model can be obtained from in-situ soil tests which investigate the various soil strata and their respective material properties. The material properties are acquired by obtaining the relative and cumulative deflections of the respective soil layers 
by use of multi-depth deflectometers (MDDs) and back-calculating the stiffness of the soil layer using the known deflections and loading magnitudes [7]. The element types used to model the subgrade strata are basic first order solid elements with interaction properties as discussed in Section 6.3. Quadratic elements are not required for this case as the elements only experience small vertical deflections and do not experience significant bending. The coefficients of friction between the various subgrade strata are very difficult to determine accurately; a general value of 0.6 is therefore used as a coefficient of friction between the soil layers [31]. The small vertical deflections obtained means that the models are not very sensitive to lateral movement between soil layers, justifying the usage of a general coefficient of friction value.

\section{Square Plate Bearing Test}

Figure 6.4 illustrates the 3D solid element ABAQUS FEA model used for the square PBT of the Amandelbult layout Section 3, and shows the boundary conditions and loaded area used for the analysis. The boundary conditions restrain displacement in the normal directions for their respective sides, whilst the loaded area is constrained as a rigid analytical surface, meaning the nodes on this surface have the exact same displacement, thereby simulating the stiff bearing plate. The size of the model was chosen as $3000 \mathrm{~mm} \times 3000 \mathrm{~mm}$ so that the boundaries of the model are far enough from the loaded area as not to influence the results.

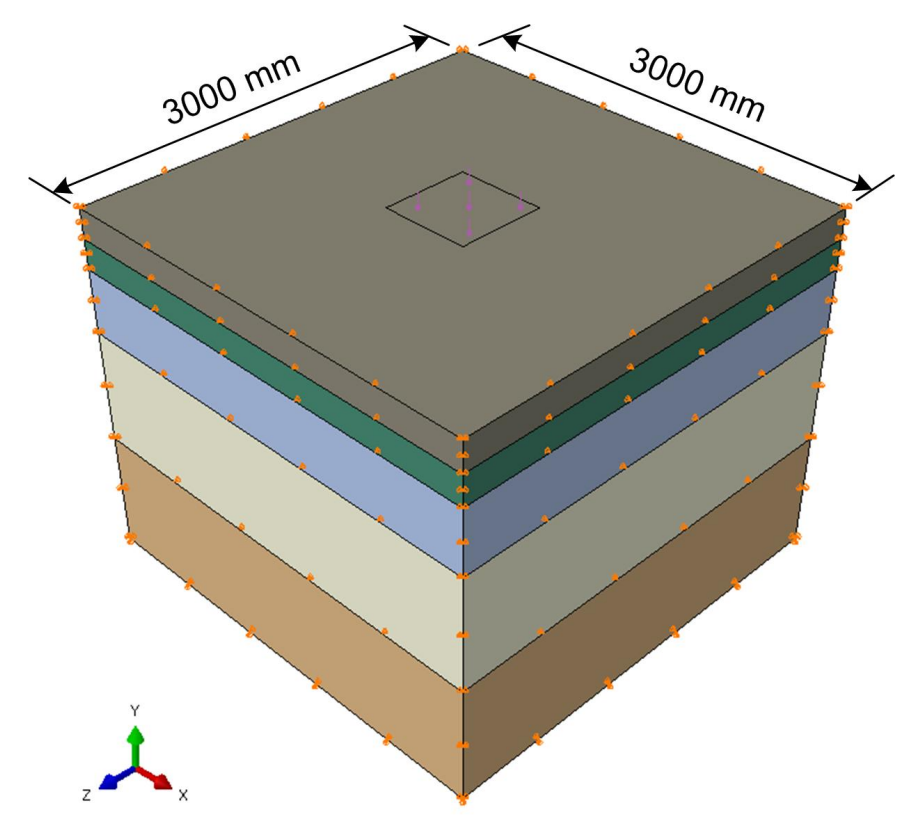

Figure 6.4: Square Plate Bearing Test

A presentation of typical results of the 3D FEA square PBT as performed by means of ABAQUS are provided in Figure 6.5 which is cut on the symmetry axis in the x-direction, and shows the deflections of the finite elements in the soil layers. 


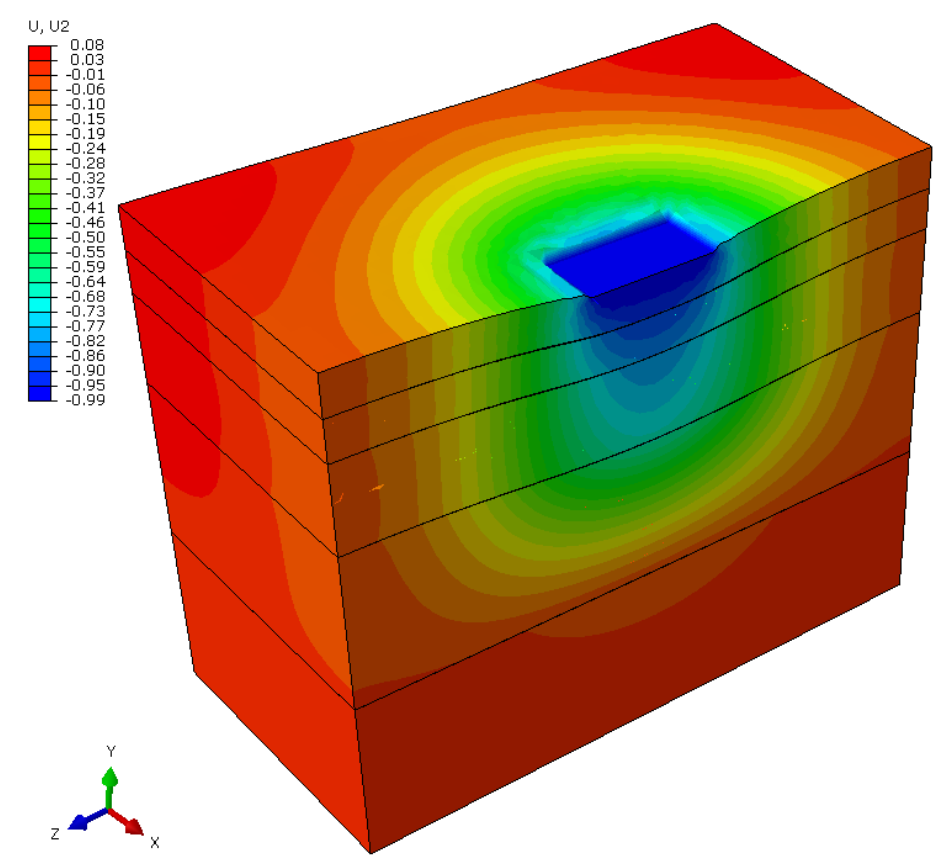

Figure 6.5: Square Plate Bearing Test displacements

\section{Rectangular Plate Bearing Test}

The rectangular PBTs are performed in a similar manner as the square PBT, but the length of the models are now the characteristic length for the respective soil conditions and beam bending stiffness. The loading area of the rectangular PBT spans the entire length of the FEA model, in order to simulate the infinitely long beam. Illustrations of the rectangular PBT finite element model and displacement result model are illustrated in Figures 6.6 and 6.7 respectively. 


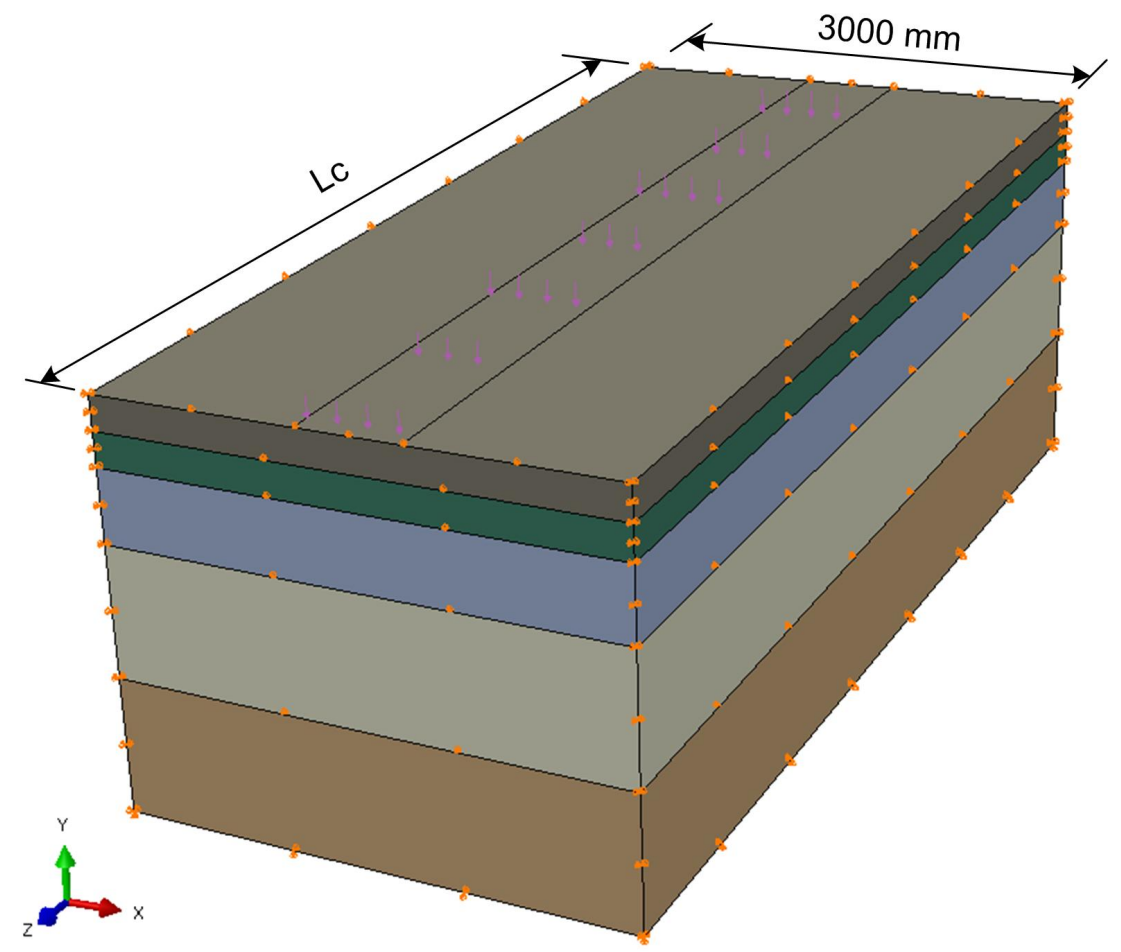

Figure 6.6: Rectangular Plate Bearing Test

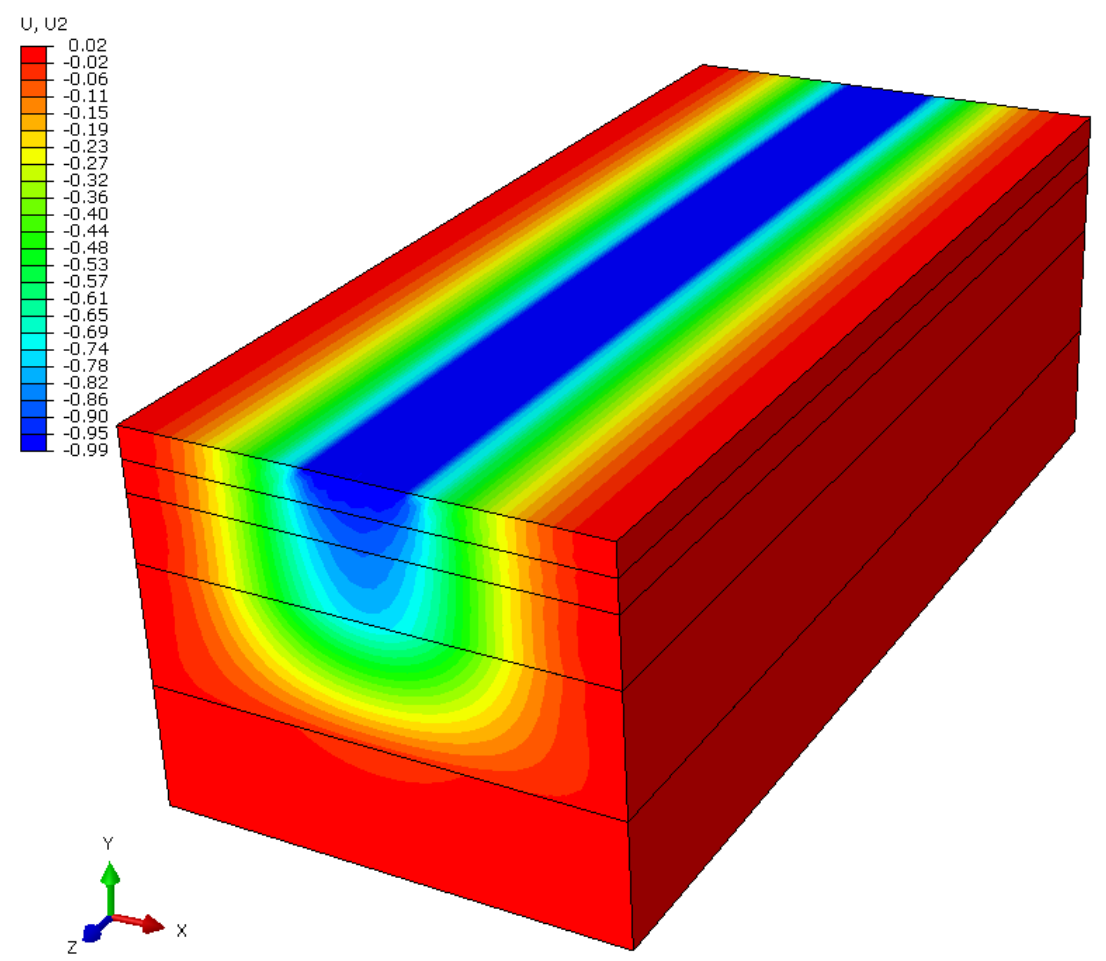

Figure 6.7: Rectangular Plate Bearing Test displacements 


\section{Plate Bearing Test Results}

The results for the finite element PBT of the subgrade analyses are summarised in Table 6.3 below.

Table 6.3: Modulus of Subgrade Reaction Analysis Results

\begin{tabular}{lccc}
\hline Section & $\begin{array}{c}\text { Square PBT, } \mathrm{k}_{1} \\
{\left[\mathrm{~N} / \mathrm{mm}^{2} / \mathrm{mm}\right]}\end{array}$ & $\begin{array}{c}\text { Rectangular PBT, } \mathrm{k}_{\mathrm{s}} \\
{\left[\mathrm{N} / \mathrm{mm}^{2} / \mathrm{mm}\right]}\end{array}$ & $\begin{array}{c}\mathrm{k}_{\mathrm{s}} / \mathrm{k}_{1} \\
-\end{array}$ \\
\hline Amandelbult Layout 1 & 0.345 & 0.169 & 0.490 \\
Amandelbult Layout 2 & 0.194 & 0.100 & 0.510 \\
Amandelbult Layout 3 & 0.251 & 0.126 & 0.500 \\
Pilbara Ore Line & 0.250 & 0.127 & 0.510 \\
\hline
\end{tabular}

From these results it is concluded that there is a definite linear ratio between results obtained from the finite element model square-and rectangular PBTs, as the modulus of subgrade reaction of rectangular footings of characteristic length obtain approximately $50 \%$ the value of the square PBTs. The linear relationship between the square-and rectangular PBTs is illustrated in Figure 6.8. which illustrates a linear trendline with a Coefficient of Determination, $\mathrm{R}^{2}$, of 0.9991 .

\section{PBT Analysis Results}

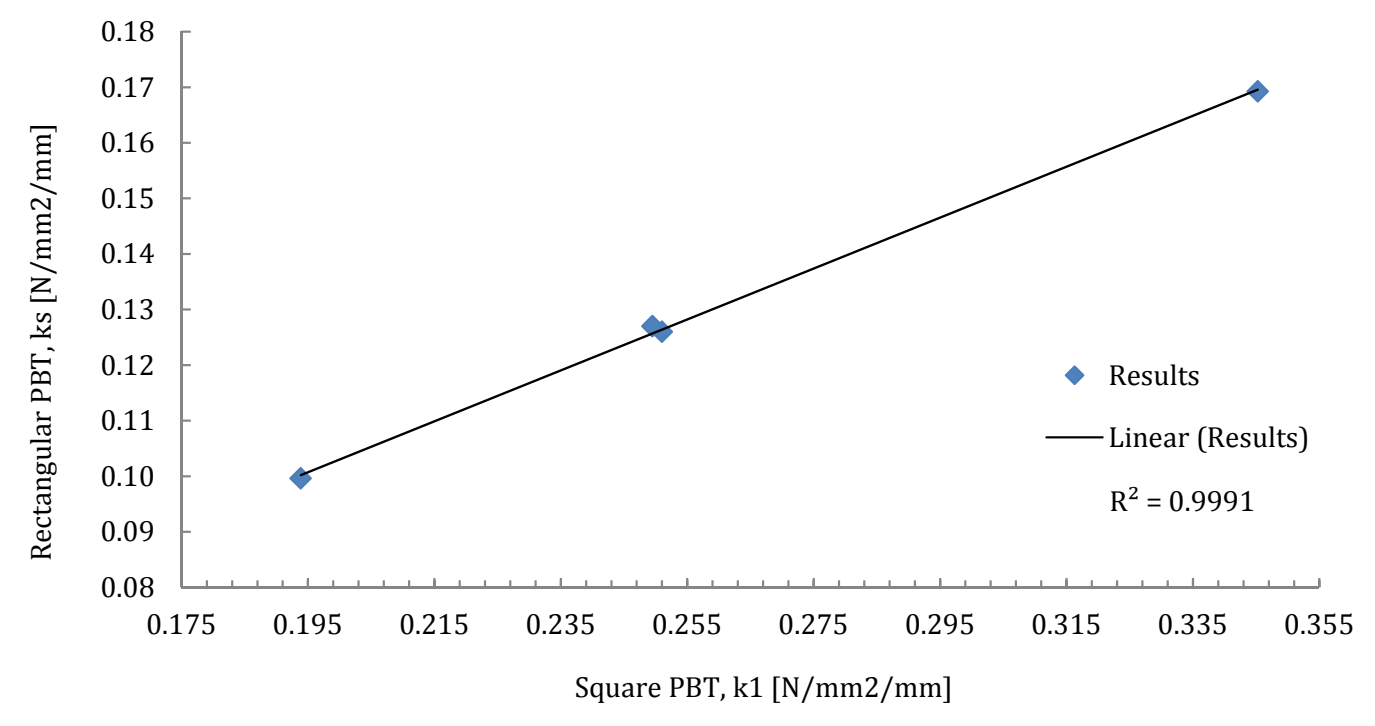

Figure 6.8: Plate Bearing Tests Results

The coefficient of determination is a ratio of sum of squares and is a widely used measure for a regression model. The $\mathrm{R}^{2}$ statistic is often referred to as the amount of variability in the data sample space by the regression model. The $\mathrm{R}^{2}$ value should be used with caution for polynomial and non-linear trendlines, but is accepted as a good approximation for linear trendlines, as is 
the case for this regression model [32]. An $\mathrm{R}^{2}$ value of 0.9991 is a very high value, indicating a very accurate trendline relative to the results obtained.

The in-situ soil formation sections' properties of four sections were available for comparison between square PBTs and rectangular PBTs, and provided consistent linear results with a very high coefficient of determination. The four soil formations used for the FEA demonstrate a variation in subgrade properties which can be found at distinct TT railway sections. A larger sample space would yield more conclusive results, but this requires more in-situ soil formation analyses which are difficult and costly to obtain. The accurate trendline approximation indicates that the proposed method of using a SF of 0.5 times the square PBT result (as defined in Equation 6.4.6) provides an accurate modulus of subgrade reaction for an infinitely long, rectangular footing, as is the case for the TT railway system. Applying this SF of 0.5 yields Equation 6.5.1, as indicated below.

$$
k_{s}=0.5 \times k_{1}
$$

The SF of 0.5 obtained from the FEA does not correlate with the factor of 0.67 as prescribed previously by Equation 6.4.5 which actually represents an overestimation of soil support stiffness by $17 \%$ which will produce an underestimation of deflections, bending moments and shear forces. The $0.5 \mathrm{SF}$ therefore represents a safer and more accurate estimation of actual in-situ conditions, and will be used for the FEA models in this investigation.

\subsubsection{Modulus of Subgrade Reaction Range}

The ranges used to quantify the performance of an elastic medium is listed in Table 6.4 [4], and represents the modulus of subgrade reaction for a square PBT. These ranges are a good indication on the performance and quality of a supporting medium, and are used in the sensitivity analysis of the TT system in Chapter 8

Table 6.4: Range of Elastic Constants

\begin{tabular}{lccc}
\hline Elastic Constant & Unit & Poor & Good \\
\hline Foundation modulus, $\mathrm{k}_{\mathrm{s}}$ & {$\left[\mathrm{N} / \mathrm{mm}^{2} / \mathrm{mm}\right]$} & 0.02 & 0.20 \\
Foundation coefficient, $\mathrm{k}$ & {$\left[\mathrm{N} / \mathrm{mm}^{2}\right]$} & 9 & 90 \\
Spring constant, $\mathrm{k}_{\mathrm{d}}$ & {$[\mathrm{N} / \mathrm{mm}]$} & 5.5 & 55 \\
\hline
\end{tabular}

\subsubsection{Limitations of Subgrade Analysis}

Most methods of soil analysis are based on the idealisation of soil behaviour which assumes that the soil exhibits linear, homogeneous, and isotropic behaviour for the calculation of vertical stresses in the strata. Most soils do not satisfy the assumption of linear elasticity, and can vary 
significantly over short distances in depth or in plan due to changes in strata thicknesses, vertical stiffness, water table position and consolidation of the strata. The allowable bearing capacity of clays is limited either by settlement considerations or an adequate factor of safety against shear failure, whereas for sands it depends on the density index, stress history, position of the water table, and footing size [28]. The water table position affects both the settlement and bearing capacity, as the bearing capacity of a saturated sand within the significant depth of influence, as demonstrated previously, can be roughly halved due to the effective unit weight of the saturated sand. This in turn reduces the lateral confining pressure whereby settlement occurs. The vibrations of the passing bogies can also cause settlement if the subgrade is not sufficiently compacted prior to installation of the structure [28].

An in-situ subgrade analysis, such as a PBT, should take the region subgrade types, possible water table position, and rainfall season into consideration in order to obtain the worst case scenario when the water table is at its highest when calculating the soil stiffness. The influence of the water table on the FEM subgrade analysis is considered negligible, as the stiffnesses obtained from back-calculation of the deflections simulate the actual stiffnesses of the subgrade strata at that specific test position at that time frame, therefore taking the water table into account.

\subsection{D Static Tubular Track Model}

This section comprises a description of the 3D solid finite element model subjected to static loading as used in ABAQUS with model design parameters as discussed in Section 6.2 A static analysis does not take inertial effects into account, but can be used to solve linear or nonlinear problems. The inertial effects will only be taken into account during the dynamic analyses which are performed in the following chapter. Similarly as in the 2D beam models as described in the previous chapter, the $3 \mathrm{D}$ solid finite element model used in this chapter is based on the geometry and design details of Amandelbult Layout station 3. The section of the TT railway system being investigated is illustrated in Figure 6.9 and also shows the mesh used for the analyses, whereas the whole model is illustrated in Figure 6.10. This model represents the most complex FEM model used for the static analysis of the TT railway system, and is assumed to represent the most accurate simulation of the response of the TT railway system to static loading. 


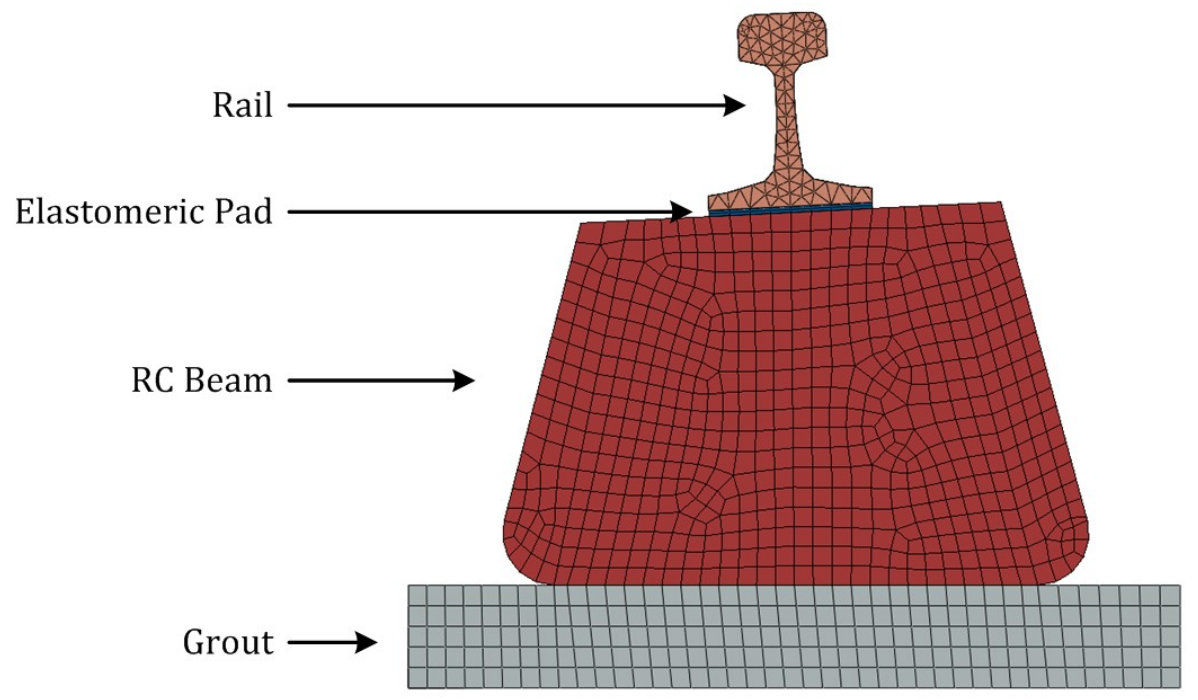

Figure 6.9: 3D Solid Element Section Mesh

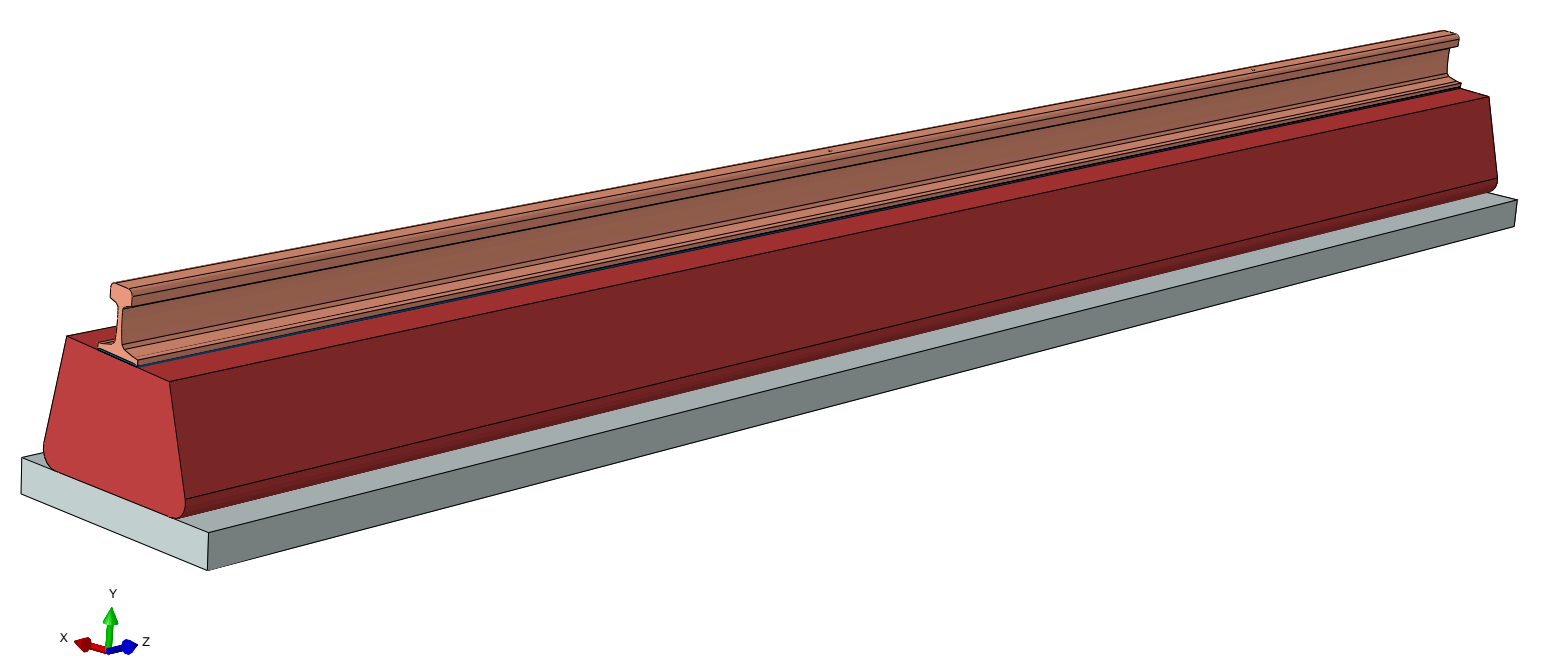

Figure 6.10: 3D Solid Element Model

The two point loads representing the wheel loads are applied as distributed loads on a small elliptical area, as obtained by means of Hertz Contact theory as described in Chapter 3 . The boundary conditions are applied at the free ends and restrain translation in the longitudinal and lateral ( $\mathrm{x}$ and $\mathrm{z}$ ) directions, as well as the rotation about the $\mathrm{x}$-axis. Vertical support is provided by means of an elastic foundation interaction at the bottom of the grout layer, the value of which represents the modulus of subgrade reaction as obtained for the rectangular, infinitely long rectangular PBT of Amandelbult Layout station 3 in Section 6.4. 


\subsection{D Static Model Analysis Results}

The results of the 3D solid finite element model are attached and discussed in this section. Similarly to the results obtained from the ABAQUS 2D beam and Double Beam model, there is a definite pressure distribution occurring as a result of the elastomeric pad, which allows for localised deflections in the rail and bending moments and shear force distribution along a larger longitudinal length of the RC beam, as will be discussed in further detail in this section.

\section{Displacement}

An illustration of the vertical displacements in the $3 \mathrm{D}$ solid finite element model is shown in Figure 6.11, and demonstrates the localised deflections at the load points on the rail. Figure 6.12 indicates that the maximum displacement at the centerline of the rail is $-1.16 \mathrm{~mm}$, whereas the maximum displacement on the centerline of the $\mathrm{RC}$ beam is $-0.95 \mathrm{~mm}$.

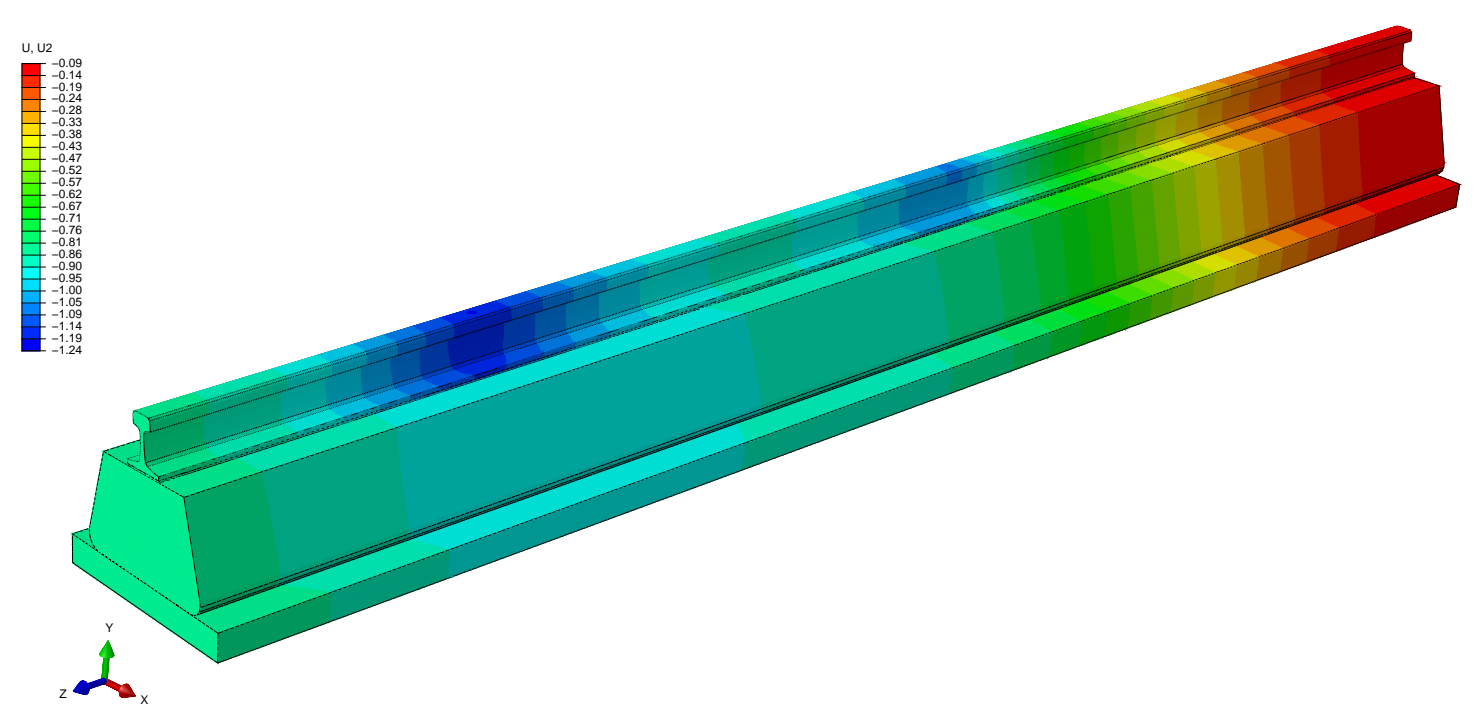

Figure 6.11: ABAQUS 3D Model Displacements 


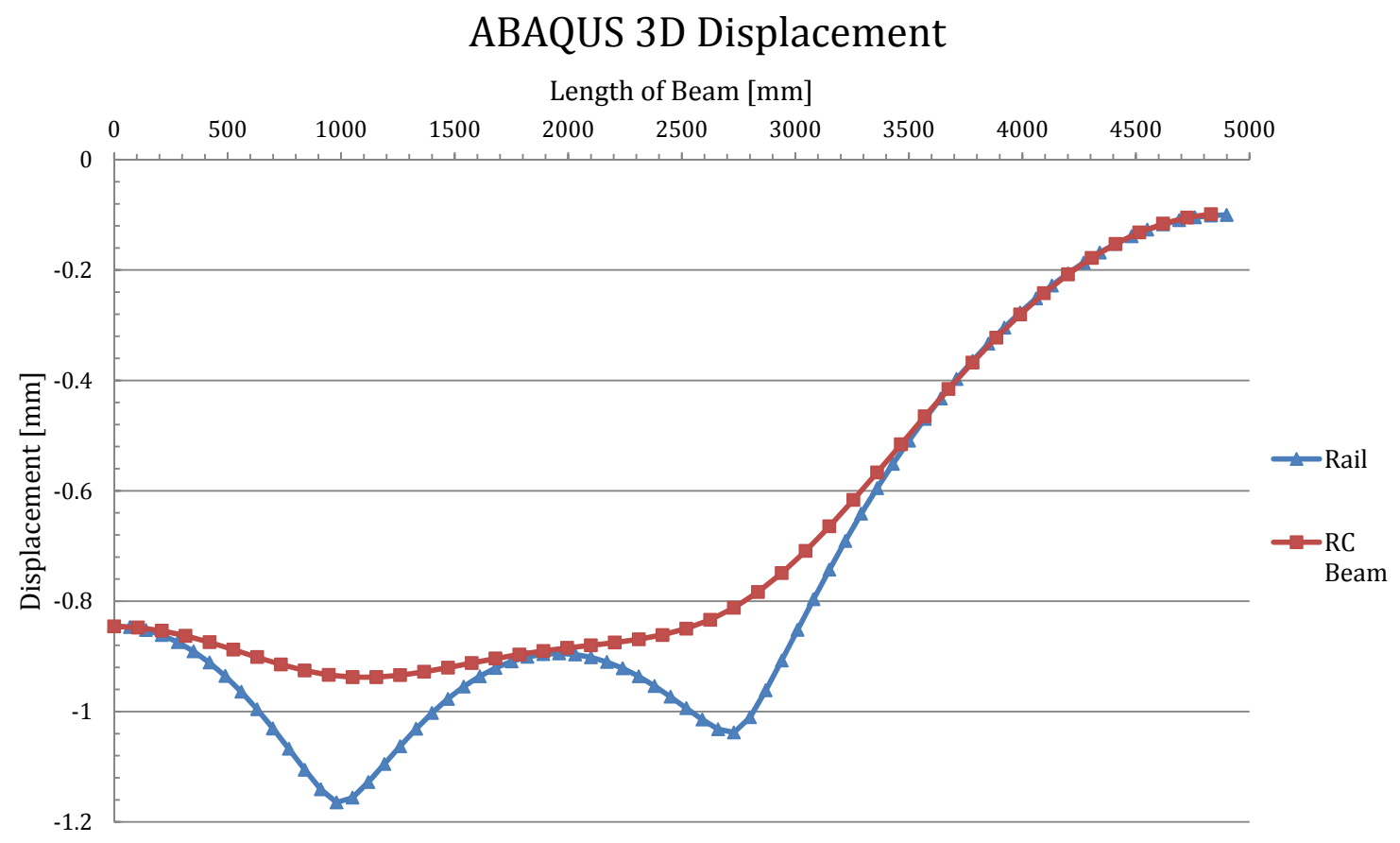

Figure 6.12: ABAQUS 3D Model Displacements

\section{Bending Moment Diagram}

The maximum bending moments in the rail and $\mathrm{RC}$ beam, as illustrated in Figure 6.13 are the same with a value of $12.4 \mathrm{kNm}$, whereas the minimum bending moments for the rail and $\mathrm{RC}$ beam are $-2.78 \mathrm{kNm}$ and $-10.9 \mathrm{kNm}$ respectively. The $\mathrm{RC}$ beam's bending stresses at the maximum bending moment are $\sigma^{+}=2.56 \mathrm{MPa}$ and $\sigma^{-}=-2.19 \mathrm{MPa}$, whereas at the minimum bending moment the bending stresses are $\sigma^{+}=2.25 \mathrm{MPa}$ and $\sigma^{-}=-1.93 \mathrm{MPa}$ respectively. 


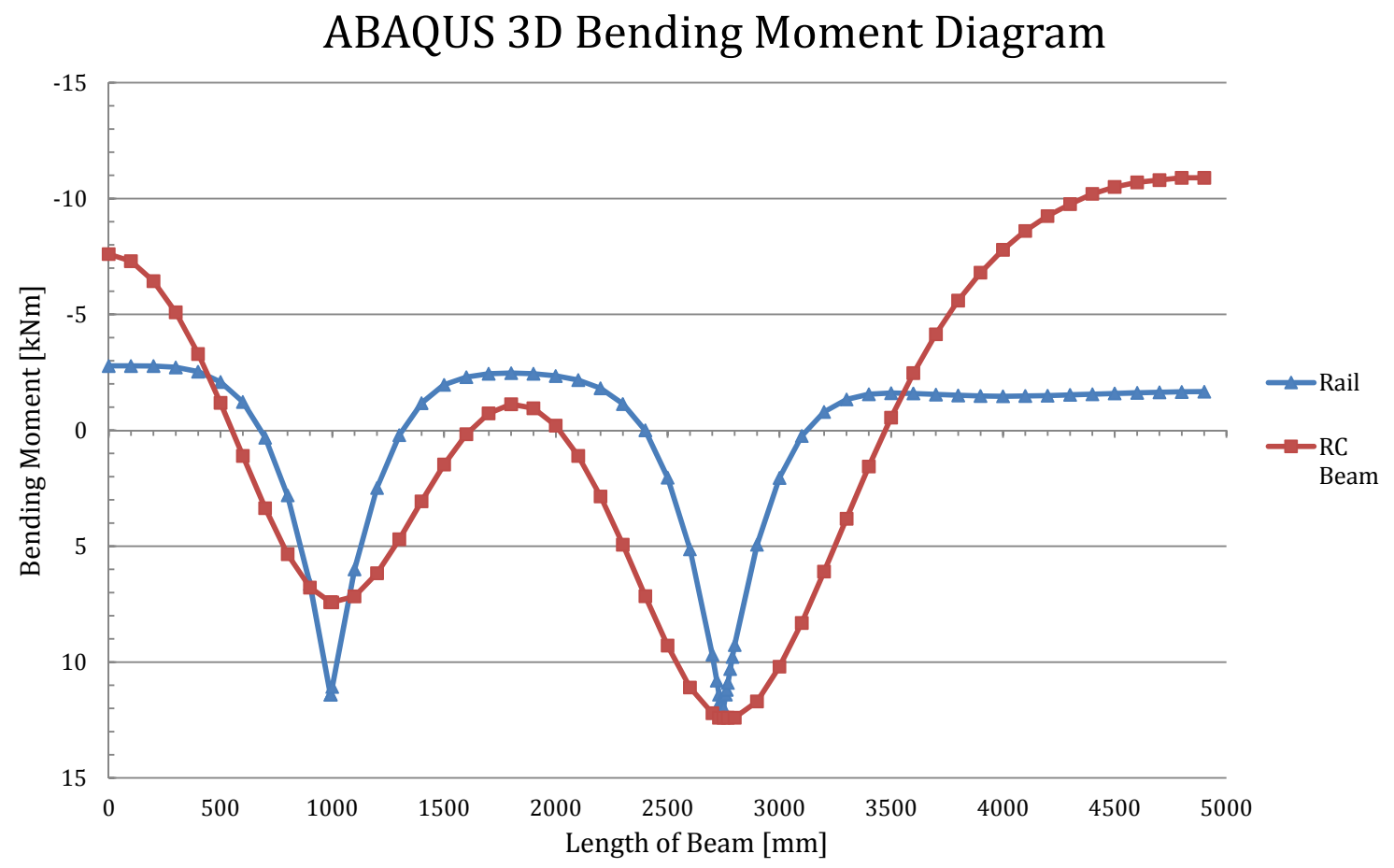

Figure 6.13: ABAQUS 3D Model Bending Moment Diagram

\section{Shear Force Diagram}

The maximum shear force in the rail and $\mathrm{RC}$ beam are $58.8 \mathrm{kN}$ and $27.9 \mathrm{kN}$ respectively, as illustrated in Figure 6.14. The curves of the rail and $\mathrm{RC}$ beam are similar as the curves obtained using the ABAQUS 2D beam and Double Beam models in the previous chapter, where the RC beam demonstrated an almost harmonic curve, attributable to the distribution of the shear forces over a larger area on the $\mathrm{RC}$ beam due to the influence of the elastomeric pad. 


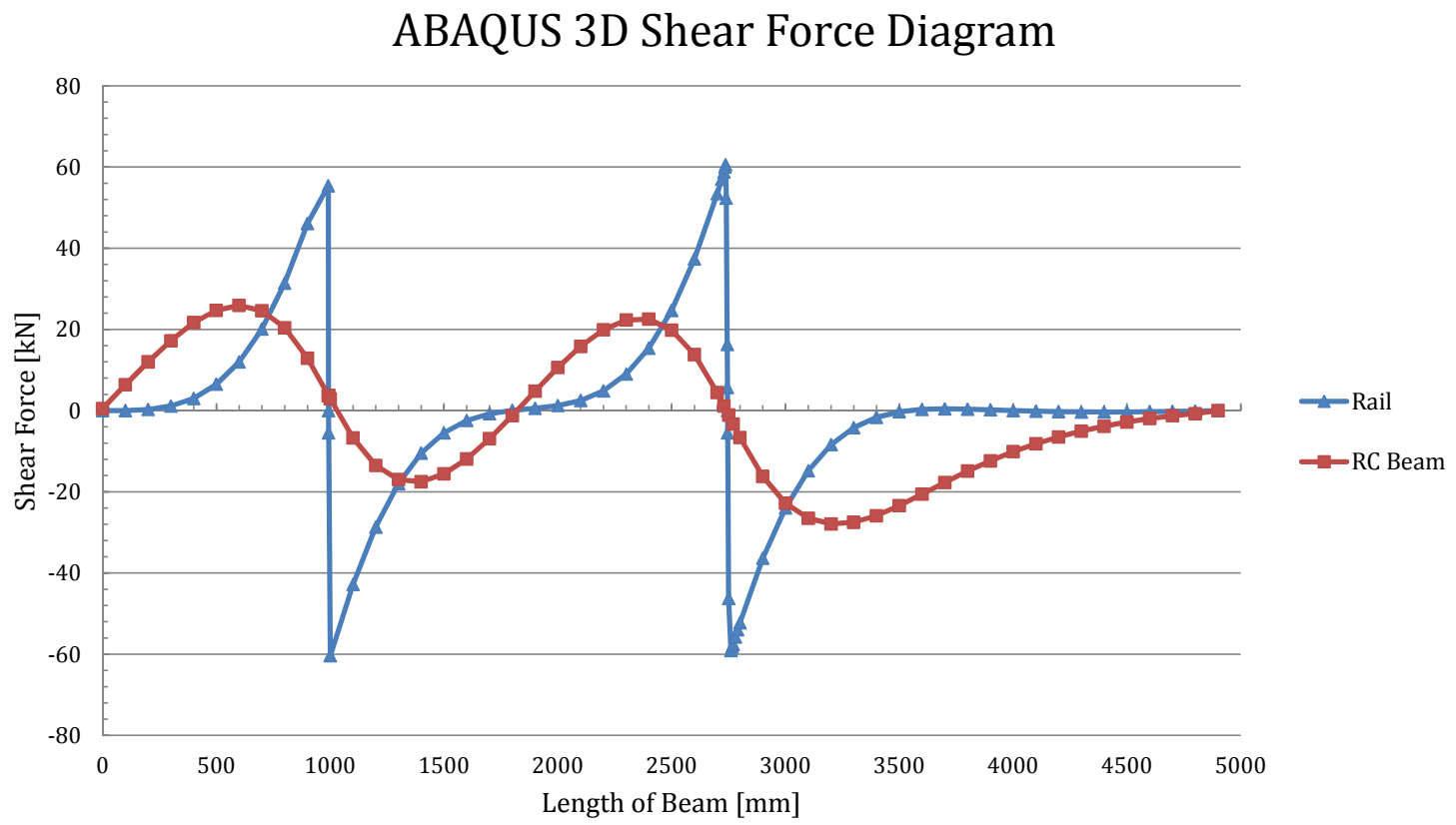

Figure 6.14: ABAQUS 3D Model Shear Force Diagram

\section{Soil Pressure Distribution}

The soil pressure distribution as obtained in the $2 \mathrm{D}$ analyses are assumed to be linearly distributed along the width of the supporting beam, but this is of course an approximation of actual conditions. When a footing is loaded, the supporting soil actually deflects in a bowlshaped depression of which the shape is dependant on the soil type and rigidity of the footing, but is assumed to be linearly distributed for design purposes [33]. Uniform and non-uniform soil bearing pressure examples are illustrated in Figure 6.15

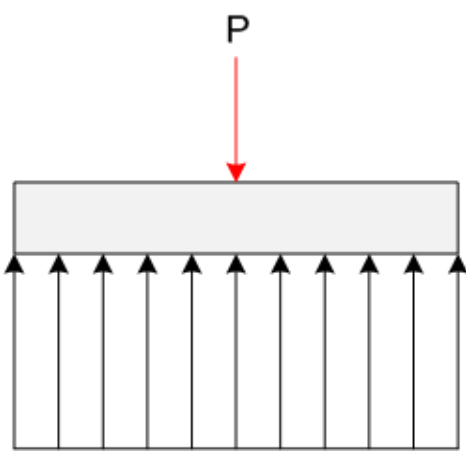

(a) Uniform Pressure

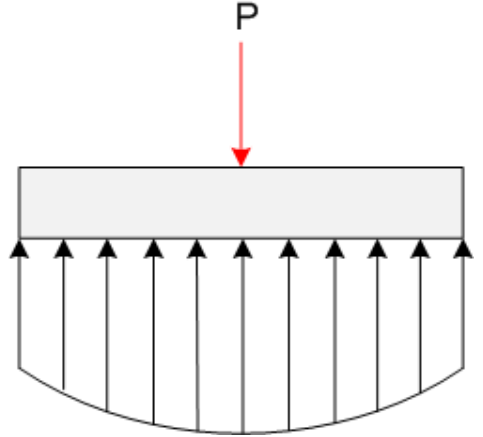

(b) Sandy Soil Non-Uniform Pressure

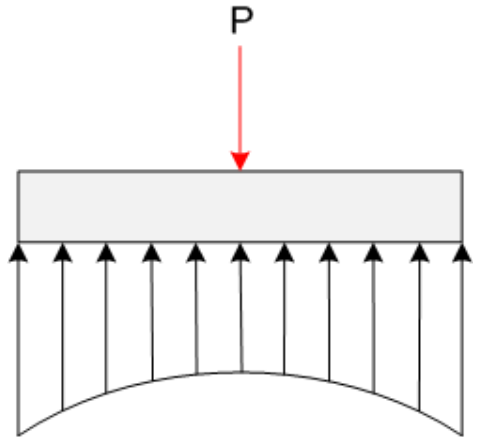

(c) Clay Soil Non-Uniform Pressure

Figure 6.15: Soil Pressure Distributions [5]

The soil pressure under the grout layer is illustrated in Figure 6.16 and demonstrates the pressure 
peak zones under the TT railway system. As can be seen, the actual pressure distribution is clearly not uniform nor linearly distributed, which is due to the fact that rails are fixed at conicities of either 1:20 or 1:40 which therefore load the TT system at a slight angle. The supporting grout layer is not rigid, causing the peak displacement in the center of the beam where the load is greatest.

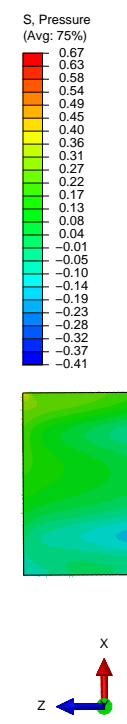

Figure 6.16: ABAQUS 3D Model Soil Pressure under Grout Layer

If the assumption was made that the soil pressure is linearly distributed as in the 2D beam models, the soil pressure obtained would be as illustrated in Figure 6.17. The soil pressure is obtained by using the deflections of the grout layer at its center line, and indicates a maximum soil pressure of approximately $118 \mathrm{kPa}$. 


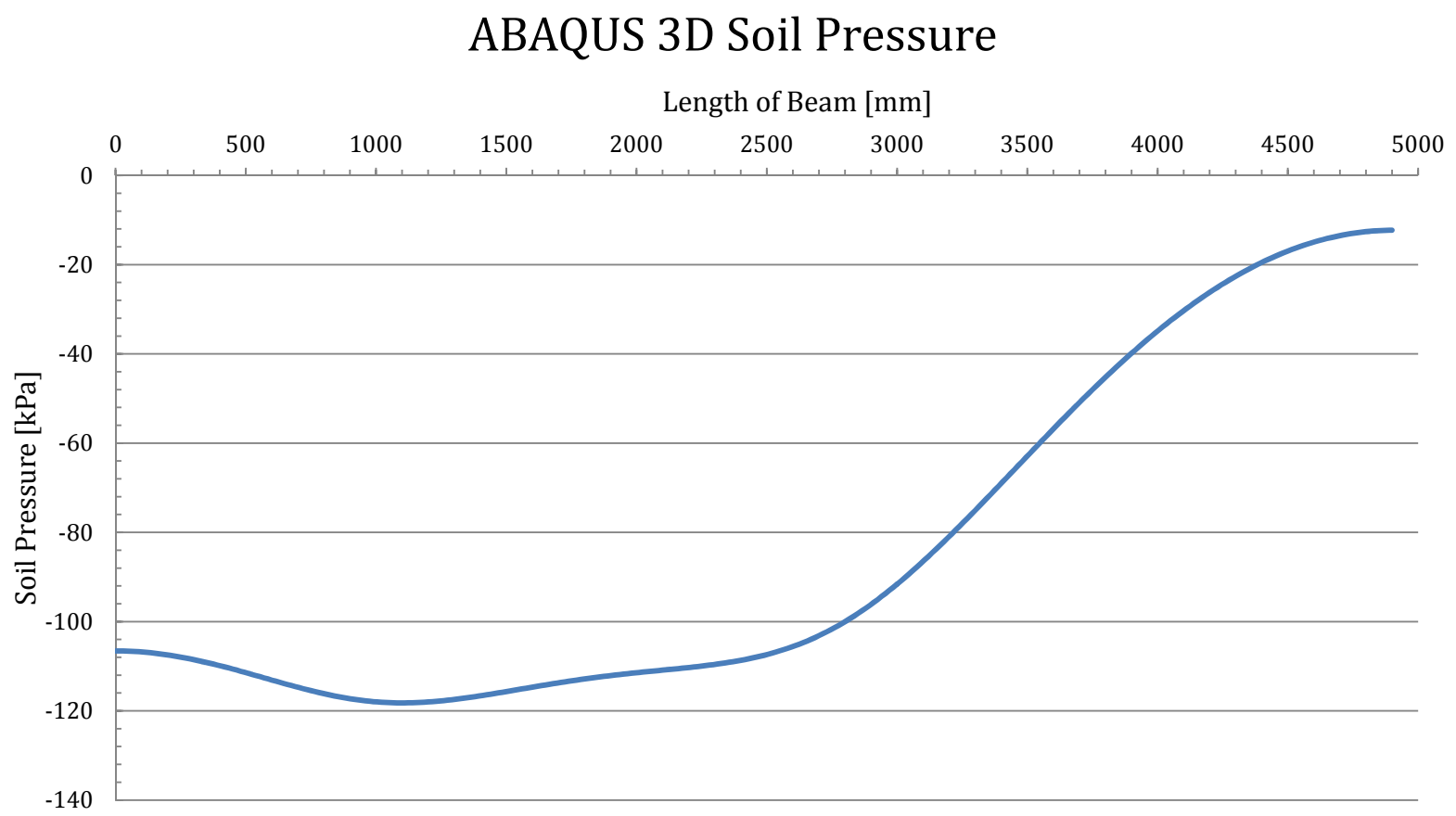

Figure 6.17: ABAQUS 3D Model Soil Pressure under Grout Layer

The pressure acting on the $\mathrm{RC}$ beam is illustrated in Figure 6.18 and demonstrates how much the load has been distributed from the top of the rails where it was a small distributed load. The railway components therefore successfully distribute the localised pressure at the point loads through the railway system's various components, which is the main purpose of the system. This occurrence reduces localisation of the shear forces in the rail and $\mathrm{RC}$ beam and allows for more effective design of the steel reinforcement in the RC beam.

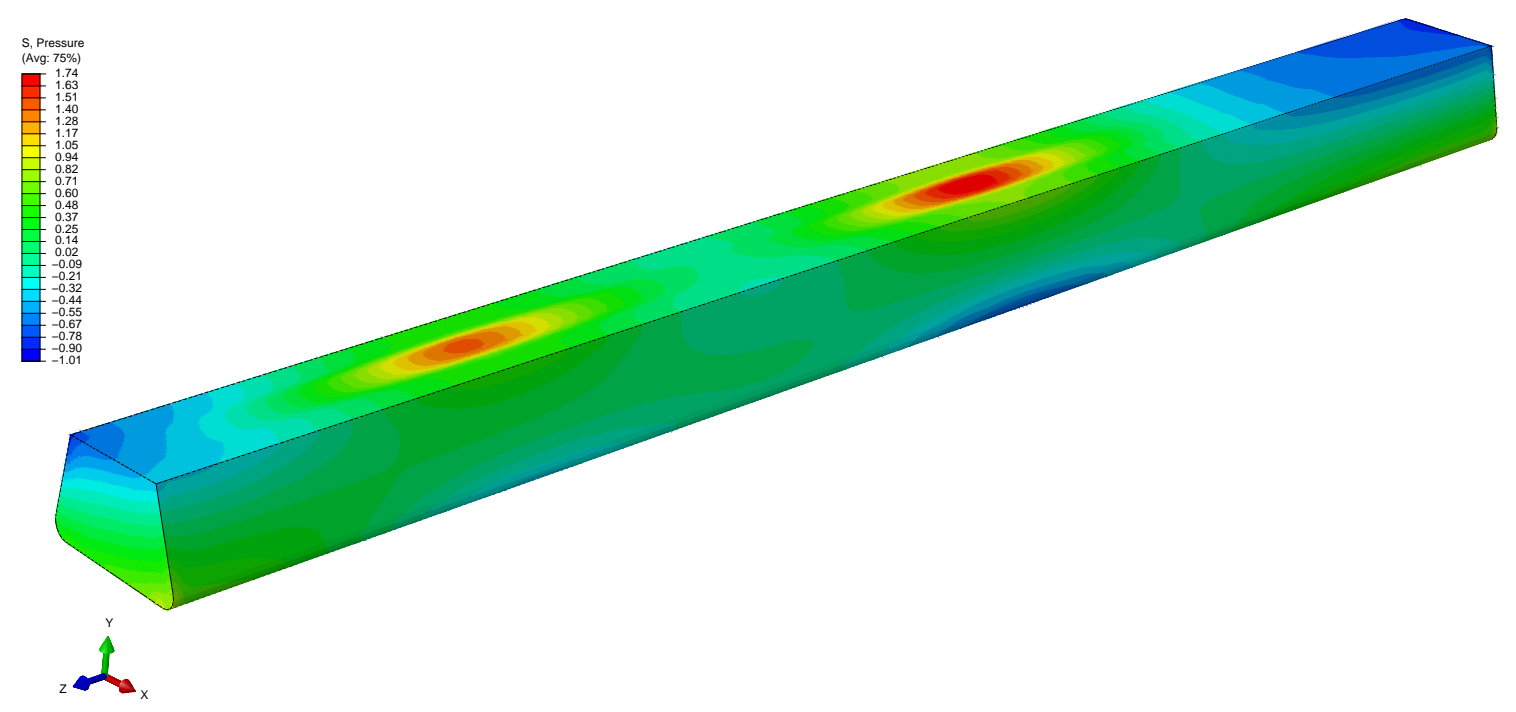

Figure 6.18: ABAQUS 3D Model RC Pressure 


\subsection{Conclusions}

This chapter investigated the usage of solid finite elements in ABAQUS which, similarly as the $2 \mathrm{D}$ beam FEA models, can be used to model the TT railway system. A static analysis is performed to analyse the displacements, bending moments (BM) and shear forces obtained from the FEA 3D model, which will be compared to the 2D beam and theoretical models investigated in Chapter 5. A summary of the results from the static 3D ABAQUS FEA is illustrated in Table 6.5

Table 6.5: ABAQUS 3D Results Summary

\begin{tabular}{lcccc}
\hline & $\begin{array}{c}\text { Maximum deflection } \\
{[\mathrm{mm}]}\end{array}$ & $\begin{array}{c}\text { Maximum BM } \\
{[\mathrm{kNm}]}\end{array}$ & $\begin{array}{c}\text { Minimum BM } \\
{[\mathrm{kNm}]}\end{array}$ & $\begin{array}{c}\text { Maximum Shear Force } \\
{[\mathrm{kN}]}\end{array}$ \\
\hline \multirow{2}{*}{ Rail } & 1.16 & 12.4 & -2.78 & 58.8 \\
RC Beam & 0.95 & 12.4 & -10.9 & 27.9 \\
\hline
\end{tabular}

A detailed investigation was performed to analyse the relationship between square PBTs and rectangular, infinitely long PBTs using 3D finite solid elements. A linear, statistically significant relationship was found between the PBT analysis methods, which can be used to modify the results of square PBTs of in-situ tests to represent the subgrade support of rectangular, infinitely long PBTs as required for modeling the TT railway system. 


\section{Chapter 7}

\section{Dynamic Finite Element Analysis}

\subsection{Introduction}

This chapter investigates the dynamic nature of the Tubular Track (TT) railway system by performing a dynamic analysis using a three-dimensional (3D) ABAQUS solid element model similar to the static model used in Chapter 6 .

\subsection{D Dynamic Tubular Track Model}

The purpose of the dynamic analysis is to obtain the maximum displacements, bending moments, and shear forces in the rail and RC beam caused by the passing bogies for investigation of the proposed DAF empirical method, and the comparison of the maximum dynamic displacement with the field test results. The DAF is also known as the deformation response factor, $\mathrm{R}_{\mathrm{d}}$, which is the ratio of the dynamic displacement, $\mathrm{u}_{0}$, to the static displacement, $\mathrm{u}_{\mathrm{st}}$, as indicated in Equation 7.2.1] [34].

$$
R_{d}=\frac{u_{0}}{u_{s t}}
$$

A dynamic analysis, unlike a static analysis, takes inertia and damping of the system into account. Dynamic analysis of a system can sometimes lead to resonance, depending on whether the applied load's frequency resembles one of the natural frequencies of a system. Structures are characterised by their response to frequencies and are dependant on the structure's mass, damping and stiffness [35]. Every non-conservative system exhibits some form of energy loss due to internal friction and nonlinear material behaviour [26]. Damping of the TT system is applied by means of the classic Rayleigh Damping method which is satisfactory for a linear system as is the case for this investigation. Rayleigh damping is an empirical method which is used to damp all frequencies. Damping is assumed to be a linear combination of the mass and stiffness matrices, and is in the following form:

$$
[C]=\alpha[M]+\beta[K]
$$


where:

$$
\begin{aligned}
\mathrm{C} & =\text { Damping matrix of the physical system } \\
\mathrm{M} & =\text { Mass matrix } \\
\mathrm{K} & =\text { Stiffness matrix } \\
\alpha & =\text { Mass-proportional constant } \\
\beta & =\text { Stiffness-proportional constant }
\end{aligned}
$$

The damping ratio, $\zeta_{\mathrm{i}}$, can additionally be calculated as follows [36]:

$$
\zeta_{i}=\frac{\alpha}{2 \omega_{i}}+\frac{\beta \omega_{i}}{2}
$$

Where $\omega_{i}$ is the natural circular frequency of the system for the $i^{\text {th }}$ mode. The damping ratio is therefore proportional to the natural frequencies of the system.

The mass-proportional damping constant, $\alpha$, dominates for low frequencies, whereas the stiffnessproportional constant, $\beta$, dominates for high frequencies [26]. The magnitudes of these damping factors play a large role in this type of analysis where the loads are well below ultimate and serviceability limit states.

In an implicit analysis such as the one performed in this section, numerical damping is also applied in order to obtain convergence. The Hilber-Hughes-Taylor integrator as used in this analysis allows the adjustment of the numerical damping magnitude by modifying the $\alpha$ parameter. Setting the $\alpha$ to 0 results in no damping, and therefore applies the Newmark $\beta$-method, with $\beta=0.25$ and $\gamma=0.5$. Maximum damping is applied when the $\alpha$ value is set to $-1 / 3$, and gives a damping ratio of about $6 \%$ when the time increment equals $40 \%$ of the period of oscillation [26]. Damping in an implicit dynamic analysis can therefore be applied as material and numerical damping.

The dynamic behaviour of a railway track can be simulated by solving the equations of motion fully at each of a series of time steps with very small increments [12]. The dynamic analysis is performed by applying static loads with time-dependant amplitudes. This is done by applying a factor to the load at specific times when a wheel bogey is passing the point on the beam. The four wheels with the closest proximities (two wheels at ends of two adjacent vehicles) traveling at approximately $43 \mathrm{~km} / \mathrm{h}$ are used for the dynamic analysis, as these will produce the greatest combined displacements. The effect of the other loads are negligible after a short distance and time, and can therefore be ignored. The loading positions are spaced at $100 \mathrm{~mm}$ increments, as illustrated in Figure 7.1. The $100 \mathrm{~mm}$ increments were found to provide acceptable accuracy as well as analysis time. An illustration of one of the amplitude loads is shown in Figure 7.2 . illustrating the four wheel loads passing the point. The total length of the FEA model used for the dynamic analysis is $4900 \mathrm{~mm}$, which is similar to the length of the static analysis. The actual length should actually be equal to the distance between the inner bogies of a train vehicle (4343 $\mathrm{mm}$ for the CR11 vehicles), but as proven previously when the load is more then $2000 \mathrm{~mm}$ from 
a point, the displacement it causes at said point is negligibly small. Choosing a longer length is therefore acceptable, and can also be used for comparison with the static analysis.

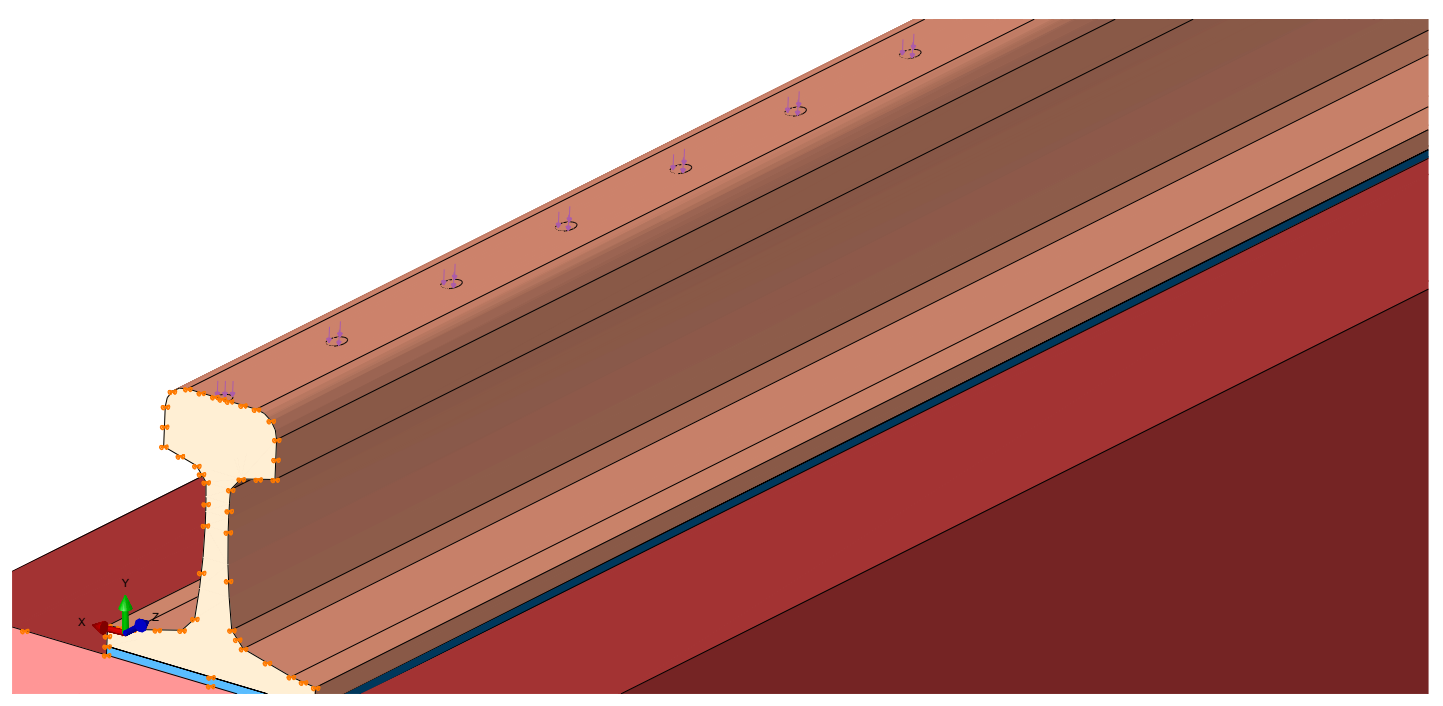

Figure 7.1: Loading Positions of Dynamic Model

\section{Load Amplitude}

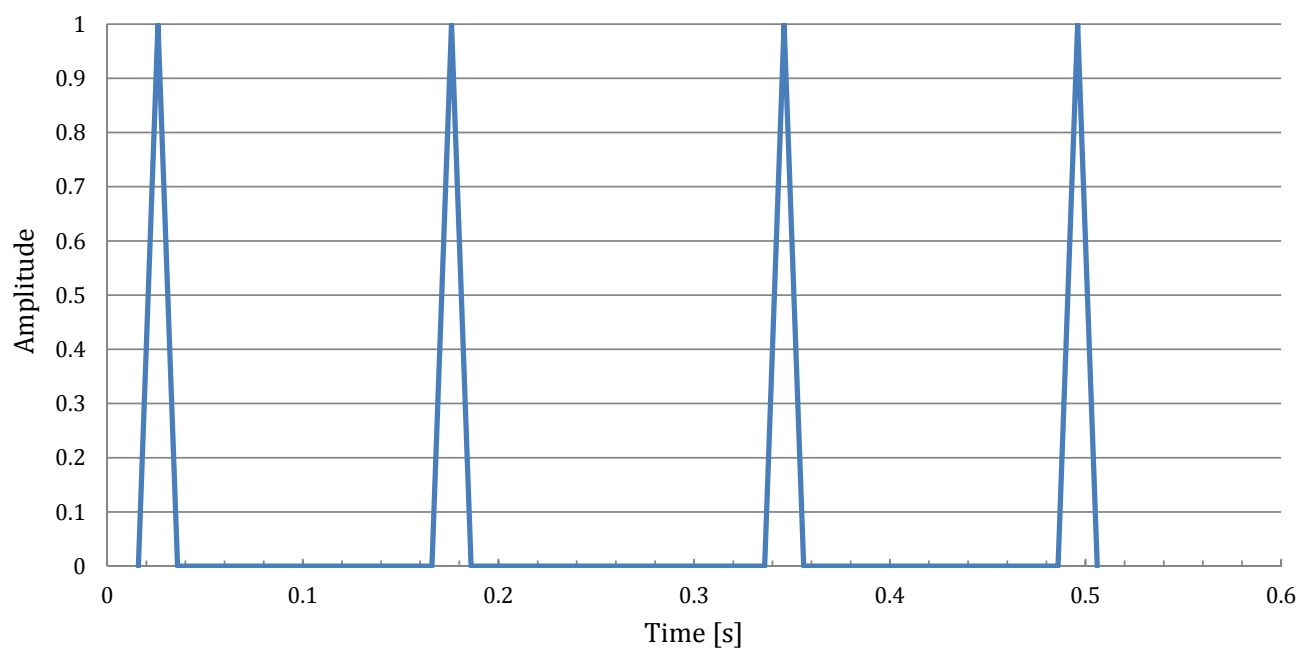

Figure 7.2: Example of a Load Amplitude

\subsection{D Model Dynamic Analysis Results}

In order to verify the accuracy of the dynamic analysis it was compared to the results from the static analysis. The influence of the damping is firstly investigated as this has a significant influence on the obtained results, especially bending moments and shear forces with sharp peaks as found for the rail in static FEA. The load excitation frequencies have previously been proven to 
be well below the natural frequencies of the TT system. The presence of resonance is therefore highly unlikely, allowing the disregard of damping in these analyses. Removing the damping means that the only difference between the static and dynamic analysis is the inertial effects present in the dynamic system. The influence of the damping factors and inertia are investigated by performing a sensitivity analysis using the static and dynamic analysis methods for varying conditions as follows:

\subsubsection{Dynamic Sensitivity Analysis}

As stated previously, the response of the 3D dynamic FEA model is dependant on the magnitude of the damping and also the time which the the nodes are actively loaded. The time which a node is loaded is required in order to obtain the best approximation of actual conditions, as the actual movement of a load is not feasible for modeling. This is due to the fact that the loads are applied to small elliptical areas, which influence the mesh of the model. Since the meshing cannot be modified during an analysis, the loads have to be spaced at certain intervals. A sensitivity analysis is therefore required to investigate the response of the system for varying time increments and damping magnitude. The $\Delta \mathrm{t}$ parameter used in the sensitivity analysis represents the the time it takes for a node to be fully loaded to having no load, and is analysed as being either $0.004 \mathrm{~s}$ which means a nodal load is zero before the next node is loaded, or $0.008 \mathrm{~s}$ which means the nodal loads overlap, as indicated in Figure 7.3 .

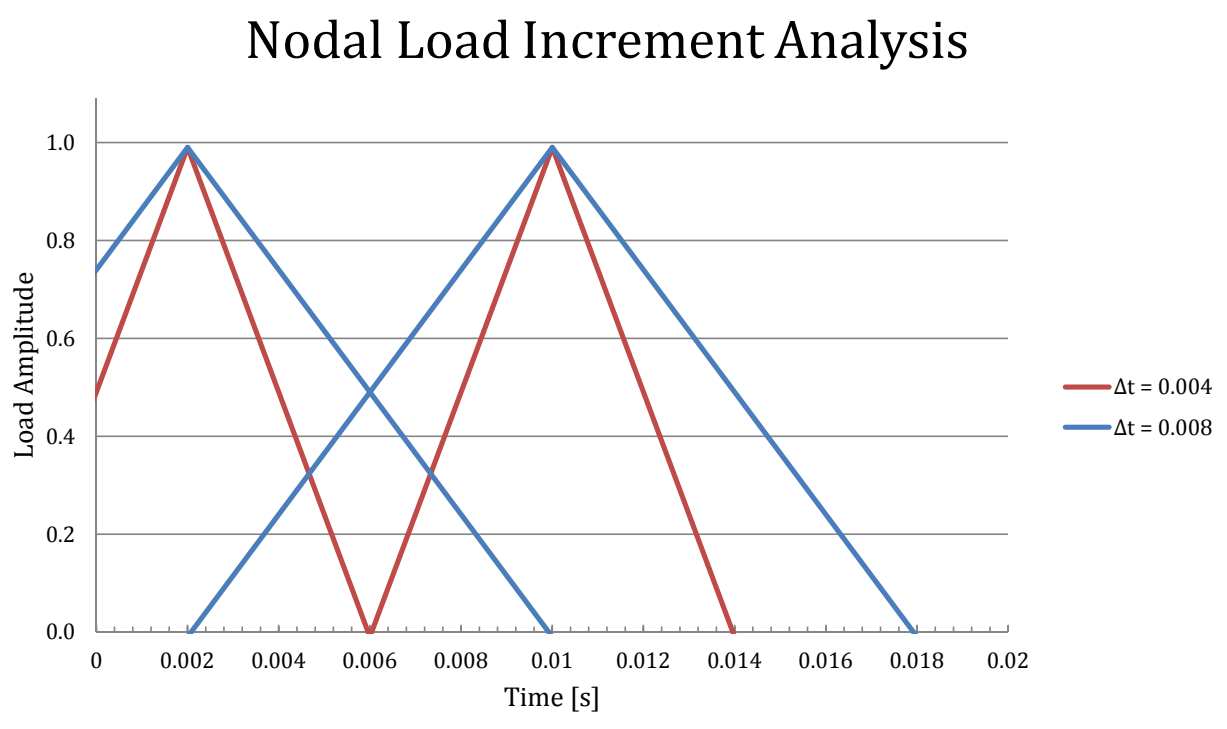

Figure 7.3: Nodal Load Increments

The sensitivity analysis is performed by analysing a TT railway section based on the static model, but which is only $500 \mathrm{~mm}$ in length. The time between the dynamic loads are such that inertia does not influence the results, therefore simulating a static analysis unless damping is also applied. The only varying parameters are therefore the time increments and damping magnitude. The optimum time step represents the time which a loading zone takes to reach 
its maximum from its minimum value, or vice versa. The influence of the time increment is investigated first by ignoring damping for the purpose of comparison with the static model. The results of the dynamic sensitivity analysis are compared to a similar static model for validation. Once the optimum time increment is obtained, the Rayleigh damping factors, $\alpha$ and $\beta$, can be incremented in order to investigate the influence of the damping on the full-scale 3D finite element model. The results of the dynamic sensitivity analysis are indicated in Table 7.1

Table 7.1: Dynamic Damping and Time Step Sensitivity Analysis

\begin{tabular}{|c|c|c|c|c|c|c|c|}
\hline & & & Rail & & & RC Beam & \\
\hline$\alpha, \beta$ & $\begin{array}{l}\Delta \mathrm{t} \\
{[\mathrm{s}]}\end{array}$ & $\begin{array}{c}\mathrm{w} \\
{[\mathrm{mm}]}\end{array}$ & $\begin{array}{c}\text { Bending } \\
\text { Moment } \\
{[\mathrm{kNm}]}\end{array}$ & $\begin{array}{c}\text { Shear } \\
\text { Force } \\
{[\mathrm{kN}]}\end{array}$ & $\begin{array}{c}\mathrm{w} \\
{[\mathrm{mm}]}\end{array}$ & $\begin{array}{c}\text { Bending } \\
\text { Moment } \\
{[\mathrm{kNm}]}\end{array}$ & $\begin{array}{c}\text { Shear } \\
\text { Force } \\
{[\mathrm{kN}]}\end{array}$ \\
\hline $\begin{array}{c}\text { Static } \\
\text { Dynamic }\end{array}$ & - & 3.68 & 5.36 & 36.94 & 3.24 & 0.32 & 3.03 \\
\hline 0.025 & 0.004 & 1.48 & 0.60 & 10.30 & 1.35 & 0.12 & 2.00 \\
\hline 0 & 0.008 & 3.67 & 5.37 & 20.30 & 3.24 & 0.38 & 2.95 \\
\hline 0.025 & 0.008 & 3.40 & 1.15 & 22.53 & 3.23 & 0.24 & 3.90 \\
\hline 0.05 & 0.008 & 3.37 & 0.69 & 14.77 & 3.23 & 0.13 & 1.10 \\
\hline 0.1 & 0.008 & 3.35 & 0.39 & 7.70 & 3.23 & 0.08 & 0.01 \\
\hline 0.2 & 0.008 & 3.33 & 0.21 & 3.93 & 3.23 & 0.06 & 0.00 \\
\hline
\end{tabular}

As can be seen in Table 7.1, the static analysis and dynamic analysis with no damping and $\Delta \mathrm{t}$ with a value of 0.008 correspond well, whereas the $\Delta \mathrm{t}$ value of $0.004 \mathrm{~s}$ does not obtain similar results as the static analysis. The optimum time increment is therefore proven to be $0.008 \mathrm{~s}$. The addition of damping with Rayleigh coefficients of $2.5 \%$ compared to no damping obtains a difference in displacements of approximately $8 \%$ in the rail and $0.3 \%$ in the RC Beam. The bending moments and shear forces are found to be very sensitive to the increase in damping, whereas the displacements are not as sensitive. This indicates that the damping magnitude to be applied in the dynamic analyses should be chosen with due consideration. The actual damping magnitude present in the TT system is unknown, and the determination of which falls outside the scope of this dissertation. The displacements of the TT system, though, are not very sensitive to the variation in damping, meaning the displacements can still be compared to the field test displacement results for the verification of the analysis models. The bending moments and shear forces are however sensitive to damping, comparing the bending moments and shear forces of the dynamic and static analyses for the verification of the DAF is therefore not possible.

\subsubsection{Full-Scale Dynamic FEA with no Damping}

The previous section investigated the influence of damping and time increment magnitudes, but the results obtained do not necessarily indicate that the bending moment and shear force 
diagrams are accurate when compared to a full-scale model. In this section the shape of the bending moments and shear forces are investigated for a model with no damping, in order to verify whether the bending moment and shear force diagrams obtained are also accurate when compared to a static FEA. The results of this investigation should conclude whether the dynamic model used for the analysis of the TT system is valid. The bending moments and shear forces are obtained for a specific time increments simulating the static load configuration to obtain the bending moments and shear forces in the rail and $\mathrm{RC}$ beam.

As can be seen in Figures 7.4 and 7.5 which illustrate the bending moment and shear force diagrams for when the time $=0.218 \mathrm{~s}$, which represents the time when the applied loading is similar to the static load configuration. As can be seen in Figure 7.4 the shapes of both the RC beam and rail are similar to the shapes obtained for the static analyses. The first load is applied at $992 \mathrm{~mm}$, whereas the second load is applied at $\mathrm{x}=2700 \mathrm{~mm}$. The first load, however, isn't active at the same time the second one is, which explains the lower bending moment and shear force at that location. The sharp peaks obtained in the results of the rail are similar as in the static models where damping isn't taken into consideration. These results thereby conclude that there are definite similarities between the static and implicit dynamic analyses.

\section{Bending Moment Diagram}

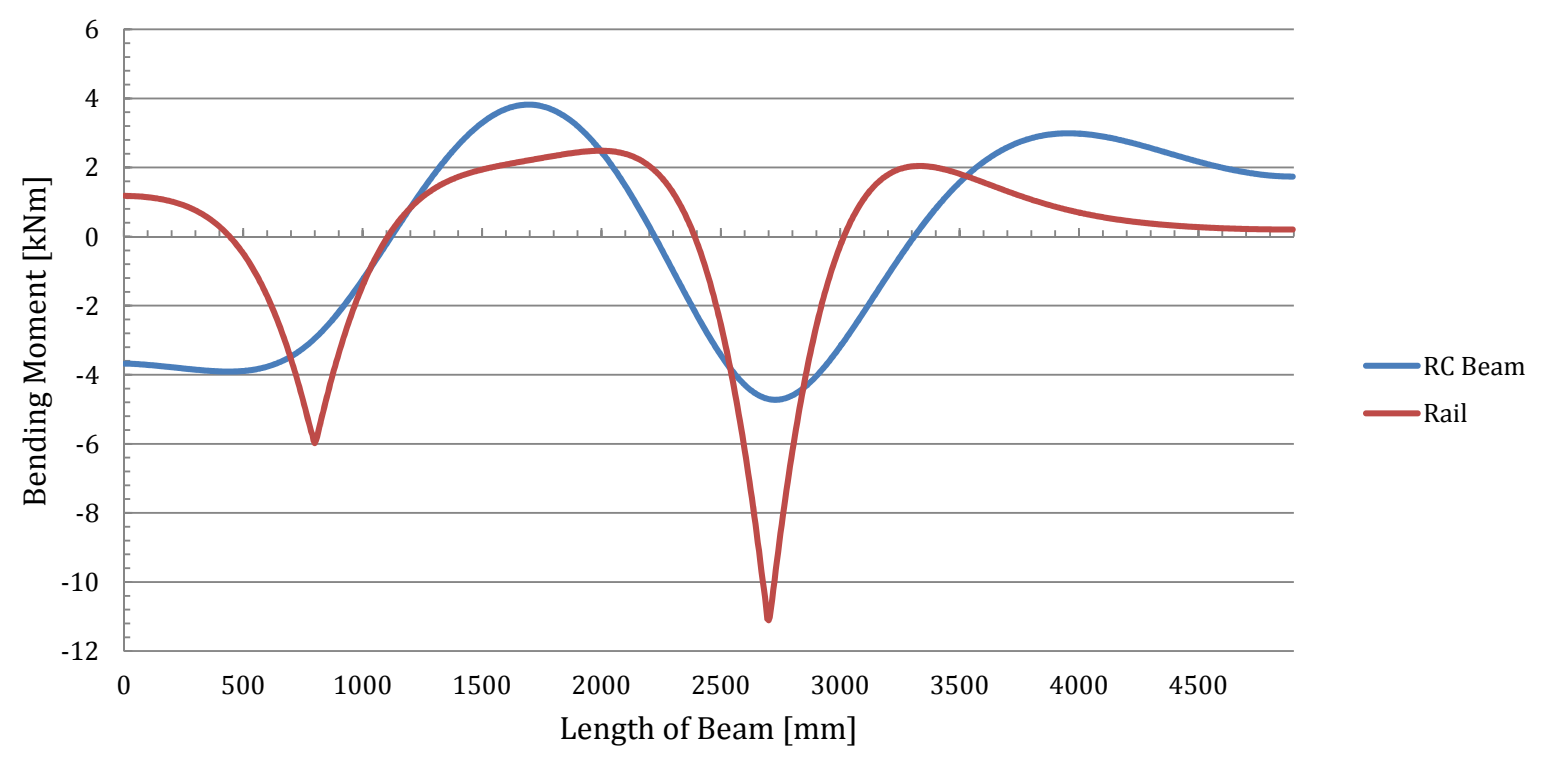

Figure 7.4: Bending Moment Diagram for $\mathrm{t}=0.218 \mathrm{~s}$ with no Damping 


\section{Shear Force Diagram}

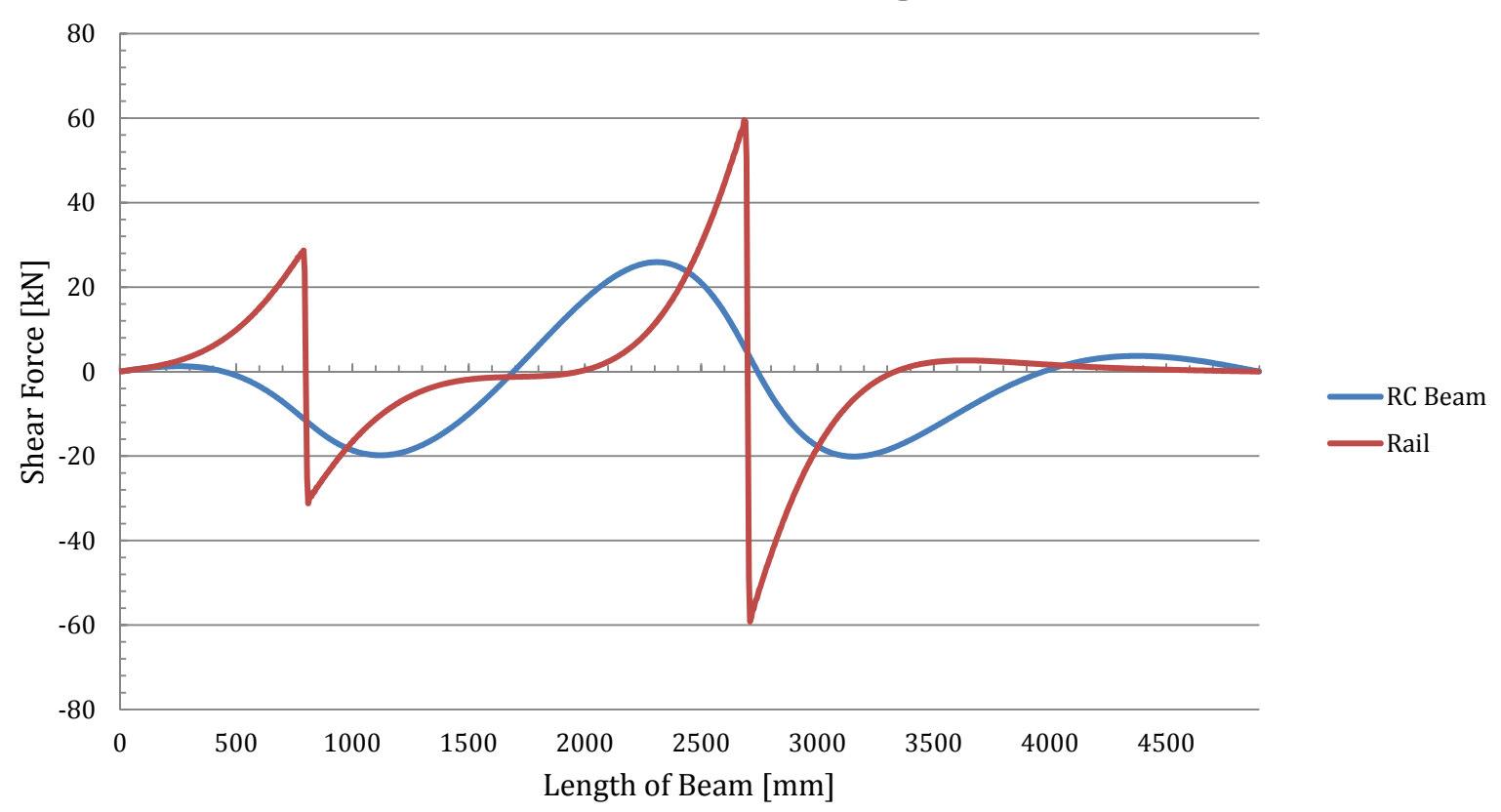

Figure 7.5: Shear Force Diagram for $\mathrm{t}=0.218 \mathrm{~s}$ with no Damping

\subsubsection{Dynamic FEA of TT System}

In the previous section it was shown that a time step $\Delta \mathrm{t}$ of $0.008 \mathrm{~s}$ is an acceptable choice for a dynamic loading analysis, as it achieves similar displacements as a static FEA for low damping coefficients. The bending moment and shear force diagrams are found to be very dependant on the damping coefficients, and can therefore not be used for the comparison of the implicit analysis and the static analysis applying the DAF. The full-scale dynamic FEA model investigated in this section is therefore based on these findings, and will be used for the comparison with the field test results in the following chapter. The Rayleigh material damping coefficients $\alpha$ and $\beta$ are set as $2.5 \%$ as the displacement in the $\mathrm{RC}$ beam is not sensitive to the damping coefficients. The displacements for the whole time step is obtained at the center of the beams underneath a loading area, and is illustrated in Figure 7.6. The time step in Figure 7.6 is representative of two loads passing that point of the system. The maximum displacement obtained for the RC beam is the most important result, as this will be used for the procurement of the DAF, and will subsequently be used for the comparison with the field test results. The maximum displacement in the $\mathrm{RC}$ beam is found to be $1.03 \mathrm{~mm}$. 


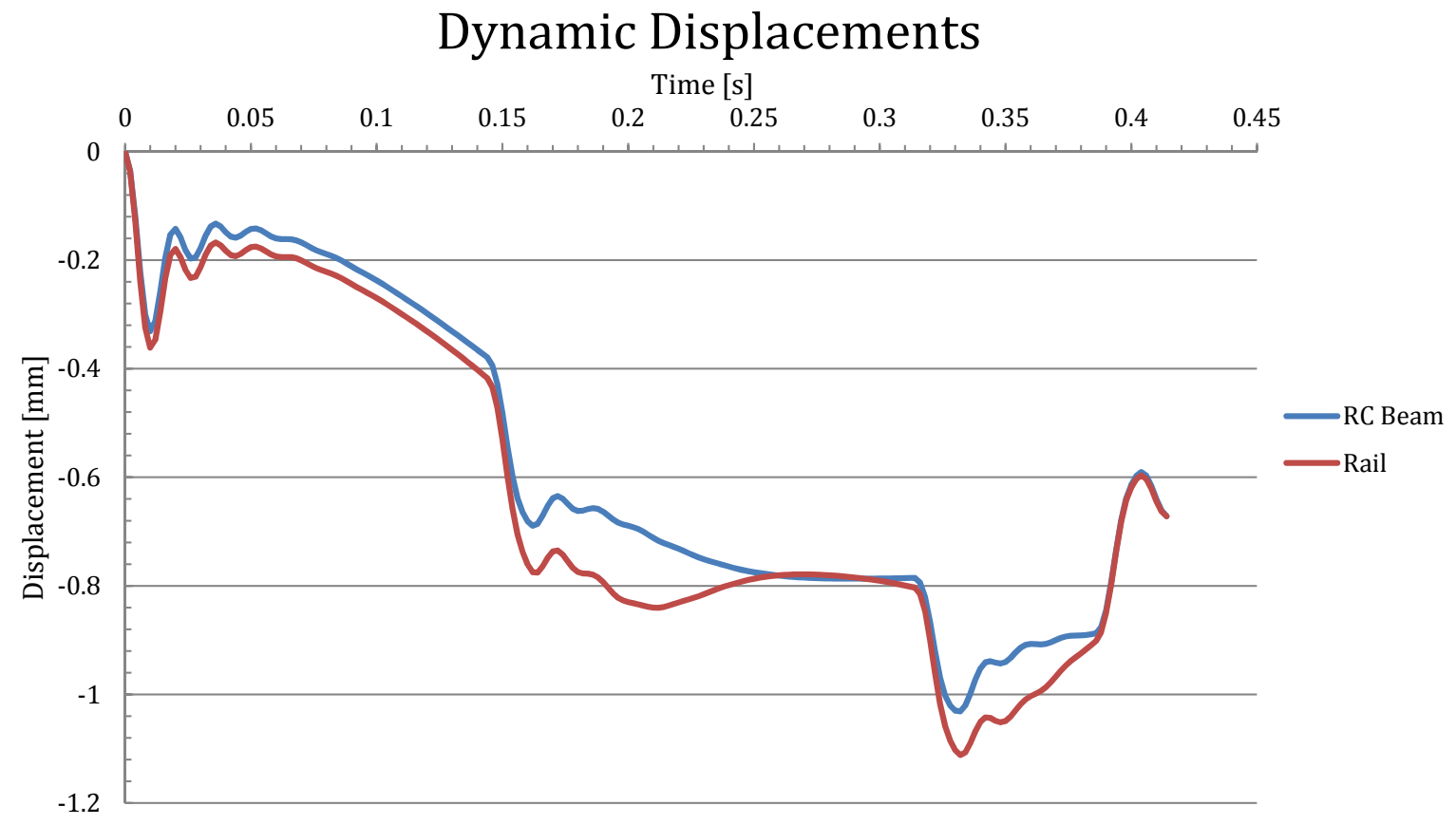

Figure 7.6: Dynamic Displacements

\subsection{Conclusions}

A sensitivity analysis is performed to investigate the sensitivity of the TT railway system to Rayleigh damping coefficients, as well as the optimum time step increment for the simulation of the dynamic loads. The optimum time step increment is found to be equal to the time it takes for the wheel to travel to the adjacent loading zone, whereby the the load of the acting wheel is never fully removed from the model.

The displacements of the $\mathrm{RC}$ beam are found not to be sensitive to the damping coefficients, whereas the rail is somewhat more sensitive. The bending moments and shear forces are found to be very sensitive to the magnitude of the damping coefficients, and should therefore be chosen with due consideration. A dynamic FEA is performed using the results of the dynamic sensitivity analysis to obtain the maximum displacement in the $\mathrm{RC}$ beam, which will be compared to the maximum displacement of the static analysis in Chapter 8 to obtain the DAF specific the Amandelbult Layout section 3, which will subsequently be compared to field test results to verify the accuracy of the modeling techniques to actual in-situ displacements. 


\section{Chapter 8}

\section{Evaluation of FEA Results}

\subsection{Introduction}

The comparison of the results obtained in Chapters 5 and 6 are performed in this chapter to verify the accuracy and validity of the various proposed modeling techniques for the purpose of recommending an analysis method(s) for future analysis and design of the Tubular Track (TT) railway system. The proposed empirical method used to amplify a static analysis to represent a dynamic analysis using a Dynamic Amplification Factor (DAF) is compared to an implicit dynamic analysis, as performed in Chapter 7, to determine the accuracy of the proposed empirical amplification method. The maximum displacement of the dynamic FEA is subsequently compared to field test results, in order to validate the finite element analysis (FEA) models investigated in this dissertation. A sensitivity analysis of the modulus of subgrade reaction and load magnitude is subsequently performed to determine whether and to what extent the TT railway system is sensitive to variations in these design parameters.

In the previous chapters it has been found that the interactions between the components play a large role on the results obtained. An investigation of a single beam is therefore performed in the following section to compare the analysis methods and modeling techniques without the interactions between the components playing a role, as there is only one component.

\subsection{Interaction Analysis}

A simple beam on elastic foundation analysis was conducted theoretically and analytically to determine the accuracy of the various analysis methods and their mesh densities. This comparison removes the influence of interactions between components by analysing a simple single beam on elastic foundation or spring support. The analysis involves a single square beam supported by an elastic foundation with a single point load as illustrated in Figure 8.1. This analysis should give a clear indication on how big a role the interactions between the components play.

For the purpose of this exercise, a square beam of $40 \mathrm{MPa}$ concrete which is $2000 \mathrm{~mm}$ in length 


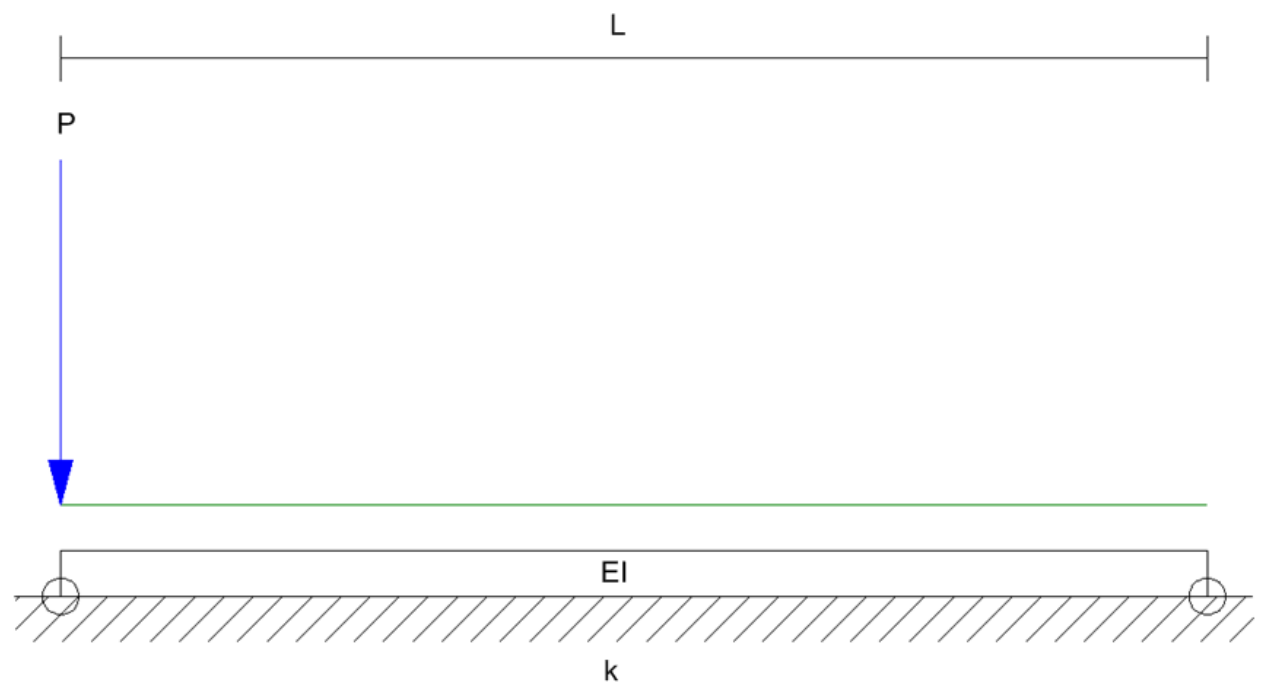

Figure 8.1: Single Beam Analysis Illustration

and $50 \mathrm{~mm}$ in width and height is used. The material properties of the beam are chosen as follows:

$$
\begin{aligned}
\mathrm{E} & =28 \mathrm{MPa} \\
\nu & =0.3 \\
\mathrm{P} & =20 \mathrm{kN} \\
\mathrm{L} & =2000 \mathrm{~mm} \\
\mathrm{k} & =0.084 \mathrm{~N} / \mathrm{mm}^{2} \\
\mathrm{I} & =\frac{1}{12} b h^{3}=52.08 .10^{3} \mathrm{~mm}^{4}
\end{aligned}
$$

By applying Winkler's elastic foundation model as discussed in Section 3.1 .2 and derived in Section 3.1 .3 the theoretical maximum displacement, bending moment and shear force are calculated as follows:

$$
\begin{gathered}
w(0)=-\frac{P}{8 E I \mu^{3}}=-13.88 \mathrm{~mm} \\
M(0)=\frac{P}{4 \mu}=3.43 \mathrm{kNm} \\
V(0)=P=20 \mathrm{kN}
\end{gathered}
$$

Analysis models similar to the square beam were created using PROKON frame analysis and ABAQUS 2D beam and 3D solid elements. Illustrations of the PROKON frame analysis model and the ABAQUS 3D solid element analysis are illustrated in Figures $8.2 \mathrm{a}$ and $8.2 \mathrm{~b}$ respectively. 


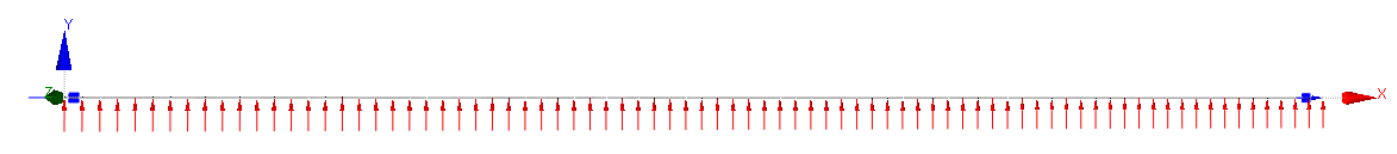

(a) PROKON Frame Analysis Model Illustration

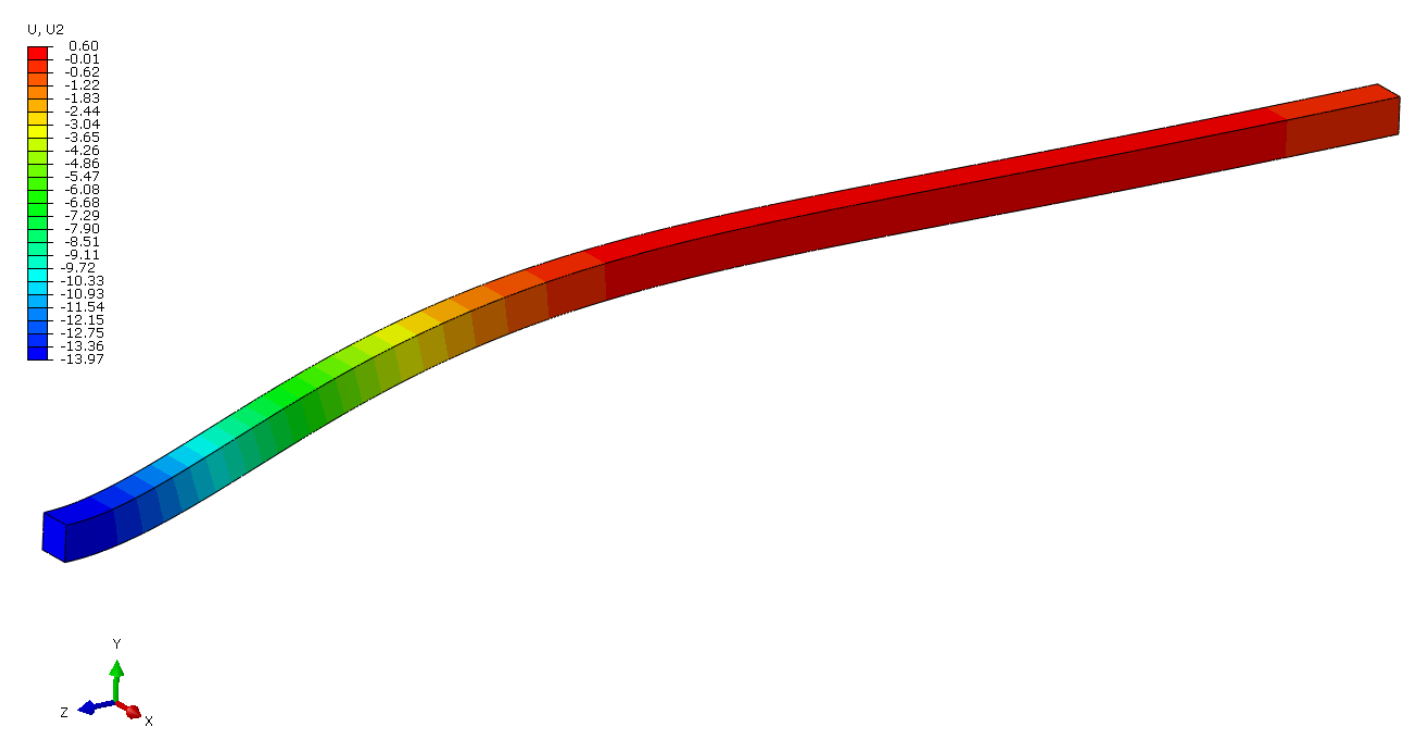

(b) ABAQUS 3D Beam Model Illustration Illustrating the Vertical Displacements

Figure 8.2: ABAQUS and PROKON Model Illustrations

\subsubsection{Interaction Analysis Results}

Figure 8.3 illustrates the vertical displacements of the various analysis methods, and indicates the similarities between the displacements of the various modeling techniques. The displacements of the various methods are exactly the same and match the theoretical results, and therefore validate the usage of spring support at the nodes of the beams used in the $2 \mathrm{D}$ beam analyses, as it provides similar results as the elastic foundations in the 3D solid analysis. Similarly as with the displacements, when the bending moment diagrams of the analyses are compared, as illustrated in Figure 8.4 it is concluded that the bending moments are also the exact same for the various analysis methods. Since the displacements and bending moments of the analysis methods are the same, the shear force diagram will also be as the shear force is obtained by integrating the bending moment diagram. The results obtained therefore indicate the similarity between the various analysis methods for a single beam. The only variation in results obtained using these analysis methods are therefore dependant on interactions between their respective components. 


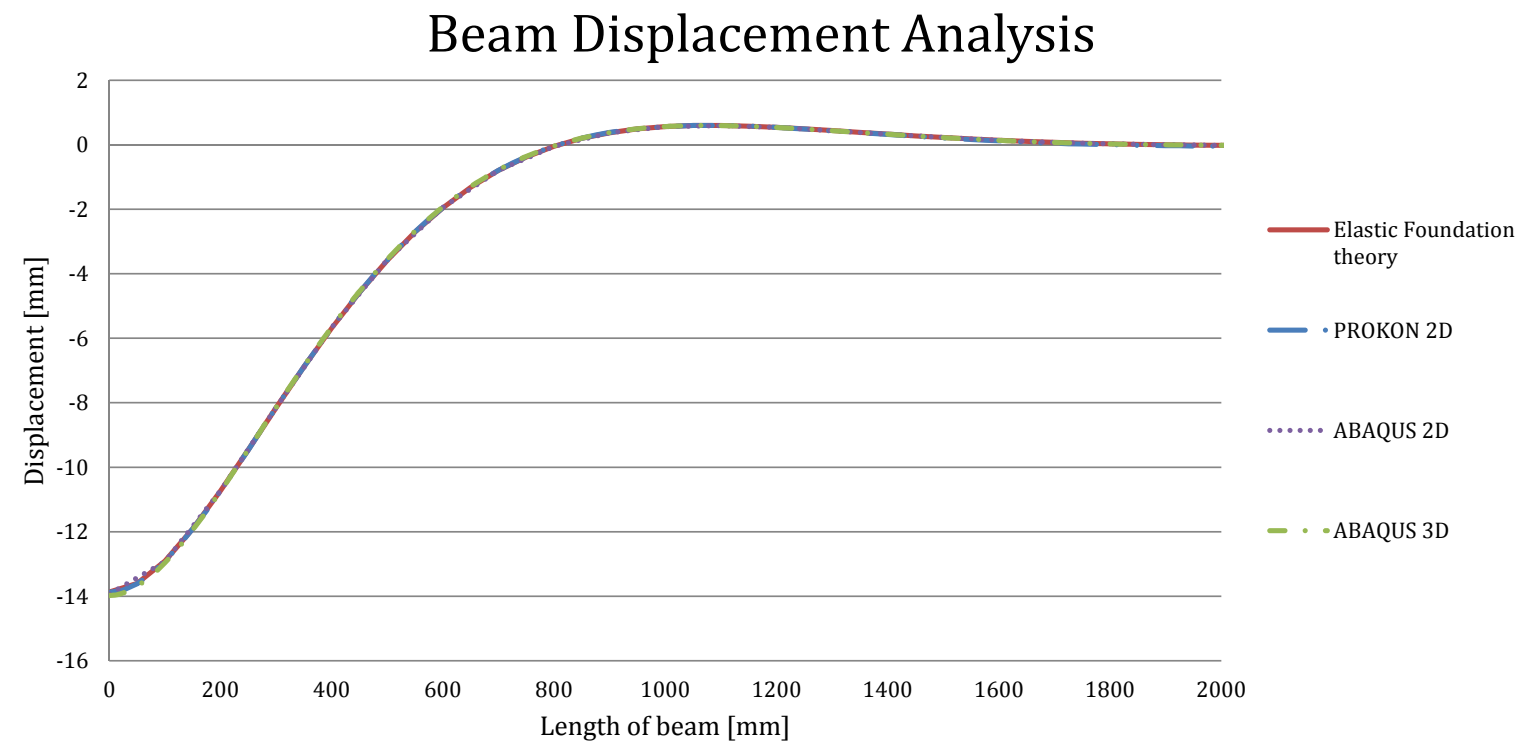

Figure 8.3: Comparison Between Displacements of Various Analysis Methods

Bending Moment Diagram

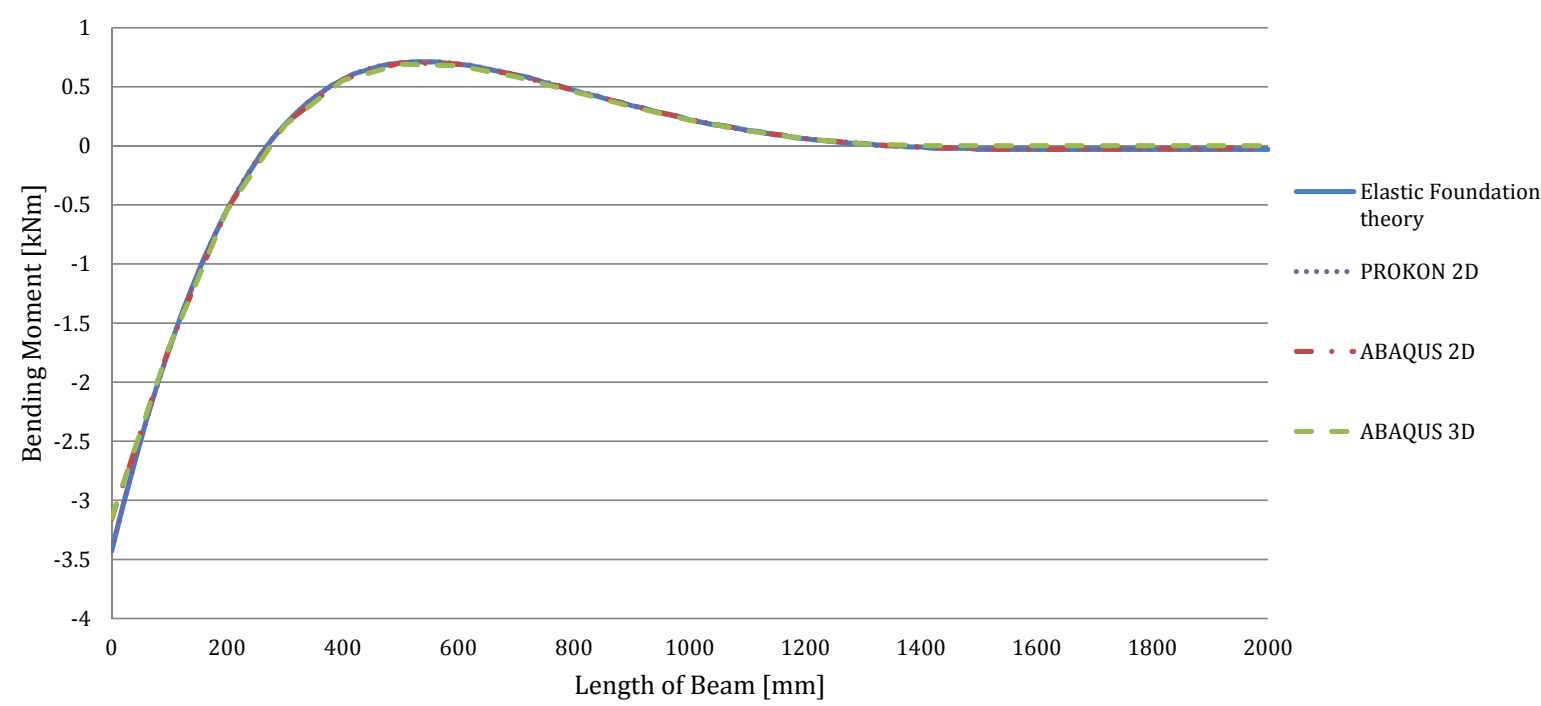

Figure 8.4: Comparison Between Bending Moments of Various Analysis Methods

When analysing the TT railway system which consists of several components i.e. the rail, reinforced concrete $(\mathrm{RC})$ beam, and grout; the effects of the interactions between the components are 
very important, due to the fact that the friction, slip and load distribution due to the elastomeric pad affect the results obtained. When using the Transformed-Section method one simplifies the beam system by removing the interactions between the various parts, thereby assuming that the system will have no slip or relative displacement between the parts. The localised deflections which occur in the rail due to the elastomeric pad are also nullified by using the TransformedSection method. This has the same effect as connecting the various beams with fixed rigid links, as opposed to pinned rigid links. This effect is illustrated in Figure 8.5 which represents the displacements of a TT railway system section subjected to a single load as investigated in the previous section. The results indicate a $29 \%$ difference in maximum displacement between the pinned and fixed rigid links, whereas the fixed rigid links obtain similar results when modeling the system as a single beam using the Transformed-Section Method. The maximum bending moments obtained are $10.92 \mathrm{kNm}$ for the fixed rigid links model and $28.59 \mathrm{kNm}$ for the pinned rigid links model, indicating a significant difference of $262 \%$ in maximum bending moment in the reinforced concrete $(\mathrm{RC})$ beam.

\section{Displacement Analysis}

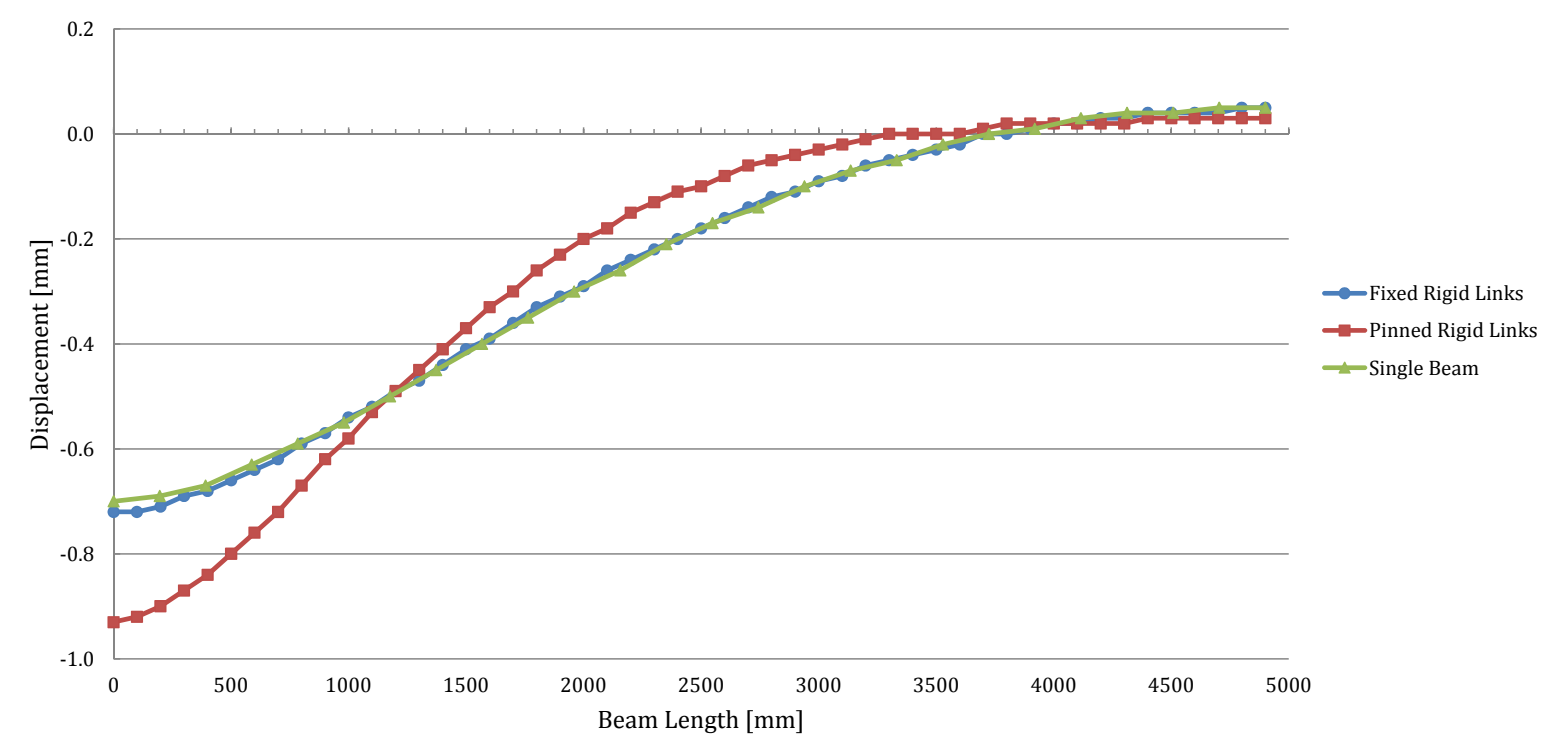

Figure 8.5: Comparison of the Effects of Rigid Links Connections 


\subsection{Comparison of Static Analysis Methods}

The comparison of the various FEA methods is performed in this section. Similarly to chapters 5 and 6 the focus will be on the rail and RC beam as these are the most important components for design of the TT railway system. The analysis models being compared are as follows:

- PROKON 2D Beam

- Single Beam on Elastic Foundation

- Double Beam Method

- ABAQUS 2D Beam

- ABAQUS 3D Solid Elements

\section{Displacement}

The displacement of the rail and $\mathrm{RC}$ beam are illustrated in Figures 8.6 and 8.7 respectively. As can be seen, there is a definite variation in curves between some of the analysis methods used. There are, however, similarities between the curves and values of the three analysis methods which takes the influence of the elastomeric pad into account, namely the Double Beam method, ABAQUS 2D beam, and the ABAQUS 3D solid element model which have maximum displacements in the rail of $1.24 \mathrm{~mm}, 1.19 \mathrm{~mm}$ and $1.17 \mathrm{~mm}$ respectively. One would assume that the ABAQUS 3D solid element model represents the most accurate simulation as it represents the most detailed model which takes more variables into account such as friction, shear deformation and small geometric deformation.

The maximum displacement of the 3D ABAQUS model rail and the Double Beam model rail vary by approximately $6 \%$, whereas the 3D ABAQUS and 2D ABAQUS models differ by 1.7 $\%$ which illustrate very similar results, as it can be assumed that a variation of less than $10 \%$ represents acceptable similarities. Due to the absence of the elastomeric pad in the PROKON $2 \mathrm{D}$ and Single Beam method, the displacement in the analysis models' rail shows very different results than the other more complex models mentioned earlier. As stated in Chapter 5 , the PROKON FEA model obtains the same displacement for the rail, RC beam, and grout layer due to the usage of pinned rigid links without the addition of the elastomeric pad's influence on the system. The displacements obtained by PROKON can therefore give a good representation of the deflections in the RC beam, but the rail's local deflections cannot be investigated. 


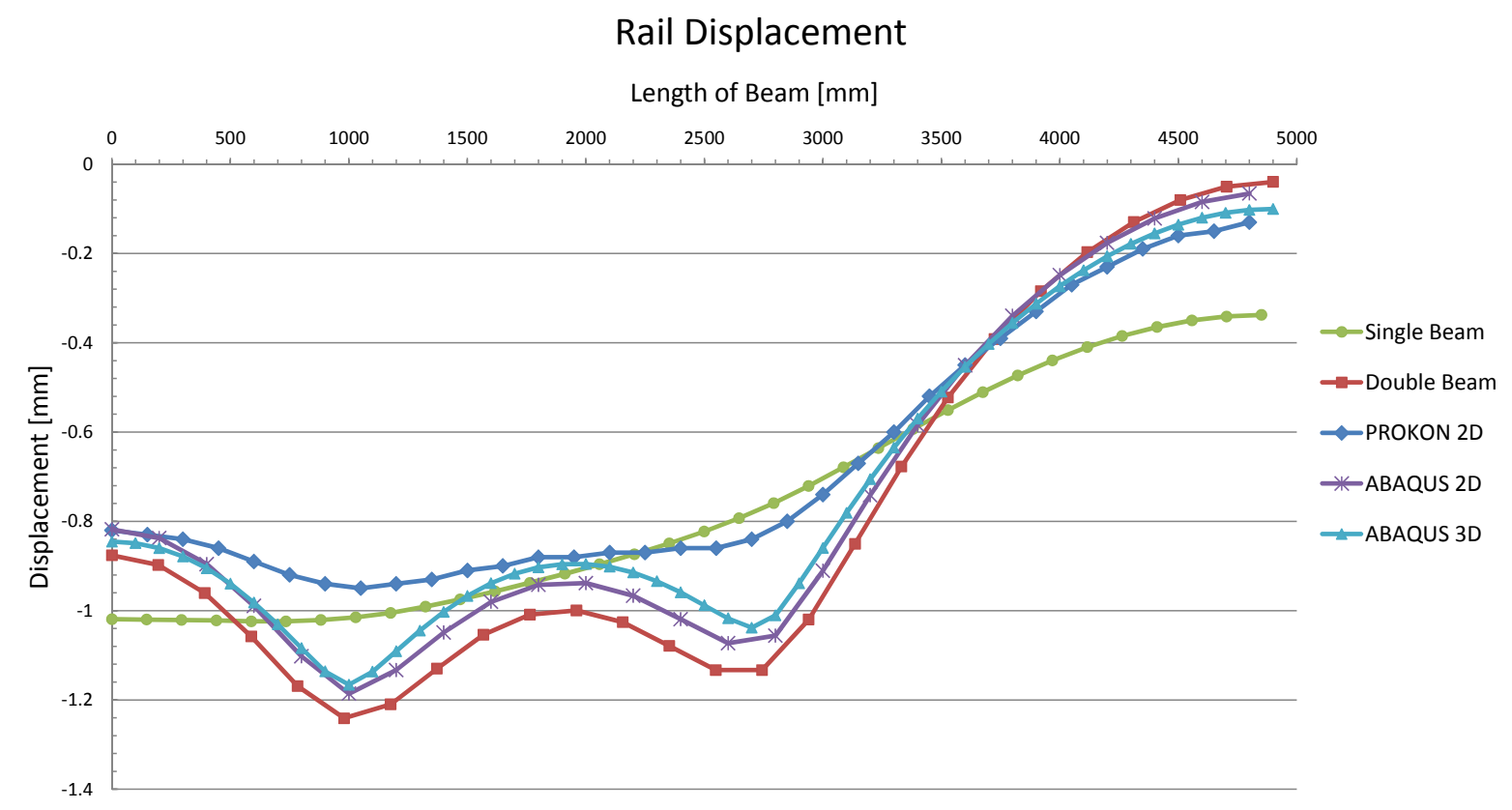

Figure 8.6: Rail Displacements

The variation in displacement curves in the RC beam illustrated in Figure 8.7 as opposed to the rail, shows much more similar results and maximum displacements with a maximum variation of $2 \%$ between the Double Beam methods, PROKON 2D, ABAQUS 2D and ABAQUS 3D. The Single Beam method is the only exception as it exhibits different results and curve to the other models used, due to the fact that the Single Beam model is equivalent to a system using fixed rigid links, as proven in Section 8.2 .

\section{Bending Moment Diagram}

The importance of the addition of the elastomeric pad is again indicated in the bending moment diagrams of the rail and $\mathrm{RC}$ beam which are illustrated in Figures 8.8 and 8.9 respectively. The bending moments of the Single Beam method are not illustrated in these figures, as it represents the total bending moment of the single beam, and can therefore not be used to analyse the separate components. The displacements of the Single Beam method can, however, be differentiated several times to obtain the bending moments and shear forces of the respective components, but these would not be accurate as the displacements obtained were already proven to be inaccurate. The differentiation would therefore be meaningless. A bending moment, as discussed in Chapter 3 represents the second integration of a displacement curve, meaning any small variation of the displacement causes a significantly larger variation in bending moment obtained, and even more so for a shear force.

Similarly as with the displacement results, the Double Beam method, ABAQUS 2D and ABAQUS $3 \mathrm{D}$ models show very similar bending moment results. The $2 \mathrm{D}$ PROKON model illustrates very 


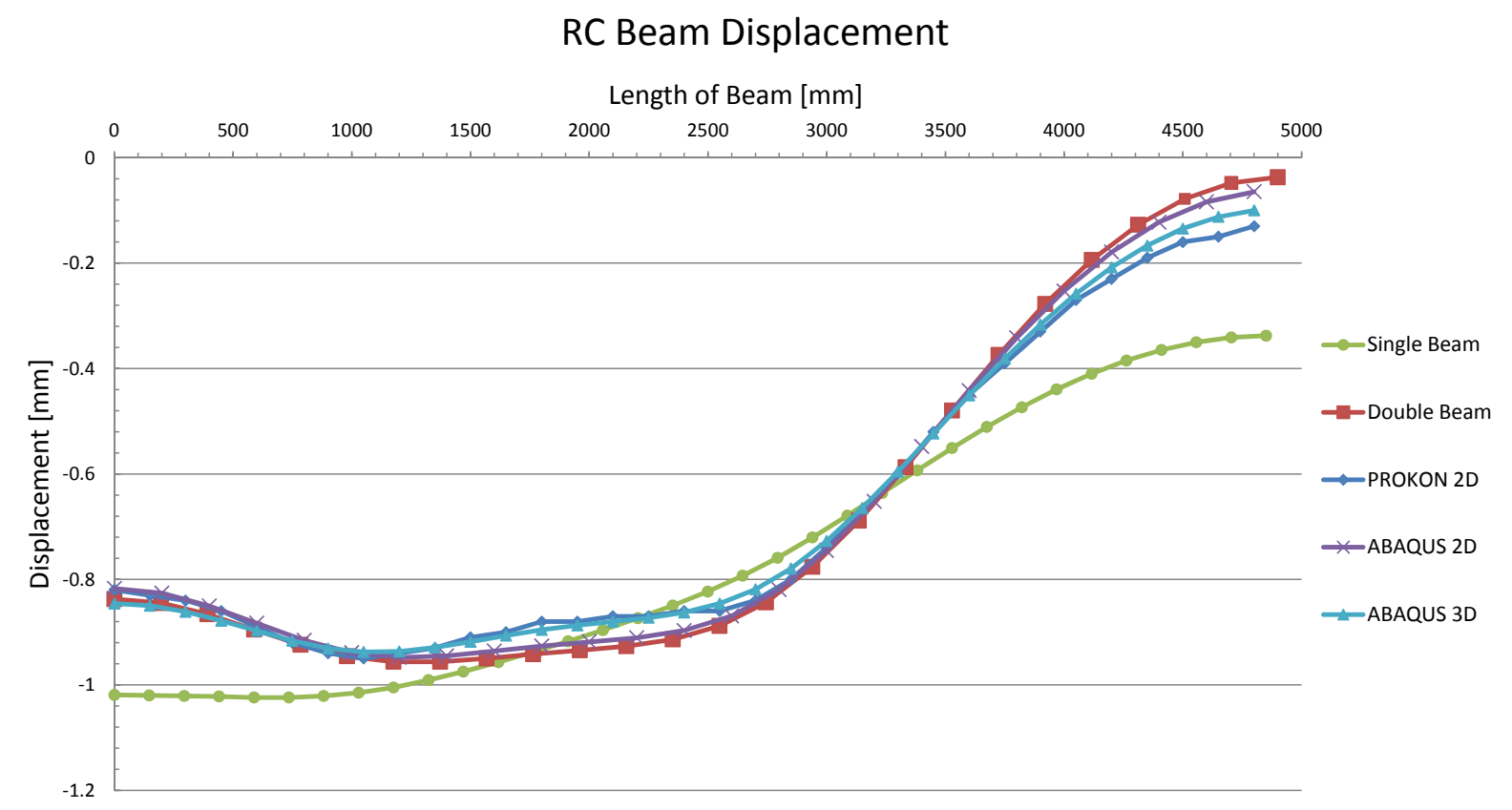

Figure 8.7: RC Beam Displacements

different results compared to the other models, with a maximum bending moment in the rail of $3.14 \mathrm{kNm}$, compared to $14.3 \mathrm{kNm}$ obtained for the Double Beam method, indicating a significant difference of $455 \%$. The maximum bending moments of the Double Beam method and ABAQUS 3D model have a variation of $8 \%$ whereas the ABAQUS 2D and 3D models vary by $17 \%$ which is more significant than the variation obtained in the displacement results. This variation seems quite large, but it has to be taken into account that these variations represents a difference of $2.1 \mathrm{kNm}$ and $1 \mathrm{kNm}$ respectively, which is not a significant amount for design. Similar results are obtained when analysing the minimum bending moments which indicates a maximum variation between the Double Beam method and ABAQUS 3D model being $47 \%$, but represents a difference of $1.3 \mathrm{kNm}$, which is insignificant for the design of the system. The Double Beam method is the model which illustrates slightly larger bending moments relative to the other models, and therefore represents the most conservative analysis method for design. 


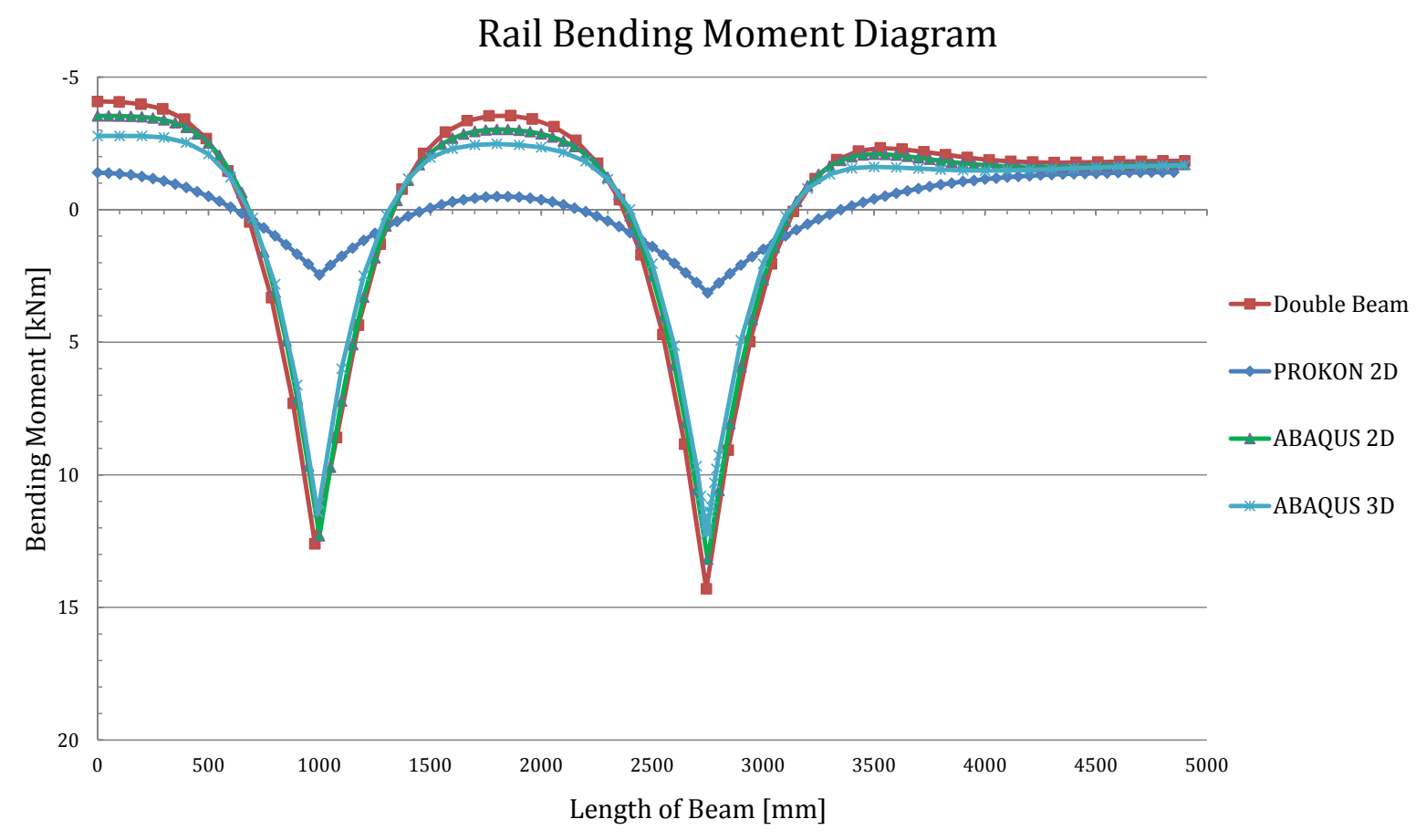

Figure 8.8: Comparison of Rail Bending Moment Diagrams

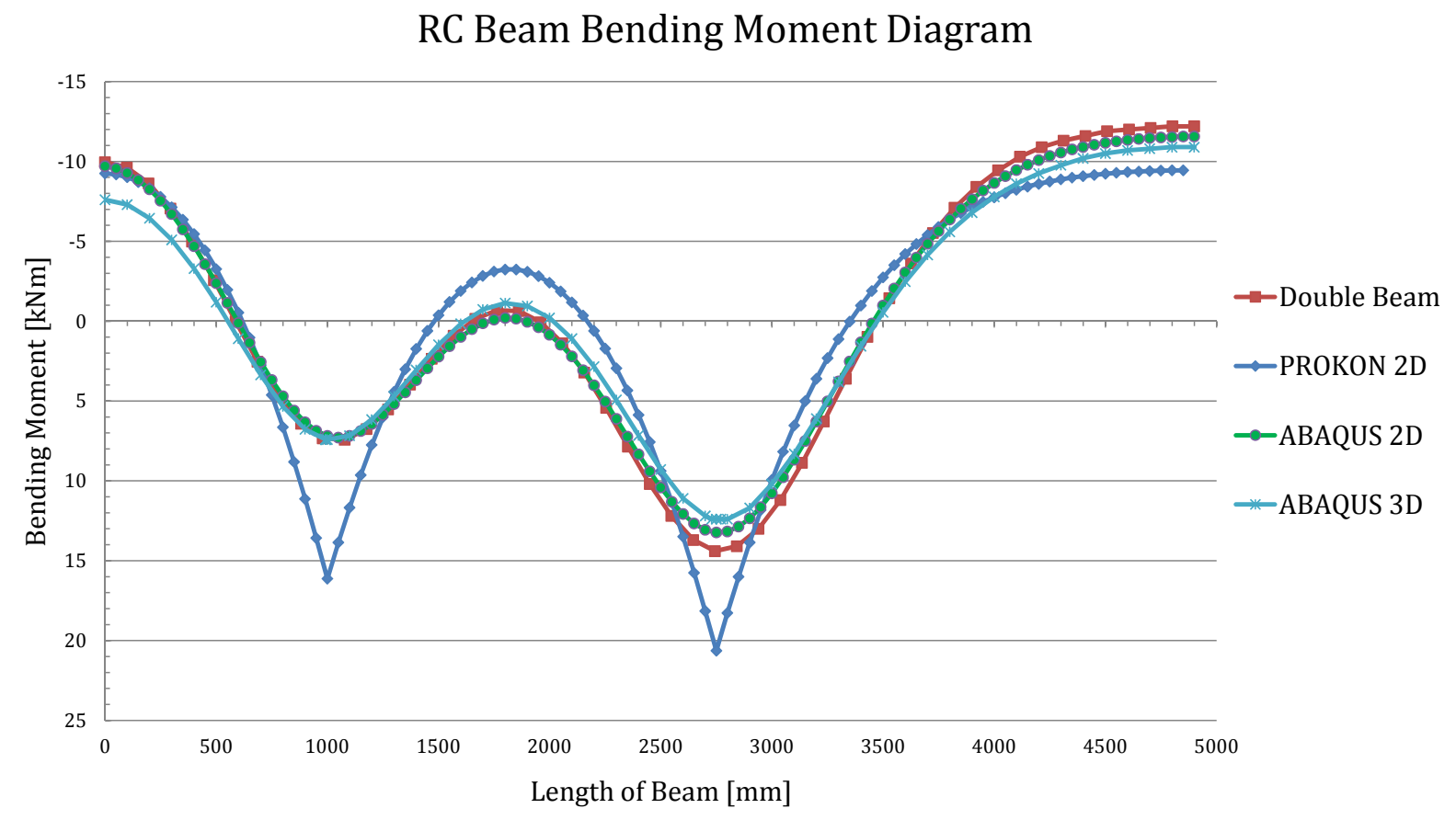

Figure 8.9: Comparison of RC Beam Bending Moment Diagrams

The bending moments in the $\mathrm{RC}$ beam illustrate the same similarities and variation between the analysis methods as found in the bending moment diagrams of the rail. Due to the addition of the elastomeric pad in the Double Beam method, ABAQUS 2D and ABAQUS 3D models, the 
bending moments in the RC beam do not demonstrate the sharp transitional pinnacles as the PROKON 2D model, but rather a more gradual curve. This effect is due to the load spreading effect of the elastomeric pad which reduces the maximum bending moment in the RC beam. The PROKON 2D model demonstrates that the largest bending moments are found in the RC beam while the rail has a relatively small maximum bending moment. The other models demonstrate dissimilar results, with the rail actually having a similar maximum bending moment as the RC beam. This outcome is due to the fact that the displacements of the beams in the PROKON $2 \mathrm{D}$ model require the usage of rigid links, which subsequently causes various components of the system to have the same displacements. As stated previously, the bending moment is the second integration of the displacement curve times the Young's modulus and moment of inertia of the beam, i.e.

$$
M=-E I \frac{d^{2} w}{d x^{2}}
$$

Since the bending stiffness, EI, of the rail is $3.64 \times 10^{12} \mathrm{Nmm}^{2}$, and that of the RC beam $2.41 \times 10^{13} \mathrm{Nmm}^{2}$, it is calculated that the bending stiffness of the RC beam is 6.6 times larger than that of the rail, and since the displacements are the same the bending moment of the RC beam must also be 6.6 times larger than the bending moment of the rail, which is the case. The results of the PROKON 2D model are therefore inaccurate due to the disregard of the elastomeric pad, and the model subsequently underestimates the maximum bending moment in the rail by a significant amount of approximately $320 \%$, whereas it overestimates the maximum bending moment in RC beam by approximately $56 \%$.

\section{Shear Force Diagram}

The shear forces, similarly to the bending moments, of the Single Beam method are not discussed or included in this section, as the shear forces discussed in this section are of the separate components and not the total shear forces of the whole beam. The shear force diagrams of the rail and $\mathrm{RC}$ beam are illustrated in Figures 8.10 and 8.11 respectively, and again show very similar results for the Double Beam method, ABAQUS 2D and ABAQUS 3D models with the maximum variation between these models' maximum shear values being $6.5 \%$ for the rail and $5.8 \%$ for the $\mathrm{RC}$ beam. The shear forces in the $\mathrm{RC}$ beam are distributed over a larger area, thereby decreasing the maximum shear force peak and does also not demonstrate the large sharp pinnacle as obtained by using the PROKON 2D model. The results of the PROKON 2D model is again dissimilar to the other models, which is to be expected. The shear force in a beam is calculated as follows:

$$
V=-E I \frac{d^{3} v}{d x^{3}}
$$

The bending stiffness of the RC beam is 6.6 times larger than that of the rail, resulting in the shear force in the RC beam being approximately 6.6 times larger than that of the rail due to the similar displacements of the two beams as calculated by PROKON. The shear force therefore determined by PROKON underestimates the maximum shear force in the rail by a very significant amount of approximately $570 \%$, and overestimates the maximum shear force in the RC beam by approximately $100 \%$. The maximum shear force in the rail is found to be approximately 
Rail Shear Force Diagram

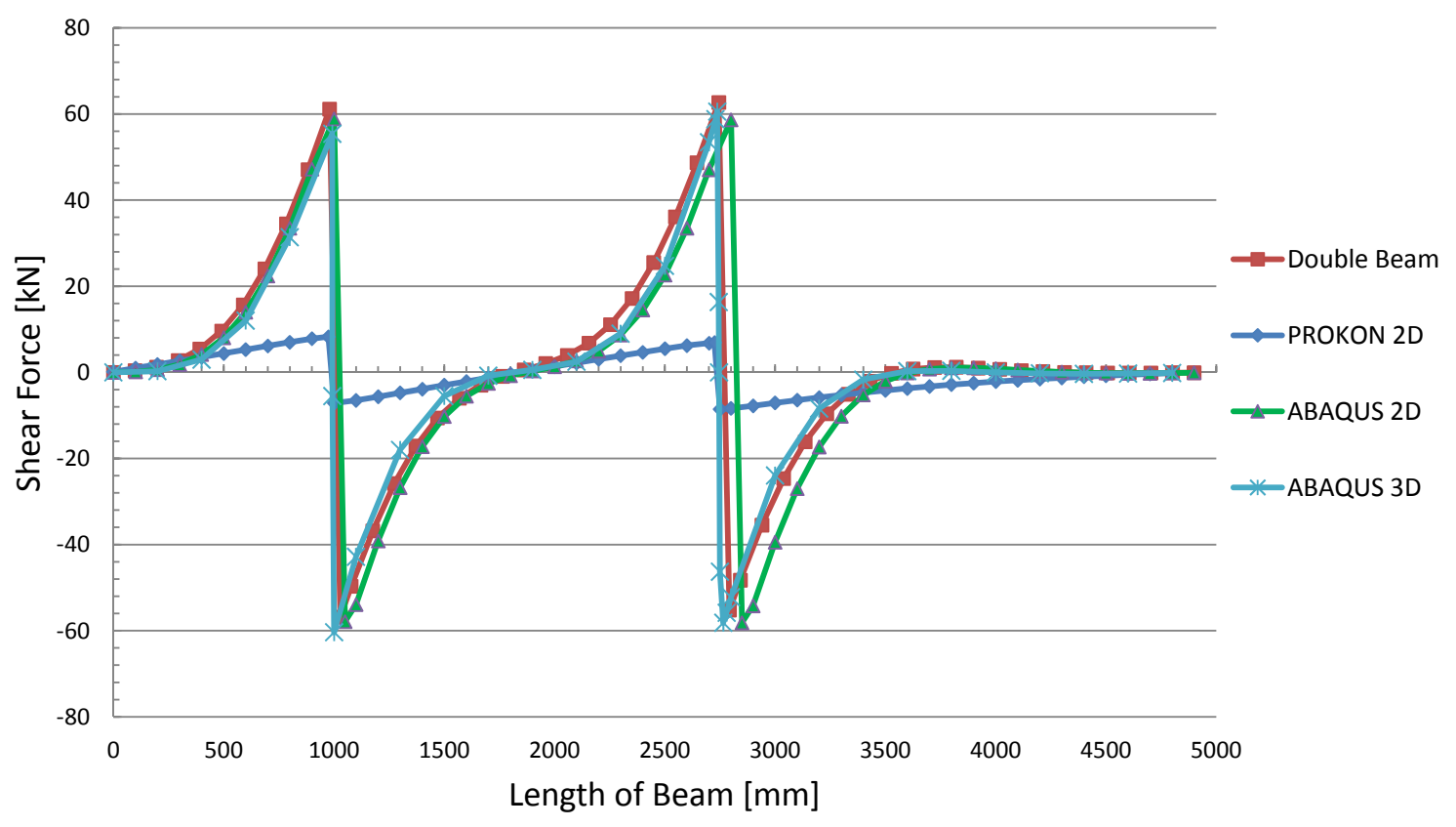

Figure 8.10: Comparison of Rail Shear Force Diagrams

$60 \mathrm{kN}$, whereas in the RC beam it is found to be approximately $26 \mathrm{kN}$.

\section{RC Beam Shear Force Diagram}

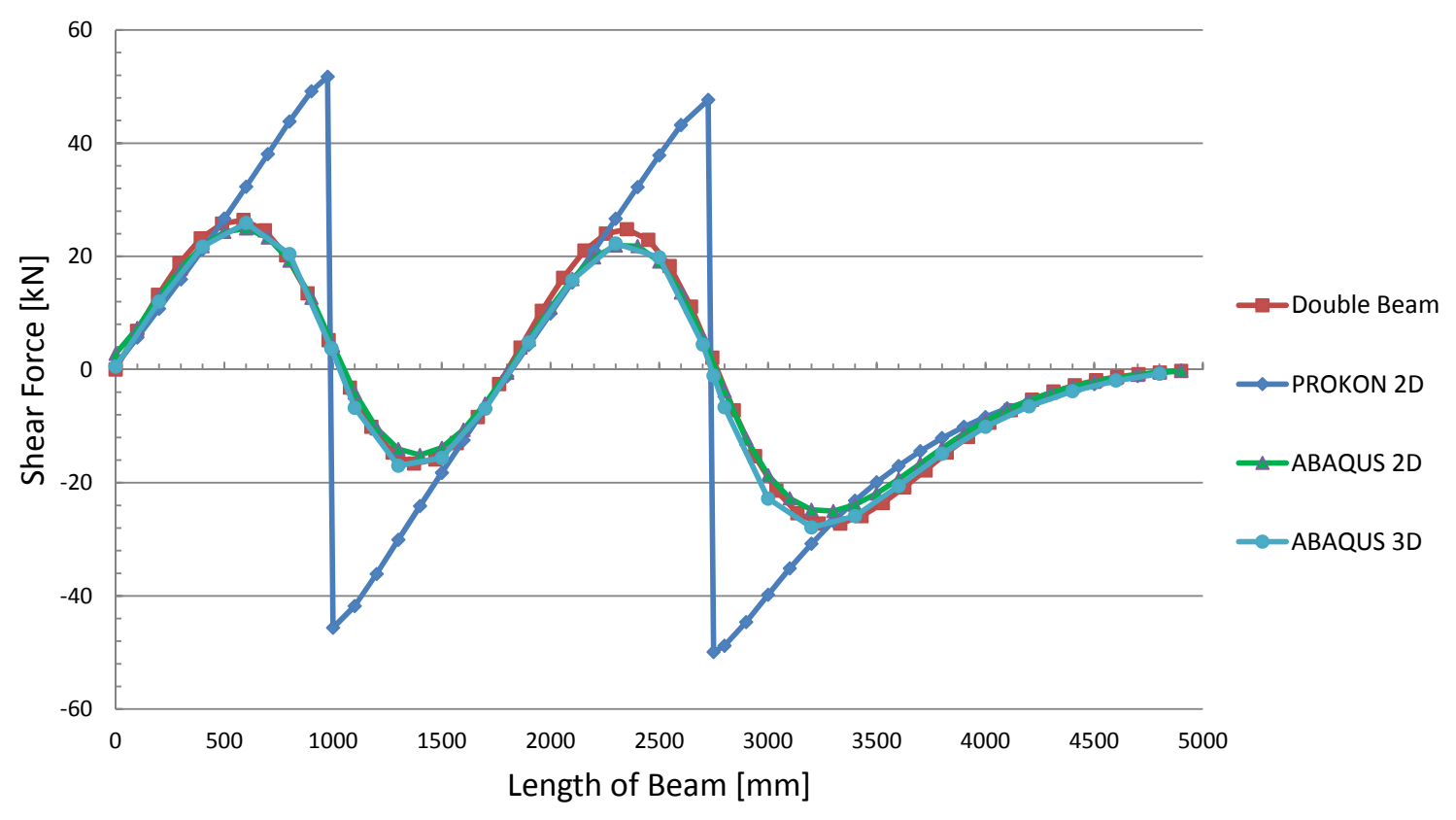

Figure 8.11: Comparison of RC Beam Shear Force Diagrams 


\section{Soil Pressure Distribution}

The soil pressure distributions of the various analysis methods are illustrated in Figure 8.12 , and show how all the models except for the Single Beam model obtain similar results and a maximum soil pressure of approximately $120 \mathrm{kPa}$. The soil pressure distribution is dependant on the deflections of the supporting layer and the modulus of subgrade reaction of the supporting subgrade.

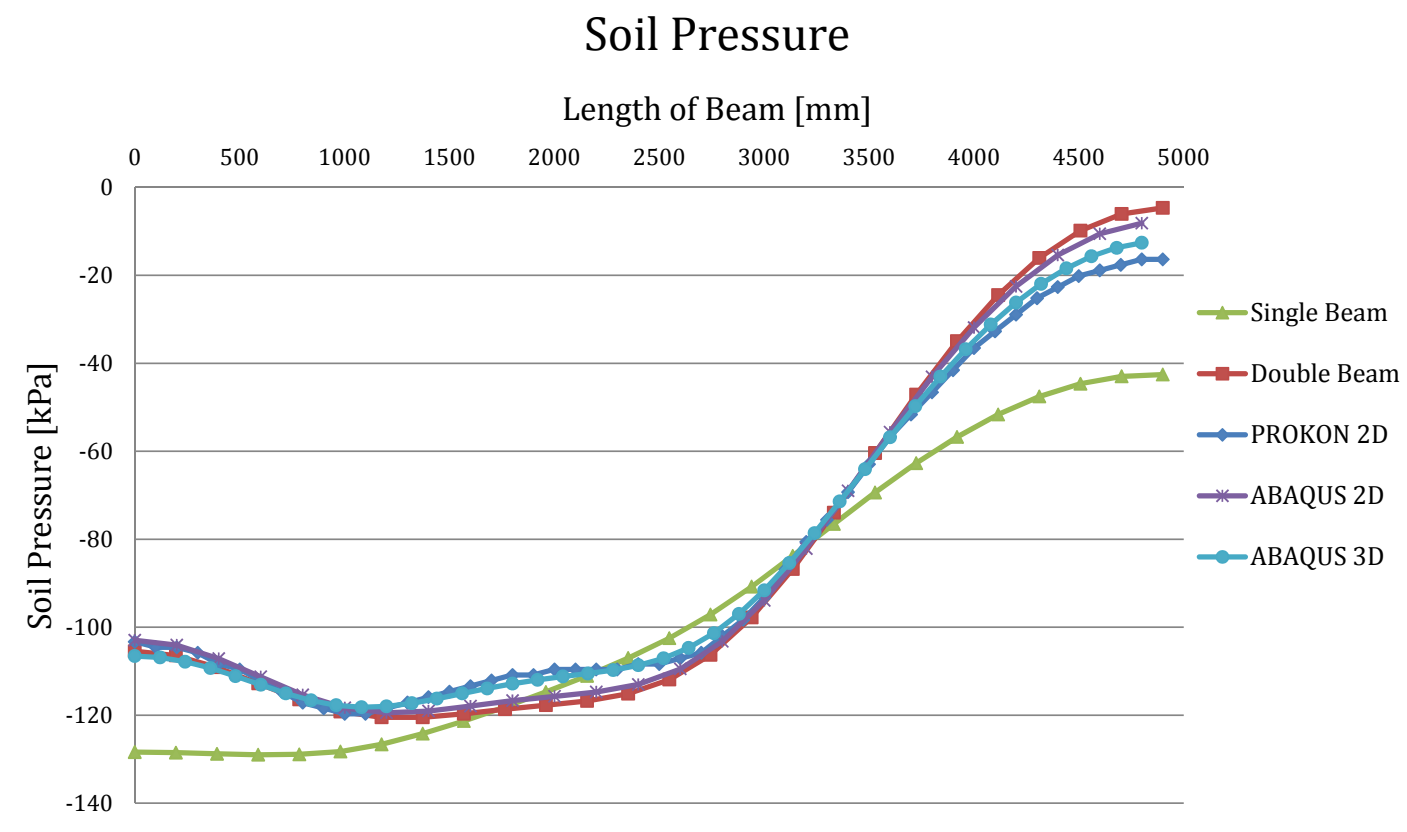

Figure 8.12: Comparison of Soil Pressure Distributions

\subsection{Dynamic Amplitude Factor Analysis}

It is important to note that the DAF used in this investigation is obtained by performing an implicit analysis to obtain the maximum displacement caused by dynamic loading. In practise the DAF is actually obtained by means of the empirical methods as described in Chapter 3 For the purpose of verifying the accuracy of the proposed analysis methods of this investigation, the empirical method cannot be used as this would obtain a DAF which is subjectively chosen by the analyst. The maximum displacement of the dynamic analysis, representing $u_{0}$, is calculated as $1.03 \mathrm{~mm}$, whereas the static analysis displacement, representing $\mathrm{u}_{\mathrm{st}}$, yields a $0.95 \mathrm{~mm}$ displacement in the RC beam. By applying Equation 8.4.1 as illustrated below, one can obtain the DAF of a respective railway section by using the static and dynamic displacements.

$$
R_{d}=\frac{u_{0}}{u_{s t}}
$$

By using the displacements as obtained for the Amandelbult Layout section 3, the deformation response factor, or DAF, of the RC beam is calculated as 1.084. The DAF is subsequently applied 
to a static load to simulate the dynamic effects of multiple bogies passing the loading point, as explained in Chapter 3.3 and illustrated in Equation 8.4 .2 below.

$$
P_{d}=D A F \times P_{s t}
$$

where

$$
\begin{aligned}
& P_{d}=\text { Dynamic load } \\
& P_{s t}=\text { Static load }
\end{aligned}
$$

This DAF can now be used for the comparison with the in-situ test results for the verification of the proposed analysis models, and is performed in the following section.

\subsection{Field Test Results Comparison}

The proposed analysis methods have been compared and verified relative to each other, and subsequently identified which analysis methods can be used to analyse the TT railway system accurately. The DAF specific to the Amandelbult Layout section 3 has been calculated in the previous section, and is applied to a static load for the purpose of validating the analysis methods. The results of the proposed analysis methods are to be compared to in-situ field test results to verify whether the results are accurate. This analysis is performed in this section, and ultimately investigates the accuracy of the proposed models relative to field test results.

The results of the in-situ deflection measurements at the Amandelbult Layout section 3, are shown in Table 8.1. The displacements represent the total deflection of 6 multi-depth deflectometers (MDDs) which were situated at various depths in the soil layers, and indicate the deflections measured at the passing of 8 bogies over the test site. 
Table 8.1: Amandelbult Layout Section 3 Deflection Measurements [7]

\begin{tabular}{ccc}
\hline $\begin{array}{c}\text { Time } \\
{[\mathrm{s}]}\end{array}$ & $\begin{array}{c}\text { Displacement } \\
{[\mathrm{mm}]}\end{array}$ & $\begin{array}{c}\text { Load } \\
{[\mathrm{kN}]}\end{array}$ \\
\hline 55.874 & 0.923 & 102.27 \\
56.025 & 0.867 & 98.36 \\
56.397 & 0.827 & 88.11 \\
56.547 & 0.852 & 92.41 \\
56.720 & 0.877 & 94.75 \\
56.871 & 0.877 & 99.24 \\
57.239 & 0.738 & 88.50 \\
57.388 & 0.786 & 74.93 \\
\hline Average $=$ & 0.843 & 92.32 \\
\hline
\end{tabular}

As can be seen in Table 8.1, the wheel loads and their respective displacements are relatively inconsistent. The average of the wheel loads and respective displacements are therefore used to represent an approximation of the average displacement. The average load, $92.32 \mathrm{kN}$, is multiplied with the DAF of 1.084 as obtained in Section 8.4 to represent an approximated dynamic load with the value of $100 \mathrm{kN}$. Once again, the Double Beam method is used to analyse this representative load at Amandelbult Layout station 3, although ABAQUS could also have been used. The displacement of the RC beam, as stated previously, is assumed to be equal to the deflection under the beam, as minimal geometric deformation occurs. The obtained displacement using the Double Beam method is calculated as $0.767 \mathrm{~mm}$.

This result indicates a difference of $9.8 \%$, or $0.075 \mathrm{~mm}$, between the in-situ deflection measurements, and the deflections of the dynamic Double Beam method analysis and is therefore considered be accurate relative to the approximated in-situ result. There are, of course, limitations to this comparative analysis, such as the variability of the bogey loads whereby the usage of the averaged bogey loads and deflections are required, and the unknown Rayleigh damping coefficients which have a lesser influence. Nevertheless, the similarity between the dynamic displacements and field test results are within an acceptable range, thereby verifying the usage of the elastic foundation theory, Double beam and ABAQUS 2D and 3D models for the analysis of the TT railway system. 


\subsection{Design Sensitivity Analysis}

The displacements, bending moments, and shear forces obtained from an analysis of the TT system are dependant on specific input parameters, such as the modulus of subgrade reaction as obtained from an in-situ plate bearing test (PBT) analysis, components' material properties and dimensions, and the magnitude of the bogey loads. The soil formations under the TT system are mostly irregular, and can therefore yield an unpredictable modulus of subgrade reaction magnitude depending on the location used for the PBT analysis. The bogey loads of train vehicles can also vary significantly, as trains and carriages have irregular and varying loads. The material properties and dimensions of the steel rails do not vary significantly, whereas for the concrete beams it can vary slightly, but not enough to obtain significant variation.

A sensitivity analysis is therefore performed in this section to investigate the sensitivity of the modulus of subgrade reaction and load magnitude on the maximum displacement, bending moment, and shear forces of the TT railway system using the Double Beam method. The Double Beam method has been proven to obtain similar results as the ABAQUS 2D and 3D FEA models, but is the easiest and most conservative to use. The sensitivity analysis model is based on the Amandelbult Layout section 3 model, although the results obtained are not specific to this model and demonstrate the relative sensitivity of a general TT railway section.

\subsubsection{Modulus of Subgrade Reaction Sensitivity}

The sensitivity analysis of the response of the upper and lower beams of the TT system, representing the rail and RC beam respectively, is performed by increasing the modulus of subgrade reaction from an extremely poor soil foundation to a very strong foundation. The maximum displacement, bending moment, and shear force is obtained for the respective modulus of subgrade reaction magnitudes.

\section{Maximum Displacement}

As can be seen in Figure 8.13 the maximum deflections are very sensitive to a modulus of subgrade reaction below $0.125 \mathrm{~N} / \mathrm{mm}^{2} / \mathrm{mm}$, and is relatively constant for higher values. Small variation in the modulus of subgrade reaction below $0.125 \mathrm{~N} / \mathrm{mm}^{2} / \mathrm{mm}$ obtains significant variation in displacement. The displacements become very large for a very poor subgrade stiffness, as expected. 


\section{Modulus of Subgrade Reaction Sensitivity Analysis}

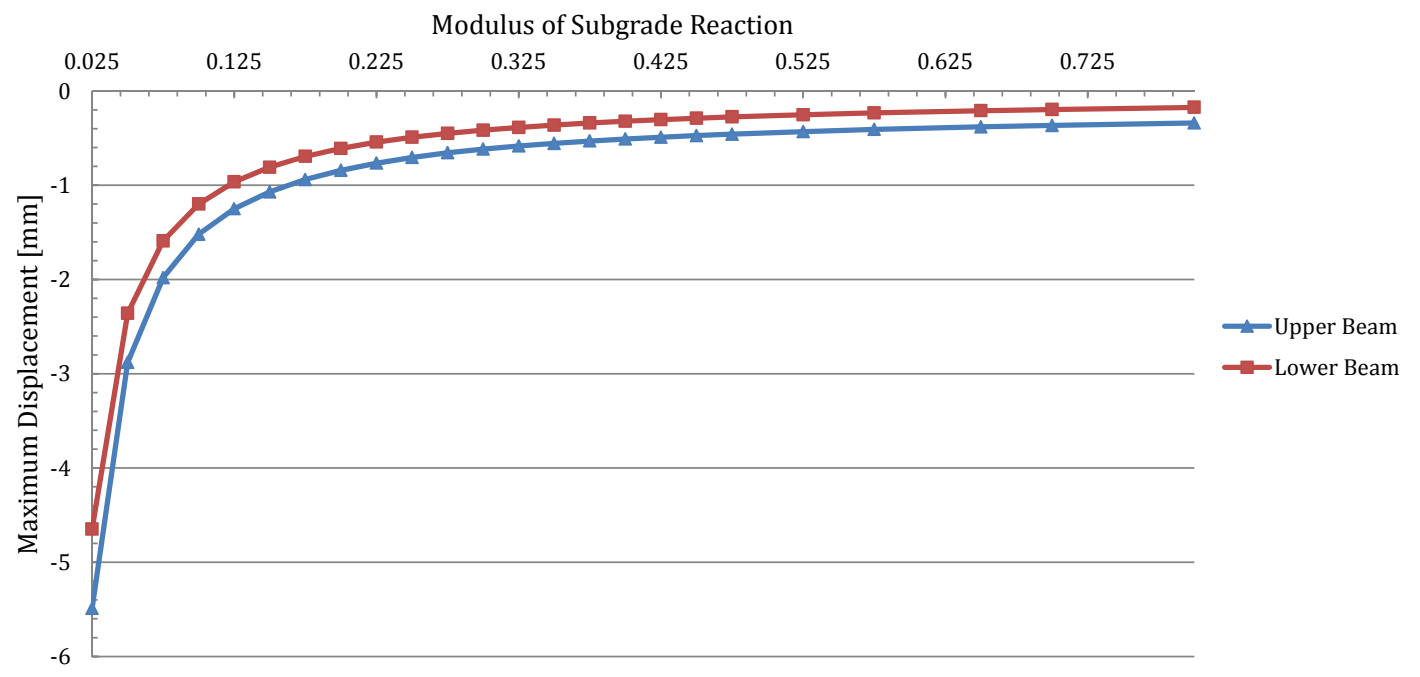

Figure 8.13: Maximum Displacements

\section{Maximum Bending Moment}

As can be seen in Figure 8.14 the maximum bending moment of the upper beam is virtually constant and is therefore not sensitive to the modulus of subgrade reaction, whereas the maximum bending moment of the lower beam is relatively sensitive to the varying modulus of subgrade reaction, especially when the modulus of subgrade reaction is below $0.15 \mathrm{~N} / \mathrm{mm}^{2} / \mathrm{mm}$.

\section{Modulus of Subgrade Reaction Sensitivity Analysis}

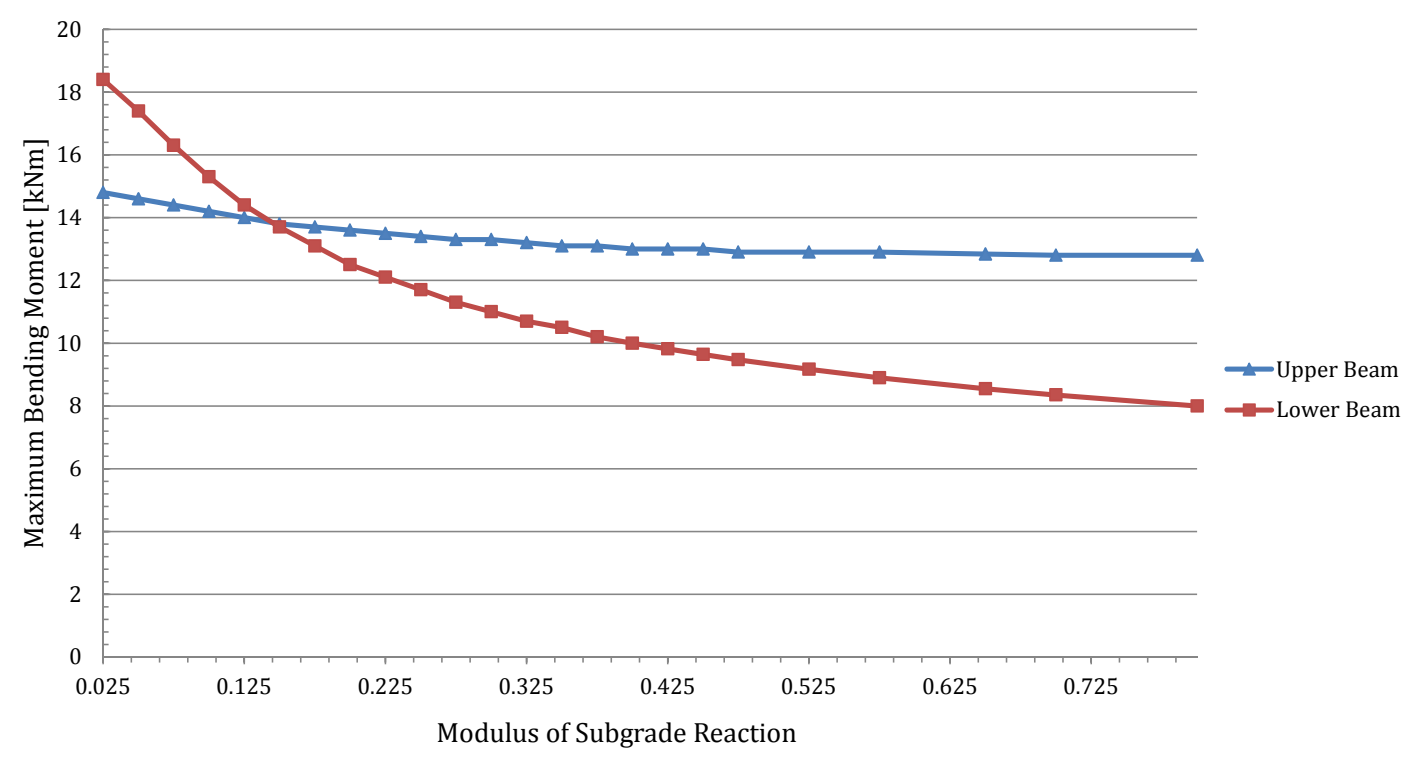

Figure 8.14: Maximum Bending Moments 


\section{Maximum Shear Force}

The maximum shear forces, as illustrated in Figure 8.15, demonstrate that the shear forces are not sensitive to the magnitude of the modulus of subgrade reaction and will therefore not influence the required shear steel reinforcement. Both the upper and lower beams demonstrate a relatively constant maximum shear force value.

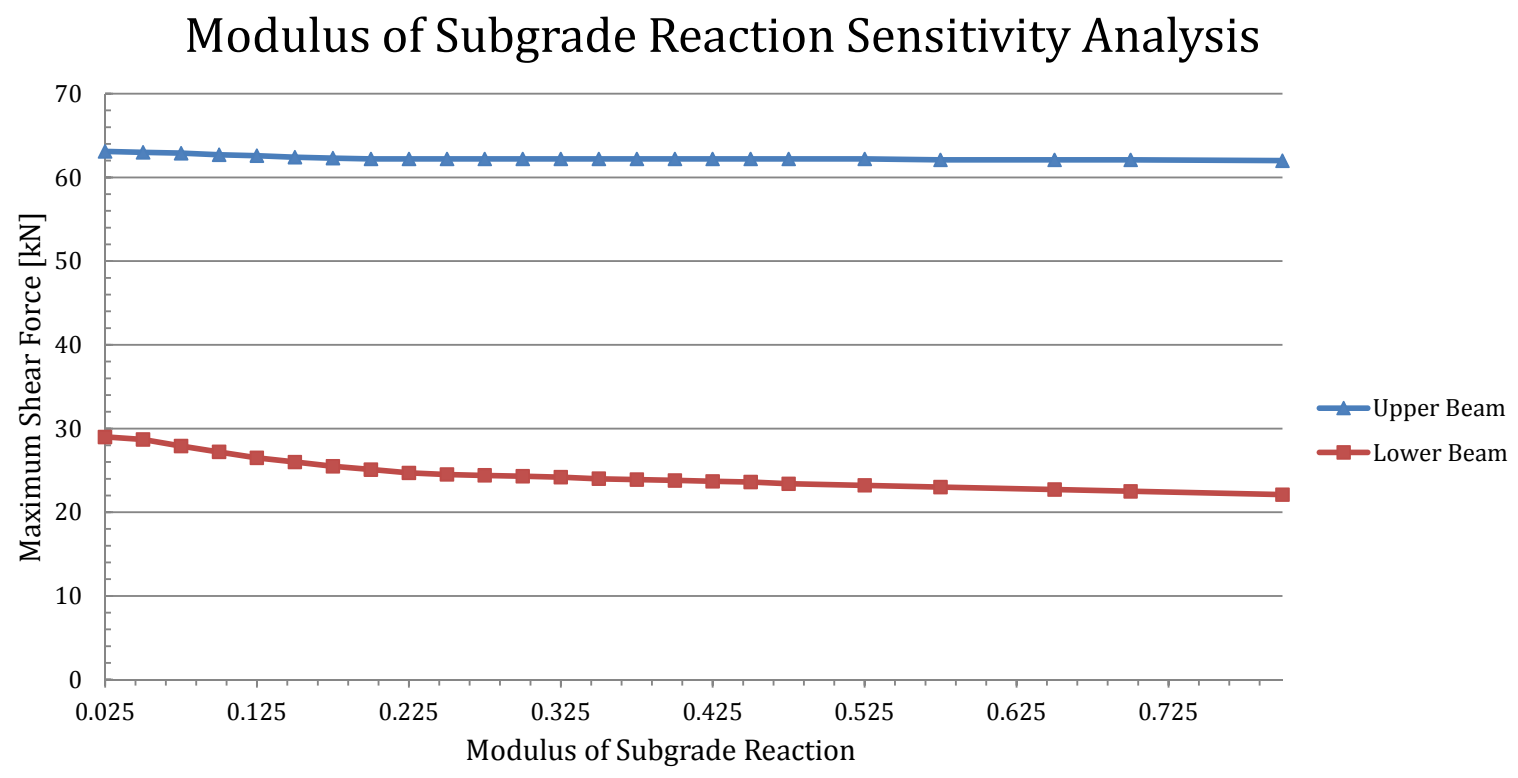

Figure 8.15: Maximum Shear Forces

\section{Foundation Modulus Sensitivity Summary}

The transition stiffness of $0.125 \mathrm{~N} / \mathrm{mm}^{2} / \mathrm{mm}$ represents the modulus of subgrade reaction for a infinitely long, rectangular footing. This corresponds to a modulus of subgrade reaction of $0.25 \mathrm{~N} / \mathrm{mm}^{2} / \mathrm{mm}$ for square footing, using Equation 6.5.1. The elastic soil range as indicated in Table 6.4 indicates that this a modulus of subgrade reaction larger than or equal to the value of $0.2 \mathrm{~N} / \mathrm{mm}^{2} / \mathrm{mm}$ represents a "good" soil foundation, which corresponds to the results obtained.

\subsubsection{Load Magnitude Sensitivity}

The load magnitude sensitivity analysis is performed by increasing the load magnitude from $60 \mathrm{kN}$ up to $200 \mathrm{kN}$ in increments of $10 \mathrm{kN}$, and subsequently obtaining the maximum displacement, bending moments, and shear forces in the rail and RC beam, similarly as in the modulus of subgrade sensitivity analysis. 


\section{Maximum Displacement}

As can be seen in Figure 8.16 the variation in the load magnitude causes a linear change in maximum displacement in both the rail and $\mathrm{RC}$ beam, although the variation is not as substantial as in the sensitivity analysis of the modulus of subgrade reaction. The maximum displacement in the upper beam increases by approximately $1 \mathrm{~mm}$ when the load is increased from $60 \mathrm{kN}$ to 200 $\mathrm{kN}$, whereas the RC beam's displacement increases by approximately $1.4 \mathrm{~mm}$. This demonstrates that the deflections in the TT railway system are sensitive to variation in loading magnitude.

\section{Load Magnitude Sensitivity Analysis}

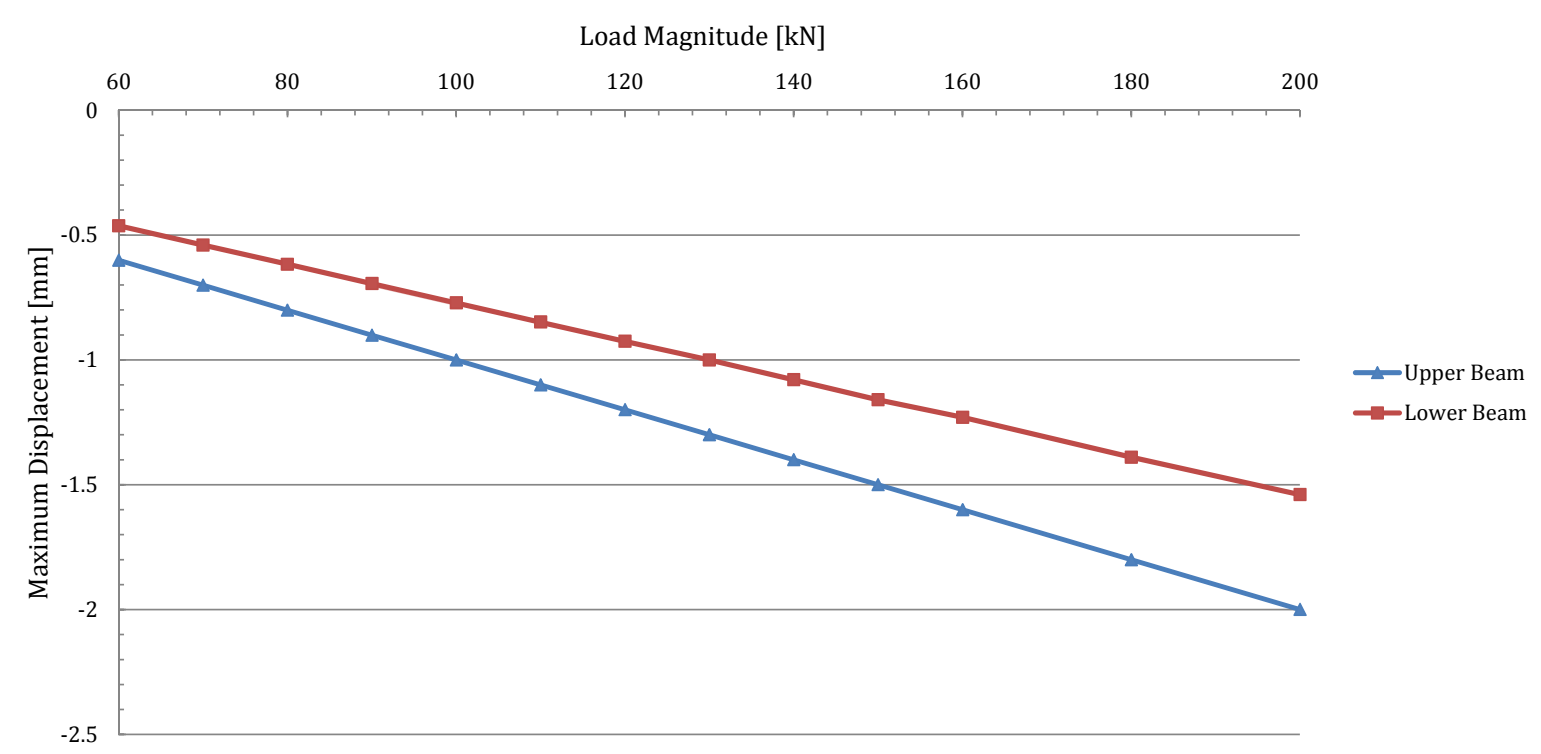

Figure 8.16: Maximum Displacements

\section{Maximum Bending Moment}

The maximum bending moments, as illustrated in Figure 8.17 demonstrate that the bending moments of the rail and RC beam are almost identical, and again have a linear increase with regard to load magnitude. This result correlates well with the bending moments obtained from the previous analyses, where the maximum bending moments in the rail and $\mathrm{RC}$ beam are very similar. Figure 8.17 also indicates that the maximum bending moment is quite sensitive to the magnitude of the loading, as it increases by approximately $320 \%$ over the load magnitude range. 


\section{Load Magnitude Sensitivity Analysis}

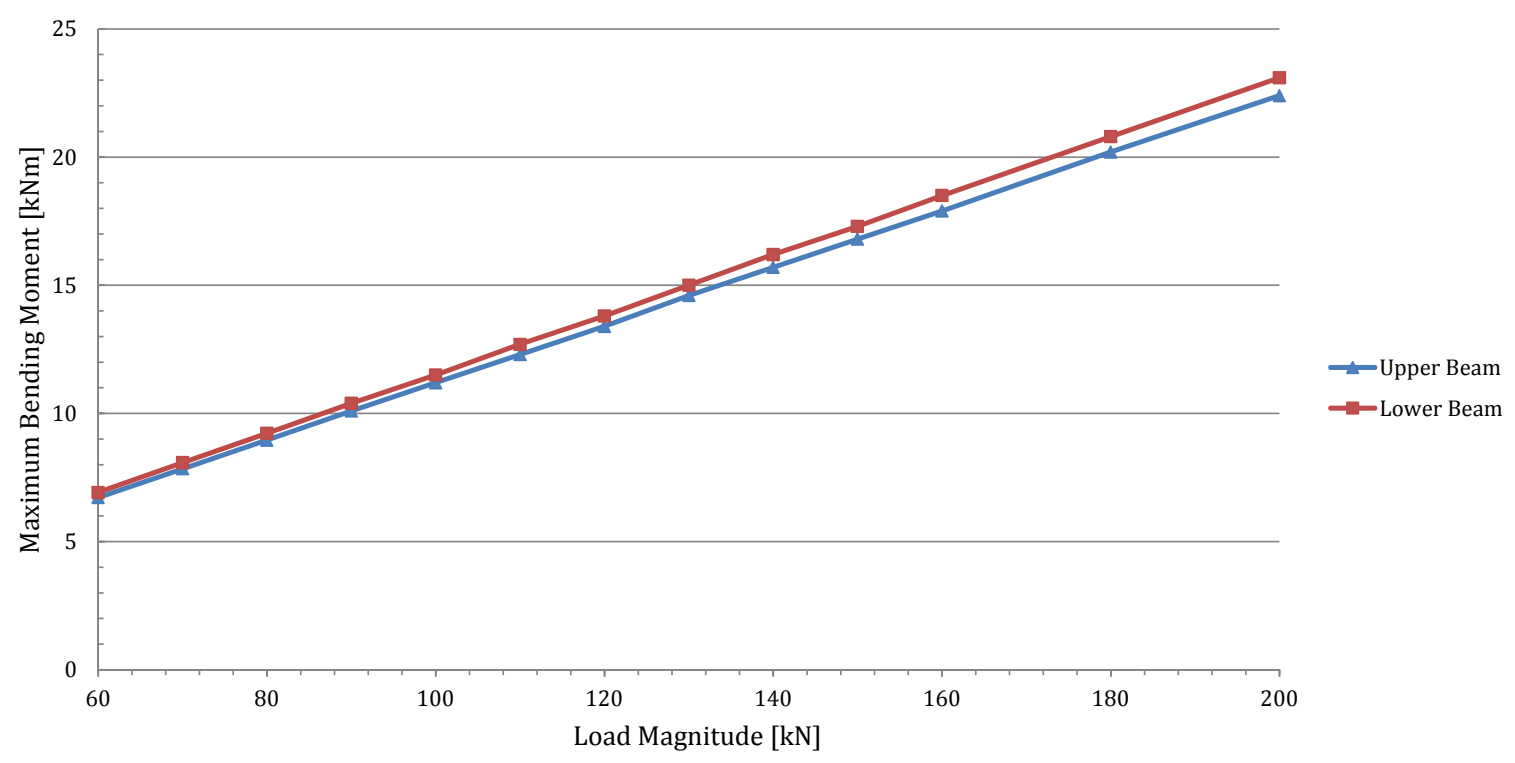

Figure 8.17: Maximum Bending Moments

\section{Maximum Shear Force}

The maximum shear forces in the rail and $\mathrm{RC}$ beam are illustrated in Figure 8.18 , which indicates that a linear variation is again obtained. The RC beam is not very sensitive to the variation in load magnitude, and only varies by approximately $320 \%$. The rail, on the other hand, is much more sensitive to the variation in load magnitude, and varies by approximately $400 \%$ over the loading range. 


\section{Load Magnitude Sensitivity Analysis}

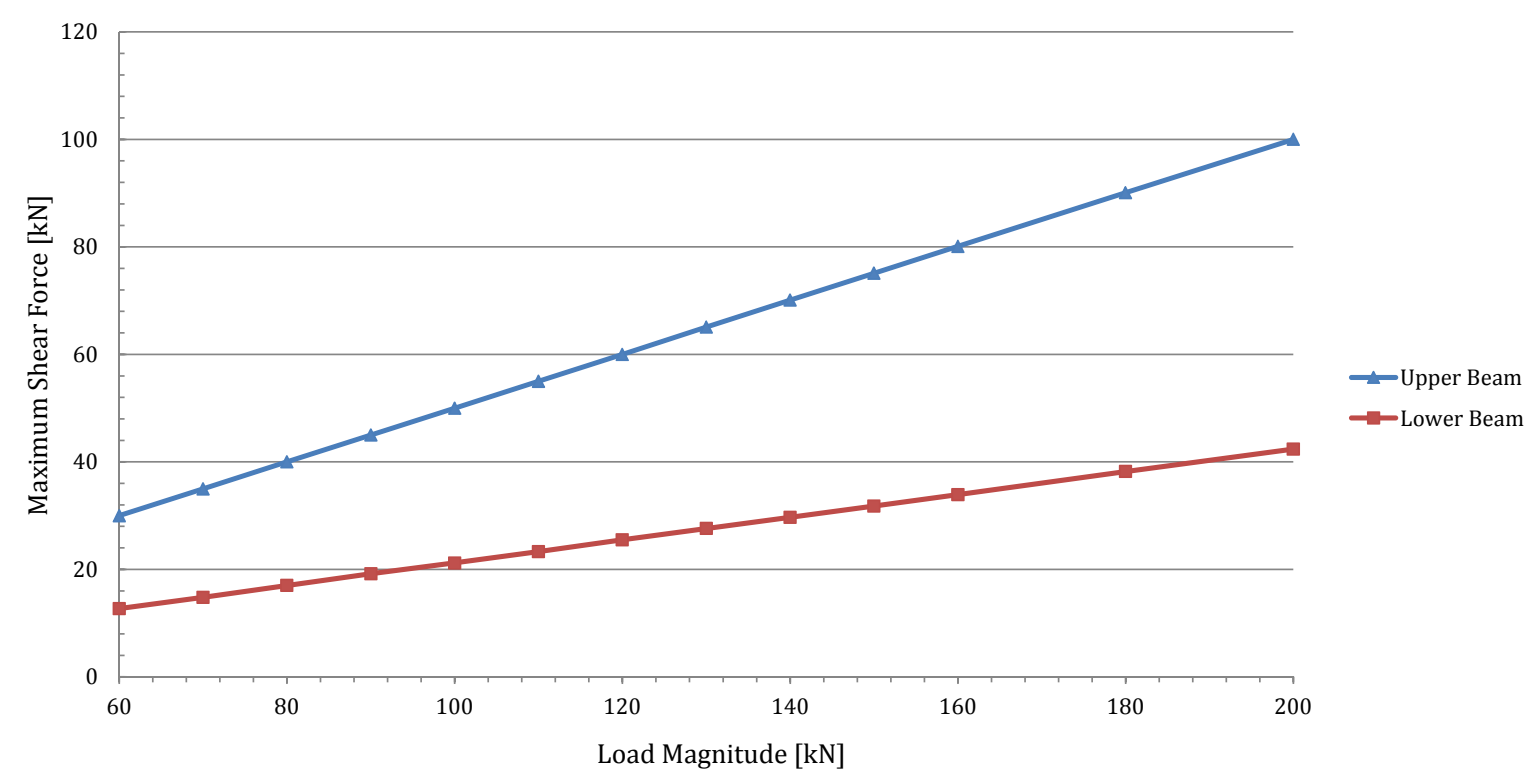

Figure 8.18: Maximum Shear Forces

\subsection{Conclusions}

The comparison of the analysis methods yield conclusive results on which analysis models can accurately simulate the TT railway system. The models which include the influence of the elastomeric pad yield very similar results and can be assumed to be accurate since these models represent vast variation in sophistication. The models found to yield similar results are the Double Beam method, ABAQUS 2D and ABAQUS 3D. The theoretically derived Double Beam method which is based on elastic foundation principles is the simplest of the three models, and represents a modified Winkler elastic foundation model where two beams are connected by springs. The ABAQUS 2D beam model is slightly more sophisticated and makes use of explicit beam elements and spring supports, also with springs representing the elastomeric pad connecting the rail and RC beam. The ABAQUS 3D model represents the most sophisticated model and uses 3D solid finite elements to analyse the TT railway system, and geometrically models the elastomeric pad. The results of the theoretical models therefore correspond with those of the complex 3D solid element model.

The proposed PROKON 2D model is found to be unacceptable for the analysis and design of the TT railway system, due to the fact that it does not model the elastomeric pad. Disregarding the influence of the elastomeric pad yields severe underestimations of the bending moments and shear forces in the rail (320\% and $570 \%$ respectively), and equally severe overestimations of the bending moments and shear forces in the RC beam (56\% and $100 \%$ respectively). This effectively leads to severe underdesign of the steel rail, and overdesign of the RC beam. The 
PROKON model is therefore conservative for design of the $\mathrm{RC}$ beam, and unconservative for the design of the rail. The result of specifying a smaller rail profile could possibly force the RC beam to be subjected to larger bending moments and shear forces than for what it was originally designed for, thereby nullifying or possibly even exceeding the amount for which it was overdesigned. This effectively accelerates material fatigue, which might be the possible cause of the small cracks in the $\mathrm{RC}$ beams which have been found on some TT railway sections, which is currently being investigated.

The Double Beam method obtains slightly larger displacements than the ABAQUS 2D and 3D models (approximately $6 \%$ ) and represents the recommended analysis method due to it obtaining the largest displacements of the three analysis techniques, and will therefore also obtain slightly larger bending moments and shear forces than the other methods and represents the most conservative method for analysis and design. This model is also the simplest of the three analysis techniques and takes only a fraction of the time required to analyse relative to the other analysis methods. Whereas the other analysis methods'results must still be extracted and analysed. As previously mentioned a Graphical User Interface (GUI) has been created for the purpose of analysing any TT railway sections given the appropriate input variables, and provides the results required for the analysis and design of a TT railway section. A summary of the results obtained from the various static analyses are provided in Tables 8.2 and 8.3 respectively.

Table 8.2: Rail Results Summary

\begin{tabular}{lcccc}
\hline & $\begin{array}{c}\text { Maximum Deflection } \\
{[\mathrm{mm}]}\end{array}$ & $\begin{array}{c}\text { Maximum BM } \\
{[\mathrm{kNm}]}\end{array}$ & $\begin{array}{c}\text { Minimum BM } \\
{[\mathrm{kNm}]}\end{array}$ & $\begin{array}{c}\text { Maximum Shear Force } \\
{[\mathrm{kN}]}\end{array}$ \\
\hline Single Beam & 1.02 & - & - & - \\
Double Beam & 1.24 & 14.30 & -4.08 & 62.70 \\
PROKON & 0.95 & 2.94 & -1.40 & 8.50 \\
ABAQUS 2D & 1.18 & 13.20 & -3.53 & 58.90 \\
ABAQUS 3D & 1.16 & 12.40 & -2.78 & 58.80 \\
\hline
\end{tabular}

Table 8.3: RC Beam Results Summary

\begin{tabular}{lcccc}
\hline & $\begin{array}{c}\text { Maximum deflection } \\
{[\mathrm{mm}]}\end{array}$ & $\begin{array}{c}\text { Maximum BM } \\
{[\mathrm{kNm}]}\end{array}$ & $\begin{array}{c}\text { Minimum BM } \\
{[\mathrm{kNm}]}\end{array}$ & $\begin{array}{c}\text { Maximum Shear Force } \\
{[\mathrm{kN}]}\end{array}$ \\
\hline Single Beam & 1.02 & - & - & - \\
Double Beam & 0.96 & 14.30 & -12.20 & 27.20 \\
PROKON & 0.95 & 20.63 & -9.46 & 49.90 \\
ABAQUS 2D & 0.95 & 13.20 & -11.60 & 24.94 \\
ABAQUS 3D & 0.95 & 12.40 & -10.90 & 27.90 \\
\hline
\end{tabular}


The proposed method of applying a DAF to a static load to simulate a dynamic load by means of an empirical approximation has also been investigated in this chapter, and the results have verified that this empirical method can be used to obtain the displacements of the TT railway system subjected to dynamic loading. A DAF was obtained for the reference section and used for the comparison of displacements of a FEM model with in-situ deflection test results, and indicated that the deflections obtained from the analysis models were within $10 \%$ of the field test displacements. This is within an acceptable range, given the approximations required for the investigation. The proposed analysis methods have therefore been compared and verified relative to each other as well as field test results, and subsequently verified that the Double Beam method, ABAQUS 2D and 3D models can be used to analyse the TT railway system accurately, whereas the PROKON 2D model was inaccurate in obtaining the displacement of the rail, and conservative for the RC beam design.

A modulus of subgrade reaction sensitivity analysis has been performed to analyse the sensitivity of the displacements, bending moments, and shear forces on the magnitude of the modulus of subgrade reaction. The maximum displacements have been found to be very sensitive for a modulus of subgrade reaction below $0.125 \mathrm{~N} / \mathrm{mm}^{2} / \mathrm{mm}$, whereas it was relatively constant for higher values. The maximum bending moment in the lower beam was also sensitive for a modulus of subgrade reaction below $0.125 \mathrm{~N} / \mathrm{mm}^{2} / \mathrm{mm}$, whereas the maximum bending moment in the upper beam and the maximum shear forces in both beams were basically constant for a varying modulus of subgrade reaction. The sensitivity analysis therefore indicates that the maximum displacement and bending moment in the lower beam is sensitive for a modulus of subgrade reaction below $0.125 \mathrm{~N} / \mathrm{mm}^{2} / \mathrm{mm}$ for a rectangular, infinitely long beam. This value represents a modulus of subgrade reaction of $0.25 \mathrm{~N} / \mathrm{mm}^{2} / \mathrm{mm}$ for a square PBT, when applying the obtained shape factor. An accurate estimation of the modulus of subgrade reaction for an in-situ PBT is therefore very important for analysis and design of the TT railway system.

An additional load magnitude sensitivity analysis was performed, and indicated that the displacements, bending moments, and shear forces were linearly dependant on the load magnitude. The displacements and bending moments were found to be sensitive to changes in the load magnitude. The maximum shear force in the RC beam was not found to very sensitive, unlike in the rail which indicated that the maximum bending moment was relatively sensitive to the loading magnitude. 


\section{Chapter 9}

\section{Conclusions and Recommendations}

This chapter presents the conclusions and recommendations based on the findings in this dissertation. Suggestions for future research based on issues which fell outside this investigation's scope are subsequently made.

\subsection{Conclusions}

The following conclusions are drawn from each section:

\section{Elastic Foundation Theory}

- Subgrade support can be simplified by means of the elastic foundation theory which models the support as an elastic spring stiffness. This eliminates the need to geometrically model the subgrade strata in finite element models.

- A square plate bearing test (PBT) must preferably be performed using a plate with a similar width as the supporting grout layer, in order to take potentially weak deep soil strata into account. The size of the plate can however be reduced, but should then be extrapolated to a width equal to that of the supporting grout width. Extrapolation of the stiffness should however be avoided as much as possible, in order to obtain an accurate simulation of the subgrade stiffness.

- The result of a square PBT can be modified to represent the modulus of subgrade reaction of a rectangular, infinitely long footing as there is a linear relationship between the modeling techniques. This is required to obtain the actual stiffness for the correct footing shape of the TT railway system.

\section{Application of Loads}

- The load combination representing eight wheels of two adjacent vehicles on an infinitely long beam can be simplified to two loads on a finite beam by applying symmetry conditions. 


\section{Finite Element Analysis Models}

- The Single Beam on elastic foundation model which applies the Transformed-Section method provides a good representation of the maximum displacement in the Tubular Track (TT) railway system, but cannot accurately calculate the bending moments or shear forces in the individual components. The displacements of the Single Beam on elastic foundation model is similar to 2D ABAQUS and PROKON beam models using fixed rigid links. The rigid links also do not allow vertical displacements of components relative to each other, and therefore ignore the effects of the elastomeric pad between the rail and reinforced concrete $(\mathrm{RC})$ beam.

- An investigation of a single beam on an elastic foundation was performed using the various analysis methods as proposed in this investigation, in order to compare the analysis models without the influence of interactions between components. This analysis verified that the various analysis models obtained similar displacements, bending moments, and shear forces, indicating that the interactions between the components played the largest part in the variation in results between the various models investigated. The most important interaction being the elastomeric pad between the rail and $\mathrm{RC}$ beam.

- The Double Beam method, ABAQUS 2D beam, and ABAQUS 3D solid elements models obtain very similar displacements, soil pressure distributions, bending moment and shear force diagrams in both the rail and $\mathrm{RC}$ beam. This is due to the addition of the elastomeric pad in the FEA models, which allows for localised deflections and load distributions in the rail.

- PROKON can accurately obtain the deflections in the RC beam, but cannot be used to obtain the displacement in the rail, or the bending moments and shear forces in the $\mathrm{RC}$ beam and rail due to the usage of the rigid links in the model. PROKON underestimates the bending moments and shear forces in the rail by $320 \%$ and $570 \%$ respectively, and overestimates bending moments and shear forces in the RC beam by $56 \%$ and $100 \%$ respectively. The result of underdesigning the rail could potentially force the $\mathrm{RC}$ beam to be subjected to larger bending moments and shear forces than for what it was originally designed for, thereby nullifying or potentially even exceeding the amount for which it was overdesigned. This effectively accelerates material fatigue, which might be the possible cause of the small cracks in the $\mathrm{RC}$ beams which have been found on some TT railway sections, which is currently being investigated.

- The Double Beam method obtains slightly larger displacements, bending moments and shear forces than the ABAQUS 2D and 3D models, and therefore represents the most conservative analysis method for design. As it is also the simplest theoretical model, a Graphical User Interface (GUI) program was created for the analysis of TT railway sections. 


\section{Sensitivity Analysis of Modulus of Subgrade Reaction}

- The sensitivity analysis of the modulus of subgrade reaction indicates that the maximum displacements in the rail and $\mathrm{RC}$ beam are sensitive for a modulus of subgrade reaction below $0.125 \mathrm{~N} / \mathrm{mm}^{2} / \mathrm{mm}$. The maximum displacements in the beams, however, are not sensitive for a modulus of subgrade reaction above this value. The maximum bending moment in the rail is found not to be very sensitive to the variation in the modulus of subgrade reaction, although the $\mathrm{RC}$ is sensitive for a foundation modulus below $0.15 \mathrm{~N} / \mathrm{mm}^{2} / \mathrm{mm}$. An accurate estimation of the modulus of subgrade reaction for an in-situ PBT is therefore very important for analysis and design of the TT railway system. The maximum shear forces were found not to be sensitive to the variation in foundation modulus, and were nearly constant throughout the investigated range.

\section{Sensitivity Analysis of Load Magnitude}

- An increase in loading magnitude from $60 \mathrm{kN}$ to $200 \mathrm{kN}$ obtained only a linear increase in displacement in the rail and RC beam of $300 \%$ and $330 \%$ respectively, indicating that the maximum displacements in the beams are sensitive to the loading magnitude. The maximum bending moments and shear forces were also found to increase linearly, and indicated to be sensitive to the variation in loading magnitude, which is as expected.

\section{Sensitivity Analysis of Rayleigh Damping Coefficients}

- The displacements of the $\mathrm{RC}$ beam are found not to be sensitive to variation in the damping coefficients, whereas the rail is found to be slightly more sensitive. The bending moments and shear forces however are found to be very sensitive to the variation in damping coefficients. Due care should therefore be taken when applying the Rayleigh damping factors in dynamic analysis models, as this could indicate significantly smaller bending moments and shear forces which are used for design. The theoretical models are quasi-static models which do not take inertial effects or damping into account.

\section{Application of Dynamic Amplitude Factor}

- By applying a DAF to a static load to simulate a dynamic load obtains an accurate dynamic displacement, when compared to a finite element dynamic analysis performed using ABAQUS 3D solid elements. This verifies the usage of a DAF in a static FEA to simulate a dynamic analysis of the TT railway system. For general analyses the DAF is obtained via empirical methods which are subjectively chosen by the analyst. This empirical method obtains larger DAFs than obtained in this investigation, but this is preferable for the purpose of design using safety factors. 


\section{Accuracy of FEM models vs. Field Test Results}

- By applying the DAF specific to the Amandelbult Layout section 3 FEA model, it is verified that the displacements correlate well with the displacement results of field test results, therefore verifying the validity of using the Double Beam method, ABAQUS 2D beam, and ABAQUS 3D solid element FEA for the analysis of the TT railway system.

\subsection{Recommendations}

Based on the conclusions of this investigation, the following recommendations are made for the analysis of the TT railway system:

The TT railway system can be accurately modeled using either the Double Beam method which models the elastomeric pad as a spring stiffness between the rail and RC beam, ABAQUS 2D beams which also models the elastomeric pad as a spring support between the rail and RC beam, or ABAQUS 3D solid elements which geometrically models the elastomeric pad. The Double Beam method represents a simple theoretical model which can be analysed within minutes, given the required input variables. The ABAQUS 2D beam and 3D solid element model are much more complex to model accurately . The Double Beam method obtains slightly larger displacements, bending moments and shear forces than the other proposed methods, but are still accurate relative to field test results. Obtaining the required results from a 3D ABAQUS FEM model is a time-consuming process and requires complex and expensive analysis software. It is therefore recommended that the analysis method used for the general analysis of the TT railway system where only vertical loads are investigated be the Double Beam method, as the results are sufficiently accurate and reliable whilst the Double Beam method is also the most basic model to use. The Double Beam GUI MATLAB program can be utilised for analysing the TT railway system, as attached in Appendix C. This MATLAB GUI program can be converted to JAVA if required, but this falls outside this investigation's scope and requirements.

The modulus of subgrade reaction which is required for the analysis of the TT railway system can either be obtained using in-situ square PBTs or by FEA using solid elements. As subgrade material properties are rarely known or obtained, it is recommended that square PBTs be performed at the prospective sites to be used by the TT railway system. The plates used in the square PBT should preferably be of similar width as the supporting grout layer of the TT system, or at least as close as possible depending on the difficulty and capability of applying the load on the plate to obtain the required displacement for the procurement of the modulus of subgrade reaction. The modulus of subgrade must then be extrapolated for the rectangular, infinitely long shape using the shape factor (SF) of 0.5 as obtained in this investigation.

As stated in the above section, the bending moments and shear forces in the TT railway system are very sensitive to small changes in the Rayleigh material damping coefficients, $\alpha$ and $\beta$. The actual damping coefficients to be used for further detailed analyses should therefore be 
investigated further if required, or can be assumed to be very small (less than or equal to $2.5 \%$ ), depending on the level of safety required.

\subsection{Suggestions for Future Research}

The following suggestions for future research are made as a result of this investigation:

The SF for a rectangular, infinitely long beam was obtained by investigating the subgrade stiffness of four TT railway sections. The finite element method (FEM) models used for these analysis were very simplified models based on soil parameters which made assumptions on the soil's homogeneity, isotropy, and linearity. These are of course assumptions that do not simulate actual soil conditions, and can vary quite substantially for short distances. It is therefore recommended that future research be carried out to investigate methods of accurately modeling subgrade strata using the FEM.

The comparison of the square and rectangular PBTs was based on four TT railway section, and provided a linear relationship between the two loading conditions and modeling techniques. It is recommended that more subgrade formations be investigated for the procurement of a relationship of a larger sample space which will hold more statistical merit, and also for the comparison with in-situ test PBT results.

Premature cracks found in RC beams at some TT sections are currently being investigated. The cracks caused due to accelerated material fatigue can influence the results obtained. It is therefore recommended that the influence of a cracked concrete beam on the displacements, bending moments and shear forces be investigated.

The TT RC beams are made up of 5 to $6 \mathrm{~m}$ long sections with gaps between the sections of approximately $10 \mathrm{~mm}$. This gap was not taken into account in this investigation, as it is not in the scope of this investigation which investigates general track analysis and design. It is suggested that the influence of the gap be investigated in order to study the additional displacements caused by the break in continuous support of the rail. 


\section{Bibliography}

[1] Electronic URL, July 2011.

Available at: www.tubulartrack.co.za

[2] Electronic URL, July 2012.

Available at: http://marvelwriting.com/wp-content/uploads/2010/11/ S-100829-003-Train-Tracks.jpg

[3] South African Steel Construction Handbook. 6th edn. The South African Institute of Steel Construction, 2008.

[4] Esveld, C.: Modern Railway Track. 2nd edn. MRT-Productions; Delft University of Technology, 2001.

[5] Robberts, J.M. and Marshall, V.: Analysis and Design of Concrete Structures. 1st edn. Nuclear Structural Engineering (Pty) Ltd, 2008.

[6] F. Shaw, Personal Communication. April 2012.

[7] Powell, A.F and Shaw, F.J: Finite element analysis of tubular track formation layer stiffness at Amandelbult. Technical Report BBC0950 version 1, Spoornet, May 2006.

[8] Electronic URL, November 2012.

Available at: http://www.engineeringtoolbox.com/friction-coefficients-d_778. html

[9] Tubular Track, Personal Communication. Tubular Track (Pty) Ltd, Silverton, Pretoria 2011.

[10] Furno, R.J.: Formation measurements on tubular and conventional track at Amandelbult for the period nov 2004 to aug 2005. Technical Report BBC0943 version 1, Spoornet, March 2006.

[11] Agarwal, M.M.: Indian Railway Track. 12th edn. Prabha \& Co., 1998.

[12] Iwnicki et al.: Handbook of Railway Vehicle Dynamics. Taylor \& Francis Group, 2006.

[13] Shaw, F.J.: Finite element analysis on tubular and conventional track for the Pilbara iron ore line. Technical report, Transnet, November 2007. 
[14] Hetenyi, M.: Beams on Elastic Foundation. Ann Arbor: The University of Michigan Press, 1971.

[15] Gazetas, G.: Analysis of machine foundation vibrations: state of the art. Soil Dynamics and Earthquake Engineering, vol. 2, 1983. Rensselaer Polytechnic lnstitute, Troy, New York, USA.

[16] Foppl, A.: Vorlesungen uber Technische Mechanik. Leipzig, B. G. Teubner, 1907.

[17] Eisenberger M. et al.: Stability of beams on elastic foundation. Computers 63 Structures, vol. 24, no. 1, pp. 135-139, September 1986. Faculty of Engineering, Techion - Israel Institure of Technoloy, Haifa, Israel.

[18] Dunaiski, P.E.: Balke op elastiese ondersteuning. Lecture notes: Theory of Structures 324.

[19] Craig, Roy R. Jr. : Mechanics of Materials. 2nd edn. John Wiley \& Sons, 2000.

[20] Klingel, W.: Uber den Lauf der Eisenbahnwagen auf Gerarder Bahn. Organ Fortsch, 1883.

[21] Johnson, K.L.: Contact Mechanics. Cambridge University Press, 1985.

[22] Pérez Winkler, A.R.: An Investigation of Overhead Crane Wheel / Rail / Girder Interaction. Master's thesis, University of Stellenbosch, 2003.

[23] Study of optimum rail inclination and gauge related to wheel profiles adapted to wear. Tech. Rep. ORE C116 RP 10, Utrecht, 1981.

[24] Cook et al.: Concepts and Applications of Finite Element Analysis. 4th edn. John Wiley \& Sons, 2002. University of Wisconsin - Madison.

[25] PROKON Structural Analysis \&3 Design user manual, 2012.

[26] ABAQUS v6.10-2 user manual. Dassault Simulia Systèmes, 6th edn, 2012.

[27] Deladi, E.L.: Static Friction in Rubber-Metal Contacts with Application to Rubber Pad Forming Processes. Ph.D. thesis, University of Twente, 2006.

[28] Craig, R.F.: Craig's Soil Mechanics. 7th edn. Spon Press, 2008.

[29] Bowles, Joseph E: Foundation Design and Analysis. Civil Engineering Series, 5th edn. McGraw-Hill, 1996.

[30] Jenkins, K., Personal Communication. University of Stellenbosch, July 252012.

[31] Stanford University. Electronic URL, 112012.

Available at: http://www.stanford.edu/ tyzhu/Documents/Some\%20Useful\%20Numbers. pdf

[32] Montgomery, D.C and Runger, G.C..: Applied Statistics and Probability for Engineers. 4th edn. John Wiley \& Sons, 2007. 
[33] Fang, H.Y. (ed.): Foundation Engineering Handbook. 2nd edn. Kluwer Academic Publishers.

[34] Chopra, Anil K.: Dynamics of Structures. 3rd edn. Pearson Prentice Hall, 2007. University of California at Berkeley.

[35] Chowdury, I. and Dasgupta, S.P: Computation of Rayleigh damping coefficients for large systems. Tech. Rep..

[36] Goisan, I.: Dynamic analysis with damping for free standing structures using mechanical event simulation. Tech. Rep., West Coast Engineering Group Ltd.

[37] Abdul Hussein, H.M.: Effects of flexural rigidity and soil modulus on the linear static analysis of raft foundations. Journal of Babylon University/Pure and Applied Sciences, vol. 19, no. 2, pp. 740-752, 2011.

[38] Aeberhard et al: Post- tensioned concrete in building construction: Post-tensioned foundations. VSL INTERNATIONAL LTD., Berne / Switzerland, 1988.

[39] Bhatti, M.A.: Advanced Topics in Finite Element Analysis of Structures. John Wiley \& Sons, 2006.

[40] Burland et al.: Behaviour of Foundations and Structures. Building Research Establishment current paper. Building Research Establishment, 1978.

[41] Chandra, S. et al: A finite element study of beam on reinforced granular beds with sand drains. International Association for Computer Methods and Advances in Geomechanics (IACMAG), Goa, India, October 2008.

[42] Dey et al: Distribution of modulus of subgrade reaction beneath beams on elastic foundation. In: International Conference Development of Urban Areas and Geotechnical Engineering, vol. 1, p. 6. St. Petersburg, Russia, 2008.

[43] Freyer, R.V.: Performance evaluation of the tubular test section at Amandelbult station. Technical Report BBC0947 version 1, Spoornet, March 2006.

[44] Kok, A.W.M.: Lumped impulses, discrete displacements and a moving load analysis. Tech. Rep., Delft University of Technology, Faculty of Civil Engineering.

[45] Norris et al.: Structural Design for Dynamic Loads. 1959. Massachusetts Institute of Technology.

[46] Oostermeier, K.H. and Kok, A.W.M.: Dynamic behaviour of railway superstructures. HERON, vol. 45 , no. $1,2000$.

[47] Polach, O.: Wheel profile design for the targeted conicity and a wide contact spreading. In: 8Th International Conference on Contact Mechanics and Wear of Rail/Wheel Systems. Firenze, Italy, September 2009. 
[48] Pron, A.D.C. and van den BOL, M.E.: Winkler-Pasternak-Kerr foundations - notes on boundary conditions. BCRA, Trondheim, 1998.

[49] Spears, R.E. and Jensen, S.R.: Approach for selection of Rayleigh damping parameters used for time history analysis. Idaho National Laboratory, Prague, Czech Republic, July 2009.

[50] V. Gagin, P. Ivanilov: Analysis of lengthy structures resting on multi-layer soil foundation taking into account stochastic behaviour of soil. Studia Geotechnica et Mechanica, vol. XXX, no. $3-4,2008$.

[51] Yokoyama, T.: Vibration analysis of Timoshenko beam-columns on two-parameter elastic foundations. vol. 61, pp. 995-1007. Department of Mechanical Engineering, Okayama University of Science, Okayama 700, Japan, 1996.

[52] Engelbrecht, J.C., Personal Communication. University of Stellenbosch, August 182012. 


\section{Appendices}




\section{Appendix A}

\section{Modal Analysis Results}

The mode shapes and corresponding natural frequencies are indicated in the appendix. Only the first five natural frequencies are investigated, as they are the most important for the occurrence of resonance.

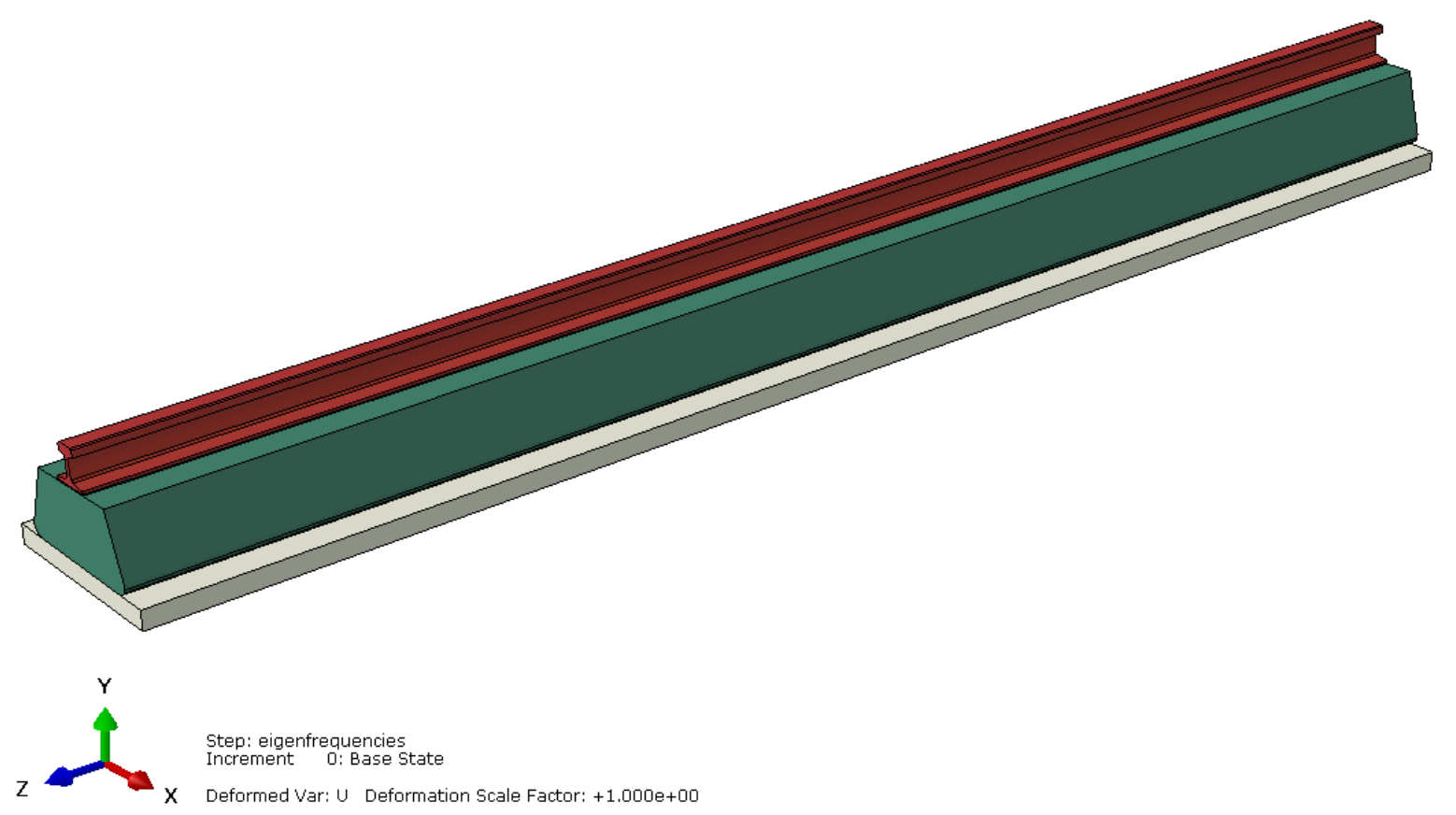

Figure A.1: Mode Base State 

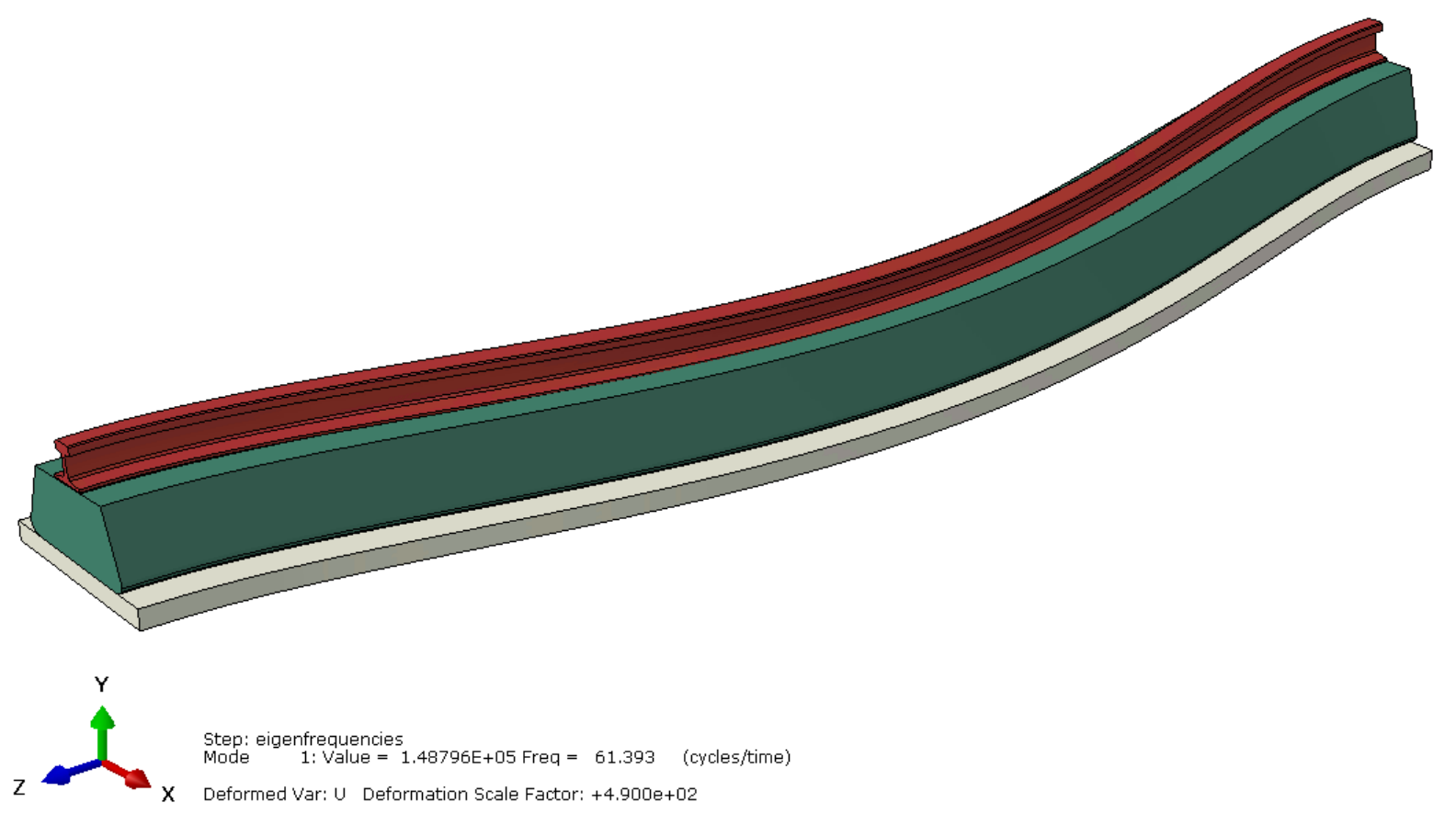

Figure A.2: Mode Shape 1

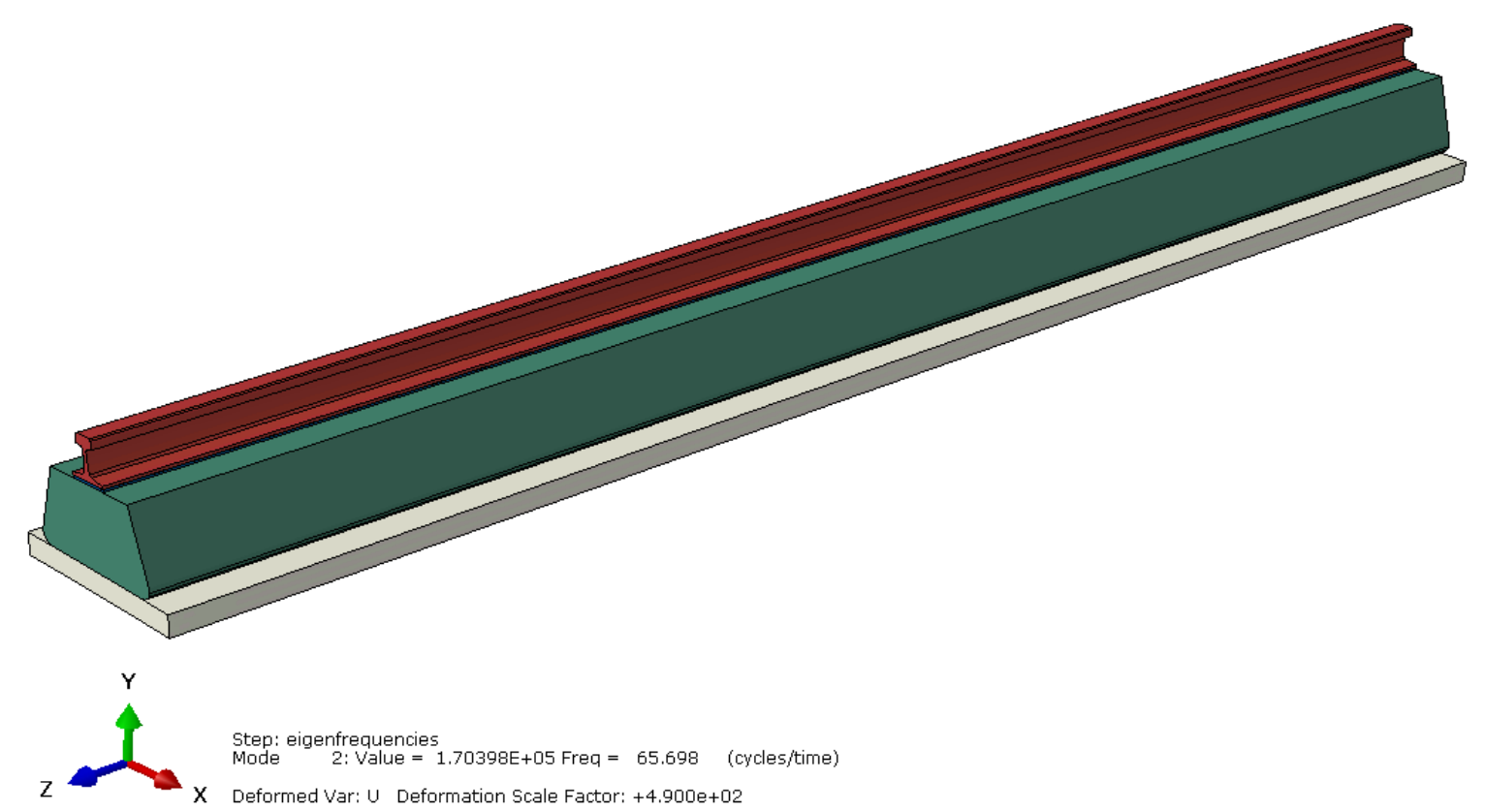

Figure A.3: Mode Shape 2 

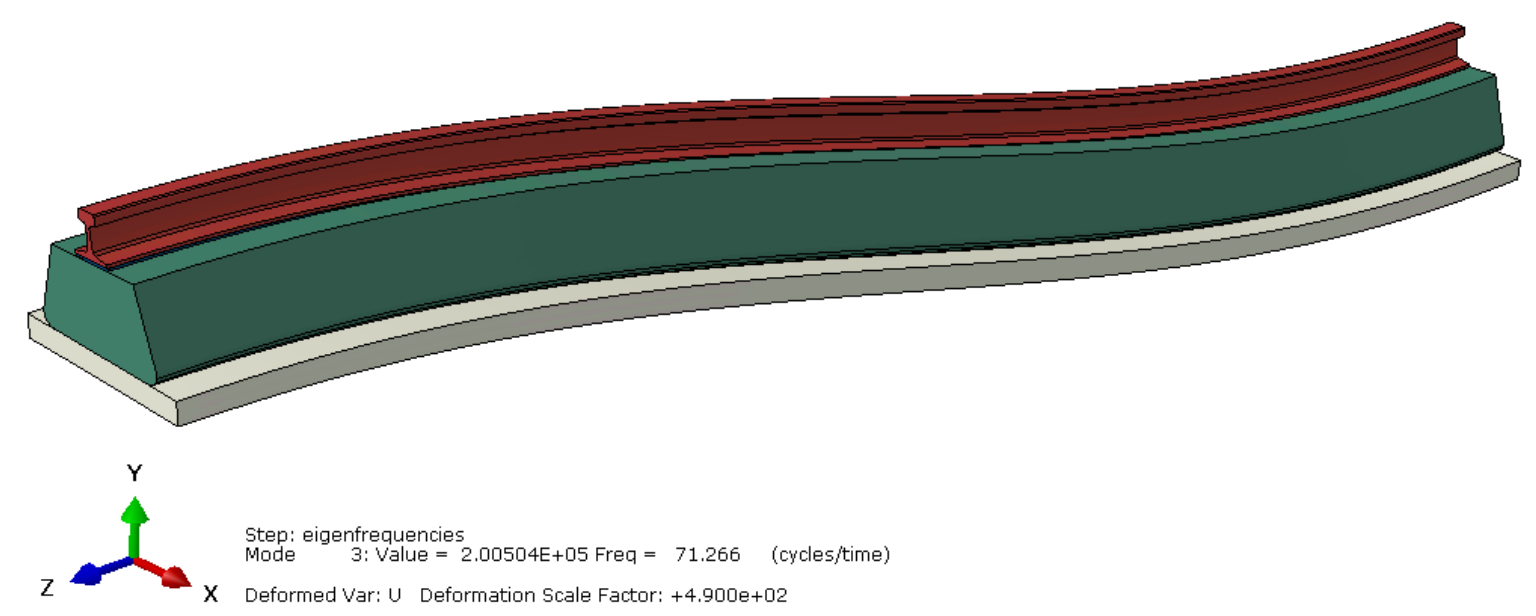

Figure A.4: Mode Shape 3

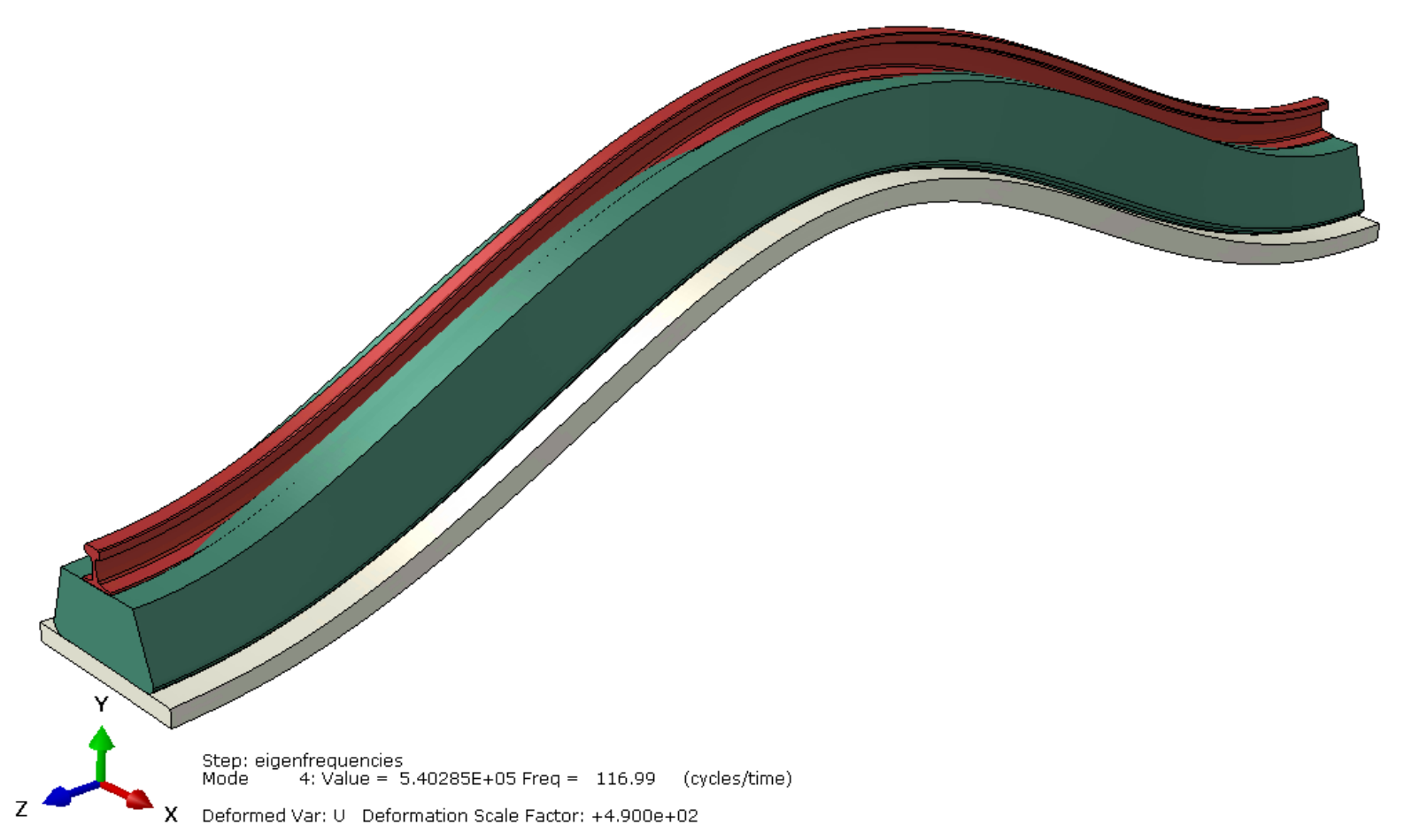

Figure A.5: Mode Shape 4 


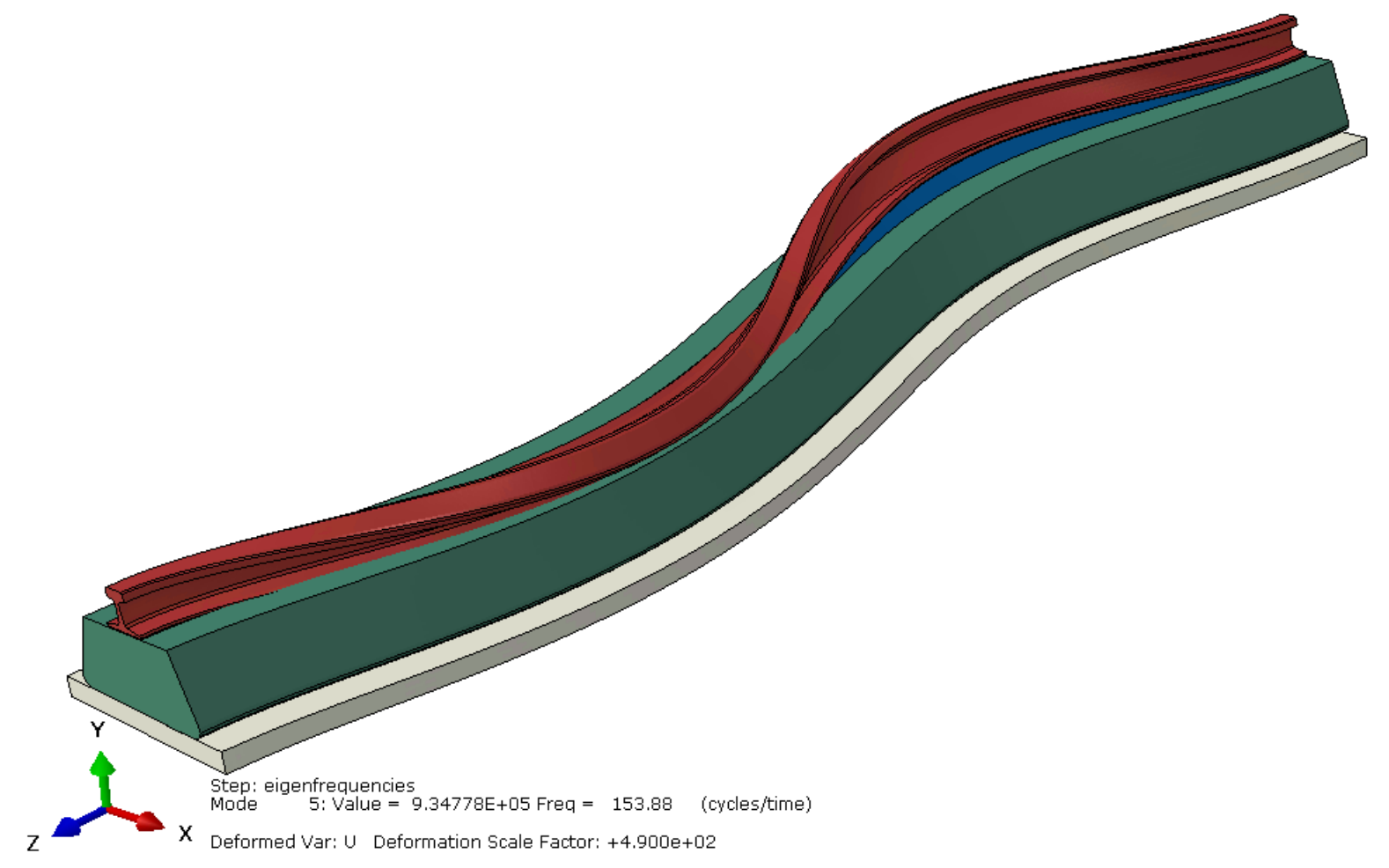

Figure A.6: Mode Shape 5 


\title{
Appendix B
}

\section{Hertz Contact Area Java Application}

\author{
B.1 Class App
}

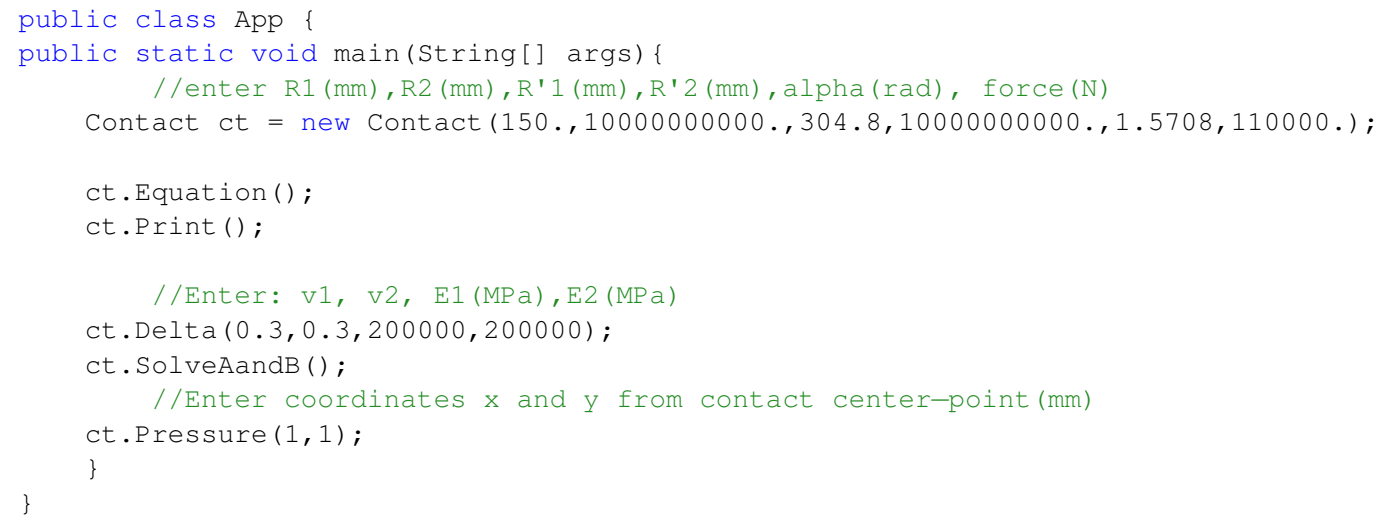




\section{B.2 Class Contact}

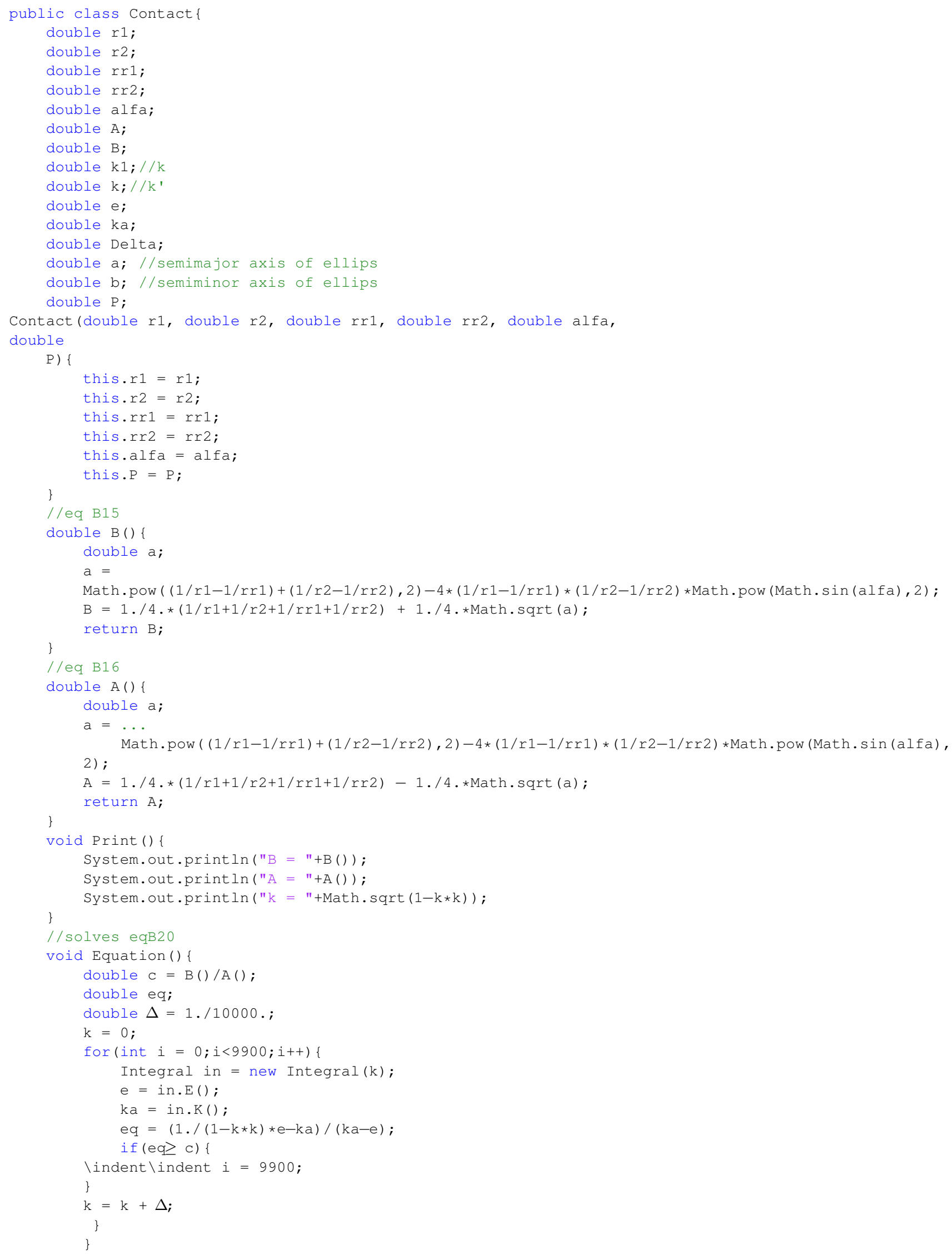




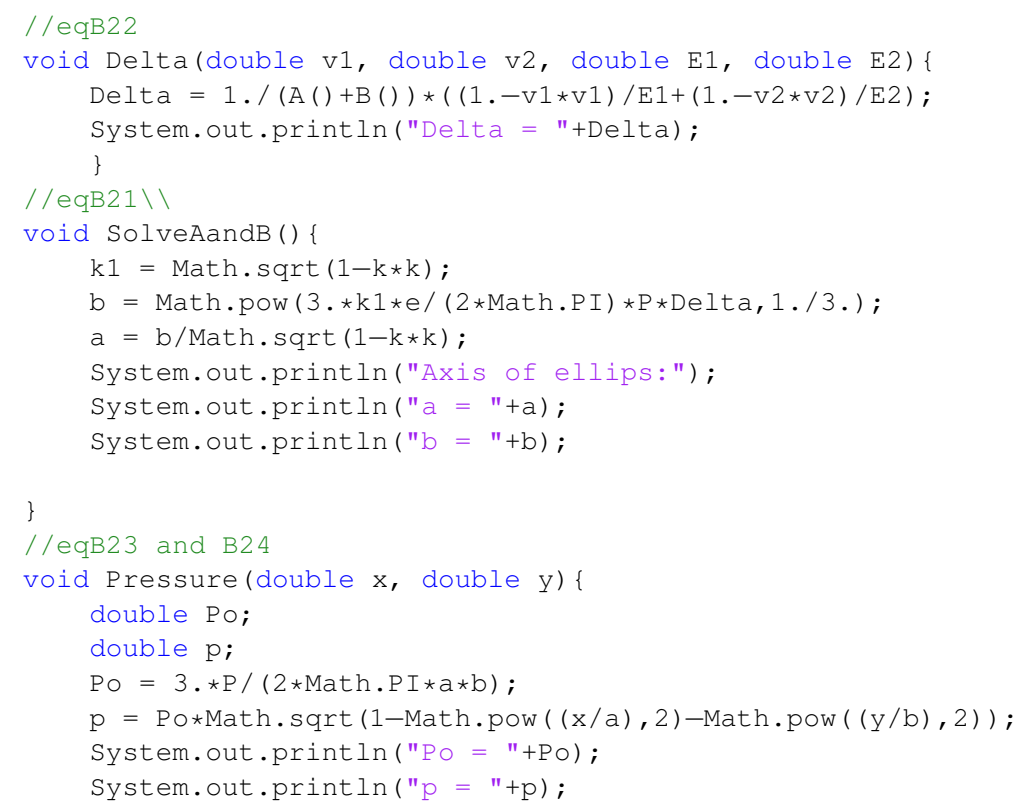




\section{B.3 Class Integral}

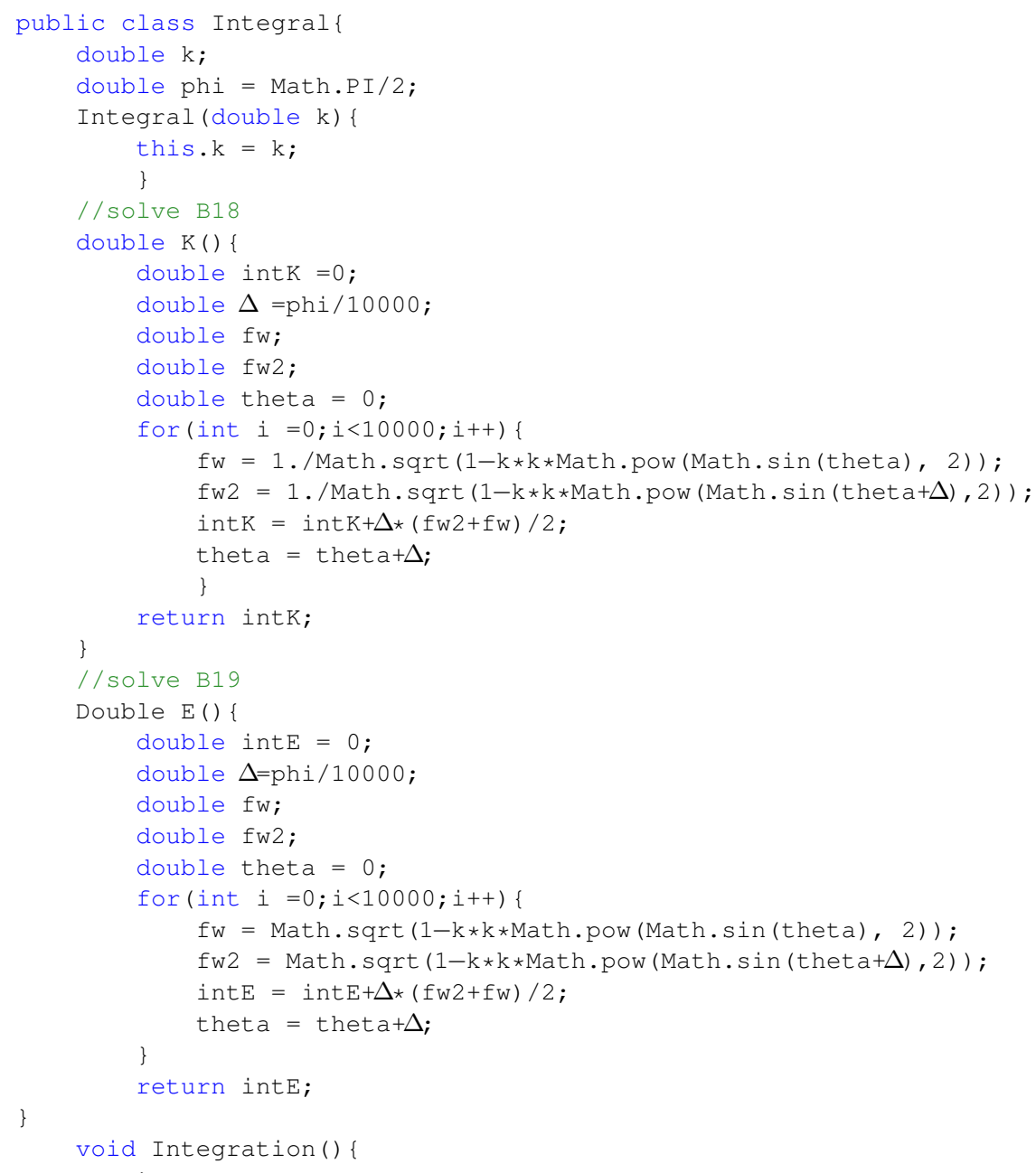




\section{Appendix C}

\section{Elastic Foundation MATLAB GUI Model}

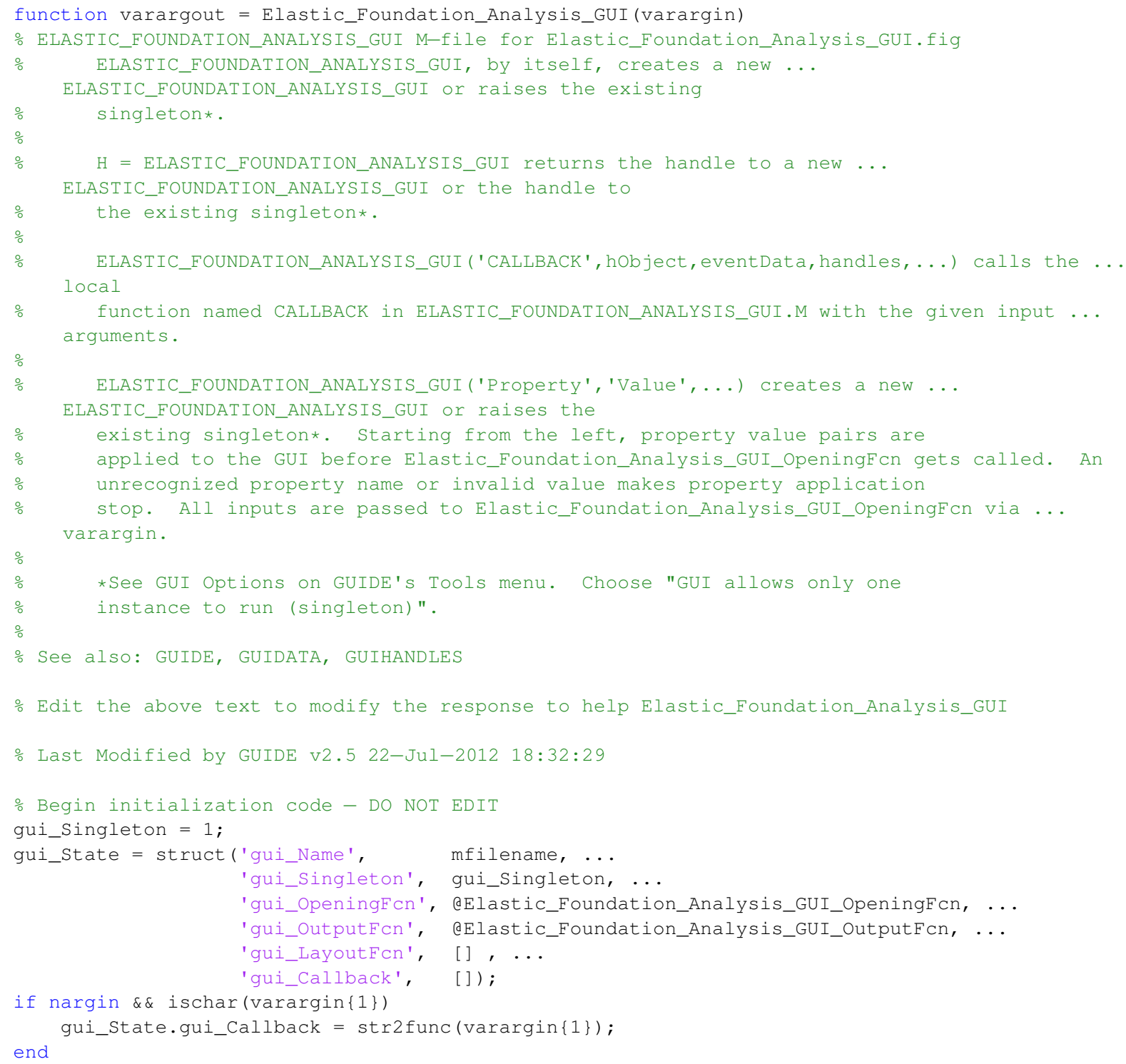




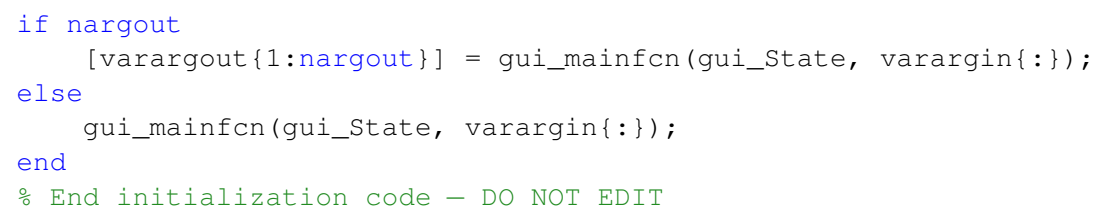


else

set (handles.analysisbutton, 'enable', 'on') ;

end

\% Executes during object creation, after setting all properties.

function edit1_CreateFcn(hobject, eventdata, handles)

\% hobject handle to editl (see GCBO)

\% eventdata reserved - to be defined in a future version of MATLAB

\% handles empty - handles not created until after all createFcns called

if ispc \&\& isequal (get (hobject, 'BackgroundColor'), get(0, 'defaultuicontrolBackgroundColor')) set (hobject, 'BackgroundColor', 'white'); end

function edit2_Callback(hobject, eventdata, handles)

I1 = get (handles.edit2, 'String');

ㄴ Executes during object creation, after setting all properties.

function edit2_createFcn(hobject, eventdata, handles)

if ispc \&\& isequal (get (hobject, 'BackgroundColor'), get(0, 'defaultuicontrolBackgroundColor')) set (hobject, 'BackgroundColor', 'white'); end

function edit3_callback(hobject, eventdata, handles)

function edit3_createFcn(hobject, eventdata, handles)

if ispc \&\& isequal (get (hobject, 'BackgroundColor'), get(0,'defaultuicontrolBackgroundColor')) set (hobject, 'BackgroundColor', 'white') ; end

function edit4_Callback(hobject, eventdata, handles)

$\mathrm{k} 1=\operatorname{get}($ handles.edit 4, 'String');

\% Executes during object creation, after setting all properties.

function edit4_CreateFcn(hobject, eventdata, handles)

if ispc \&\& isequal (get (hobject, 'BackgroundColor'), get(0,'defaultuicontrolBackgroundColor')) set (hobject, 'BackgroundColor', 'white');

end

function edit5_Callback(hobject, eventdata, handles)

\% Executes during object creation, after setting all properties.

function edit5_createFcn(hobject, eventdata, handles)

if ispc \&\& isequal (get (hobject, 'BackgroundColor'), get(0,'defaultuicontrolBackgroundColor')) set (hobject, 'BackgroundColor', 'white') ;

end

function edit6_Callback(hobject, eventdata, handles)

\% Executes during object creation, after setting all properties.

function edit6_createFcn(hobject, eventdata, handles)

if ispc \&\& isequal (get(hobject, 'BackgroundColor'), get(0, 'defaultUicontrolBackgroundColor')) set (hobject, 'BackgroundColor', 'white') ; end

function edit7_callback(hobject, eventdata, handles)

function edit7_createFcn(hobject, eventdata, handles) 
if ispc \&\& isequal (get (hobject, 'BackgroundColor'), get(0, 'defaultuicontrolBackgroundColor')) set (hobject, 'BackgroundColor', 'white') ; end

function edit10_Callback(hobject, eventdata, handles)

$\mathrm{E} 2$ = get (handles.edit10, 'String');

\% - Executes during object creation, after setting all properties.

function edit10_createFcn(hobject, eventdata, handles)

if ispc \&\& isequal (get (hobject, 'BackgroundColor'), get(0,'defaultuicontrolBackgroundColor')) set (hobject, 'Backgroundcolor', 'white') ; end

function edit11_Callback(hobject, eventdata, handles)

I2 = get (handles.edit11, 'String');

\% Executes during object creation, after setting all properties.

function edit11_createFcn(hobject, eventdata, handles)

if ispc \&\& isequal (get(hobject, 'BackgroundColor'), get(0, 'defaultuicontrolBackgroundColor')) set (hobject, 'BackgroundColor', 'white') ; end

function edit12_Callback(hobject, eventdata, handles)

$\mathrm{k} 2$ = get (handles.edit12, 'String');

function edit12_createFcn(hobject, eventdata, handles)

if ispc \&\& isequal (get (hobject, 'BackgroundColor'), get(0, 'defaultuicontrolBackgroundColor')) set (hobject, 'BackgroundColor', 'white') i end

$\div$ Executes on button press in analysisbutton.

function analysisbutton_Callback(hobject, eventdata, handles)

set (handles.text115, 'String', 'Status: analysing data')

drawnow;

format compact

format short eng

syms A B x

syms k1 k2 E1 I1 E2 I2

syms real y1 y2 thetal betal kappal $\mathrm{M}$ V mu

syms $\mathrm{P}$

syms A1 A2 B1 B2 $x$ method

syms k_eq E I w v_h v_p Irc E1 E2 I1 I2 k1 k2 IC Ec

syms $\mathrm{V}$ theta kappa $\mathrm{M} \mathrm{V}$

$\mathrm{E} 1=$ str2double (get (handles.edit1, 'String'));

$\mathrm{E} 2$ = str2double (get (handles.edit24, 'String'));

I1 = str2double (get (handles.edit22, 'String')) ;

I2 = str2double (get (handles.edit25, 'String'));

Irc $=$ str2double (get (handles.edit25, 'String'));

$\mathrm{k} 1=$ str2double (get (handles.edit23, 'String')) ;

$\mathrm{k} 2=\operatorname{str} 2$ double (get (handles.edit26, 'String')) ;

$\mathrm{P}=1000 *$ str 2 double (get (handles.edit27, 'String'));

$\mathrm{a}=\operatorname{str} 2$ double $($ get (handles.edit29, 'String')) /2;

$\mathrm{b}=$ str2double (get (handles.edit30, 'String'))

$c=\operatorname{str} 2$ double (get (handles.edit31, 'String')) /2;

$\mathrm{V}=$ str2double (get (handles.edit28, 'String'))

$\mathrm{br}=\operatorname{str} 2 \mathrm{double}(\operatorname{get}($ handles.edit32, 'String'));

$\mathrm{bg}=$ str2double (get (handles.edit33, 'String'))

tval = get (handles.popupmenu2, 'Value');

phival = get (handles.popupmenu3, 'Value');

$\mathrm{F}=$ get (handles.popupmenul, 'Value');

method $=$ get (handles.popupmenu4, 'Value'). 


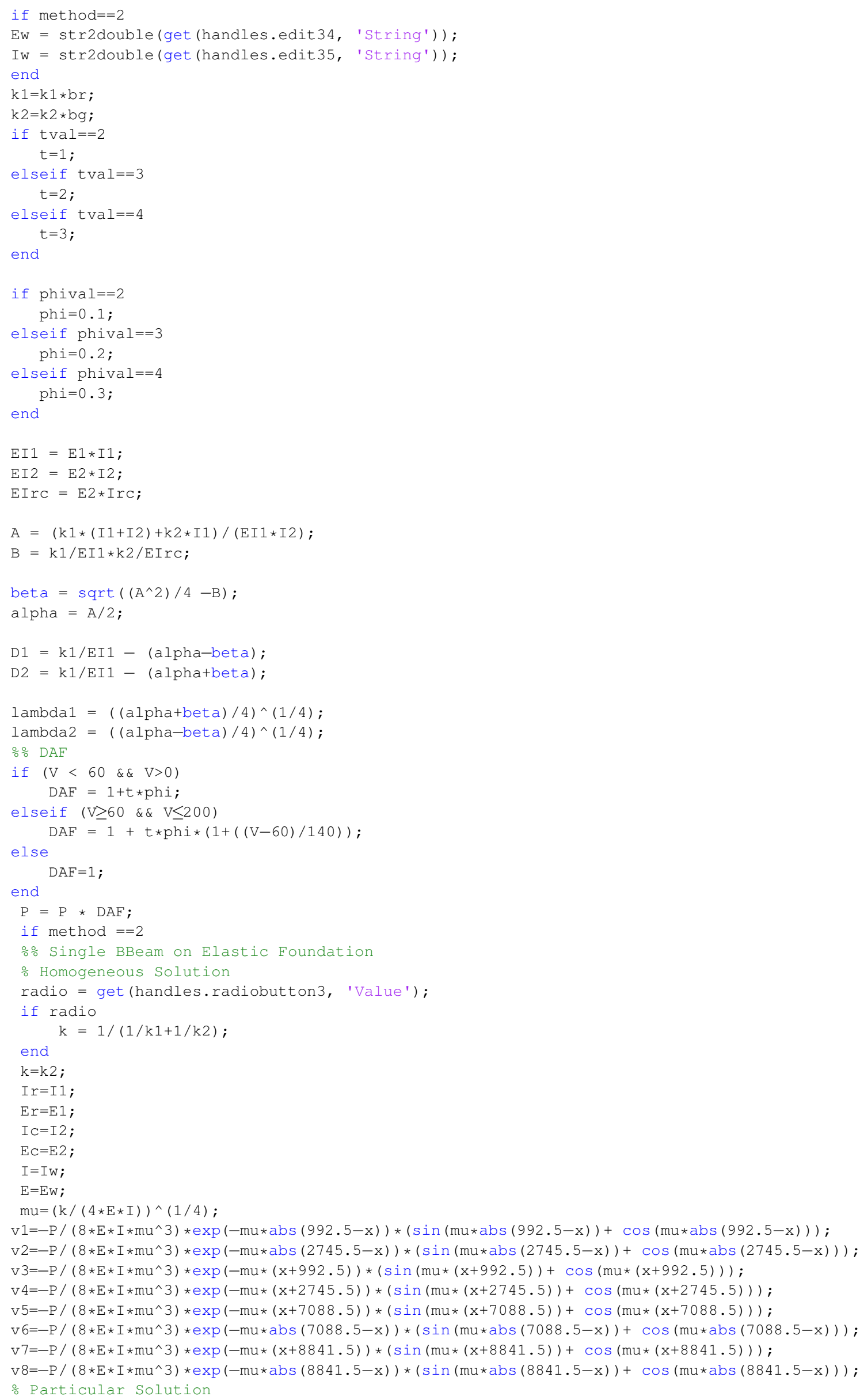




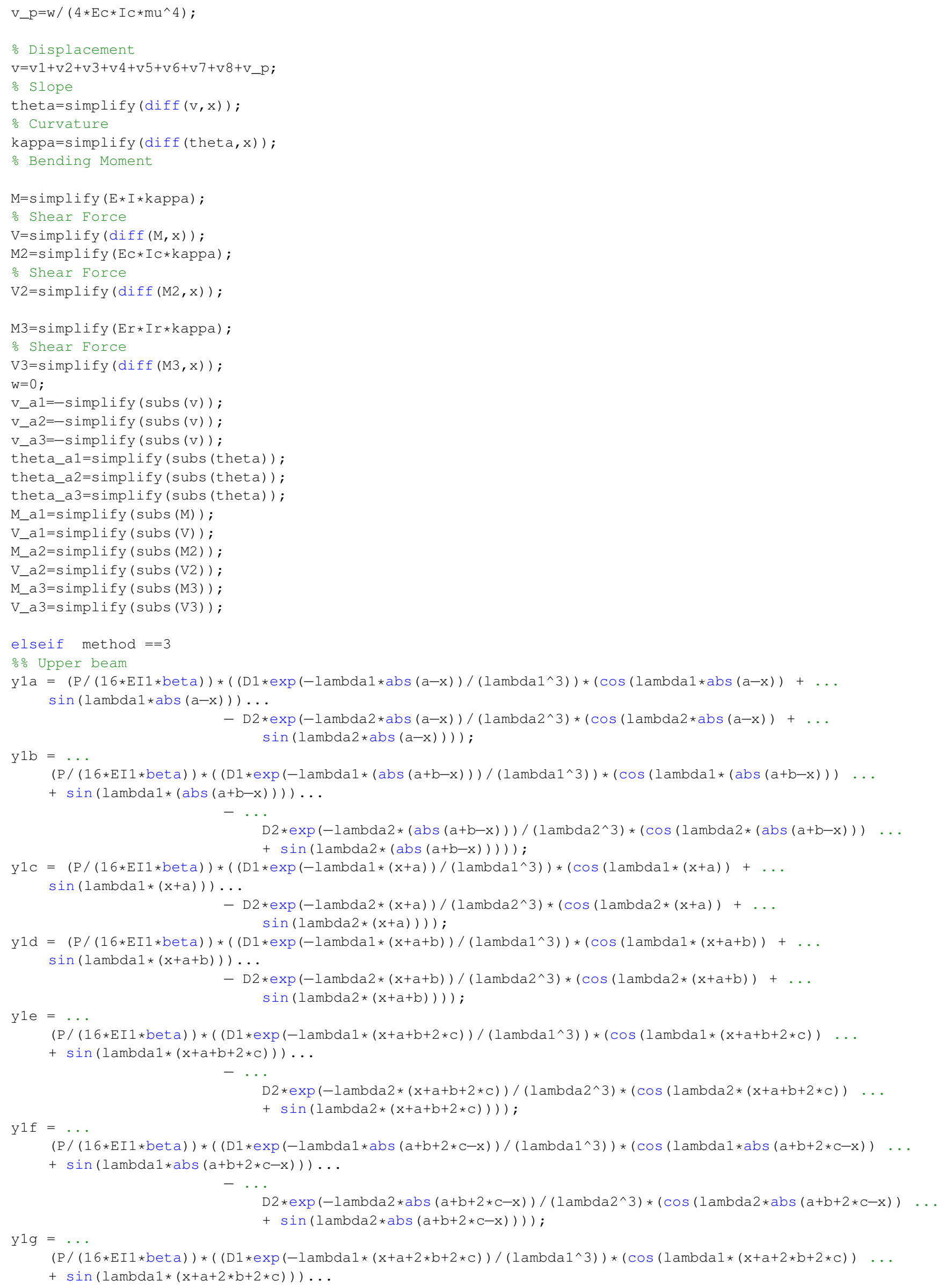




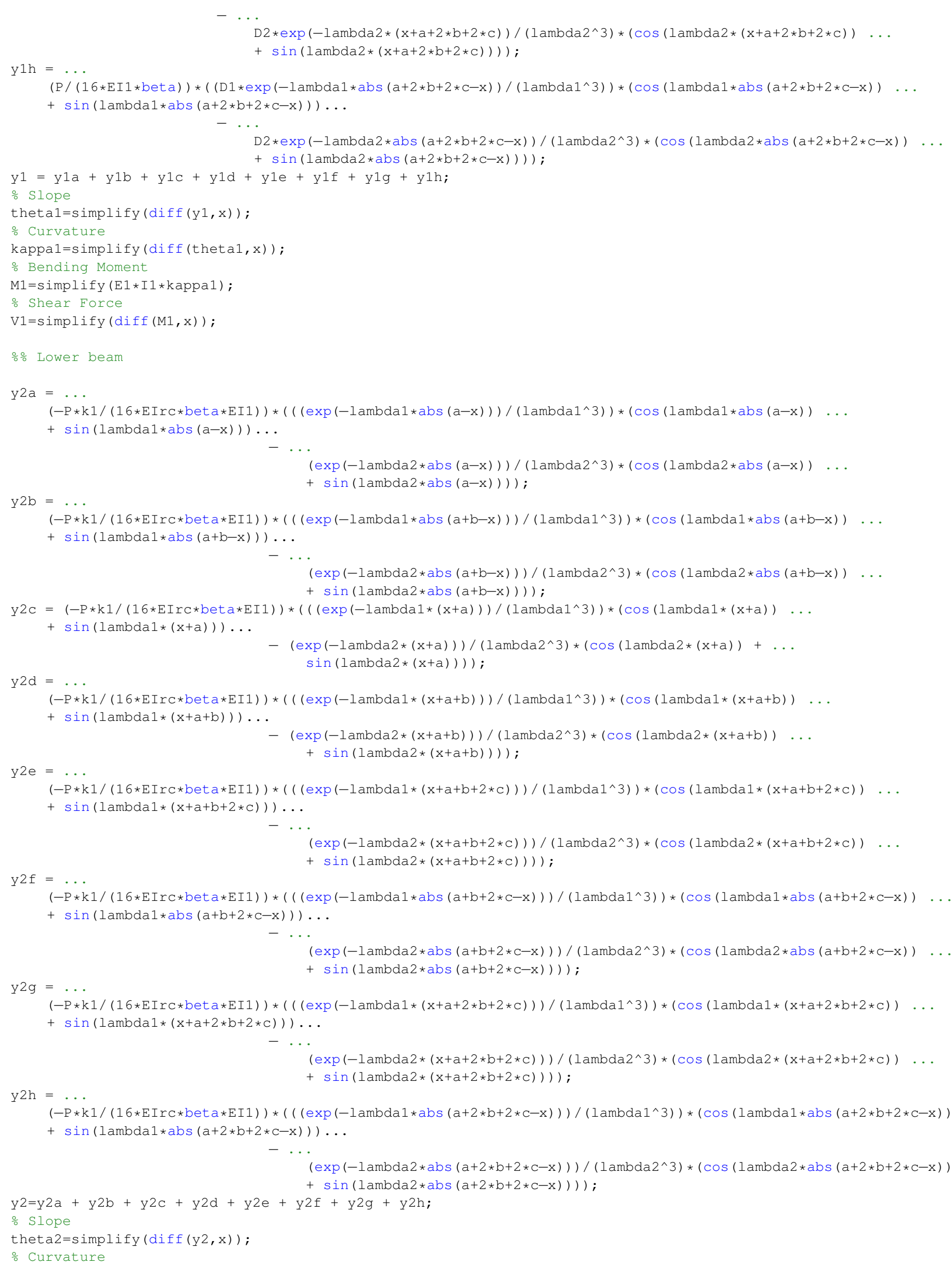




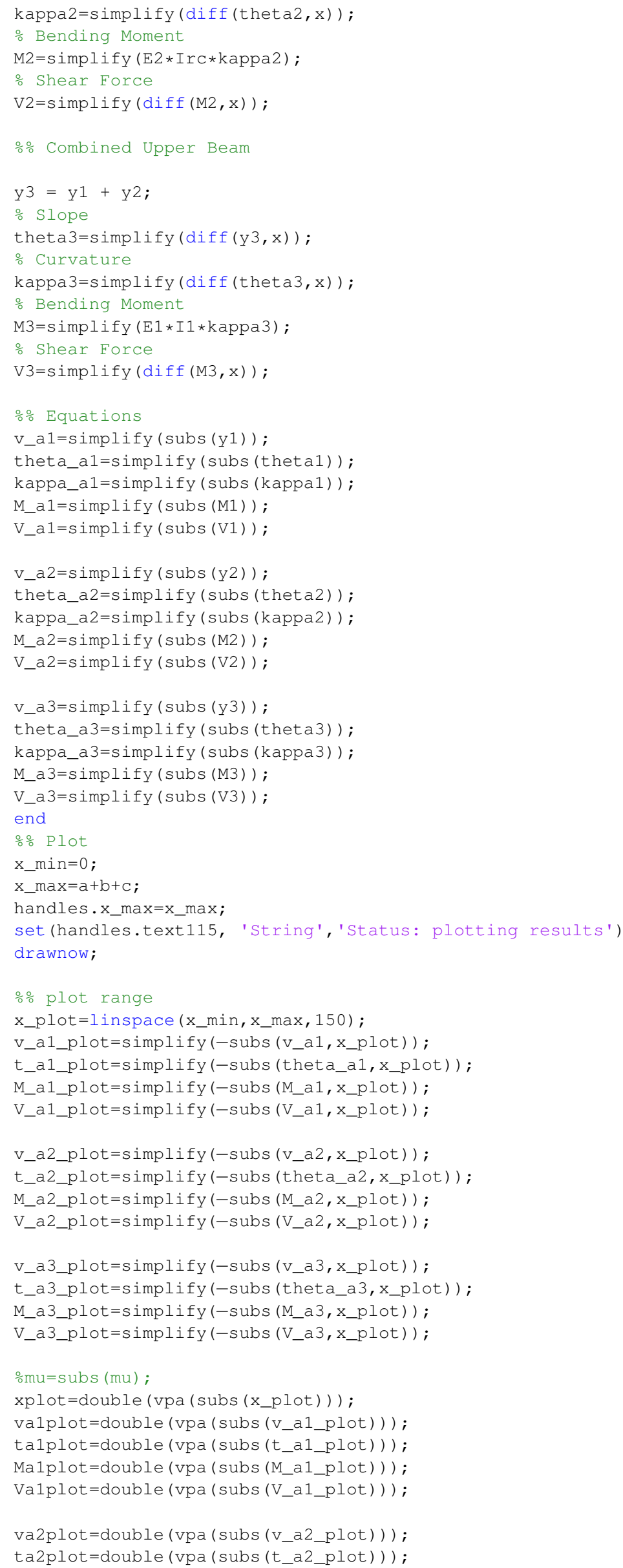


Ma2plot=double $(\operatorname{vpa}(\operatorname{subs}($ M_a2_plot $)))$;

Va2plot=double $\left(\operatorname{vpa}\left(\operatorname{subs}\left(V_{\text {_a2_plot }}\right)\right)\right)$;

va3plot $=$ double $\left(\operatorname{vpa}\left(\operatorname{subs}\left(v \_a 3 \_p l o t\right)\right)\right)$;

ta3plot $=$ double $\left(\operatorname{vpa}\left(\operatorname{subs}\left(t \_a 3 \_p l o t\right)\right)\right)$;

Ma3plot $=$ double $(\operatorname{vpa}(\operatorname{subs}($ M_a3_plot $)))$;

Va3plot=double $\left(\operatorname{vpa}\left(\operatorname{subs}\left(V \_a 3 \_p l o t\right)\right)\right)$;

응 Pressure Plots

if method $==2$

$\mathrm{p}=\mathrm{k} / \mathrm{bg} * \mathrm{v} \_\mathrm{a} 1$;

p_plot=simplify (subs (p,x_plot)) ;

plplot=double $(\operatorname{vpa}(-\operatorname{subs}($ p_plot $)))$;

p2plot=double $(\operatorname{vpa}(-\operatorname{subs}($ p_plot $)))$;

elseif method==3

$\mathrm{p} 1=\mathrm{k} 1 / \mathrm{br} *-(\mathrm{y} 1-\mathrm{y} 2) ;$

$\mathrm{p} 2=\mathrm{k} 2 / \mathrm{bg} * \mathrm{y} 2$;

p1_plot=simplify (subs (p1,x_plot)) ;

plplot=double (vpa (-subs (p1_plot)) );

p2_plot=simplify (subs (p2,x_plot));

p2plot $=$ double (vpa $(-\operatorname{subs}($ p2_plot $)))$;

end

handles.plplot $=$ plplot $* 10^{\wedge} 3$;

handles.p2plot $=\mathrm{p} 2 \mathrm{plot} * 10^{\wedge} 3$;

$\%$

handles.valplot = valplot;

handles.va2plot = va2plot;

handles.va3plot $=$ va3plot;

handles.xplot $=$ xplot;

handles.talplot = talplot;

handles.ta2plot = ta2plot;

handles.ta3plot = ta3plot;

handles.Maplot = Malplot;

handles.Malplot = Malplot;

handles.Ma2plot= Ma2plot;

handles.Ma3plot = Ma3plot;

handles.Vaplot = Valplot;

handles.Valplot $=$ Valplot;

handles.Va2plot = Va2plot;

handles.Va3plot = Va3plot;

digits (3);

mindisp1 = min (va1plot); mindisp2 = $\min ($ va2plot); $\operatorname{mindisp3}=\min ($ va $3 p l o t) ;$

maxdisp1 = $\max (v a 1 p l o t) ; \operatorname{maxdisp} 2=\max (v a 2 p l o t) ; \operatorname{maxdisp} 3=\max (v a 3 p l o t)$;

$\operatorname{maxb} 1=\max \left(\right.$ Malplot) $/ 10^{\wedge} 6 ; \operatorname{maxb} 2=\max ($ Ma2plot $) / 10^{\wedge} 6 ; \operatorname{maxb} 3=\max (\operatorname{Ma} 3 \mathrm{plot}) / 10^{\wedge} 6 ;$

$\operatorname{minb1}=\min \left(\right.$ Malplot) $/ 10^{\wedge} 6 ; \operatorname{minb} 2=\min \left(\right.$ Ma2plot) $/ 10^{\wedge} 6 ; \operatorname{minb} 3=\min (\operatorname{Ma} 3 \mathrm{plot}) / 10^{\wedge} 6 ;$

$\operatorname{maxV1}=\max (\mathrm{Va} 1 \mathrm{plot}) / 1000 ; \operatorname{maxV} 2=\max (\mathrm{Va} 2 \mathrm{plot}) / 1000 ; \operatorname{maxV} 3=\max (\mathrm{Va} 3 \mathrm{plot}) / 1000 ;$

$\operatorname{minV1}=\min ($ Valplot) $/ 1000 ; \operatorname{minV} 2=\min ($ Va2plot) $/ 1000 ; \operatorname{minV3}=\min ($ Va3plot $) / 1000 ;$

set (handles.text82, 'visible', 'on');

set (handles.text100, 'visible', 'on');

set (handles.text84, 'visible', 'on');

set (handles.text101, 'visible', 'on');

set (handles.text85, 'visible', 'on');

set (handles.text102, 'visible', 'on');

set (handles.text94, 'visible', 'on');

set (handles.text103, 'visible', 'on');

set (handles.text110, 'visible', 'on');

set (handles.text113, 'visible', 'on');

set (handles.text82, 'String', mindisp3)

set (handles.text100, 'String', mindisp2)

set (handles.text84, 'String', maxb3)

set (handles.text101, 'String', maxb2)

set (handles.text85, 'String', minb3)

set (handles.text102, 'String', minb2)

set (handles.text94, 'String', maxV3)

set (handles.text103, 'String', maxV2)

set (handles.text110, 'String', minv3) 
set (handles.text113, 'String', minV2)

drawnow:

handles.v_al=v_a1; handles.v_a2 $=$ v_a2; handles.v_a3= v_a3;

handles.t_a1= theta_a1; handles.t_a2= theta_a2; handles.t_a3=theta_a3;

handles.M_a1 = M_a1/10^6; handles.M_a2= M_a2/10^6; handles.M_a3= M_a3/10^6;

handles.V_al=V_a1/10^3; handles.V_a2=V_a2/10^3; handles.V_a3=V_a3/10^3;

handles.mindisp1 = min (valplot); handles.mindisp2 = min(va2plot); handles.mindisp3 = ... $\min (v a 3 p l o t) ;$

handles.maxdisp1 = $\max (v a 1 p l o t) ;$ handles.maxdisp2 = $\max (v a 2 p l o t) ;$ handles.maxdisp3 = ... $\max (v a 3 p l o t) ;$

handles.maxb1 $=\max \left(\right.$ Malplot) $/ 10^{\wedge} 6$; handles.maxb2 $=\max ($ Ma2plot $) / 10 \wedge 6$; handles.maxb3 = .. $\max ($ Ma3plot) /10^6;

handles.minb1 =min (Ma1plot) $/ 10^{\wedge} 6$; handles.minb2 = $\min \left(\right.$ Ma2plot) $/ 10^{\wedge} 6$; handles.minb3 = .. $\min (\mathrm{Ma} 3 \mathrm{plot}) / 10^{\wedge} 6$;

handles.maxV1 = $\max (V a 1 p l o t) / 1000 ;$ handles.maxV2 = $\max (V a 2 p l o t) / 1000 ;$ handles.maxV3 = .. $\max (\mathrm{Va} 3 \mathrm{plot}) / 1000$;

handles.minV1 = min(Va1plot) $/ 1000$; handles.minV2 = min(Va2plot) $/ 1000$; handles.minV3 = .. $\min (\mathrm{Va} 3 \mathrm{plot}) / 1000$;

guidata (hobject, handles)

set (handles.text115, 'String', 'Status: analysis complete')

drawnow;

set (handles.popupmenul, 'enable', 'on') ;

$y=$ wavread('C: \Users \verlinde \Desktop \Thesis \MATLAB \Short_Beep_Tone.wav');

wavplay (y)

\% Executes on button press in pushbutton2.

function pushbutton2_Callback(hobject, eventdata, handles)

function edit13_Callback (hobject, eventdata, handles)

$\mathrm{P}=$ get (handles.edit13, 'String');

function edit13_CreateFcn(hobject, eventdata, handles)

if ispc \&\& isequal (get (hobject, 'BackgroundColor'), get(0, 'defaultuicontrolBackgroundColor')) set (hobject, 'BackgroundColor', 'white') ; end

function edit17_callback(hobject, eventdata, handles)

$\mathrm{a}=$ get (handles.edit17, 'String');

function edit17_CreateFcn(hobject, eventdata, handles)

if ispc \&\& isequal (get(hobject, 'BackgroundColor'), get(0, 'defaultuicontrolBackgroundColor')) set (hobject, 'BackgroundColor', 'white') ; end

function edit18_Callback (hobject, eventdata, handles)

$\mathrm{b}=$ get (handles.edit18, 'String');

function edit18_CreateFcn(hobject, eventdata, handles)

if ispc \&\& isequal (get (hobject, 'BackgroundColor'), get(0, 'defaultuicontrolBackgroundColor')) set (hobject, 'BackgroundColor', 'white') ; end

function edit19_Callback(hobject, eventdata, handles)

$\mathrm{c}=$ get (handles.edit19, 'String');

function edit19_createFcn(hobject, eventdata, handles)

if ispc \&\& isequal (get(hobject, 'BackgroundColor'), get(0, 'defaultuicontrolBackgroundColor')) set (hobject, 'BackgroundColor', 'white') ; end 
function Untitled_1_Callback(hobject, eventdata, handles)

ㄴ Executes during object creation, after setting all properties. function loadill_CreateFcn(hobject, eventdata, handles)

oaxes (handles.loadill, 'loadill')

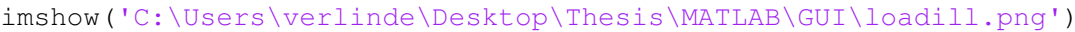

\% - Executes on selection change in listbox1.

function listbox1_Callback(hobject, eventdata, handles)

\% Executes during object creation, after setting all properties.

function listbox1_createFcn(hobject, eventdata, handles)

if ispc \&\& isequal (get (hobject, 'BackgroundColor'), get(0, 'defaultuicontrolBackgroundColor')) set (hobject, 'BackgroundColor', 'white') ;

end

$\div$ - Executes on selection change in popupmenul.

function popupmenul_Callback(hobject, eventdata, handles)

\% Determine the selected data set.

str $=$ get (hobject, 'String');

val = get (hobject, 'Value');

axes (handles.axisfigs)

xplot $=$ handles.$x p l o t$;

valplot=handles.va1plot; va2plot=handles.va2plot; va3plot=handles.va3plot;

ta2plot=handles.ta2plot; ta3plot=handles.ta3plot;

Maplot=handles.Maplot/10^6; Ma2plot=handles.Ma2plot/10^6; Ma3plot=handles.Ma3plot/10^6;

Vaplot=handles.Vaplot/10^3; Va2plot=handles.Va2plot/10^3; Va3plot=handles.Va3plot/10^3;

plplot $=$ handles.p1plot;p2plot $=$ handles.p2plot; method= get (handles.popupmenu4, 'Value');

if method==2

switch str $\{\mathrm{val}\}$

case 'Please select results'

case 'Load spacing illustration'

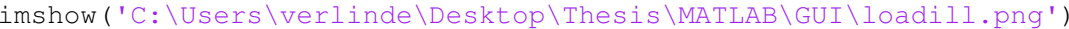

case 'Displacements'

$\mathrm{F}=1$;

img $=$ plot (xplot, va2plot);

title('Displacement vs. beam length graph', 'FontWeight','bold')

grid on;

xlabel ('Length of beam [mm]')

ylabel ('Displacement [mm]')

case 'Rotation'

$\mathrm{F}=2$;

img $=$ plot (xplot, ta2plot);

title('Slope vs. beam length graph', 'FontWeight','bold')

grid on;

xlabel ('Length of beam [mm]')

ylabel ('slope (theta) [rad]')

case 'Bending moment diagram'

$\mathrm{F}=3$;

img = plot (xplot, Maplot, xplot,Ma2plot, xplot,Ma3plot);

legend('Whole Beam', 'Lower Beam', 'Upper Beam')

title('Bending moment vs. beam length graph', 'FontWeight','bold')

grid on;

xlabel ('Length of beam [mm]')

ylabel('Bending moment [kNm]')

case 'Shear force diagram'

$\mathrm{F}=4$;

img = plot (xplot, Vaplot, xplot,Va2plot, xplot,Va3plot);

legend('Whole Beam', 'Lower Beam', 'Upper Beam')

title('Shear force vs. beam length graph', 'FontWeight', 'bold')

grid on;

xlabel ('Length of beam [mm]') 


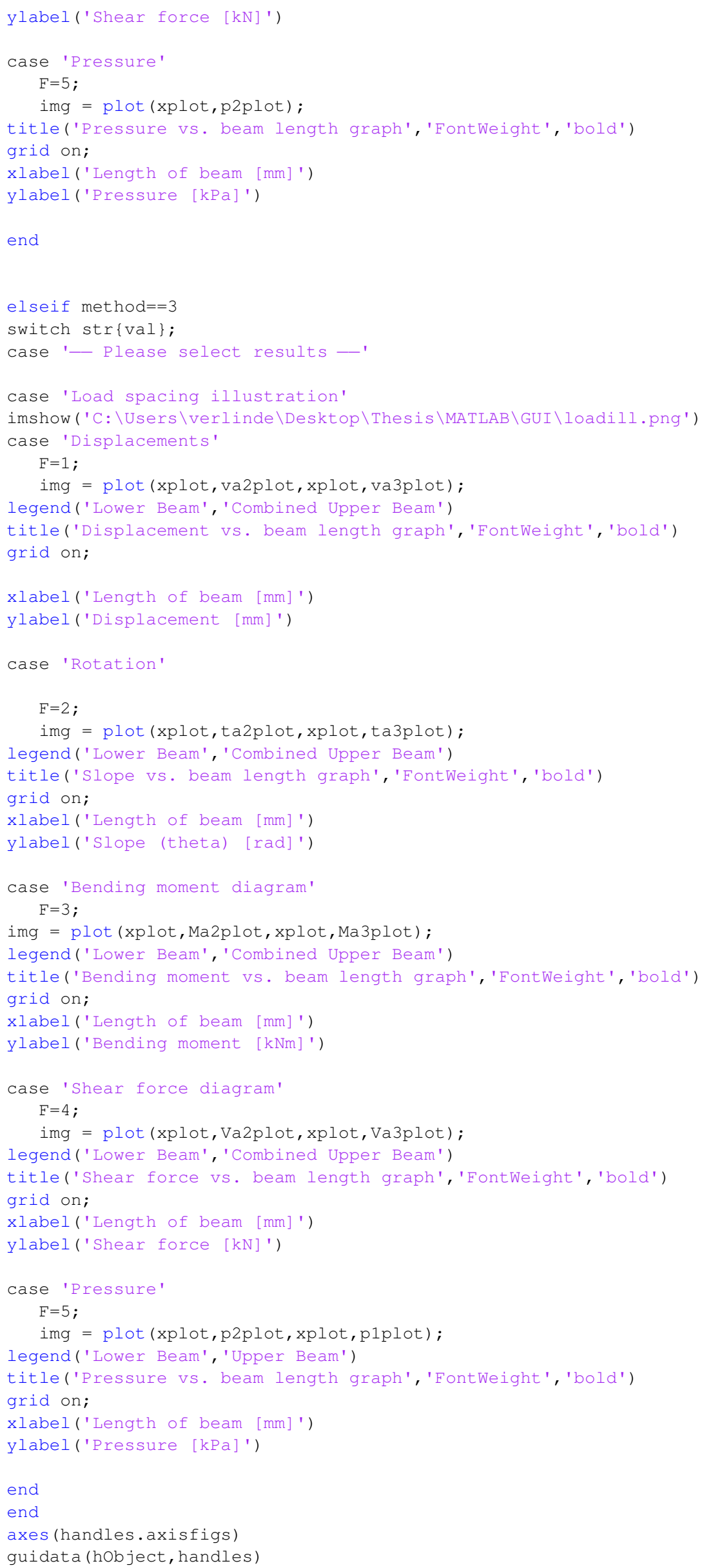


function popupmenu1_CreateFcn(hobject, eventdata, handles)

if ispc \&\& isequal (get (hobject, 'BackgroundColor'), get(0,'defaultuicontrolBackgroundColor')) set (hobject, 'BackgroundColor', 'white') ; end

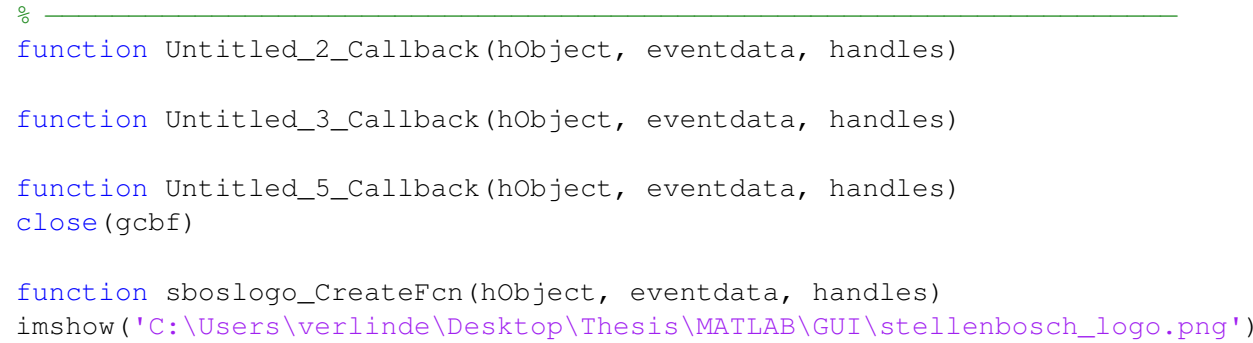

\% - Executes during object creation, after setting all properties.

function text42_CreateFcn(hobject, eventdata, handles)

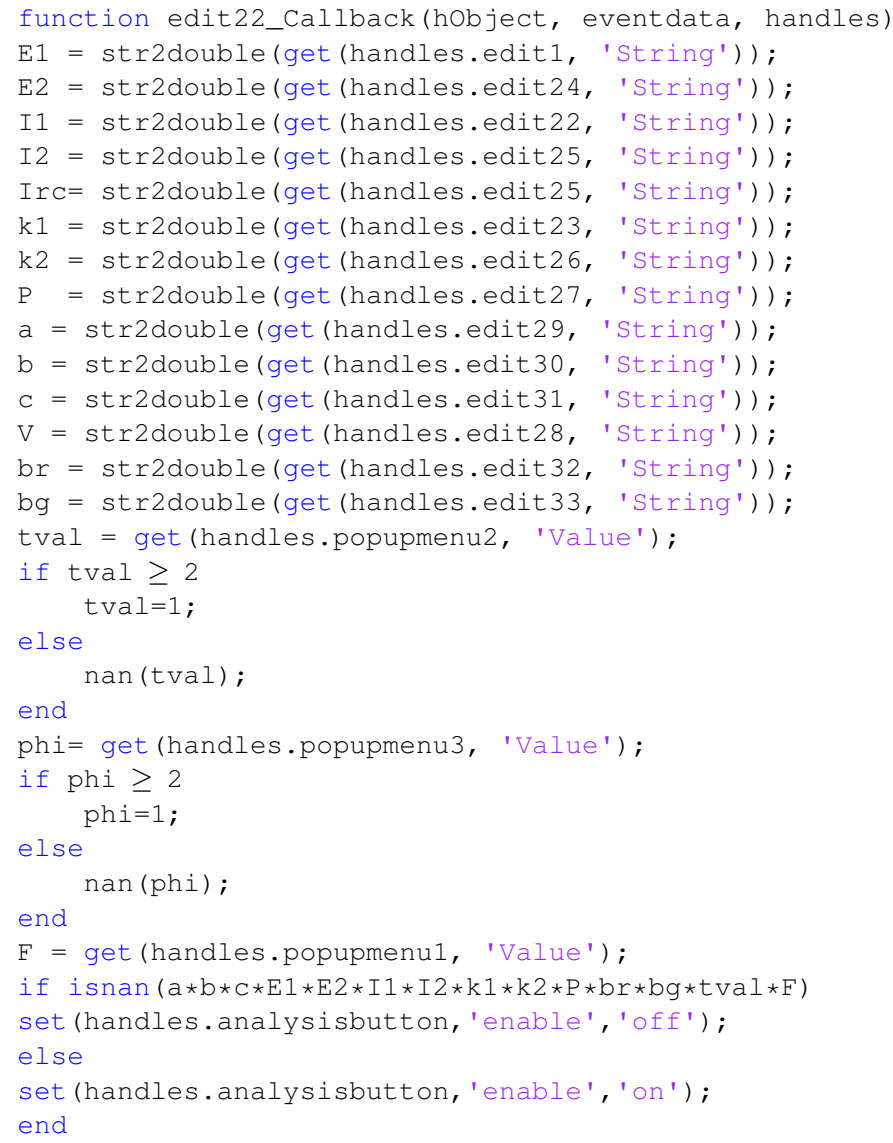




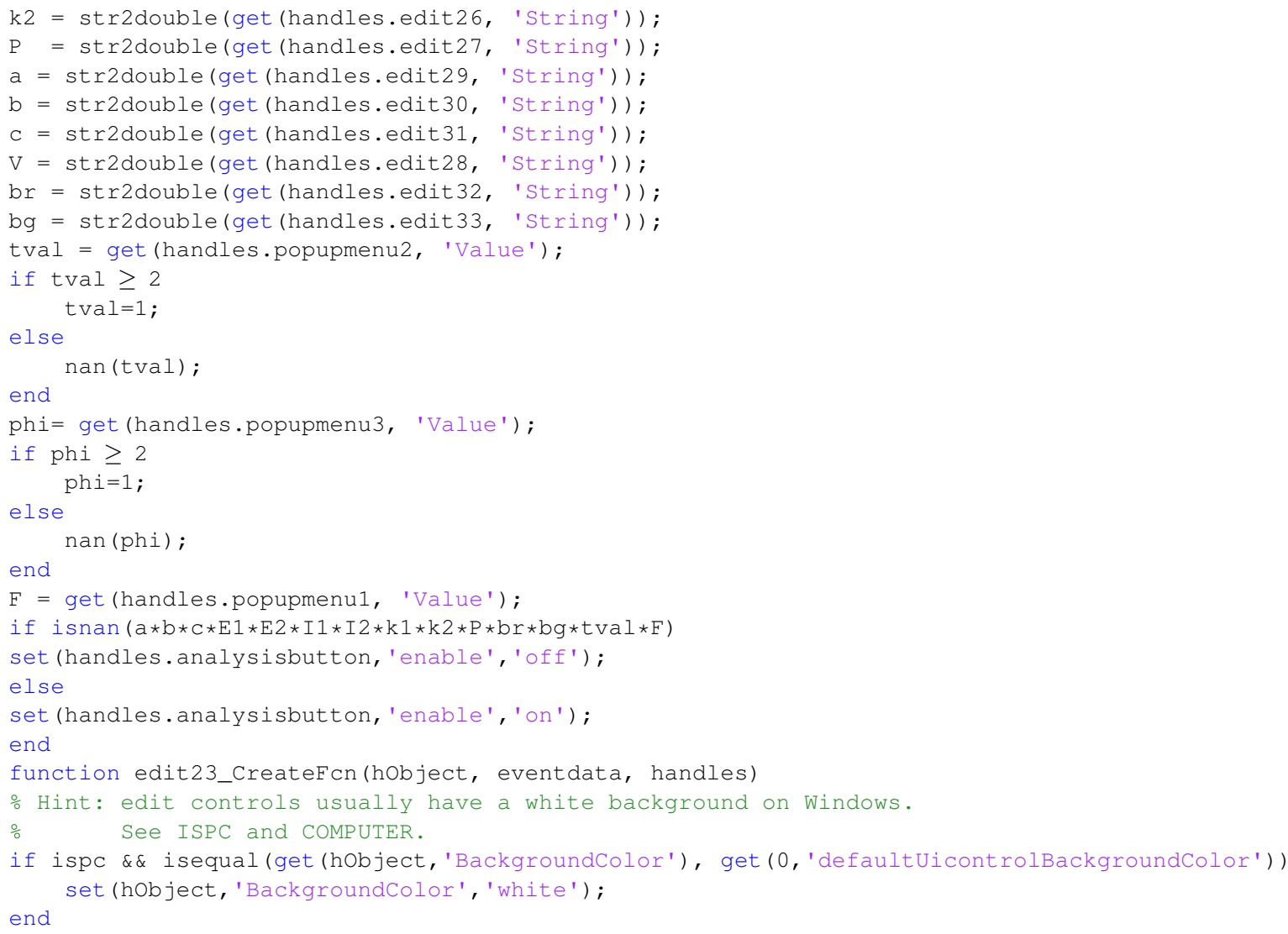



end

set (hobject, 'BackgroundColor', 'white') ;

function edit25_callback(hobject, eventdata, handles)

$\mathrm{E} 1$ = str2double (get (handles.edit1, 'String'));

$\mathrm{E} 2$ = str2double (get (handles.edit24, 'String'));

I1 = str 2 double (get (handles.edit22, 'String'));

I2 = str2double(get (handles.edit25, 'String'));

IrC $=$ str2double (get (handles.edit25, 'String'));

$\mathrm{k} 1=$ str2double (get (handles.edit23, 'String')) ;

$\mathrm{k} 2$ = str2double (get (handles.edit26, 'String'));

$\mathrm{P}=$ str2double (get (handles.edit27, 'String')) ;

$\mathrm{a}=\operatorname{str} 2$ double (get (handles.edit29, 'String'));

$\mathrm{b}=\operatorname{str} 2$ double (get (handles.edit30, 'String'));

$\mathrm{c}=$ str2double (get (handles.edit31, 'String'));

$\mathrm{V}=$ str2double (get (handles.edit28, 'String'));

$\mathrm{br}=$ str2double (get (handles.edit32, 'String')) ;

$\mathrm{bg}=\operatorname{str} 2$ double (get (handles.edit33, 'String'));

tval = get (handles.popupmenu2, 'Value');

if $t v a l \geq 2$

tval=1;

else

nan (tval) ;

end

phi= get (handles.popupmenu3, 'Value');

if $p h i \geq 2$

phi=1;

else

$\operatorname{nan}(\mathrm{phi})$;

end

$\mathrm{F}=$ get (handles.popupmenul, 'Value');

if isnan $(\mathrm{a} * \mathrm{~b} * \mathrm{C} * \mathrm{E} 1 * \mathrm{E} 2 * \mathrm{I} 1 * \mathrm{I} 2 * \mathrm{k} 1 * \mathrm{k} 2 * \mathrm{P} * \mathrm{br} * \mathrm{bg} * \operatorname{tval} * \mathrm{~F})$

set (handles.analysisbutton, 'enable', 'off') ;

else

set (handles.analysisbutton, 'enable', 'on' ) ;

end

function edit25_CreateFcn(hobject, eventdata, handles)

if ispc \&\& isequal (get (hobject, 'BackgroundColor'), get(0, 'defaultuicontrolBackgroundColor')) set (hobject, 'BackgroundColor', 'white') ; end

function edit26_Callback(hobject, eventdata, handles)

$\mathrm{E} 1$ = str2double (get (handles.edit1, 'String'));

$\mathrm{E} 2$ = str2double (get (handles.edit24, 'String'));

I1 = str2double (get (handles.edit22, 'String'));

I2 = str2double (get (handles.edit25, 'String'));

Irc $=$ str 2 double (get (handles.edit 25, 'String'));

$\mathrm{k} 1$ = str2double (get (handles.edit23, 'String')) ;

$\mathrm{k} 2$ = str2double (get (handles.edit26, 'String')) ;

$\mathrm{P}=$ str 2 double (get (handles.edit27, 'String')) ;

$\mathrm{a}=\operatorname{str} 2$ double (get (handles.edit29, 'String'));

$\mathrm{b}=\operatorname{str} 2$ double (get (handles.edit30, 'String'));

$c=$ str2double (get (handles.edit31, 'String'));

$\mathrm{V}=$ str2double (get (handles.edit28, 'String')) ;

$\mathrm{br}=\operatorname{str} 2 \mathrm{double}(\operatorname{get}($ handles.edit32, 'String'));

$\mathrm{bg}=$ str2double (get (handles.edit33, 'String'));

tval = get (handles.popupmenu2, 'Value');

if $t v a l \geq 2$

tval=1;

else

nan (tval);

end

phi= get (handles.popupmenu3, 'Value');

if $p h i \geq 2$

phi=1;

else

nan (phi) ;

end 
$\mathrm{F}=$ get (handles.popupmenul, 'Value');

if isnan $(\mathrm{a} * \mathrm{~b} * \mathrm{C} * \mathrm{E} 1 * \mathrm{E} 2 * \mathrm{I} 1 * \mathrm{I} 2 * \mathrm{k} 1 * \mathrm{k} 2 * \mathrm{P} * \mathrm{~b} r * \mathrm{bg} * \operatorname{tval} \star \mathrm{F})$

set (handles.analysisbutton, 'enable', 'off') ;

else

set (handles.analysisbutton, 'enable ', 'on') ;

end

function edit26_createFcn(hobject, eventdata, handles)

if ispc \&\& isequal (get (hobject, 'BackgroundColor'), get(0, 'defaultuicontrolBackgroundColor')) set (hobject, 'BackgroundColor', 'white') ; end

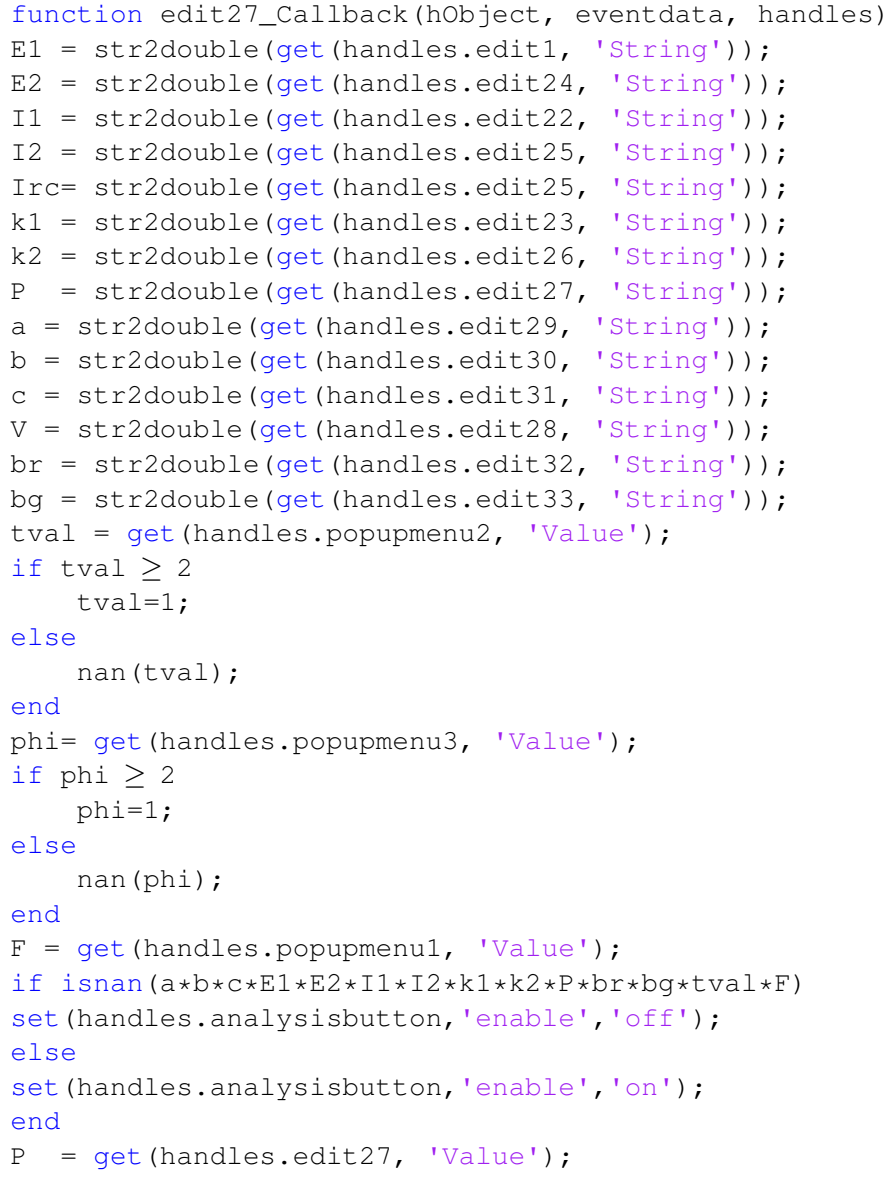




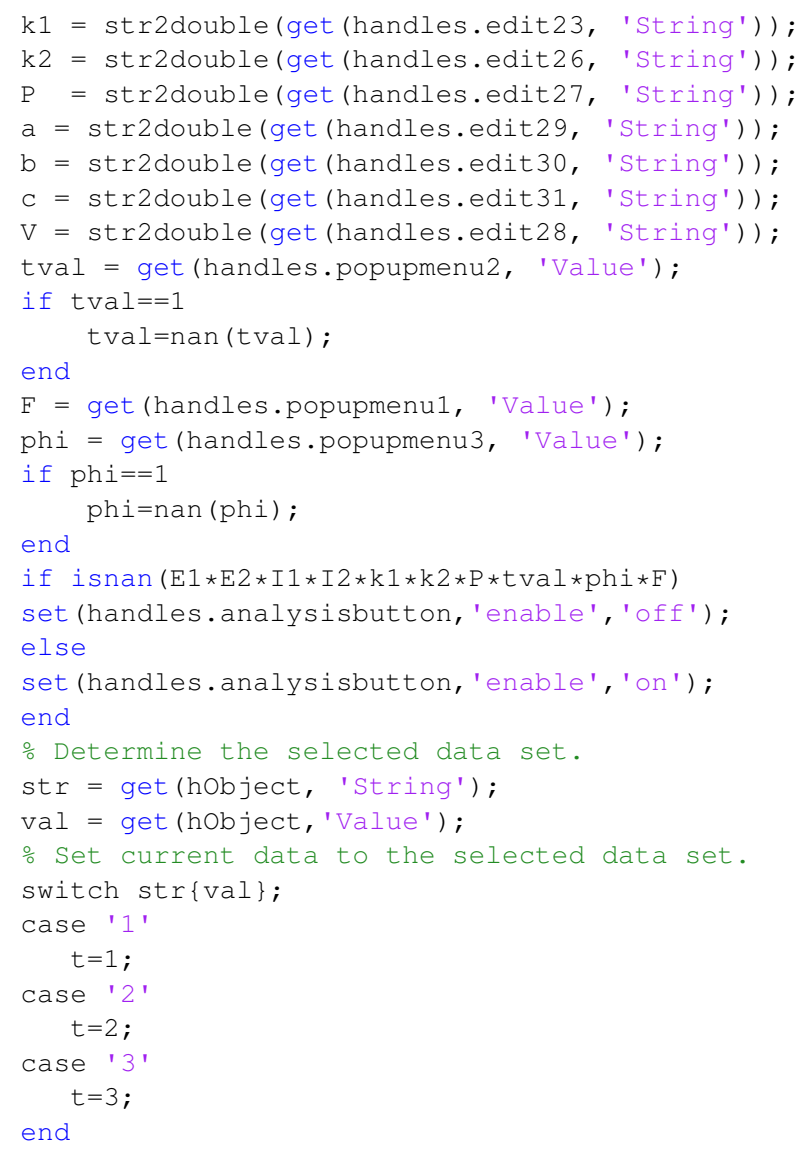

ㄴ Executes during object creation, after setting all properties. function popupmenu2_CreateFcn (hobject, eventdata, handles)

if ispc \&\& isequal (get(hobject, 'BackgroundColor'), get(0, 'defaultuicontrolBackgroundColor')) set (hobject, 'BackgroundColor', 'white') ; end

function popupmenu3_Callback (hobject, eventdata, handles)

$\mathrm{E} 1$ = str2double (get (handles.edit1, 'String'));

$\mathrm{E} 2$ = str2double (get (handles.edit24, 'String'));

I1 = str2double (get (handles.edit22, 'String'));

I2 = str2double (get (handles.edit25, 'String'));

Irc $=\operatorname{str} 2$ double (get (handles.edit25, 'String')) ;

$\mathrm{k} 1=\operatorname{str} 2 \mathrm{double}(\operatorname{get}($ handles.edit23, 'String'));

$\mathrm{k} 2=\operatorname{str} 2$ double (get (handles.edit26, 'String'));

$\mathrm{P}=$ str2double (get (handles.edit27, 'String')) ;

$\mathrm{a}=\operatorname{str} 2$ double (get (handles.edit29, 'String'));

$\mathrm{b}=$ str2double (get (handles.edit30, 'String'));

$\mathrm{c}=$ str2double (get (handles.edit31, 'String'));

$\mathrm{V}=$ str2double (get (handles.edit28, 'String')) ;

tval = get (handles.popupmenu2, 'Value');

if $\mathrm{tval}==1$

tval=nan (tval);

end

$\mathrm{F}=$ get (handles.popupmenul, 'Value');

phi = get (handles.popupmenu3, 'Value');

if $\mathrm{phi}==1$

phi=nan (phi);

end

$F=$ get (handles.popupmenul, 'Value');

if isnan $(\mathrm{a} * \mathrm{~b} * \mathrm{C} * \mathrm{E} 1 * \mathrm{E} 2 * \mathrm{I} 1 * \mathrm{I} 2 * \mathrm{k} 1 * \mathrm{k} 2 * \mathrm{P} * \mathrm{tval} * \mathrm{ph} \mathrm{V} * \mathrm{~F})$

set (handles.analysisbutton, 'enable', 'off') ;

else

set (handles.analysisbutton, 'enable', 'on' ) ;

end

- Determine the selected data set.

str $=\operatorname{get}($ hobject, 'String'); 


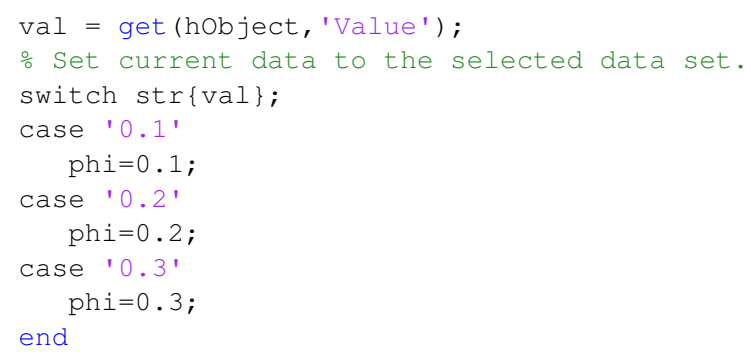




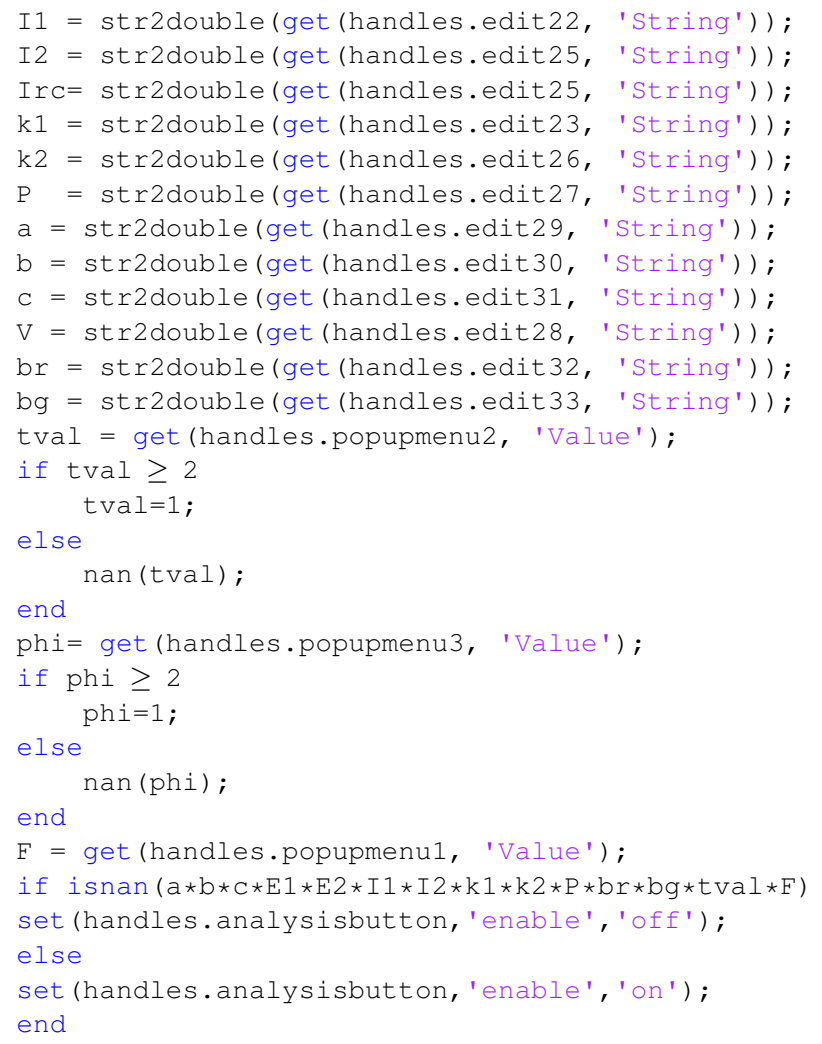


function edit31_CreateFcn(hobject, eventdata, handles)

if ispc \&\& isequal (get (hobject, 'BackgroundColor'), get(0,'defaultuicontrolBackgroundColor')) end set (hobject, 'BackgroundColor', 'white');

ㄴ Executes during object creation, after setting all properties.

function axisfigs_CreateFcn(hobject, eventdata, handles)

function axisfigs4_CreateFcn(hobject, eventdata, handles)

function axisfigs_DeleteFcn(hobject, eventdata, handles)

function axisfigs_ButtonDownFcn(hobject, eventdata, handles)

function analysisbutton_CreateFcn(hobject, eventdata, handles)

function pushbutton5_Callback(hobject, eventdata, handles)

[f p]=uiputfile('*.pdf', 'Save as PDF');

newFig=figure;

axisfigs=copyobj (handles.axisfigs, newFig);

print (newFig, '-dpdf', [f p]);

function text82_CreateFcn(hobject, eventdata, handles)

function togglebutton2_Callback(hobject, eventdata, handles)

function pushbutton9_Callback(hobject, eventdata, handles)

function pushbutton10_Callback(hobject, eventdata, handles)

set (handles.edit1, 'String', ' ')

set (handles.edit24, 'String',' ')

set (handles.edit22, 'String', ' ')

set (handles.edit25, 'String',' ')

set (handles.edit23, 'String', ' ')

set (handles.edit26, 'String',' '')

set (handles.edit27, 'String',' ')

set (handles.edit29, 'String',' ')

set (handles.edit30, 'String',' ' ')

set (handles.edit31, 'String', ' ')

set (handles.edit28, 'String', ' ')

set (handles.edit1, 'String', ' ')

set (handles.edit32, 'String', ' ')

set (handles.edit33, 'String', ' ')

set (handles.edit34, 'String',' ')

set (handles.edit35, 'String', ' ')

clear all;

$\mathrm{ClC}$;

$\div$

function Untitled_8_Callback(hobject, eventdata, handles)

function resultexport_Callback(hobject, eventdata, handles)

set (handles.text115, 'String', 'status: exporting results to command window')

drawnow;

clc;

$\mathrm{x}=0$;

counter $=0$;

$a=\operatorname{str} 2$ double (get (handles.edit29, 'String')) /2;

$\mathrm{b}=$ str2double (get (handles.edit30, 'String')) ;

$c=$ str2double (get (handles.edit31, 'String')) /2;

v_al=handles.v_a1;

v_a2=handles.v_a2;

v_a3=handles.v_a3;

M_a2 handles.M_a2;

M_a3=handles.M_a3;

V_a2=handles.V_a2;

V_a3=handles. V_a3; 


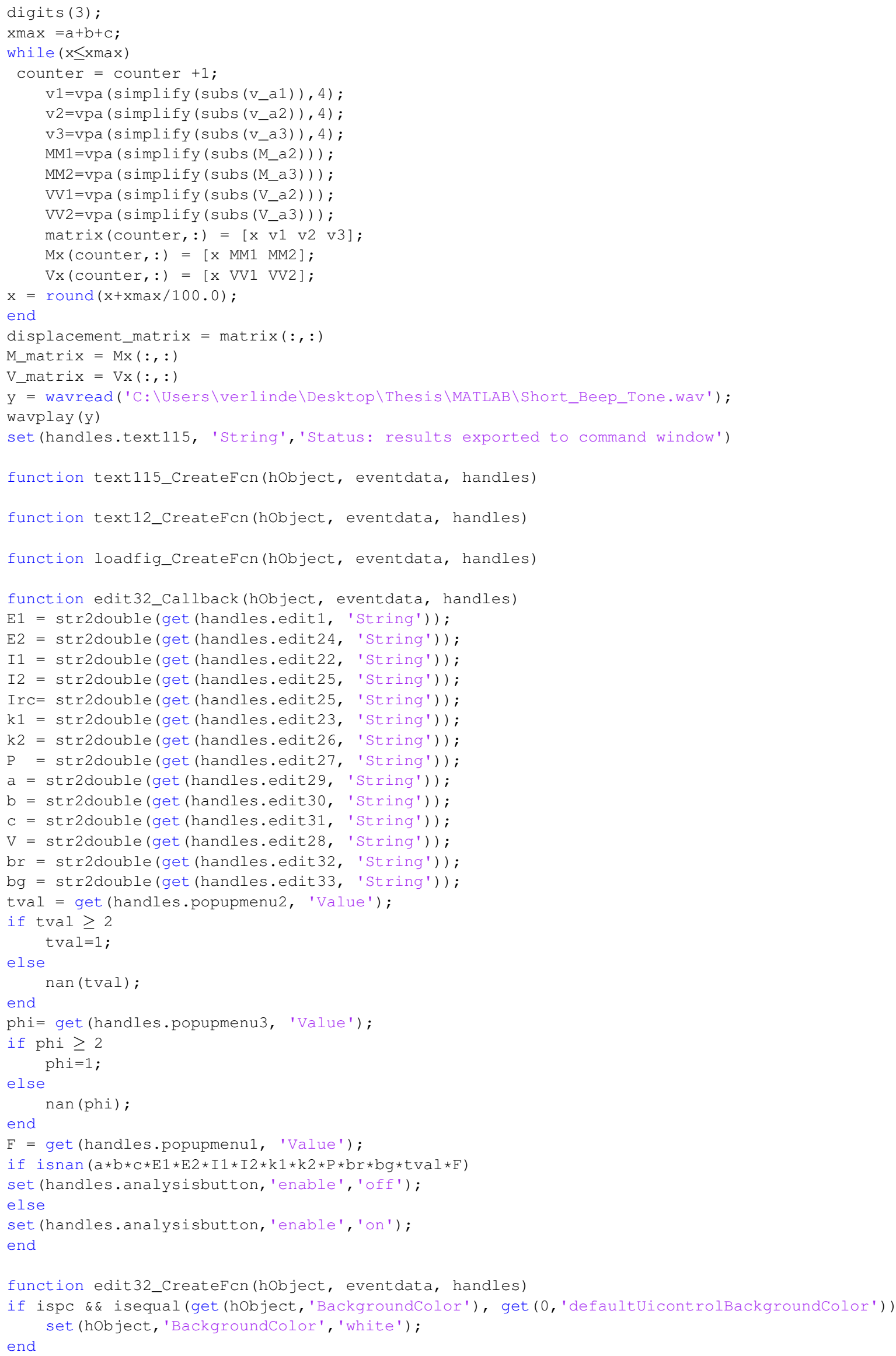




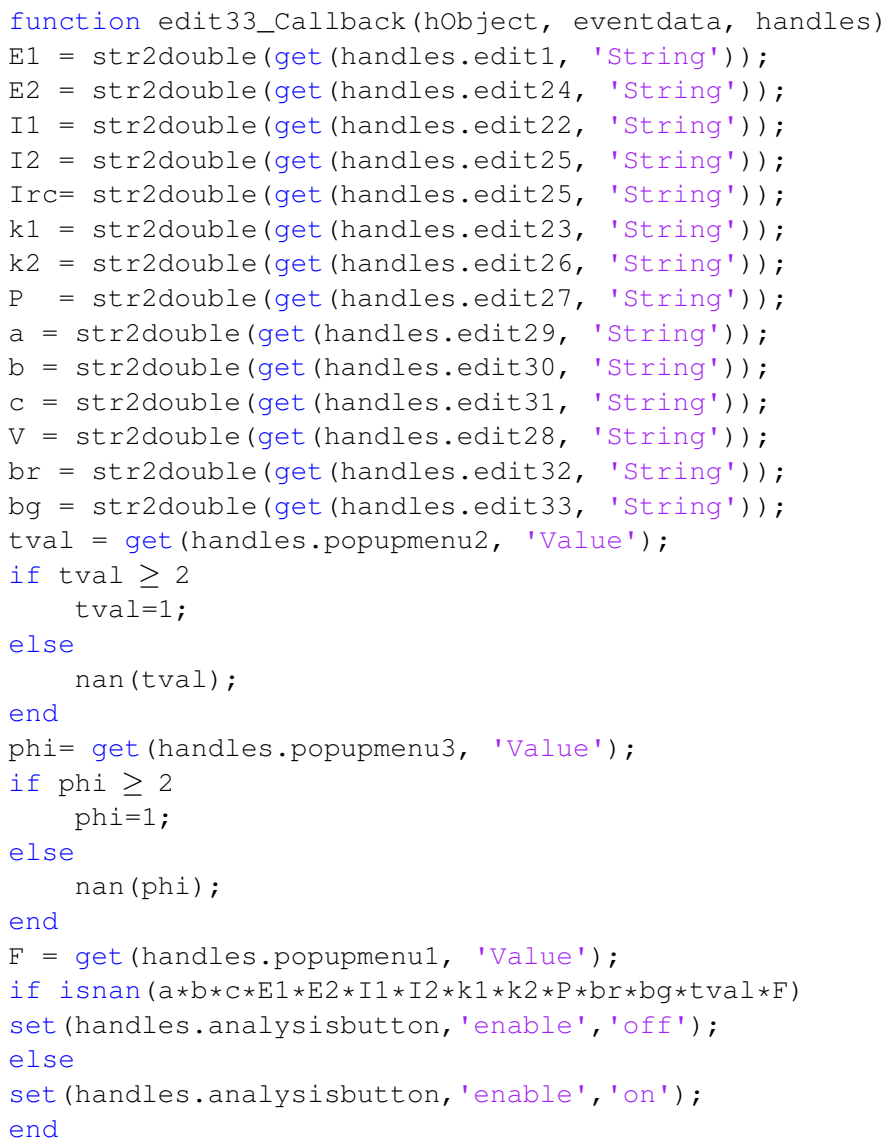


end

handles . method=method;

function popupmenu4_CreateFcn(hobject, eventdata, handles)

if ispc \&\& isequal (get(hobject, 'BackgroundColor'), get(0, 'defaultUicontrolBackgroundColor')) set (hobject, 'BackgroundColor', 'white'); end

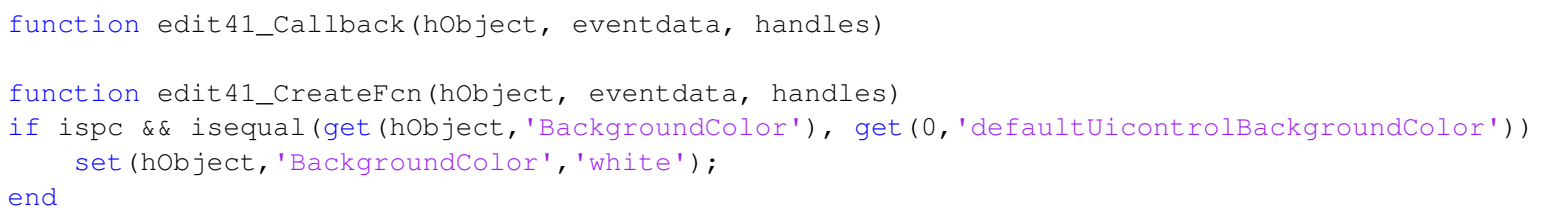


end

function edit34_Callback(hobject, eventdata, handles)

function edit34_createFcn(hobject, eventdata, handles)

if ispc \&\& isequal (get (hobject, 'BackgroundColor'), get(0, 'defaultuicontrolBackgroundColor')) set (hobject, 'BackgroundColor', 'white') ; end

function uipanel12_CreateFcn(hobject, eventdata, handles) 